ISSN 2413-1407 (Print), 2587-8549 (Online)

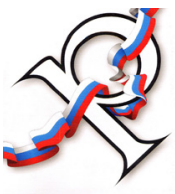

\section{РЕГИОНОЛОГИЯ} REGIONOLOGY

\section{Том 27, № 4, 2019 (октябрь - декабрь)}

Сквозной номер выпуска - 109

Научный журнал

УЧРЕДИТЕЛЬ И ИЗДАТЕЛЬ:

федеральное государственное бюджетное образовательное учреждение высшего образования «Национальный исследовательский Мордовский государственный университет им. Н. П. Огарёва»

430005, Россия, Республика Мордовия, г. Саранск, ул. Большевистская, 68

\title{
АДРЕС РЕДАКЦИИ:
}

430005, Россия, Республика Мордовия, г. Саранск, ул. Большевистская, 68/1

Тел./факс: +7 (8342) 48-14-24, +7 (8342) 32-86-14

Журнал издается с 1992 года. Периодичность издания - 4 раза в год

\section{DOI: $10.15507 / 2413-1407$}

\section{Russian Journal of Regional Studies}

\author{
Vol. 27, No. 4, 2019 (October - December) \\ Continuous issue 109 \\ Scholarly journal \\ FOUNDER AND PUBLISHER:
}

Federal State Budgetary Educational Institution of Higher Education

"National Research Ogarev Mordovia State University"

68 Bolshevistskaya St., Saransk 430005, Republic of Mordovia, Russia

EDITORIAL OFFICE:

68/1 Bolshevistskaya St., Saransk 430005, Republic of Mordovia, Russia Tel/Fax: +7 8342 481424, +7 8342328614

Published since October 1992. Publication frequency: quarterly

e-mail: regionology@mail.ru, redreg@mrsu.ru

http://regionsar.ru 
Основное содержание журнала составляют оригинальные научные статьи, посвященные актуальным проблемам региональной политики, экономики и социологии, анализу комплексного развития регионов Российской Федерации и зарубежных стран. Наименование и содержание рубрик журнала соответствуют отраслям науки и группам специальностей научных работников на основании Номенклатуры научных специальностей, по которым присуждаются ученые степени:

\section{ЭКОНОМИКА}

социология

политология

Журнал осуществляет научное рецензирование всех поступающих в редакцию статей с целью экспертной оценки.

Политика редакционной коллегии журнала базируется на современных юридических требованиях в отношении клеветы, авторского права, законности и плагиата, поддерживает Кодекс этики научных публикаций, сформулированный Комитетом по этике научных публикаций, и строится с учетом этических норм работы редакторов и издателей, закрепленных в Кодексе поведения и руководящих принципах наилучшей практики для редактора журнала и Кодексе поведения для издателя журнала, разработанных Комитетом по публикационной этике (СОРЕ).

Журнал индексируется и архивируется в Российском индексе научного цитирования (РИНЦ), реферативной базе данных ERIH PLUS, научной электронной библиотеке «КиберЛенинка», электроннобиблиотечной системе «Лань», базе данных Ulrichsweb Global Serials Directory, Немецкой национальной экономической библиотеке Лейбница.

Журнал является членом Directory of Open Access Journals (DOAJ), Ассоциации научных редакторов и издателей (АНPИ), CrossRef и международного сообщества рецензентов Publons.

Журнал входит в Перечень рецензируемых научных изданий, в которых должны быть опубликованы основные научные результаты диссертаций на соискание ученой степени кандидата наук, на соискание ученой степени доктора наук, по научным специальностям и соответствующим им отраслям.

Социально-экономические и общественные науки

08.00.05 - Экономика и управление народным хозяйством (по отраслям и сферам деятельности)

22.00.04 - Социальная структура, социальные институты и процессы

23.00 .02 - Политические институты, процессы и технологии

23.00.04 - Политические проблемы международных отношений, глобального и регионального развития 
The main contents of the Journal are original scientific papers devoted to topical issues of regional policy, economy and sociology, as well as to the analysis of the integrated development of the regions of the Russian Federation and other countries. The names and content of the Journal's sections correspond to the fields of science and groups of specialties of scientific workers in accordance with the Nomenclature of Scientific Specialties in which academic degrees are awarded:

\section{ECONOMICS}

SOCIOLOGY

\section{POLITICAL SCIENCE}

The Journal conducts scientific review of all papers submitted to the editorial office for the purpose of their expert evaluation.

Editorial staff's policy is based on modern legal requirements concerning libel, copyright, legitimacy, plagiarism, ethical principles, kept in community of leading scientific issues publishers. Journal's editorial policy is based upon traditional ethical principles of Russian academic periodicals; it supports Academic Periodicals Ethical Codex, stated by Committee on Publication Ethics (Russia, Moscow) and it is formed in account of standards of ethics of editors' and publishers' work confirmed by Code of Conduct and Best Practice Guidelines for Journal Editors and Code of Conduct for Journal Publishers, developed by Committee on Publication Ethics (COPE).

The Journal is indexed and archived in Russian Index of Scientific Citation, in ERIH PLUS reference index, in CyberLeninka scientific electronic library, in Lan electronic library system, in UlrichsWeb Global Serials Directory international reference database of periodicals and in German National Library of Economics (ZBW).

The journal is a member of the Directory of Open Access Journals (DOAJ), Assotiation of Scientific Editors and Publishers (ASEP), CrossRef and the international community of reviewers Publons.

The Journal is included in the List of the peer-reviewed scientific publications where the main scientific results of Ph. D. and doctoral theses (by applicants for Candidate of Sciences and Doctor of Sciences degrees) in scientific specialties and their respective branches of science should be published.

\section{Socio-Economic and Social Sciences}

Economics and national economy management

Social structure, social institutions and processes

Political institutions, processes and technology

Political issues of international relations, global and regional development 


\section{РЕДАКЦИОННАЯ КОЛЛЕГИЯ}

Вдовин Сергей Михайлович - главный редактор, ректор ФГБОУ ВО «МГУ им. Н. П. Огарёва», кандидат экономических наук, доцент, ORCID: https:/orcid.org/ 0000-0001-7363-1389, rector@adm.mrsu.ru (Саранск, Россия)

Полутин Сергей Викторович - заместитель главного редактора, директор НИИ регионологии ФГБОУ ВО «МГУ им. Н. П. Огарёва», доктор социологических наук, профессор, ORCID: https://orcid.org/0000-0003-0399-4154, polutin.sergei@yandex.ru (Саранск, Россия)

Гордина Светлана Викторовна - ответственный секретарь, член Европейской ассоциации научных редакторов (EASE), кандидат педагогических наук, ORCID: https:// orcid.org/0000-0003-2265-418X, inted@adm.mrsu.ru, inted@mail.ru (Саранск, Россия)

Ахмад Наср Салех Мохамад - профессор бухгалтерского учета, факультет бухгалтерского учета Университета Гарьяна, генеральный директор Института персонала Ливийской академии, ORCID: https://orcid.org/0000-0002-2057-2220,nassr_ahmad@yahoo.co.uk (Гарьян, Ливия)

Бахлов Игорь Владимирович - заведующий кафедрой всеобщей истории, политологии и регионоведения ФГБОУ ВО «МГУ им. Н. П. Огарёва», доктор политических наук, доцент, ORCID: https://orcid.org/0000-0001-6886-5762, bahlov@mail.ru (Саранск, Россия)

Барыгин Игорь Николаевич - профессор кафедры европейских исследований ФГБОУ ВО «Санкт-Петербургский государственный университет», доктор политических наук, профессор, ORCID: https://orcid.org/0000-0002-8143-3136, ibarygin@gmail.com (Санкт-Петербург, Россия)

Большаков Андрей Георгиевич - заведующий кафедрой конфликтологии ФГАОУ ВО «Казанский (Приволжский) федеральный университет», доктор политических наук, доцент, ORCID: https://orcid.org/0000-0002-5036-000X, bolshakov_andrei@mail.ru (Казань, Россия)

Гришин Виктор Иванович - ректор ФГБОУ ВО «Российский экономический университет им. Г. В. Плеханова», доктор экономических наук, профеccop, rector@rea.ru (Москва, Россия)

Дахин Андрей Васильевич - заведующий кафедрой философии и политологии Нижегородского института управления - филиала ФГБОУ ВО «Российская академия народного хозяйства и государственной службы при Президенте Российской Федерации», доктор философских наук, профессор, ORCID: https://orcid.org/ 0000-0001-5907-706X, nn9222@rambler.ru (Нижний Новгород, Россия)

Дружинин Павел Васильевич - заведующий отделом моделирования и прогнозирования регионального развития Института экономики ФГБУН «Карельский научный центр Российской академии наук», доктор экономических наук, доцент, ORCID: https:// orcid.org/0000-0001-5303-0455, pdruzhinin@mail.ru (Петрозаводск, Россия)

Дулина Надежда Васильевна - профессор кафедры социологии ФГАОУ ВО «Волгоградский государственный университет», доктор социологических наук, професcop, ORCID: https://orcid.org/0000-0002-6471-7073,nv-dulina@yandex.ru (Волгоград, Россия) 
Кизима Сергей Анатольевич - заведующий кафедрой международных отношений Академии управления при Президенте Республики Беларусь, доктор политических наук, професcop, ORCID: https://orcid.org/0000-0003-0725-5391, kizima@mail.ru (Минск, Республика Беларусь)

Ковалев Виктор Антонович - профессор кафедры политологии и международных отношений ФГБОУ ВО «Сыктывкарский государственный университет им. Питирима Сорокина», доктор политических наук, доцент, ORCID: https://orcid.org/ 0000-0003-3691-4106, vant_2000@mail.ru (Сыктывкар, Россия)

Лапин Анатолий Евгеньевич - заведующий кафедрой экономического анализа и государственного управления ФГБОУ ВО «Ульяновский государственный университет», доктор экономических наук, профессор, ORCID: https://orcid.org/0000-0003-1467-0358, eagov01@mail.ru (Ульяновск, Россия)

Макарова Марина Николаевна - профессор кафедры социологии ФГБОУ ВО «Удмуртский государственный университет», доктор социологических наук, доцент, ORCID: https://orcid.org/0000-0003-3176-6386, makmar11@mail.ru (Ижевск, Россия)

Немировский Валентин Геннадьевич - главный научный сотрудник учебно-научной лаборатории кафедры общей и экономической социологии ФГАОУ ВО «Тюменский государственный университет», доктор социологических наук, профессор, ORCID: https://orcid.org/0000-0002-4076-465X, valnemirov@mail.ru (Тюмень, Россия)

Резник Галина Александровна - заведующий кафедрой маркетинга и экономической теории ФГБОУ ВО «Пензенский государственный университет архитектуры и строительства», доктор экономических наук, профессор, ORCID: https:/orcid.org/ 0000-0003-4575-1812, reznikga@gmail.com (Пенза, Россия)

Садвокасова Айгуль Какимбековна - руководитель Центра по изучению межэтнических и межконфессиональных отношений в Центрально-Азиатском регионе Академии государственного управления при Президенте Республики Казахстан, доктор социологических наук, ORCID: https://orcid.org/0000-0002-3467-0833, aigul-kaz@yandex.ru (Астана, Казахстан)

Симанавичене Жанета - заведующий лабораторией инноваций в предпринимательстве Университета Миколаса Ромериса, доктор экономических наук, профессор, ORCID: https://orcid.org/0000-0001-6008-2405, zasiman@mruni.eu (Вильнюс, Литва)

Спринчан Сергей Леонидович - ученый секретарь и ведущий научный сотрудник Института юридических и политических исследований Академии наук Молдовы, доктор политологии, доцент, ORCID: https://orcid.org/0000-0002-7411-9958, sprinceans@yahoo.com (Кишинев, Республика Молдова)

Туровский Ростислав Феликсович - вице-президент Центра политических технологий, доктор политических наук, доцент, ORCID: https://orcid.org/0000-0001-8496-3098, rft777@mail.ru (Москва, Россия)

Шалаев Владимир Павлович - декан факультета социальных технологий ФГБОУ ВО «Поволжский государственный технологический университет», доктор философских наук, профессор, ORCID: https://orcid.org/0000-0001-9155-695X, shalaevvp@volgatech.net (Иошкар-Ола, Россия) 


\section{EDITORIAL BOARD}

Sergey M. Vdovin - Editor-in-Chief, Rector of National Research Mordovia State University, Ph. D. (Economics), Associate Professor, ORCID: https://orcid.org/ 0000-0001-7363-1389, rector@adm.mrsu.ru (Saransk, Russia)

Sergey V. Polutin - Deputy Editor-in-Chief, Director of Research Institute of Regionology, National Research Mordovia State University, Dr. Sci. (Sociology), Full Professor, ORCID: https://orcid.org/0000-0003-0399-4154, polutin.sergei@yandex.ru (Saransk, Russia)

Svetlana V. Gordina - Executive Editor, Member of European Association of Science Editors (EASE), Ph. D. (Pedagogy), ORCID: https://orcid.org/0000-0003-2265-418X, inted@adm.mrsu.ru, inted@mail.ru (Saransk, Russia)

Nassr S. M. Ahmad - Professor of Accounting, Faculty of Accounting, University of Gharyan, General Manager of Human Resources Development Institute, Libyan Academy, ORCID: https://orcid.org/0000-0002-2057-2220, nassr_ahmad@yahoo.co.uk (Ghrian, Libya)

Igor V. Bakhlov - Head of Department, Department of World History, Political Science and Regional Studies, National Research Mordovia State University, Dr. Sci. (Political Science), Associate Professor, ORCID: https://orcid.org/0000-0001-6886-5762, bahlov@mail.ru (Saransk, Russia)

Igor N. Barygin - Professor, Department of European Studies, St. Petersburg State University, Dr. Sci. (Political Science), Full Professor, ORCID: https://orcid.org/ 0000-0002-8143-3136, ibarygin@gmail.com (St. Petersburg, Russia)

Andrey G. Bolshakov - Head of Department, Department of Conflict Resolution, Kazan (Volga) Federal University, Dr. Sci. (Political Science), Associate Professor, ORCID: https://orcid.org/0000-0002-5036-000X, bolshakov_andrei@mail.ru (Kazan, Russia)

Andrey V. Dakhin - Head of Department, Department of Philosophy and Political Science, Nizhny Novgorod Institute of Management - Branch of the Russian Presidential Academy of National Economy and Public Administration, Dr. Sci. (Philosophy), Full Professor, ORCID: https://orcid.org/0000-0001-5907-706X, nn9222@rambler.ru (Nizhny Novgorod, Russia)

Pavel V. Druzhinin - Head of Department, Department of Modeling and Prognostication of Regional Development, Institute of Economics, Karelian Research Center of the Russian Academy of Sciences, Dr. Sci. (Economics), Associate Professor, ORCID: https://orcid.org/0000-0001-5303-0455, pdruzhinin@mail.ru (Petrozavodsk, Russia)

Nadezhda V. Dulina - Professor, Department of Sociology, Volgograd State University, Dr. Sci. (Sociology), Full Professor, ORCID: https://orcid.org/0000-0002-6471-7073, nv-dulina@yandex.ru (Volgograd, Russia)

Viktor I. Grishin - Rector of Plekhanov Russian University of Economics, Dr. Sci. (Economics), Full Professor, rector@rea.ru (Moscow, Russia)

Sergey A. Kizima - Head of Department, Department of International Relations, Academy of Public Administration under the Aegis of the President of the Republic of Belarus, Dr. Sci. (Political Science), Full Professor, ORCID: https://orcid.org/ 0000-0003-0725-5391, kizima@mail.ru (Minsk, Republic of Belarus) 
Viktor A. Kovalev - Professor, Department of Political Science and International Relations, Pitirim Sorokin Syktyvkar State University, Dr. Sci. (Political Science), Associate Professor, ORCID: https://orcid.org/0000-0003-3691-4106, vant_2000@mail.ru (Syktyvkar, Russia)

Anatoly E. Lapin - Head of Department, Department of Economic Analysis and Public Administration, Ulyanovsk State University, Dr. Sci. (Economics), Full Professor, ORCID: https://orcid.org/0000-0003-1467-0358, eagov01@mail.ru (Ulyanovsk, Russia)

Marina N. Makarova - Professor, Department of Sociology, Udmurt State University, Dr. Sci. (Sociology), Associate Professor, ORCID: https://orcid.org/0000-0003-3176-6386, makmar11@mail.ru (Izhevsk, Russia)

Valentin G. Nemirovskiy - Chief Researcher at the Training and Research Laboratory, Department of General and Economic Sociology, Tyumen State University, Dr. Sci. (Sociology), Full Professor, ORCID: https://orcid.org/0000-0002-4076-465X, valnemirov@mail.ru (Tyumen, Russia)

Galina A. Reznik - Head of Department, Department of Marketing and Economic Theory, Penza State University of Architecture and Construction, Dr. Sci. (Economics), Full Professor, ORCID: https://orcid.org/0000-0003-4575-1812, reznikga@gmail.com (Penza, Russia)

Aigul K. Sadvokassova - Director of the Center for the Study of Interethnic and Interfaith Relations in the Central Asian Region, Academy of Public Administration under the President of the Republic of Kazakhstan, Dr. Sci. (Sociology), ORCID: https://orcid.org/0000-0002-3467-0833, aigul-kaz@yandex.ru (Astana, Republic of Kazakhstan)

Vladimir P. Shalaev - Dean, Faculty of Social Technologies, Volga State University of Technology, Dr. Sci. (Philosophy), Full Professor, ORCID: https://orcid.org/ 0000-0001-9155-695X, shalaevvp@volgatech.net (Yoshkar-Ola, Russia)

Žaneta Simanavičienė - Head of Business Innovation Laboratory, Mikolas Romeris University, Dr. Sci. (Economics), Full Professor, ORCID: https://orcid.org/0000-0001-6008-2405, zasiman@mruni.eu (Vilnius, Lithuania)

Serghei L. Sprincean - Academic Secretary and Leading Researcher, Institute of Legal and Political Research, Academy of Sciences of Moldova, Dr. Sci. (Political Science), Associate Professor, ORCID: https://orcid.org/0000-0002-7411-9958, sprinceans@yahoo.com (Chisinau, Republic of Moldova)

Rostislav F. Turovsky - Vice-President, Center for Political Technologies, Dr. Sci. (Political Science), Associate Professor, ORCID: https://orcid.org/0000-0001-8496-3098, rft777@mail.ru (Moscow, Russia) 


\section{СОДЕРЖАНИЕ}

\section{Экономика и управление народным хозяйством}

К. Ю. Волошенко, Т. Е. Дрок. Эконометрический анализ влияния интенсивности трансграничности на уровень экономической сложности на примере стран Европы

Е. Б. Дворядкина, Е. А. Белоусова. Лучшие практики пространственного развития: возможность адаптации в отношении муниципальных районов

И. Б. Юленкова. Факторы инновационного развития региона 661

А. В. Смирнова, М. О. Дашкова. Анализ правовой и инфраструктурной основы научно-технологической сферы в регионах России: потенциал и перспективы формирования связности территорий страны

\section{Политическая регионалистика. Этнополитика}

Л. Р. Рустамова. Проблемы и перспективы приграничного сотрудничества еврорегионов с участием России

И. Г. Напалкова, А. С. Солдатова, К. В. Курочкина. Специфика развития этнонационального пространства современной России как фактор нациестроительства: стратегический ситуационный анализ

\section{Социальная структура, социальные институты и процессы}

К. В. Фофанова, А. А. Сычев. Факторы миграционной привлекательности провинциального города (на примере г. Саранска) 756

Н. П. Касаткина, Н. В. Шумкова. Вторичная занятость и самозанятость студентов вузов: масштабы, структура и функции (на примере Республики Мордовия)

Ч. И. Ильдарханова, В. А. Гневашева, А. Ф. Валидова. Диалог труда и материнства в условиях социально-экономической и территориальной дифференциации в Республике Татарстан

Ю. М. Брумштейн, Н. К. Алимова. Научные журналы постсоветских государств: место в национальном и международном информационном пространстве

В. В. Козин, С. Г. Ушкин. Этносоциологические исследования в Республике Мордовия в 1990-2010 гг.: ретроспективный анализ

Информация для авторов и читателей (на рус. яз.)

Информация для авторов и читателей (на англ. яз.) 
http://regionsar.ru

ISSN 2587-8549 (Print)

DOI: $10.15507 / 2413-1407.109 .027 .201904$

ISSN 2413-1407 (Online)

\section{CONTENTS}

\section{Economics and Management of National Economy}

K. Yu. Voloshenko, T. E. Drok. Econometric Analysis of the Impact of the Intensity of Transboundary Activities on the Level of Economic Complexity: The Case Study of European Countries

E. B. Dvoryadkina, E. A. Belousova. Best Practices of Spatial Development:

Possibility of Using Them in the Municipal Districts of Russia

I. B. Yulenkova. Factors in Innovative Development of a Region 661

A. V. Smirnova, M. O. Dashkova. Analysis of the Legal and Infrastructural Basis for the Scientific and Technological Sphere in the Regions of Russia: Potential and Prospects for the Formation of Connectedness of the Country's Territories

\section{Political Regional Studies. Ethnopolitics}

L. R. Rustamova. Problems and Prospects of Cross-Border Cooperation

in Euroregions with Russian Participation

I. G. Napalkova, A. S. Soldatova, K. V. Kurochkina. Specifics of the Development of the Ethno-National Space of Modern Russia as a Factor in Nation Building: A Strategic Situational Analysis 734

\section{Social Structure, Social Institutions and Processes}

K. V. Fofanova, A. A. Sychev. Factors in Migration Attractiveness of a Provincial City: The Case Study of the City of Saransk 756

N. P. Kasatkina, N. V. Shumkova. Secondary Employment and Self-Employment of Higher Education Students: The Scale, Structure and Functions (the Case Study of the Republic of Mordovia)

Ch. I. Ildarhanova, V. A. Gnevasheva, A. F. Validova. Dialogue of Labor and Motherhood in the Context of Socio-Economic and Territorial Differentiation in the Republic of Tatarstan 801

Yu. M. Brumshteyn, N. K. Alimova. Scientific Journals in the post-Soviet States:

The Place in the National and International Information Space

V. V. Kozin, S. G. Ushkin. Ethnosociological Studies in the Republic of Mordovia in 1990-2010: A Retrospective Analysis

Information for Authors and Readers of the Journal (in Russian) ...................... 880

Information for Authors and Readers of the Journal (in English) 


\section{ЭКОНОМИКА И УПРАВЛЕНИЕ НАРОДНЫМ ХОЗЯЙСТВОМ / ЕCONOMICS AND MANAGEMENT OF NATIONAL ECONOMY}

УДК 330.43(4)

DOI: $10.15507 / 2413-1407.109 .027 .201904 .602-632$

http://regionsar.ru ISSN 2587-8549 (Print) ISSN 2413-1407 (Online)

\section{Эконометрический анализ влияния интенсивности трансграничности на уровень экономической сложности на примере стран Европы}

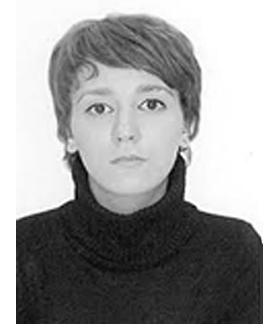

К. Ю. Волошенко

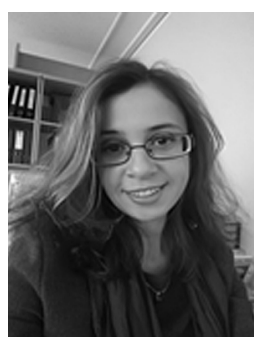

T. Е. Дрок

ФГАОУ ВО «Балтийский федеральный университет имени Иммануила Канта» (г. Калининград, Россия), *kvoloshenko@kantiana.ru

Введение. Развитие стран, регионов и отдельных экосистем происходит в парадигме инновационно-технологических изменений. В качестве определяющего элемента выступают производственные знания и компетенции. Их измерение с точки зрения трансформации в сложности продуктов, которые экспортирует страна, получило воплощение и развитие в подходе экономической сложности. Однако сегодня недостаточно внимания уделяется исследованию экономической сложности в контексте трансграничных процессов, оказывающих влияние на развитие территорий. Целью настоящего исследования является измерение влияния на примере стран Европы интенсивности трансграничных связей через показатели приграничной специализации внешнеторгового оборота на изменение экономической сложности.

Материалы и методы. Применялись методы эконометрического анализа, в качестве исходных данных для проведения расчетов и измерений использовались сведения базы данных «Комтрейд ООН», а также специальных ресурсов по

(C) Волошенко К. Ю., Дрок Т. Е., 2019

Контент доступен под лицензией Creative Commons Attribution 4.0 License.

This work is licensed under a Creative Commons Attribution 4.0 License. 
анализу экономической сложности стран - Атласа экономической сложности и Обсерватории экономической сложности.

Результаты исследования. Проведена типология стран Европы с использованием гауссовой смеси распределений, получено 3 субпанели. С использованием метода панельной коинтеграции на основе построенных моделей (объединенная модель и модели с фиксированными и случайными эффектами), которые дополнены анализом данных с применением полностью модифицированного метода наименьших квадратов и динамического метода наименьших квадратов, определена интенсивность влияния фактора трансграничности на сложность экономики. Выявлены долгосрочные зависимости между экономической сложностью и интенсивностью трансграничности.

Обсуждение и заключение. Установлено, что влияние фактора трансграничности ослабевает по мере роста экономической сложности, а при определенных условиях он оказывает отрицательное воздействие. Выявленная зависимость обусловливается возрастающей ролью глобальных процессов против трансграничных по мере усложнения экономики и ориентации преимущественно на мировой рынок. Полученные результаты имеют значение для дальнейшего развития теории экономической сложности, значительно расширяют практическую сферу ее применения, играют важную роль в понимании и последующем изучении потенциала и ограничений развития территорий, различающихся по тесноте трансграничных связей.

Ключевые слова: типология, страны Европы, трансграничность, экономическая сложность, производственные возможности (компетенции), гетерогенный панельный анализ, мировая торговля, приграничная специализация внешнеторгового оборота

Финансирование. Исследование выполнено при финансовой поддержке РФФИ и Правительства Калининградской области в рамках научного проекта № 19-410-390002.

\title{
Econometric Analysis of the Impact of the Intensity of Transboundary Activities on the Level of Economic Complexity: The Case Study of European Countries
}

\author{
K. Yu. Voloshenko", T. E. Drok \\ Immanuel Kant Baltic Federal University (Kaliningrad, Russia), \\ *kvoloshenko@kantiana.ru
}

Introduction. Development of countries, regions and individual ecosystems occurs in the paradigm of innovative and technological change, the crucial element being the production knowledge and competencies. Their ranging in terms of transforming the complexity of the products that the country exports has been embodied and developed in the approach of economic complexity. However, insufficient attention is paid to the study of economic complexity in the context of transboundary processes that impact the development of territories. The objective of this study is to measure the impact of the intensity of transboundary relations on the change in economic complexity through the case study of European countries using the indicators of transboundary specialization of foreign trade turnover. 
Materials and Methods. The study employed the methods of econometric analysis. Information from the UN Comtrade database, as well as from the special resources for analyzing the economic complexity of countries, the Atlas of Economic Complexity and the Observatory of Economic Complexity, was used as the source data for calculations and measurements.

Results. European countries have been classified into 3 subpanels based on Gaussian mixture distributions. The intensity of the impact of the transboundary activities on the complexity of the economy has been identified employing the panel cointegration method based on the constructed models (the combined model and models with fixed and random effects), which were supplemented by data analysis using the fully modified least squares method and the dynamic least squares method. Long-term interdependence between economic complexity and the intensity of transboundary activities has been identified.

Discussion and Conclusion. It has been established that the influence of the transboundary interaction factor weakens as the economic complexity increases and under certain conditions it has a negative impact. The revealed dependence is due to the increasing role of global processes rather than the transboundary ones as the economy becomes more complex and more oriented towards the global market. The research findings contribute to further development of the Theory of Economic Complexity; they significantly expand the practical scope of its application, play an important role in understanding and further research on the opportunities and limitations for the development of territories differing in the transboundary cooperation intensity.

Keywords: typology, European countries, transboundary activities, economic complexity, productive capacity (competencies), heterogeneous panel analysis, world trade, cross-border specialization of foreign trade turnover

Funding. The study was carried out with the financial support from the Russian Foundation for Basic Research and the Government of the Kaliningrad Region as part of the scientific project No. 19-410-390002.

Введение. В рамках теории экономической сложности [1] сегодня эмпирически доказано существование прямой связи между экономической сложностью и ростом национального благосостояния. Будущее национальное процветание является функцией нынешней и будущей экономической сложности: чем выше экономическая сложность, тем выше потенциал для экономического роста, а соответственно, преумножения национального богатства и создания условий для национального процветания. Для этого должны быть выполнены следующие условия: a) широкий портфель продуктов и услуг с высоким уровнем экспорта; б) высокий уровень уникальности по всем этим продуктам, т. е. немногие другие страны (предпочтительно ни одна) могут производить и экспортировать эти продукты и услуги; в) высокая сложность продуктов [2]. Сложность предполагает, что производство таких продуктов требует различных ресурсов, очень высокая доля которых предоставляется с точки зрения создания добавленной стоимости поставщиками, расположенными в той же стране. Это обусловливается или их уникальными предложениями, или чрезвычайно высокой создаваемой ими стоимостью, 
что является лучшим решением по источникам ресурсов, чем их приобретение за рубежом.

Разработка и производство передовых предложений происходят в условиях взаимозависимости, которая требует сотрудничества между различными участниками. Чем больше субъектов участвуют в этих взаимозависимостях, тем больше у страны или региона возможности использовать выгоды, полученные в результате формирования сложной цепочки создания стоимости на местном, национальном или международном уровнях. В этой связи встает вопрос о степени влияния на экономическую сложность не только внутренних, но и внешних взаимодействий участников, что наиболее ярко проявляется на уровне трансграничного сотрудничества. В последние годы во многих европейских странах фиксируется некоторое снижение интенсивности процессов трансграничного взаимодействия и отмечаются колебания в показателях экономической сложности. Соответственно требуется эмпирическая проверка гипотезы о возможном влиянии трансграничности с учетом типологии стран по степени ее интенсивности на экономическую сложность.

Цель проведенного исследования - оценка с использованием эконометрических методов влияния показателя приграничной специализации внешнеторгового оборота, который мы обозначаем как индекс интенсивности трансграничности (TII - Transboundary Intensity Index) на индекс экономической сложности (ECI - Economic Complexity Index) на примере стран Европы. В данной работе мы учитываем перечень стран Европы по определению Постоянного комитета по географическим названиям (Германия) (Ständige Ausschuss für geographische Namen (StAGN)), который не включает страны Восточной Европы.

Для изучения связи трансграничного сотрудничества и экономической сложности мы рассматриваем понятие интенсивности трансграничности. Предполагается, что чем активнее соседние страны включены в различные типы взаимных внешнеторговых операций, тем выше интенсивность трансграничности. Выдвигается гипотеза о присутствии зависимости интенсивности трансграничности и экономической сложности. Для целей исследования на интервале 1997-2017 гг. сформирована сбалансированная панель данных по показателям TII и ECI для выборки стран Европы. На основе выделяемых типов стран по интенсивности трансграничности по результатам анализа панельных данных и построения моделей делаются выводы о характере зависимости уровня экономической сложности от изменения интенсивности трансграничных процессов.

Следуя логике исследования, рассматриваются основные положения теории экономической сложности, приводятся результаты типологии стран Европы с использованием гауссовой смеси распределений, результаты эконометрического анализа панельных данных. 
Обзор литературы. Основы теории экономической сложности заложили в своих работах Р. Хаусманн и С. А. Идальго [3-7]. Экономическая сложность - это мера знаний в обществе, которая переводится на продукты, которые она производит ${ }^{1}$. Сложность экономики связана со множеством полезных знаний, встроенных в нее. Обнаружено, что страны, которые могут создавать и/или поддерживать разнообразные производственные ноу-хау, в том числе сложные, уникальные технологии, могут производить большое число разнообразных товаров, включая сложные продукты.

Сегодня проблематика экономической сложности изучается в контексте различных социальных и экономических вопросов. Так, некоторые ученые анализируют влияние экономической сложности на: экономический рост и уровень благосостояния стран $[1 ; 4 ; 8]$, неравенство доходов [9], проблемы рынка труда [2], структурные сдвиги [10]. Другие авторы обнаруживают связь с производительностью [11], прямыми иностранными инвестициями [12]. Недавно появились работы, освещающие и экологические вопросы [13].

Последние исследования в рамках теории экономической сложности концентрируются на изучении принципа связанности и в области диверсификации экономической деятельности [6;7], доминирования технологических инноваций и оптимизации распространения знаний [14-18].

С. Радошевич акцентирует внимание на технических проблемах, которые существуют и выявлены при измерении экономической сложности [19]. Это проблемы полноты торговых данных; учета в полной мере торговли услугами; использование кодов SITC (Standard International Trade Classification) или HS (Harmonized System), которые могут объединять товары, требующие различных компетенций и навыков, игнорируя различия в качестве; точность оценок из-за различий в структуре рынка между странами; данные о торговле могут не отражать фактическую добавленную стоимость конечного экспорта из-за географически разбросанных производств и фрагментации глобальных производственносбытовых цепочек (GVC).

На наш взгляд, контекст экономической сложности требует учета и такого фактора, как влияние трансграничности. Это в большей мере связано с причинами, обусловленными собственно спецификой формирования и развития трансграничных связей ${ }^{2}$. Первая причина - сохраняющееся усиление взаимодействия приграничных территорий разных стран и их контактной функции, что неизбежно способствует развитию

${ }^{1}$ Hidalgo C. A., Hartmann D. Economic Complexity, Institutions, and Income Inequality, OECD Insights. URL: http://www.oecd-ilibrary.org/economics/debate-the-issues-complexity-and-policy-making_9789264271531-е (дата обращения: 28.06.2019).

${ }^{2}$ Корнеевец В. С. Международная регионализация на Балтике. СПб., 2010. 207 с. 
трансграничных связей. Это дает основание предположить, что диверсификация экспорта стран, имеющих более высокую интенсивность трансграничных связей, будет оказываться выше. Во-вторых, нередко соседние приграничные регионы разных стран становятся конкурентами, так как сходные ресурсы и условия их развития способствуют производству единообразных товаров и услуг и выходу их на внешний рынок. Это, наоборот, может оказывать отрицательное воздействие на уровень экономической сложности и иметь обратный эффект. В-третьих, это современные условия геополитической турбулентности [20], что выражается в изменении интенсивности трансграничных связей и, в свою очередь, в разные периоды в различной степени может влиять и на экономическую сложность.

Как подтверждают результаты теоретических работ, область применения экономической сложности постоянно расширяется. Это обусловлено преимуществом использования и учетом в подходе современных трендов технологических изменений в обществе и происходящей сменой парадигмы создания ценности (стоимости). В связи с пониманием важности происходящих процессов в поддержке и развитии трансграничных взаимодействий стран растет актуальность изучения вопросов влияния их интенсивности на изменение экономической сложности.

Материалы и методы. В качестве зависимой переменной принят уровень экономической сложности, который измеряется соответствующим показателем - Индексом экономической сложности (ECI), а в качестве влияющего фактора - интенсивность трансграничности (TII). Описание методологии расчета ЕCI приводят в своих работах Р. Хаусманн и С. А. Идальго [3-5]. Ежегодные данные размещаются сегодня на двух официальных ресурсах в сети Интернет, созданных и поддерживаемых Гарвардским университетом (The Center for International Development at Harvard University) и Массачусетским технологическим институтом (The MIT Media Lab): это Атлас экономической сложности (The Atlas of Economic Complexity) ${ }^{3}$ и Обсерватория экономической сложности (Тhe Observatory of Economic Complexity) ${ }^{4}$. Признавая научную проблему определения меры интенсивности для трансграничных связей, в данной работе мы принимаем допущение о достаточности учета специализации внешнеторгового оборота в характеристике содержания взаимодействия сопредельных стран. В качестве меры интенсивности трансграничности используется широко известный коэффициент приграничной специализации внешнеторгового оборота [21]. В настоящем исследовании он обозначен в качестве индекса интенсивности трансграничности и рас-

${ }^{3}$ The Atlas of Economic Complexity. URL: http://atlas.cid.harvard.edu (дата обращения: 19.06.2019).

4 The Observatory of Economic Complexity. URL: https://atlas.media.mit.edu (дата обращения: 19.06.2019). 
считывался для каждой страны как отношение объема внешнеторгового оборота с сопредельными территориями к общему объему внешнеторгового оборота страны. В качестве источника информации использованы сведения базы данных «Комтрейд ОOH» (UN Comtrade Database) ${ }^{5}$.

Выявление и изучение влияния трансграничности на экономическую сложность в данном исследовании проводится на примере стран Европы в 1997-2017 гг. Рассматриваются страны, имеющие морские и сухопутные границы. Из исследования исключены карликовые государства: Андорра, Ватикан, Лихтенштейн, Монако, Сан-Марино, а также островные государства: Великобритания, Ирландия, Исландия, Мальта. Предварительная выборка включала 31 страну: это Австрия, Албания, Бельгия, Болгария, Босния и Герцеговина, Венгрия, Германия, Греция, Дания, Испания, Италия, Латвия, Литва, Люксембург, Нидерланды, Норвегия, Польша, Португалия, Румыния, Северная Македония, Сербия, Словакия, Словения, Финляндия, Франция, Хорватия, Черногория, Чешская Республика, Швейцария, Швеция, Эстония. По результатам сбора и анализа доступных статистических данных по указанным источникам из выборки были исключены 2 страны: Черногория - отсутствуют данные на ресурсах по индексу экономической сложности (ЕCI), а расчет индекса в настоящей работе не предусмотрен; Люксембург - в индексе экономической сложности (ECI) учитывается совместно с Бельгией. Итоговая выборка составила 29 стран.

В данном исследовании получен двумерный массив данных, одна из размерностей которых имеет временную интерпретацию, а другая пространственную. В связи с этим проведен эконометрический анализ, основанный на панельных данных. Для расчетов использовалась программа EViews v9.0.

На начальном этапе по всем странам были проанализированы значения показателей TII и ECI для каждого года на интервале 1997-2017 гг. Установлено, что связь между переменными слабая. Проведена экспериментальная кластеризация стран по различным критериям. Наилучшие результаты по статистике типологических групп были получены на основе интенсивности трансграничности (TII). Последующая типология стран с выделением кластеров проводилась с использованием ЕМ-алгоритма на основе гауссовой смеси распределений. В результате было выделено 3 кластера стран (субпанели).

Ниже дано краткое описание анализа панельных данных:

1) кросс-зависимость в панельных данных. В первую очередь проверялось наличие зависимостей между переменными внутри каждой кросс-секции данных. В нашем исследовании это предполагает присут-

${ }^{5}$ UN Comtrade Database. URL: https://comtrade.un.org (дата обращения: 19.06.2019). 
ствие корреляции между странами по показателям интенсивности трансграничности, которая проверялась на основе теста на кросс-зависимость Песарана (Pesaran), и индексу экономической сложности;

2) описание структуры панельных данных. Этот этап включал проверку условий панельной коинтеграции. С учетом возможных различий в скорости сходимости и с допущением межстрановых корреляций остатков предварительно проверяется основная гипотеза о стационарности. EViews предоставляет удобные инструменты для тестирования корневых модулей вычислительной панели, а также все три модификации (с константой, трендом, константой и трендом). Анализировалась статистика теста Хадри (Hadri Z-stat) с учетом возможной гетероскедастичности, выполненная в оценках Ньюи и Уест (Newey - West). Для оценки коинтеграционного соотношения между панельными переменными проводился тест Педрони (Pedroni-test). Тестовые статистики были сгруппированы в две категории: основанные на групповых средних и панельных статистиках. Нулевая гипотеза об отсутствии коинтеграции проверялась на уровне значимости 0,1. Решение о коинтегрированности процессов принималось, если нулевая гипотеза отвергалась для трех и более статистик из семи;

3) оценка панельных моделей. Основным этапом является определение спецификации панельных эффектов модели - объединенной модели (pooled model), с фиксированными (fixed effect model) и случайными (random effect model) эффектами. Дополнительно построены модели с использованием полностью модифицированного метода наименьших квадратов (fully modified ordinary least squares, FMOLS) и динамического метода наименьших квадратов (dynamic ordinary least squares, DOLS) [22]. Проблема выбора модели решалась с помощью стандартной техники проверки гипотез [23], а мониторинг построенных панельных моделей включал оценку их качества [24].

Результаты исследования. В последние годы практически во всех анализируемых группах стран Европы наблюдается снижение интенсивности процессов трансграничного взаимодействия, что проявляется на уровне динамики приграничной специализации внешнеторгового оборота. В этот же период аналогичная динамика отмечается и по показателю экономической сложности стран Европы. Учитывая, что индекс экономической сложности измеряется по степени распространенности и диверсификации производимой и экспортируемой продукции, можно предположить следующее объяснение фактической динамики показателя. Быстрый рост экономической сложности на исследуемом интервале 1997-2017 гг. нблюдался в тех странах, которые изначально в сравнении с ведущими странами Европы в рейтинге по ECI имели гораздо меньшие показатели сложности экономики, уровня благосостояния и темпов экономического развития (традиционно измеряемые через ВВП на душу населения). Это 
Хорватия, Чехия, Эстония, Латвия, Литва, Нидерланды, Польша, Греция, Венгрия, Румыния и Словакия. Поэтому развитие этих стран в течение 1997-2017 гг., связанное с изменением их производственной структуры и производственных возможностей за счет расширения базы знаний, обусловливало появление в экспорте более сложной продукции, что соответственно влияло и на рост ЕСI. В то же время для стран, имеющих более высокий уровень развития и ЕCI, так называемый эффект низкой (или нулевой) базы был не характерен. Учитывая, что число стран, производящих сложные продукции, росло, а появление их новых видов происходит несколько меньшими темпами, страны с изначально высокими показателями ECI в 1997 г. несколько сократили позиции, и уровень показателя для них снижался. Здесь характерны примеры следующих стран Европы, в которых происходило наибольшее абсолютное суммарное (кумулятивное) сокращение ЕCI: Италия $(-0,434)$, Австрия $(-0,341)$, Дания $(-0,333)$, Швеция $(-0,315)$, Финляндия $(-0,276)$, Германия $(-0,275)$, Франция $(-0,269)$, Бельгия $(-0,265)$.

При этом анализ динамики показателей ЕCI и ТII обнаруживает, что не по всем странам выборки присутствует прямая зависимость - рост приграничной торговли не всегда сопровождается ростом экономической сложности и наоборот. В частности, это касается таких стран, как Чехия, Эстония, Литва, Нидерланды, Польша, Норвегия, Словакия, где фиксировался рост уровня экономической сложности, однако интенсивность трансграничности за 1997-2017 гг. снижалась. Для Болгарии, Финляндии, Португалии и Швеции наблюдалась обратная ситуация - при росте трансграничной интенсивности индекс экономической сложности снижался.

По нашему мнению, фиксация прямой и обратной связи, обусловленности изменения экономической сложности и трансграничности прослеживается на уровне различий в типологических группах стран по степени интенсивности последней. В этой связи проведена типология стран по интенсивности трансграничности и последующий анализ панельных данных на уровне выделенных групп стран (субпанелей).

В целях типологии стран Европы по уровню интенсивности трансграничности предварительно был проведен регрессионный анализ данных по исходной базе для всей совокупности и каждой страны отдельно на интервале 1997-2017 гг. Для всей выборки коэффициент корреляции Пирсона $(r)$ составил 0,4386, а коэффициент детерминации $\left(R^{2}\right)$ соответственно 0,1924 ( $p=0)$. По статистике Колмогорова - Смирнова и Шапиро - Уилка гипотеза о нормальности распределения для всей выборки стран отвергается (для ТII: $p_{\mathrm{w}-\mathrm{s}}<0,01, p_{\mathrm{w}}=0$; для ЕСI: $p_{\mathrm{w}-\mathrm{s}}<0,1$, $\left.p_{\mathrm{w}}=0\right)$. Выявлено, что линейная умеренная и сильная связь ЕС̈ и Т ТІ об̆наруживается только для части стран в выборке. Следует учитывать, что оцениваемые значения $R^{2}$ и коэффициента Пирсона обладают та- 
кими недостатками, как невысокая устойчивость к выбросам значений в исходной выборке ${ }^{6}$. Также накладываются ограничения линейности и монотонности изменения данных. В этой связи дополнительно проведен анализ данных на основе непараметрической статистики с использованием коэффициента Спирмена. Для всей выборки стран значения оказались несколько ниже коэффициента Пирсона: 0,4136 ( $p=0)$. В связи с неудовлетворительными результатами дальнейший анализ по странам не приводится.

Таким образом, по результатам предварительного регрессионного анализа можно утверждать, что по исследуемым странам Европы сложилась неоднозначная ситуация. Для одних стран характерна сильная линейная связь, для других - связь между интенсивностью трансграничности и экономической сложностью либо отсутствует, либо имеет нелинейный характер. Существенное влияние на результаты исследования зависимости переменных может оказывать некорректно выбранный инструментарий. Исходная база представляет собой панельные данные, поэтому оценка связей должна проводиться с использованием эконометрических методов и моделей, причем с учетом типологических групп.

В этой связи на следующем шаге посредством гауссовой смеси распределений (GMM) проведена кластеризация стран в целях выделения субпанелей для их типологии (группировки) и последующего панельного анализа данных. Применение конечных гауссовых смесей при моделировании реальных процессов и явлений в последние годы «обосновывается и расширяется в различных областях науки и практики: в распознавании образов и речи, биологии, медицине, географии, физике и химии, нейроинформатике, социологии и экономике и др.» [25]. В процессе выделения кластеров анализируются нормально распределенные группы внутри общей выборки. В качестве преимуществ метода приводят их полезные свойства: гладкость (бесконечная дифференцируемость), идентифицируемость, полнота, разрешение [25; 26$]$.

GMM-анализ и исследование данных в настоящей работе произведены с помощью пакета scikit-learn языка программирования Рython. Реализован алгоритм последовательного добавления компонент (ЕМ-алгоритм) для подбора разбиения стран на кластеры и их последующего распределения между оптимальным количеством групп по уровню трансграничной активности. Оценка распределений позволила установить, что исходная выборка стран наилучшим образом описывается в составе трех кластеров (рис. 1).

${ }^{6}$ StatSoft. Texbook. URL: http://www.statsoft.com/Textbook/Basic-Statistics\#Correlationsb (дата обращения: 19.06.2019). 


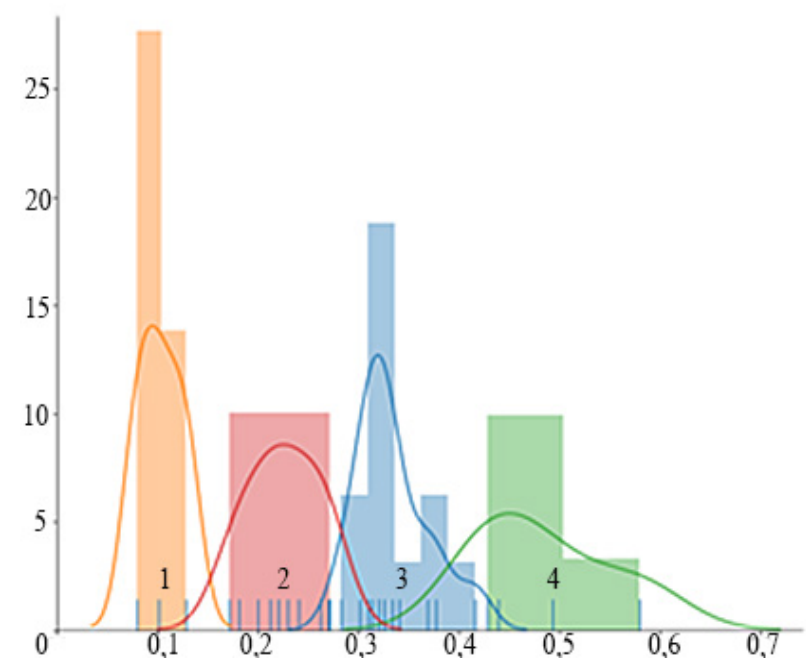

Р и с. 1. Выделение групп для типологии стран Европы с использованием ЕМ-алгоритма на основе распределения фактических значений показателей ${ }^{7}$

F i g. 1. Allocation of groups for the typology of European countries using the EM algorithm based on the distribution of actual indicator values

Как можно заметить на рисунке 1, кластеры 2 и 4 являются практически идентичными распределениями, поэтому могут быть объединены в одну типологическую группу.

Первый кластер (тип): Албания, Босния и Герцеговина, Болгария, Хорватия, Нидерланды, Норвегия, Португалия, Сербия, Словения, Швейцария, Северная Македония. Второй кластер (тип): Австрия, Бельгия, Дания, Франция, Венгрия, Италия, Латвия, Литва, Румыния, Испания. Третий кластер (тип): Чехия, Эстония, Финляндия, Германия, Греция, Польша, Словакия, Швеция. Для первой группы (субпанели) характерны наименьшие значения переменных, для второй и третьей - практически одинаковый уровень трансграничной интенсивности, однако значение экономической сложности в последней группе выше.

Для большинства стран теснота связи между интенсивностью трансграничности и экономической сложностью снижается по мере роста последней. Чем больше становится значение экономической сложности,

${ }^{7}$ Рисунок составлен авторами на базе собственных расчетов на основе Python. 
тем в меньшей степени на ее изменение оказывает влияние трансграничная активность стран. Чтобы проверить данное предположение и оценить направление воздействия интенсивности трансграничности на экономическую сложность - прямое или обратное - анализируются панельные данные и строятся эконометрические модели в соответствии с алгоритмом, описанным выше.

В отличие от простых регрессионных моделей в анализе панельных данных существует возможность учитывать индивидуальные отличия между объектами, в нашем исследовании - между странами. Кроме этого, снижается зависимость между объясняющими переменными, а следовательно, стандартные ошибки оценок, предотвращается смещение агрегированности, которое возникает при анализе временных рядов и пространственных данных [27].

Перед построением панельных моделей для анализируемых субпанелей проведена оценка качества исходных данных. К основным проблемам, которые могут возникать при использовании панельных данных, вызывать смещения и получение ложной регрессии, относятся следующие: кросс-зависимость, нестационарность, гетероскедастичность, отсутствие коинтеграции. По этой причине была проведена серия тестов на обнаружение указанных проблем для характеристики исходных панельных данных по интенсивности трансграничности и экономической сложности. В таблицах 1 и 2 приведены отдельные результаты, в то время как для проверки каждой характеристики нами применялись различные варианты тестов.

Для нашего исследования тест на наличие кросс-зависимости в панельных данных (cross-sectional dependence) предполагает проверку корреляции переменных между отдельными странами. По результатам тестирования первую панель на уровне значимости $10 \%$ мы можем считать пространственно-коррелированной, для второй и третьей - признать нулевую гипотезу об отсутствии пространственной корреляции.

Нестационарность связана со случайным блужданием значений экономической сложности и трансграничности во времени. Рассматривались традиционные тесты единичного корня: тест Левина - Лина - Чу (Levin Lin - Chu, LLC), тест Брайтунга (Breitung), тест Има - Песарана - Шина (Im - Pesaran - Shin, IPS), тест Фишера с использованием статистики Дики - Фуллера (Dickey - Fuller, ADF - Fisher) и тест Фишера, основанный на статистике Филипса - Перрона (PP - Fisher), а также все три модификации (с константой, трендом, константой и трендом) [28]. В дополнение к первому поколению тестов на наличие единичного корня использовались тесты второго поколения - расширенные тесты Дики - Фуллера (Dickey - Fuller, CADF) и Има - Песарана - Шина (Im Pesaran - Shin, CIPS) с учетом кросс-зависимости [29]. 


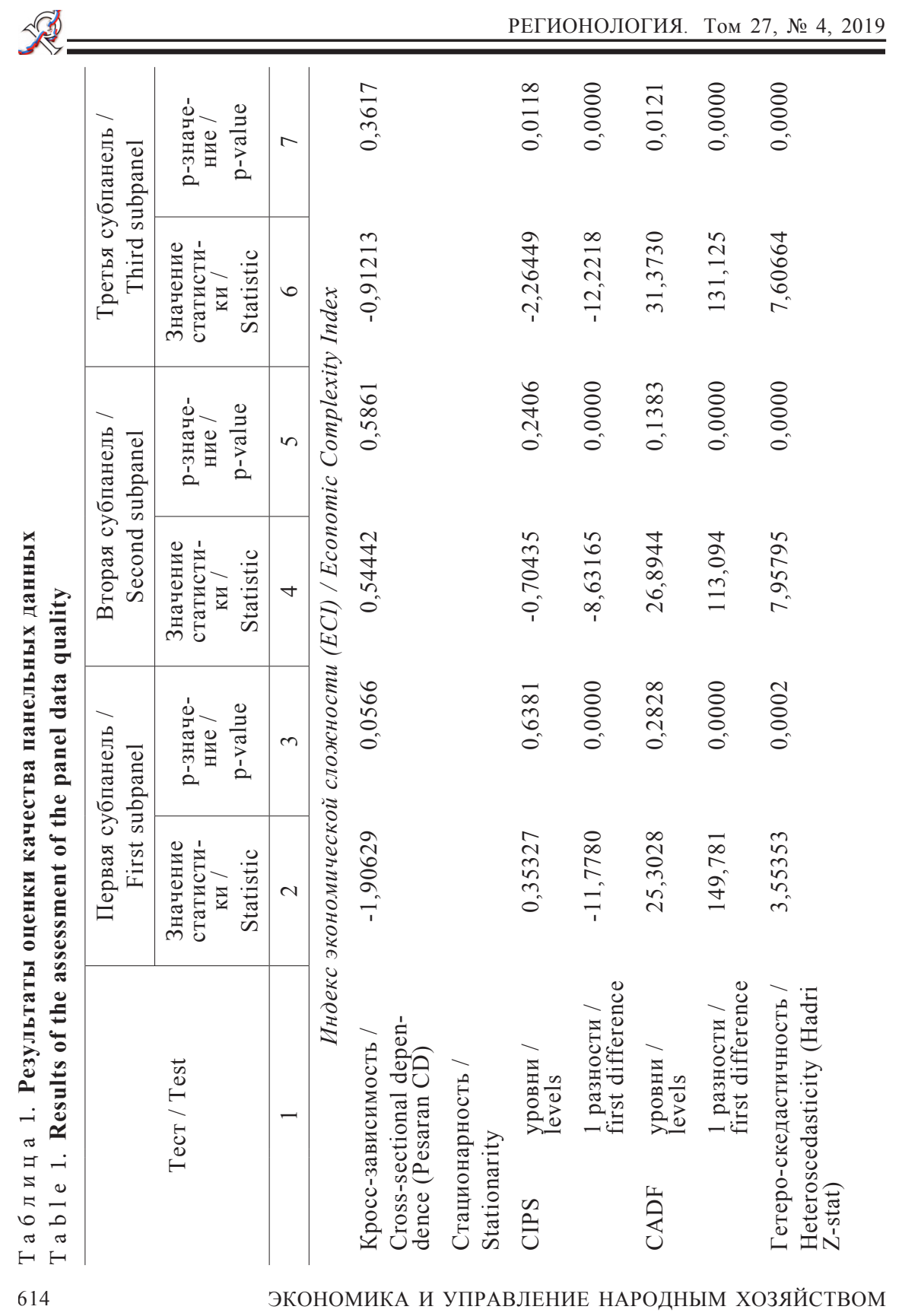




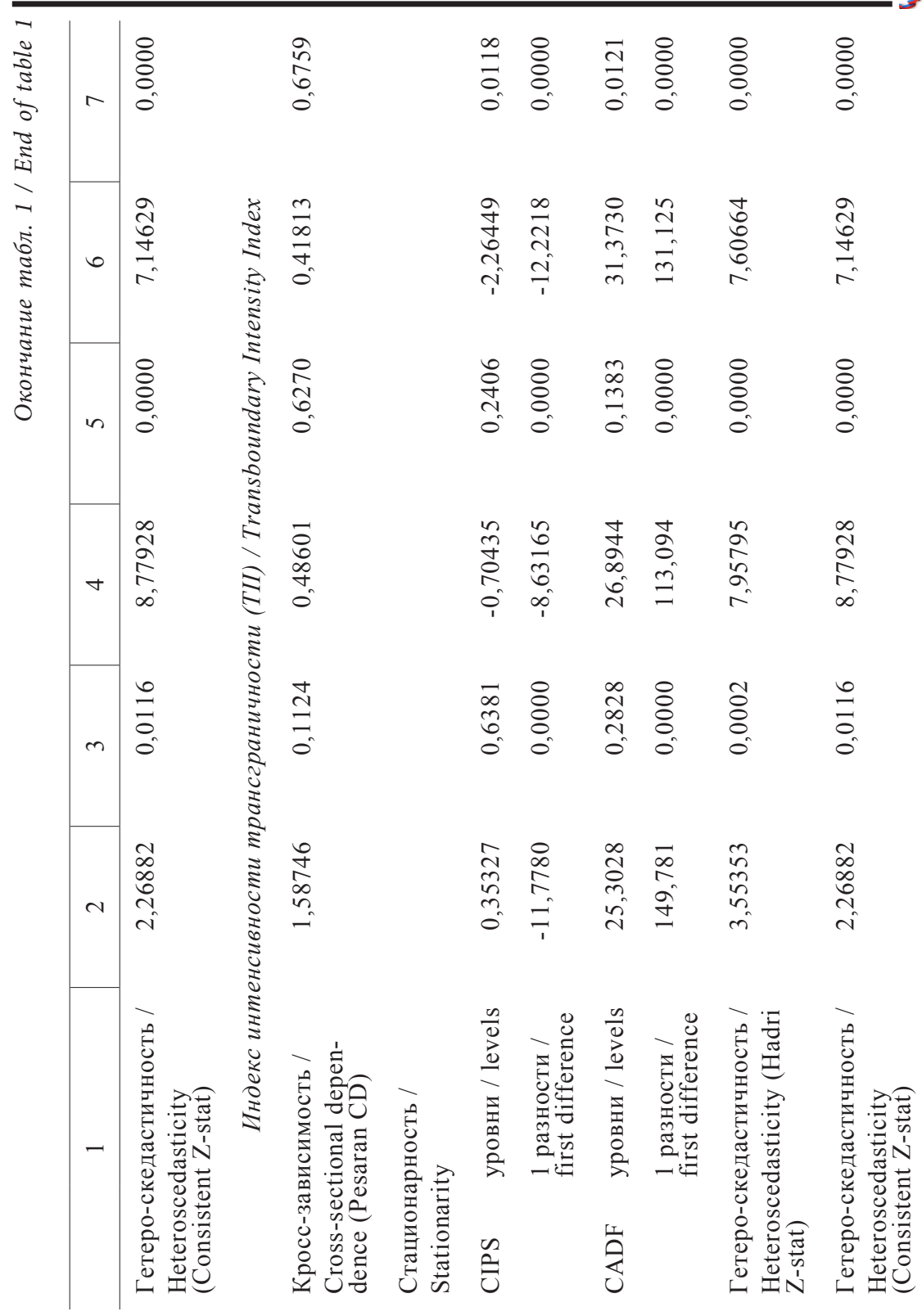




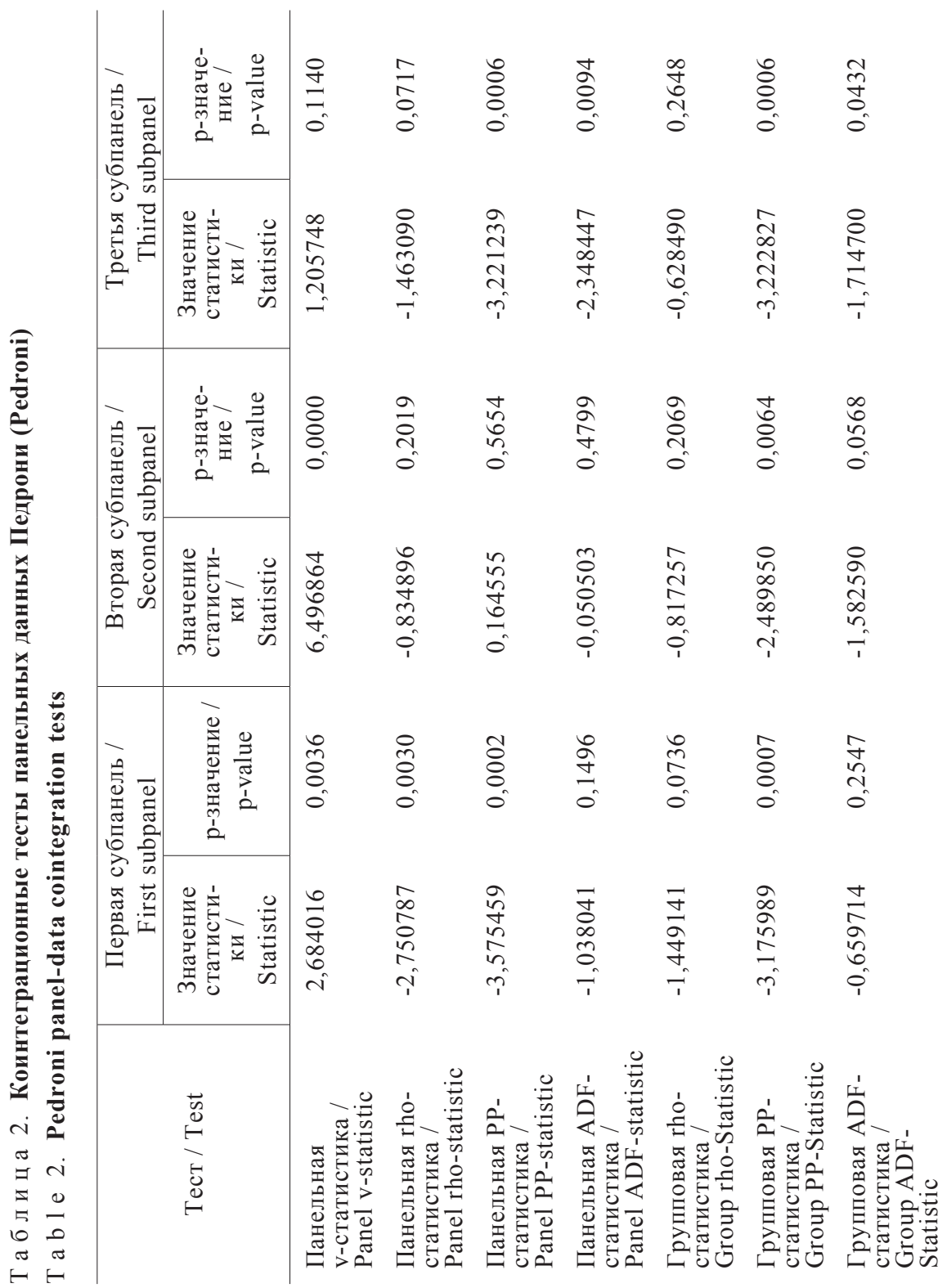


Полученные значения тестовых статистик позволяют сделать вывод, что показатели экономической сложности и интенсивности трансграничности являются реализацией нестационарного случайного процесса с порядком интегрированности 1 (I(1)). Прослеживаемые взаимосвязи не являются кажущимися и порождены наличием единичных корней. Гетероскедастичность предполагает неоднородность наблюдений и проявляется по причине объединения в панели индивидуальных рядов стран, описываемых различными случайными процессами или процессами одного характера, но с разными параметрами. В нашем исследовании на уровне значимости $5 \%$ для всех панелей мы не можем принять гипотезу об отсутствии гетероскедастичности, следовательно, данные по странам обладают неоднородностью. Коинтегрированность означает, что, несмотря на случайный (слабо предсказуемый) характер изменения объектов, существует долгосрочная зависимость между ними, которая приводит к некоторому совместному, взаимосвязанному изменению [24; 27]. Тесты подтвердили панельную коинтеграцию исходных данных по странам.

По результатам тестирования исходных данных можно сделать следующий вывод: имеется проблема пространственной корреляции и гетероскедастичности, однако ряды являются стационарными по первой разности, и фиксируется совместная интеграция, что говорит о возможности оценки долгосрочной зависимости переменных.

Далее для анализа долгосрочной зависимости переменных оценивались параметры уравнений объединенной модели (pooled model), а также моделей с фиксированными (fixed effect model) и случайными (random effect model) эффектами. Анализ производился с помощью метода наименьших квадратов (LS - Least Squares (LS and AR)). Наилучшие значения получены для спецификаций моделей с фиксированными эффектами (табл. 3). Это свидетельствует, что изменение экономической сложности имеет индивидуальные эффекты на уровне стран, инвариантные по времени в зависимости от трансграничной активности. Результат в целом подтверждает интуитивное представление о несоответствии объединенной или случайной модели для описания панельных данных. Так, в объединенной модели принимается предположение об одинаковом изменении экономической сложности в зависимости от изменения интенсивности трансграничности во все моменты времени, а в модели со случайными эффектами, наоборот, считается, что индивидуальные различия носят случайный характер и не коррелируют с изменением интенсивности трансграничности.

Проведенный тест регрессионных остатков на единичный корень свидетельствует в пользу коинтеграции между исследуемыми переменными. По третьей субпанели получены незначимые оценки для константы $C$ (свободный член уравнения). 
Т а б л и ц а 3 . Результаты оценки спецификации модели с фиксированными эффектами

$\mathrm{T}$ a b l e 3 . Results of the assessment of the specification of the fixed effects model

\begin{tabular}{|c|c|c|c|}
\hline $\begin{array}{c}\text { Спецификации } \\
\text { модели / Model } \\
\text { specifications }\end{array}$ & $\begin{array}{c}\text { Первая субпа- } \\
\text { нель / } \\
\text { First subpanel }\end{array}$ & $\begin{array}{c}\text { Вторая субпа- } \\
\text { нель/ } \\
\text { Second subpanel } \\
\end{array}$ & $\begin{array}{c}\text { Третья субпа- } \\
\text { нель / } \\
\text { Third subpanel }\end{array}$ \\
\hline \multicolumn{4}{|l|}{ (TII) } \\
\hline $\begin{array}{l}\text { Коэффициент / } \\
\text { Coefficient }\end{array}$ & 0,422918 & 3,523397 & $-2,711578$ \\
\hline $\begin{array}{l}\text { t-статистика / } \\
\text { t-statistic }\end{array}$ & 2,088087 & 11,94743 & $-7,695159$ \\
\hline $\begin{array}{l}\text { Стандартная } \\
\text { ошибка / Stan- } \\
\text { dard error }\end{array}$ & 0,202539 & 0,294908 & 0,352374 \\
\hline $\begin{array}{l}\text { p-значение / } \\
\text { p-value }\end{array}$ & 0,0380 & 0,0000 & 0,0000 \\
\hline \multicolumn{4}{|l|}{ (C) } \\
\hline $\begin{array}{l}\text { Коэффициент / } \\
\text { Coefficient }\end{array}$ & 0,603187 & 0,065611 & 2,180097 \\
\hline $\begin{array}{l}\text { t-статистика / } \\
\text { t-statistic }\end{array}$ & 10,64714 & 0,727498 & 20,34787 \\
\hline $\begin{array}{l}\text { Стандартная } \\
\text { ошибка / Stan- } \\
\text { dard error }\end{array}$ & 0,056652 & 0,090187 & 0,107141 \\
\hline $\begin{array}{l}\text { p-значение / } \\
\text { p-value }\end{array}$ & 0 & 0,4678 & 0 \\
\hline $\mathrm{R}^{2}$ & 0,971742 & 0,915823 & 0,972694 \\
\hline $\begin{array}{l}\text { Статистика Дар- } \\
\text { бина - Уотсона / } \\
\text { Durbin - Watson } \\
\text { statistic }\end{array}$ & 0,893079 & 0,648631 & 0,488015 \\
\hline $\begin{array}{l}\text { F-статистика / } \\
\text { F-statistic }\end{array}$ & $\begin{array}{c}681,5039 \\
(0,000000)\end{array}$ & $\begin{array}{c}216,5055 \\
(0,000000)\end{array}$ & $\begin{array}{c}707,9932 \\
(0,000000)\end{array}$ \\
\hline $\begin{array}{l}\text { Кросс- } \\
\text { секционный } \\
\text { хи-квадрат } \\
\text { (p-значение) / } \\
\text { Cross-section } \\
\text { chi-square } \\
\text { (p-value) }\end{array}$ & $\begin{array}{l}718,252519 \\
(0,000000)\end{array}$ & $\begin{array}{c}478,118393 \\
(0,000000)\end{array}$ & $\begin{array}{r}582,391712 \\
(0,000000)\end{array}$ \\
\hline $\begin{array}{l}\text { Статистика } \\
\text { Харке - Бера } \\
\text { (p-значение) / } \\
\text { Jarque - Bera sta- } \\
\text { tistic (p-value) }\end{array}$ & $\begin{array}{c}25,43663 \\
(0,000003)\end{array}$ & $\begin{array}{c}1455,639 \\
(0,000000)\end{array}$ & $\begin{array}{c}9,702562 \\
(0,007818)\end{array}$ \\
\hline 618 & ЭКОНОМИКА & ІРАВЛЕНИЕ НАРС & ЫМ ХОЗЯЙСТВ \\
\hline
\end{tabular}


По всем субпанелям по критерию Дарбина - Уотсона и тесту Харке - Бера на нормальность распределения, а также результатам оценки коррелограммы случайных отклонений очевидно наличие в моделях автокорреляции. Основные причины могут быть связаны как с длинным временным диапазоном, так и действием иных случайных факторов, неучтенных в модели. Поэтому коэффициенты коинтеграции оцениваются с использованием полностью модифицированного метода наименьших квадратов (FMOLS) и динамического метода наименьших квадратов (DOLS) [30]. Практика применения указанных методов в оценке экономической сложности встречается в разных работах $[13 ; 31]$. Результаты оценки уравнений моделей FMOLS и DMOLS приведены в таблице 4.

При построении моделей FMOLS и DMOLS использовались их различные модификации. Из полученных вариантов выбирались модели, которые обеспечивали наилучшие значения $R^{2}$, имели значимость коэффициентов регрессии на уровне не менее $5 \%$, положительные результаты тестирования регрессионных остатков на стационарность и значения статистики Харке - Бера для нормального распределения (для d.f. $=2$ и уровня значимости $5 \%$ не более 5,991) [32]. В результате качество и надежность DMOLS в сравнении с FMOLS и OLS-моделями оказались выше, и указанные модели использовались в дальнейшем анализе.

Для первой субпанели стран в большинстве случаев характерна прямая зависимость изменения экономической сложности при изменении интенсивности трансграничности. Согласно уравнению и спецификации модели, в среднем на интервале изменение индекса экономической сложности на 1,0 \% происходит уже при росте интенсивности трансграничности на $0,45 \%$ (рис. 2).

Для стран второй субпанели (рис. 3) изменение экономической сложности обусловливается более высокими значениями роста интенсивности трансграничности - на 1,21 \%. Учитывая, что среднее значение ЕСI во второй субпанели стран выше, с ростом экономической сложности влияние фактора трансграничности становится слабее.

Для третьей группы, учитывая, что в ее состав включены страны преимущественно с отрицательной корреляцией экономической сложности и трансграничности, получена модель, описывающая частную зависимость. В третьей субпанели рост экономической сложности сопряжен со снижением интенсивности трансграничности на 2,43 \% (рис. 4). По этой же причине выводы не могут распространяться на всю совокупность обследуемых стран, и необходим более глубокий анализ. Так, следует изучить, является ли отрицательная корреляция переменных следствием особенностей трансграничных процессов в странах, структуры экономики или продуктового пространства. Или при достижении определенного уровня экономической сложности и уровня экономического развития связь с фактором трансграничности действительно становится отрицательной. 


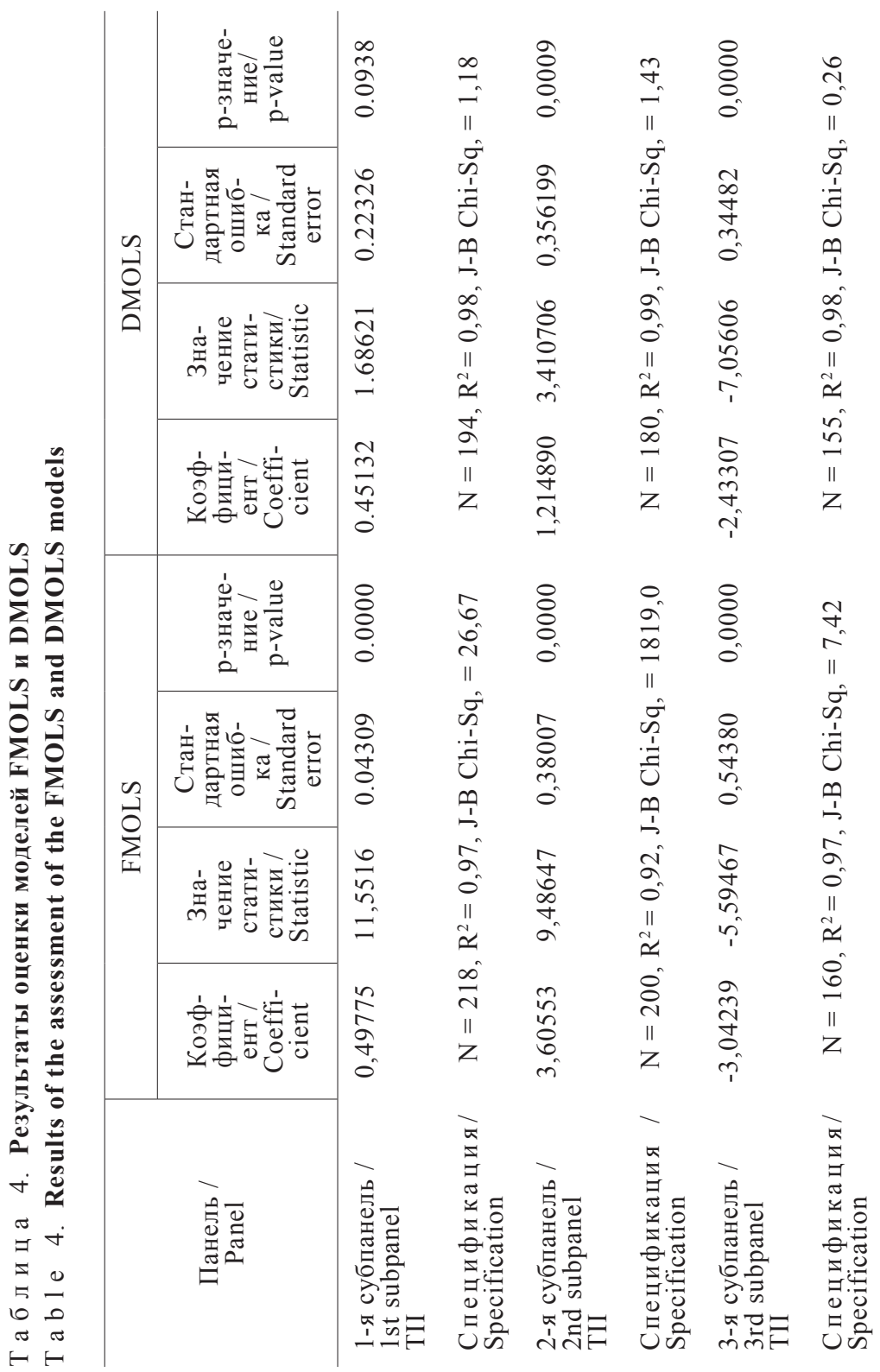



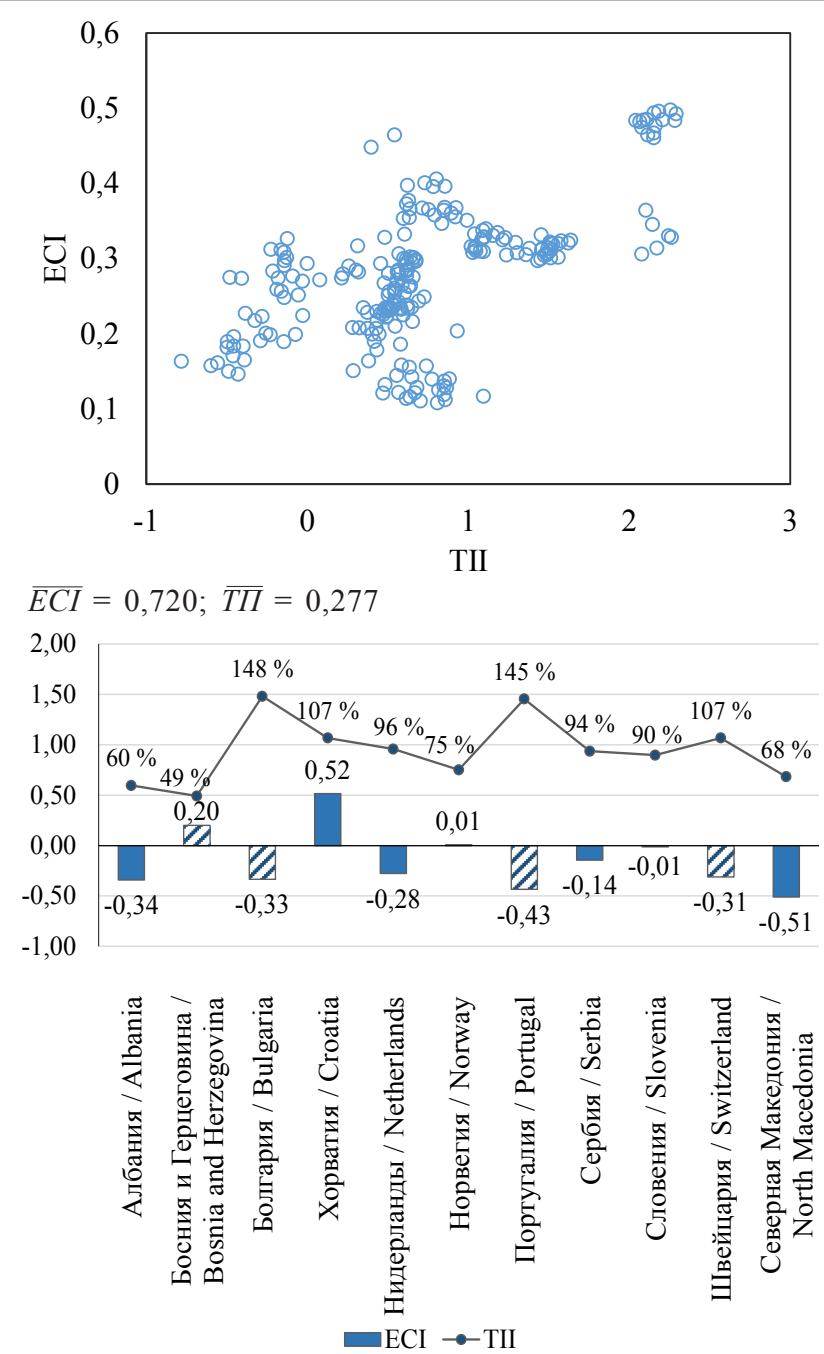

Р и с. 2. Кумулятивное изменение ЕCI и ТII за период 1997-2017 гг. по первой субпанели (1997 г. - $100 \%)^{8}$

F i g. 2. Cumulative change in the ECI and TII in the first subpanel in 1997-2017 $(1997-100 \%)$

${ }^{8}$ На рисунке 2 штриховкой выделены страны, где отсутствует прямая связь между ECI и TII на всем рассматриваемом интервале 1997-2017 гг. 


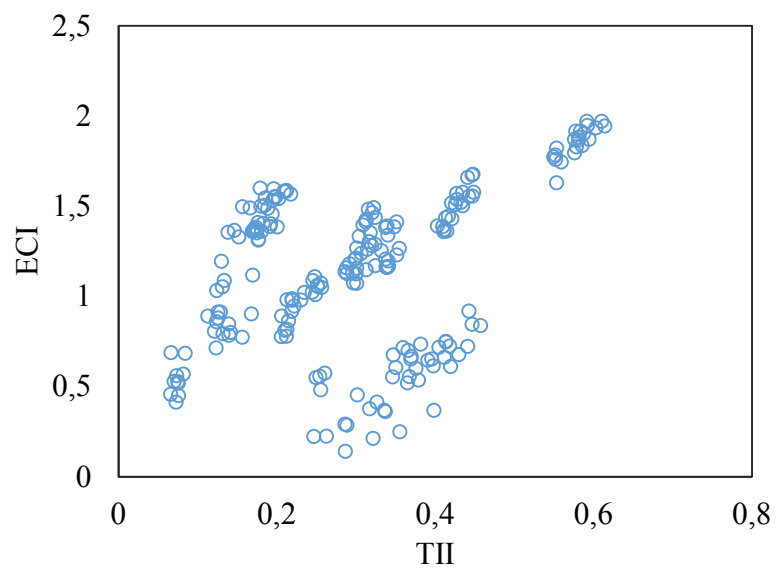

$\overline{E C I}=1,138 ; \overline{T \Pi}=0,304$

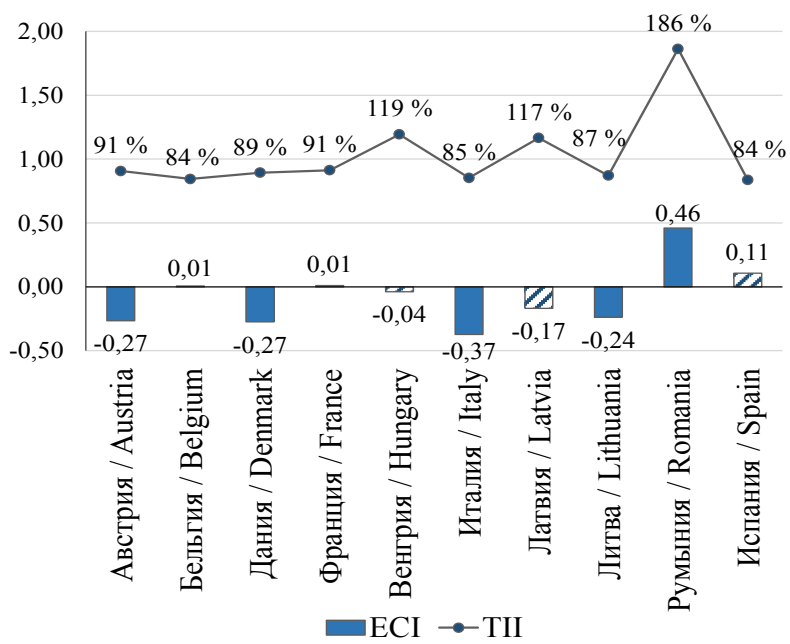

P и с. 3. Кумулятивное изменение ЕСІ и ТІІ за период 1997-2017 гг. по второй субпанели (1997 г. - $100 \%)^{9}$

F i g. 3. Cumulative change in the ECI and TII in the second subpanel in 1997-2017 $(1997-100 \%)$

${ }^{9}$ На рисунке 3 штриховкой выделены страны, где отсутствует прямая связь между ECI и TII на всем рассматриваемом интервале 1997-2017 гг. 

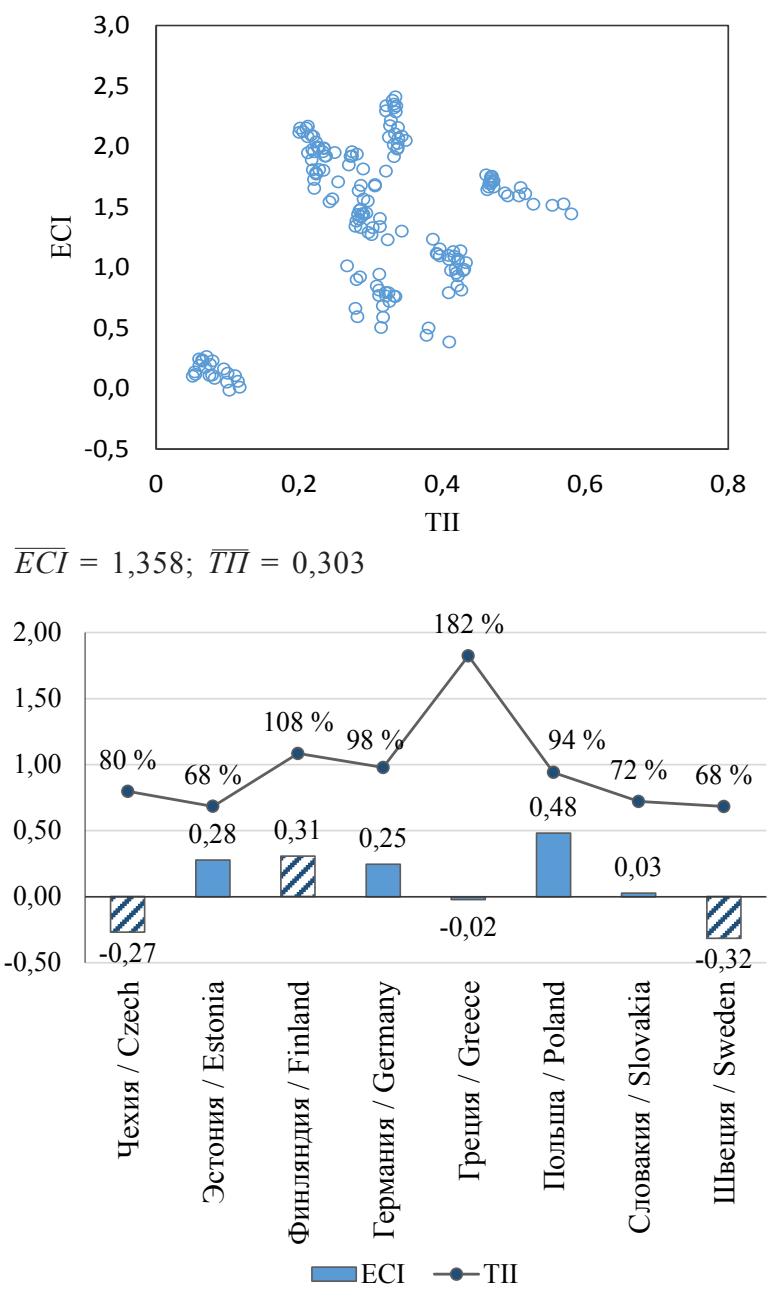

P и с. 4. Кумулятивное изменение ECI и TII за период 1997-2017 гг. по третей субпанели (1997 г. - $100 \%)^{10}$

F i g. 4. Cumulative change in the ECI and TII in the third subpanel in 1997-2017 $(1997-100 \%)$

${ }^{10}$ На рисунке 4 штриховкой выделены страны, где отсутствует обратная связь между ECI и TII на всем рассматриваемом интервале 1997-2017 гг. 
Для ответа на поставленные вопросы требуется как рассмотрение гораздо большего числа факторов в модели, так и увеличение пространственной (географической) размерности выборки стран.

Обсуждение и заключение. В настоящем исследовании обращается внимание на экономико-географический аспект экономической сложности, который выражается в зависимости ее изменения от интенсивности трансграничности. В качестве предпосылки для проверки указанной гипотезы является подтвержденное сегодня многими эмпирическими и теоретическими исследованиями значение трансграничного сотрудничества в развитии стран.

Результаты проведенного анализа позволяют сделать ряд выводов.

Обнаруживается следующая зависимость по результатам предварительной оценки типов стран (субпанелей) - для большинства стран чем выше значение экономической сложности, тем в меньшей степени на ее изменение оказывает влияние трансграничная активность стран, а связь между переменными становится обратной. Данная гипотеза проверялась авторами по результатам анализа панельных данных и построения моделей.

Анализ панельных данных установил, что показатели экономической сложности и интенсивности трансграничности являются реализацией нестационарного случайного процесса с порядком интегрированности 1 (I(1)), присутствует кросс-зависимость и характерна гетероскедастичность. Подтверждена коинтегрированность - несмотря на случайный (слабо предсказуемый) характер изменения переменных по странам, существует долгосрочная зависимость между ними.

Для оценки зависимости переменных и выявления направлений связей построены модели панельных данных следующих модификаций: OLS, FMOLS и DOLS. По OLS-моделям проводилась оценка их разновидностей - обобщенной модели, моделей с фиксированными и случайными эффектами. По результатам тестирования наилучшие значения получены для спецификаций моделей с фиксированными эффектами. Следовательно, изменение экономической сложности имеет индивидуальные эффекты, на уровне стран инвариантные по времени в зависимости от трансграничной активности. Однако во всех модификациях OLS-моделей фиксировалась автокорреляция остатков, что не позволяет признать приведенный вывод надежным. По этой причине построены DOLS и FMOLS модели, позволяющие наилучшим образом учесть проблемы гетероскедастичности и наличия кросс-зависимости данных. Надежность DMOLS в сравнении с другими моделями оказались выше, что обусловило возможность их использования в дальнейшем анализе.

Интерпретируя полученные результаты, следует признать, что оценка и анализ изменения интенсивности трансграничности и экономической 
сложности стран Европы позволили установить не только наличие их связи. Расчеты подтверждают умозрительные заключения изменения роли трансграничных связей по мере не только усложнения экономики, но и в целом экономического роста приграничных территорий. Так, для стран с формирующимися рынками при сокращении внешнеторговых барьеров усиливаются трансграничные взаимодействия с соседними странами. Это становится мощным драйвером и важным источником диверсификации и экономического развития стран. Однако последующий рост производственных возможностей в стране в условиях глобализации современного мира неизбежно ведет к активному встраиванию и включению в глобальные производственные цепочки. Следовательно, существенно смещается и география международных связей - приоритетное значение начинают приобретать интеграция в мировую экономику против дальнейшего усиления и поддержки трансграничного взаимодействия.

Соответствующие зависимости можно проследить и на уровне экономической сложности стран. На первых этапах усложнения экономики важное значение будут иметь трансграничные связи как с точки зрения возможностей наращения экспорта, так и активного научно-технологического обмена для роста собственных производственных возможностей. Это подтверждается расчетами в настоящей работе на уровне стран Европы первого типа (кластера), для которых характерна высокая эластичность изменения экономической сложности с ростом интенсивности трансграничности: Босния и Герцеговина, Болгария, Хорватия, Словения, Швейцария, Македония. Постепенное усложнение экономики снижает ее зависимость от трансграничного взаимодействия, так как на рост экономической сложности оказывают более существенное влияние другие факторы, способствующие расширению базы знаний и возможностей. Данные процессы характерны для второго выделенного нами типа стран Европы (Австрия, Бельгия, Дания, Франция, Венгрия, Италия, Латвия, Литва, Румыния, Испания) - сила воздействия трансграничности на экономическую сложность снижается, т. е. для роста экономической сложности требуется все более существенное увеличение трансграничных взаимодействий. Собственно, показатели экономической сложности для развитых стран и экспортеров сложной продукции (машины, оборудование и инструменты, металлы и материалы, химия и фармацевтика) уже не зависят от интенсивности трансграничности. Для стран третьей группы - Германия, Швеция, Финляндия, Эстония, Польша, Чехия, Греция - связь экономической сложности и трансграничности становится обратной. Таким образом, трансграничное взаимодействие, первоначально являясь фактором роста экономической сложности, замещается воздействием процессов, имеющих глобальный характер в рамках мировой экономики. 
Полученные результаты исследования позволяют сделать вывод, что по мере усложнения экономики снижается ее зависимость от трансграничного взаимодействия, так как на рост экономической сложности оказывают более существенное влияние другие факторы, в частности, способствующие расширению базы знаний и возможностей. Таким образом, для типов стран с низкой и высокой интенсивностью трансграничности характерна различная связь и влияние на экономическую сложность. В первом случае усиление трансграничных связей выступает определенным драйвером роста сложности экономики, для второго типа, наоборот, ориентация на приграничные рынки будет существенно тормозить потенциал роста сложной продукции в экспортной корзине. Международные связи и процессы глобализации по своей роли и значению начинают превалировать над трансграничными связями и процессами регионализации, несмотря на то, что в более ранних исследованиях особое значение придавалось контрактным функциям территорий.

В качестве ограничения исследования и приведенного подхода следует указать недостаточное число показателей, используемое для оценки интенсивности трансграничности, а также необходимость проверки полученных выводов на примере большего числа географических зон, включающих различные типы стран. Кроме этого, проводимый кластерный анализ и выделение типологических групп целесообразно расширить за счет включения дополнительных показателей, характеризующих уровень социально-экономического развития стран (ВВП, инвестиции, занятость, доходы населения и др.). Все указанные вопросы, безусловно, представляют методологический и практический интерес, однако в настоящем исследовании главная задача сводилась собственно к выявлению факта и характеристике присутствия связей и взаимообусловленности трансграничности и экономической сложности.

Результаты проведенного исследования значимы для понимания зависимостей между трансграничными связями и экономической сложностью. Однако больший вклад они вносят в развитие новых подходов и положений к изучению потенциала и ограничений развития территорий, различающихся по тесноте трансграничных связей с другими странами.

\section{СПИСОК ИСПОЛЬЗОВАННЫХ ИСТОЧНИКОВ}

1. The Atlas of Economic Complexity: Mapping Paths to Prosperity / R. Hausmann [et al.]. MIT Press, 2011. URL: https:/growthlab.cid.harvard.edu/files/growthlab/files/ atlas_2013_part1.pdf (дата обращения: 28.06.2019).

2. Roos G. Technology-Driven Productivity Improvements and the Future of Work: Emerging Research and Opportunities. Hershey, PA: IGI Global, 2017. 255 p. DOI: https:// doi.org/10.4018/978-1-5225-2179-2 
3. Hidalgo C. A., Hausmann R. The Building Blocks of Economic Complexity // PNAS. 2009. Vol. 106, issue 26. Pp. 10570-10575. DOI: https://doi.org/10.1073/pnas.0900943106

4. The Product Space Conditions the Development of Nations / C. A. Hidalgo [et al.] // Science. 2007. Vol. 317, issue 5837. Pp. 482-487. DOI: https://doi.org/10.1126/science.1144581

5. Hausmann R., Hidalgo C. A. How Will the Netherlands Earn its Income 20 Years from Now? A Growth Ventures Analysis for the Netherlands. The Hague: The Netherlands Scientific Council for Government Policy (WRR), 2013. 91 p. URL: https://www.wrr. $\mathrm{nl} /$ binaries/wrr/documenten/publicaties/2013/11/04/how-will-the-netherlands-earn-itsincome-20-years-from-now-74/Web074-How-will-the-Netherlands-earn-its-income-20years-from-now.pdf (дата обращения: 28.06.2019).

6. Hidalgo C. A. From Useless to Keystone // Nature Physics. 2018. Vol. 14. Pp. 9-10. DOI: https://doi.org/10.1038/nphys4337

7. The Principle of Relatedness / C. A. Hidalgo [et al.] // Unifying Themes in Complex Systems IX. ICCS 2018 / A. Morales [et al.], eds. Springer Proceedings in Complexity. Springer, Cham. Pp. 451-457. DOI: https://doi.org/10.1007/978-3-319-96661-8_46

8. Zhu S., Li R. Economic Complexity, Human Capital and Economic Growth: Empirical Research Based on Cross-Country Panel Data // Applied Economics. 2017. Vol. 49, issue 38. Pp. 3815-3828. DOI: https://doi.org/10.1080/00036846.2016.1270413

9. Linking Economic Complexity, Institutions, and Income Inequality / D. Hartmann [et al.] // World Development. 2017. Vol. 93. Pp. 75-93. DOI: https://doi.org/10.1016/j. worlddev.2016.12.020

10. Roos G., Kennedy N. Global Perspectives on Achieving Success in High and Low Cost Operating Environments. IGI Global, Hershey, PA, USA, 2014. 564 p. DOI: https://doi. org/10.4018/978-1-4666-5828-8

11. Sweet C., Eterovic D. Do Patent Rights Matter? 40 Years of Innovation, Complexity and Productivity // World Development. 2019. Vol. 115 (C). Pp. 78-93. DOI: https://doi. org/10.1016/j.worlddev.2018.10.009

12. Javorcik B., Lo Turco A., Maggioni D. New and Improved: Does FDI Boost Production Complexity in Host Countries? // Economic Journal. 2017. Vol. 128, issue 614. Pp. 2507-2537. DOI: https://doi.org/10.1111/ecoj.12530

13. Neagu O., Teodoru M. C. The Relationship between Economic Complexity, Energy Consumption Structure and Greenhouse Gas Emission: Heterogeneous Panel Evidence from the EU Countries // Sustainability. 2019. Vol. 11, issue 2. Pp. 1-29. DOI: https://doi. org/10.3390/su11020497

14. Boschma R. Relatedness as Driver of Regional Diversification: A Research Agenda // Regional Studies. 2017. Vol. 51, issue 3. Pp. 351-364. DOI: https://doi.org/10.1080/00343 404.2016.1254767

15. Alshamsi A., Pinheiro F. L., Hidalgo C. A. Optimal Diversification Strategies in the Networks of Related Products and of Related Research Areas // Nature Communications. 2018. Vol. 9, article 1328. DOI: https://doi.org/10.1038/s41467-018-03740-9

16. Economic Complexity Unfolded: Interpretable Model for the Productive Structure of Economies / Z. Utkovski [et al.] // PloS ONE. 2018. Vol. 13, issue 8. DOI: https://doi. org/10.1371/journal.pone.0200822

17. International Trade, Development Traps, and the Core-Periphery Structure of Income Inequality / D. Hartmann [et al.]. 2019. DOI: https://doi.org/10.2139/ssrn.3312097 
18. Harnessing Marine Macroalgae for Industrial Purposes in an Australian Context: Emerging Research and Opportunities / G. Roos [et al.], eds. Hershey, PA: IGI Global, 2019. 291 p. DOI: https://doi.org/10.4018/978-1-5225-5577-3

19. Radosevic S. Assessing EU Smart Specialization Policy in a Comparative Perspective // Advances in the Theory and Practice of Smart Specialization. Academic Press, 2017. Pp. 1-36. DOI: https://doi.org/10.1016/B978-0-12-804137-6.00001-2

20. Трансграничные кластеры в приморских зонах Европейской части России: инвентаризация, типологизация, идентификация факторов и перспектив развития / А. Г. Дружинин [и др.] // Балтийский регион. 2017. Т. 9, № 4. С. 29-44. DOI: https://doi. org/10.5922/2074-9848-2017-4-2

21. Межевич Н. М., Жук Н. П. Методика оценки приграничной специализации межрегиональных взаимодействий приграничных регионов и результаты пилотной оценки // Балтийский регион. 2013. Т. 1, № 15. C. 38-52. DOI: https://doi. org/10.5922/2074-9848-2013-1-3

22. Baltagi B. H. Econometric Analysis of Panel Data. John Wiley \& Sons, 2005. 388 p. URL: https:/www.wiley.com/en-us/ Econometric+Analysis +of +Panel+Data\%2C+5th+Edition-p-9781118672327 (дата обращения: 28.06.2019).

23. Brillet J. L. Structural Econometric Modelling: Methodology and Tools with Applications under EViews. 2011. 496 p. URL: http://www.eviews.com/StructModel/ structmodel.pdf (дата обращения: 28.06.2019).

24. Wooldridge J. M. Econometric Analysis of Cross Section and Panel Data. MIT Press, 2007. 1096 p. URL: https://mitpress.mit.edu/books/econometric-analysis-cross-sectionand-panel-data-second-edition (дата обращения: 28.06.2019).

25. Апраушева Н. Н., Сорокин С. В. Заметки о гауссовых смесях. М.: ВЦ РАН, 2015. 144 c. DOI: https://doi.org/10.13140/RG.2.2.33609.34404

26. Reynolds D. Gaussian Mixture Models // Encyclopedia of Biometrics / S. Z. Li, A. Jain, eds. Springer, Boston, MA, 2009. DOI: https://doi.org/10.1007/978-0-387-73003$5 \_196$

27. Ратникова Т. А. Введение в эконометрический анализ панельных данных // Экономический журнал ВШЭ. 2006. № 3. С. 492-519. URL: https:/elibrary.ru/item. asp?id=9282947 (дата обращения: 28.06.2019).

28. Копнова Е. Д., Родионова Л. А. Моделирование влияния иностранных инвестиций на продовольственную безопасность на основе моделей панельной коинтеграции // Бизнес-информатика. 2017. № 3 (41). С. 20-29. DOI: https://doi. org/10.17323/1998-0663.2017.3.20.29

29. Pesaran M. H. A Simple Panel Unit Root Test in the Presence of Cross Section Dependence // Journal of Applied Econometrics. 2007. Vol. 22, issue 2. Pp. 265-312. DOI: https://doi.org/10.1002/jae.951

30. Pedroni P. Fully Modified OLS for Heterogeneous Cointegrated Panels // Nonstationary Panels, Panel Cointegration and Dynamic Panels. Amsterdam: Elsevier, 2000. Pp. 93-130. DOI: https://doi.org/10.1016/S0731-9053(00)15004-2

31. Dogan E., Aslan A. Exploring the Relationship Among CO2 Emissions, Real GDP, Energy Consumption and Tourism in the EU and Candidate Countries: Evidence from Panel Models Robust to Heterogeneity and Cross-Sectional Dependence // Renewable and 
Sustainable Energy Reviews. 2017. Vol. 77. Pp. 239-245. DOI: https://doi.org/10.1016/j. rser.2017.03.111

32. Green W. H. Econometric Analysis. Pearson Education International. Pearson Education, 2011. 1240 p. URL: https://www.amazon.co.uk/Econometric-AnalysisInternational-William-Greene/dp/0273753568 (дата обращения: 28.06.2019).

Поступила 01.07.2019; принята к публикации 02.10.2019; опубликована онлайн 30.12.2019.

\section{Об авторах:}

Волошенко Ксения Юрьевна, директор центра социально-экономического моделирования развития региона ФГАОУ ВО «Балтийский федеральный университет имени Иммануила Канта» (236041, Россия, г. Калининград, ул. А. Невского, д. 14), кандидат экономических наук, доцент, ORCID: https://orcid.org/0000-0002-2624-0155, kvoloshenko@kantiana.ru

Дрок Татьяна Емельяновна, доцент кафедры экономики и менеджмента ФГАОУ ВО «Балтийский федеральный университет имени Иммануила Канта» (236041, Россия, г. Калининград, ул. А. Невского, д. 14), кандидат экономических наук, доцент, ORCID: https://orcid.org/0000-0002-6296-1160, tdrok@kantiana.ru

\section{Заявленный вклад авторов:}

Волошенко Ксения Юрьевна - сбор, обработка и анализ информации; подготовка первоначального варианта текста; проведение критического анализа материалов.

Дрок Татьяна Емельяновна - изучение концепции; критический анализ и доработка текста.

\section{Для цитирования:}

Волошенко К. Ю., Дрок Т. Е. Эконометрический анализ влияния интенсивности трансграничности на уровень экономической сложности на примере стран Европы // Регионология. 2019. Т. 27, № 4. С. 602-632. DOI: https://doi.org/10.15507/24131407.109.027.201904.602-632

Все авторы прочитали и одобрили окончательный вариант рукописи.

\section{REFERENCES}

1. Hausmann R., Hidalgo C.A., Bustos S., Coscia M., Simoes, A., Yildirim M.A. The Atlas of Economic Complexity: Mapping Paths to Prosperity. MIT Press; 2011. Available at: https://growthlab.cid.harvard.edu/files/growthlab/files/atlas_2013_part1. pdf (accessed 28.06.2019). (In Eng.)

2. Roos G. Technology-Driven Productivity Improvements and the Future of Work: Emerging Research and Opportunities. Hershey, PA: IGI Global; 2017. (In Eng.) DOI: https://doi.org/10.4018/978-1-5225-2179-2

3. Hidalgo C.A., Hausmann R. The Building Blocks of Economic Complexity. PNAS. 2009; 106(26):10570-10575. (In Eng.) DOI: https://doi.org/10.1073/ pnas.0900943106 
4. Hidalgo C.A., Klinger B., Barabási A.-L., Hausmann R. The Product Space Conditions the Development of Nations. Science. 2007; 317(5837):482-487. (In Eng.) DOI: https://doi.org/10.1126/science.1144581

5. Hausmann R., Hidalgo C.A. How Will the Netherlands Earn its Income 20 Years from Now? A Growth Ventures Analysis for the Netherlands Scientific Council for Government Policy (WRR). 2013. Available at: https://www.wrr.nl/ binaries/wrr/documenten/publicaties/2013/11/04/how-will-the-netherlands-earn-itsincome-20-years-from-now-74/Web074-How-will-the-Netherlands-earn-its-income20-years-from-now.pdf (accessed 28.06.2019). (In Eng.)

6. Hidalgo C.A. From Useless to Keystone. Nature Physics. 2018; 14:9-10. (In Eng.) DOI: https://doi.org/10.1038/nphys4337

7. Hidalgo C.A., et al. The Principle of Relatedness. In: Unifying Themes in Complex Systems IX. ICCS 2018. Springer Proceedings in Complexity. Springer, Cham; 2018. p. 451-457. (In Eng.) DOI: https://doi.org/10.1007/978-3-319-96661-8 46

8. Zhu S., Li R. Economic Complexity, Human Capital and Economic Growth: Empirical Research Based on Cross-Country Panel Data. Applied Economics. 2017; 49(38):3815-3828. (In Eng.) DOI: https://doi.org/10.1080/00036846.2016.1270413

9. Hartmann D., Guevara M.R., Jara-Figueroa C., Aristara N.M., Hidalgo C.A. Linking Economic Complexity, Institutions, and Income Inequality. World Development. 2017; 93:75-93. (In Eng.) DOI: https://doi.org/10.1016/j.worlddev.2016.12.020

10. Roos G., Kennedy N. Global Perspectives on Achieving Success in High and Low Cost Operating Environments. IGI Global, Hershey, PA, USA; 2014. (In Eng.) DOI: https://doi.org/10.4018/978-1-4666-5828-8

11. Sweet C., Eterovic D. Do Patent Rights Matter? 40 Years of Innovation, Complexity and Productivity. World Development. 2019; 115(C):78-93. (In Eng.) DOI: https://doi.org/10.1016/j.worlddev.2018.10.009

12. Javorcik B., Lo Turco A., Maggioni D. New and Improved: Does FDI Boost Production Complexity in Host Countries? Economic Journal. 2017; 128(614):2507-2537. (In Eng.) DOI: https://doi.org/10.1111/ecoj.12530

13. Neagu O., Teodoru M.C. The Relationship between Economic Complexity, Energy Consumption Structure and Greenhouse Gas Emission: Heterogeneous Panel Evidence from the EU Countries. Sustainability. 2019; 11(2):1-29. (In Eng.) DOI: https://doi.org/10.3390/su11020497

14. Boschma R. Relatedness as Driver of Regional Diversification: A Research Agenda. Regional Studies. 2017; 51(3):351-364. (In Eng.) DOI: https://doi.org/10.1 080/00343404.2016.1254767

15. Alshamsi A., Pinheiro F.L., Hidalgo C.A. Optimal Diversification Strategies in the Networks of Related Products and of Related Research Areas. Nature Communications. 2018; 9. (In Eng.) DOI: https://doi.org/10.1038/s41467-018-03740-9

16. Utkovski Z., Pradier M.F., Stojkoski V., Perez-Cruz F., Kocarev L. Economic Complexity Unfolded: Interpretable Model for the Productive Structure of Economies. PloS ONE. 2018; 13(8). (In Eng.) DOI: https://doi.org/10.1371/journal.pone.0200822

17. Hartmann D., Bezerra M., Lodolo B., Pinheiro F.L. International Trade, Development Traps, and the Core-Periphery Structure of Income Inequality. 2019. (In Eng.) DOI: https://doi.org/10.2139/ssrn.3312097 
18. Roos G. Cheshire A., Nayar S., Clarke S. M., Zhang W. Harnessing Marine Macroalgae for Industrial Purposes in an Australian Context: Emerging Research and Opportunities. Hershey, PA: IGI Global; 2019. (In Eng.) DOI: https://doi. org/10.4018/978-1-5225-5577-3

19. Radosevic S. Assessing EU Smart Specialization Policy in a Comparative Perspective. In: Advances in the Theory and Practice of Smart Specialization. Academic Press; 2017. p. 1-36. (In Eng.) DOI: https://doi.org/10.1016/B978-0-12804137-6.00001-2

20. Druzhinin A.G., Gorochnaya V.V., Gontar N.V., et al. Transboundary Clusters in the Coastal Cones of the European Part of Russia: Inventory, Typology, Factors, and Prospects. Baltijskij region = Baltic Region. 2017; 9(4):29-44. (In Russ., abstract in Eng.) DOI: https://doi.org/10.5922/2074-9848-2017-4-2

21. Mezhevich N.M., Zhuk N.P. Cross-Border Specialization of Interregional Interaction: Applying New Assessment Methods. Baltijskij region = Baltic Region. 2013; 1(15):38-52. (In Russ., abstract in Eng.) DOI: https://doi.org/10.5922/20749848-2013-1-3

22. Baltagi B.H. Econometric Analysis of Panel Data. John Wiley \& Sons; 2005. Available at: https://www.wiley.com/en-us/Econometric+Analysis+of+Panel+Data\%2 C+5th+Edition-p-9781118672327 (accessed 28.06.2019). (In Eng.)

23. Brillet J.L. Structural Econometric Modelling: Methodology and Tools with Applications under EViews. 2011. Available at: http://www.eviews.com/StructModel/ structmodel.pdf (accessed 28.06.2019). (In Eng.)

24. Wooldridge J.M. Econometric Analysis of Cross Section and Panel Data. MIT Press; 2007. Available at: https://mitpress.mit.edu/books/econometric-analysis-crosssection-and-panel-data-second-edition (accessed 28.06.2019). (In Eng.)

25. Aprausheva N.N., Sorokin S.V. Notes on Gaussian Mixtures. Moscow, VC RAN; 2015. (In Russ.) DOI: https://doi.org/10.13140/RG.2.2.33609.34404

26. Reynolds D. Gaussian Mixture Models. In: Encyclopedia of Biometrics. Springer, Boston, MA; 2009. (In Eng.) DOI: https://doi.org/10.1007/978-0-38773003-5 196

27. Ratnikova T.A. Introduction to Econometric Analysis of Panel Data. Ehkonomicheskij zhurnal VShEh = HSE Economic Journal. 2006; (3):492-519. Available at: https://elibrary.ru/item.asp?id=9282947 (accessed 28.06.2019). (In Russ.)

28. Kopnova E.D., Rodionova L.A. Modeling the Influence of Foreign Investments on Food Security Based on Panel Cointegration Models. Biznes-informatika = Business Informatics. 2017; (3):20-29. (In Russ., abstract in Eng.) DOI: https://doi. org/10.17323/1998-0663.2017.3.20.29

29. Pesaran M.H. A Simple Panel Unit Root Test in the Presence of Cross Section Dependence. Journal of Applied Econometrics. 2007; 22(2):265-312. (In Eng.) DOI: https://doi.org/10.1002/jae.951

30. Pedroni P. Fully Modified OLS for Heterogeneous Cointegrated Panels. In: Nonstationary Panels, Panel Cointegration and Dynamic Panels. Amsterdam: Elsevier; 2000. p. 93-130. (In Eng.) DOI: https://doi.org/10.1016/S0731-9053(00)15004-2

31. Dogan E., Aslan A. Exploring the Relationship among CO2 Emissions, Real GDP, Energy Consumption and Tourism in the EU and Candidate Countries: 
Evidence from Panel Models Robust to Heterogeneity and Cross-Sectional Dependence. Renewable and Sustainable Energy Reviews. 2017; 77:239-245. DOI: https:// doi.org/10.1016/j.rser.2017.03.111

32. Green W.H. Econometric Analysis. Pearson Education International. Pearson Education; 2011. Available at: https://www.amazon.co.uk/Econometric-AnalysisInternational-William-Greene/dp/0273753568 (accessed 28.06.2019). (In Eng.)

Submitted 01.07.2019; accepted for publication 02.10.2019; published online 30.12.2019.

About the authors:

Ksenia Yu. Voloshenko, Director, Centre for Regional Socio-Economic Development, Immanuel Kant Baltic Federal University (14 A. Nevskogo St., Kaliningrad 236041, Russia), Ph. D. (Economics), Associate Professor, ORCID: https://orcid.org/ 0000-0002-2624-0155, kvoloshenko@kantiana.ru

Tatiana E. Drok, Associate Professor, Department of Economics and Management, Immanuel Kant Baltic Federal University (14 A. Nevskogo St., Kaliningrad 236041, Russia), Ph. D. (Economics), Associate Professor, ORCID: https://orcid.org/ 0000-0002-6296-1160,tdrok@kantiana.ru

Contribution of the authors:

Ksenia Yu. Voloshenko - collection, processing and analysis of information; preparation of the initial version of the text; critical analysis of the materials.

Tatiana E. Drok - study of the concept; critical analysis and revision of the text.

For citation:

Voloshenko K.Yu., Drok T.E. Econometric Analysis of the Impact of the Intensity of Transboundary Activities on the Level of Economic Complexity: The Case Study of European Countries. Regionology $=$ Russian Journal of Regional Studies. 2019; 27(4):602-632. DOI: https://doi.org/10.15507/2413-1407.109.027.201904.602-632

The authors have read and approved the final version of the manuscript. 


\section{Лучшие практики пространственного развития: возможность адаптации в отношении муниципальных районов}

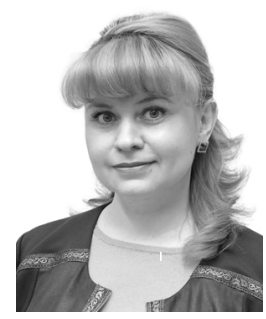

Е. Б. Дворядкина

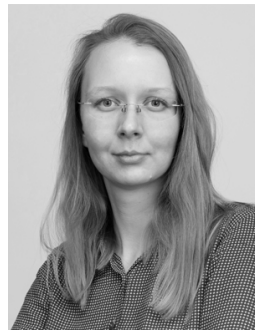

Е. А. Белоусова*

ФГБОУ ВО «Уральский государственный экономический университет»

(2. Екатеринбург, Россия),

*belousova-unir@usue.ru

Введение. Принятие национальной стратегии пространственного развития в России актуализировало разработку научно-обоснованного инструментария управления экономико-пространственным развитием на муниципальном уровне. Цель статьи - исследовать лучшие зарубежные практики пространственного развития и оценить возможности их применения для управления экономикопространственным развитием муниципальных районов Российской Федерации как основополагающего вида муниципальных образований в сельской местности. Материалы и методы. Исследование проводилось на основе компаративного метода, в рамках которого систематизировались лучшие практики зарубежных муниципальных образований, сходных по ряду условий с муниципальными районами Российской Федерации. Материалами для изучения послужили эмпирические и теоретические исследования, отчеты и методические материалы международных организаций, ассоциаций и фондов локального уровня, сайты муниципальных образований.

Результаты исследования. Систематизированный обзор лучших практик Великобритании, Швеции, Германии, Италии, Словении показал, что для экономикопространственного развития муниципальных районов востребованными могут быть практики издольного сельского хозяйства, неформального пространственного планирования, гибких решений в области транспорта, применения цифровых технологий для опросов жителей и сбора данных о муниципальном образовании, создания объектов, повышающих привлекательность территории, а также пространственного планирования для создания децентрализованной концентрации

$$
\text { (C) Дворядкина Е. Б., Белоусова Е. А., } 2019
$$


на субурбанизированных территориях. Выявленные практики могут применяться с целью корректировки направлений экономико-пространственного развития муниципальных районов с учетом уровня и тенденций изменения таких параметров экономического пространства, как насыщенность, связанность, физический базис. Обсуждение и заключение. Развитие муниципального образования необязательно должно быть направлено на рост экономических и других показателей через привлечение инвестиций, богатого населения и другого рода стимулирование; альтернативными целями пространственного развития могут быть сохранение текущих показателей, территориальной идентичности муниципального образования, снижение его отрицательного влияния на экологическую ситуацию. Результаты исследования могут быть использованы в практической деятельности органов региональной и муниципальной власти в процессе разработки и реализации документов стратегического планирования, а также для дальнейшего теоретического осмысления процесса экономико-пространственного развития муниципалитетов.

Ключевые слова: пространственное развитие, экономическое пространство, муниципальный район, сельское муниципальное образование, практика пространственного развития

\title{
Best Practices of Spatial Development: Possibility of Using Them in the Municipal Districts of Russia
}

\author{
E. B. Dvoryadkina, E. A. Belousova* \\ Ural State University of Economics (Ekaterinburg, Russia), \\ *belousova-unir@usue.ru
}

Introduction. Adoption of the national strategy of spatial development in Russia has made it especially relevant to develop a scientifically grounded toolkit for managing spatial economic development at the municipal level. The objective of the study is to investigate the foreign best practices of spatial development and to assess their applicability when controlling the spatial economic development of the municipal districts of the Russian Federation, which are the principal type of municipalities in rural areas. Materials and Methods. The research was based on the comparative method, within the framework of which the best practices of foreign municipalities similar in some respects to the municipal districts of the Russian Federation were systematized. Empirical and theoretical studies, reports and guidance materials of international organizations, associations and foundations of the local level, as well as official websites of municipalities were used as materials for this research.

Results. The systematized review of the best practices from the UK, Sweden, Germany, Italy and Slovenia has demonstrated that Russia's municipal districts can use the following practices for their economic and spatial development: sharefarming, informal spatial planning, flexible transport solutions. Municipal districts can also involve digital technologies for conducting population surveys and collecting data about the municipality, design facilities that increase the attractiveness of the territory, as well use spatial planning to create decentralized concentration in suburbanized areas. The identified practices can be adopted to readjust the directions of the economic and spatial development of municipal districts, taking into account the level and trends of changes in such parameters of the economic space as saturation, coherence and physical basis. 
Discussion and Conclusion. The development of a municipality does not necessarily have to be aimed at increasing economic and other indicators through attracting investment and wealthy population, as well as through providing other incentives. The alternative objectives of spatial development can be: to maintain the current indicators and the territorial identity of the municipality, as well as to reduce its negative impact on the environmental situation. The results of the study can be used in the practical activities of regional and municipal authorities when developing and implementing strategic planning documents, as well as for further theoretical conceptualization of the process of economic and spatial development of municipalities.

Keywords: spatial development, economic space, municipal district, rural municipality, practice of spatial development

Введение. Рассматривая пространство как «экономический феномен и содержательную форму функционирования социально-экономической системы» [1, с. 15], мы можем говорить о пространственном развитии не только как о совокупности прогрессивных изменений физического базиса и функционирующей на нем социально-экономической среды, но и как о комплексе практических мер в области региональной экономической политики, направленных на повышение качества жизни населения. Принятая в текущем году Стратегия пространственного развития Российской Федерации до 2025 г. актуализировала теоретические и методические вопросы, касающиеся управления пространственным развитием страны, в том числе относительно инструментов пространственного развития. Сфокусированность Стратегии на крупных и крупнейших городских агломерациях дополнительно обострила проблему дефицита инструментов для муниципальных образований, расположенных на сельских территориях.

Муниципальные районы являются основополагающим видом муниципальных образований в сельской местности. Результаты наших исследований экономического пространства [2; 3] позволили выделить экономико-пространственный аспект характеристики муниципального района как специфического объекта в пространстве региона, заключающийся в том, что муниципальный район:

1) рассматривается как компонент муниципального устройства, имеющий четко очерченные административные границы в пределах территории субъекта Российской Федерации;

2) является частью экономического пространства региона, в которой концентрируются специфические (немобильные) экономические ресурсы, способствующие формированию центробежного характера производственных отношений;

3) исследуется как информационно специфическая часть экономического пространства региона, порядок сосуществования и сообщения объектов и субъектов в пределах которой носит преимущественно сельскохозяйственный характер; 
4) осуществляет воспроизводственный процесс, формируемый как промежуточный итог реализации экономических интересов субъектов и экономического взаимодействия между различными точками на заданной территории;

5) в качестве структурной ячейки экономического пространства обладает необходимой информацией для реализации целей и задач гармонизированного управления городскими и сельскими поселениями как муниципалитетами низового уровня;

6) является институцией, результирующей взаимодействия в экономическом пространстве совокупности преимущественно сельских формальных и неформальных институтов;

7) представляет собой пространственное экономическое образование как совокупность преимущественно сельских поселений, по смысловому значению противостоящая крупнейшему и крупному городу и функционально дополняющая его;

8) существует как хозяйственная подсистема экономического пространства региона, обеспечивающая его целостность и устойчивость и находящаяся во взаимодействии с другими подсистемами, результатом функционирования которой является добавленная стоимость, создаваемая преимущественно видами экономической деятельности, относящимися к первичному сектору экономики.

Мы будем рассматривать муниципальный район как целостное экономико-пространственное образование, объединяющее сельские и городские поселения, что позволяет в целях разработки инструментария управления и корректировки его экономико-пространственного развития учитывать такие характеристики экономического пространства, как насыщенность, связанность и физический базис [4]. Соответственно, экономико-пространственное развитие муниципальных районов может быть направлено на:

1) рост экономической активности и экономически значимых результатов с учетом центробежного характера производственных отношений на территории;

2) сохранение и повышение качественных характеристик физического базиса, а также степени его освоенности;

$3)$ рост интегрированности муниципальных районов в экономическое пространство региона и связанности экономического пространства внутри муниципального района;

4) сбалансированное развитие сельско-городских отношений (городские и сельские поселения в пределах муниципального района; муниципальные районы и городские округа в пределах региона).

Целью настоящего исследования стало изучение лучших зарубежных практик пространственного развития с сопутствующим анализом 
их применимости для муниципальных районов Российской Федерации в контексте перспективной разработки инструментария управления и корректировки экономико-пространственного развития данного вида муниципальных образований.

Обзор литературы. Необходимость учета пространственного фактора в практической деятельности по развитию муниципальных образований подчеркивается в ряде исследований ${ }^{1}$ [5]. Как отмечают Н. Н. Киселева и В. В. Браткова, «инструменты управления пространственным ростом диверсифицируются в зависимости от типа зоны роста» [6, с. 31], а под пространственным ростом понимается снижение концентрации населения в городах-центрах, рост полупериферии и периферийных территорий, появление новых точек развития, повышение равномерности распределения населения и экономической деятельности. В исследовании А. В. Суворовой показано, что спецификой пространственного развития является «изменение структуры пространства» [7, с. 57].

В зарубежной литературе проблема пространственного развития на муниципальном уровне освещается главным образом через призму сжатия пространства как процесса сокращения численности населения и экономической активности на территориях [8-13]. Так, В. Канцлер пишет о необходимости повышать эффективность использования существующей инфраструктуры таким образом, чтобы она могла служить потребностям уменьшающегося населения и не приводила к дополнительным капитальным затратам [8]; Г.-Ж. Хосперс и Н. Реверда подробно рассматривают варианты реакций органов власти на проблему (тривиализация проблемы, противодействие, управление, использование как возможность) [9]. Латвийские ученые А. Пузулис и Л. Кууле сосредоточиваются на поисках причин оттока населения и возможностях удержать его в условиях соседства с привлекательными территориями соседних стран [11].

Вторым направлением применения пространственной точки зрения на развитие муниципальных образований является анализ вклада пространственного фактора в устойчивость развития, в особенности это касается сельских муниципальных образований, обладающих уникальными или значительными природными ресурсами [14]. Локальные природные ресурсы оказываются критичными для абсолютного большинства предприятий на территории сельского муниципалитета. Существует сильная связь между предпринимателями, их бизнесом, муниципалитетом и локальными природными ресурсами, что требует внедрения пространственного планирования, включающего, с одной стороны, системы мониторинга использования

${ }^{1}$ Маркварт Э. Э., Киселева Н. Н., Стародубровская И. В. Управление пространственными изменениями на региональном и муниципальном уровнях: учеб. пособие. М., 2018. 282 с.; Стратегирование пространственного развития и инфраструктурного обустройства территорий: моногр. / Ю. Г. Лаврикова [и др.]. Екатеринбург: Ин-т экономики УрО РАН, 2018. $178 \mathrm{c}$. 
этих ресурсов, с другой - общественно одобряемого распределения этих ресурсов между всеми стейкхолдерами на территории муниципалитета.

Ю. Г. Лаврикова и соавторы отмечают, что «необходимость учета пространственного фактора в муниципальном управлении определяется наличием не только внутренних, но и внешних факторов» ${ }^{2}$. Среди внешних факторов, по мнению исследователей, можно назвать активную конкуренцию между муниципалитетами за привлечение инвестиций, финансовых и кадровых ресурсов. И. А. Антипин и Н. В. Казакова несколько лет назад в своем исследовании отмечали, что в российской действительности «пространственный фактор недостаточно учитывается в муниципальном управлении... в первую очередь проявляется в несформированности взаимоувязки документов социально-экономического и территориального планирования» [15, с. 1012].

Таким образом, если вопрос сущностного понимания пространственного развития в научной литературе исследован достаточно глубоко, равно как и обоснована необходимость учета пространственного фактора в стратегическом планировании и развитии муниципальных образований, то в том, что касается выбора, обоснования и/или разработки конкретного инструментария управления и корректировки экономико-пространственного развития существует очевидная недосказанность. Одновременно бесспорна и необходимость увязки такого инструментария с экономикопространственными характеристиками конкретного вида муниципальных образований.

Материалы и методы. Для цели экономико-пространственного развития муниципальных районов принципиальный интерес в изучении лучших зарубежных практик представляет опыт в области развития экономической деятельности в сельских муниципалитетах (к которым относятся и муниципальные районы Российской Федерации), раскрытия и сохранения их природно-ресурсного, демографического, экологического потенциала, улучшения инфраструктурного обеспечения, выстраивания сельско-городских взаимоотношений.

В целях исследования лучших практик пространственного развития целесообразно обращаться к опыту муниципальных образований стран, достигших высокого уровня социально-экономического развития. Основной интерес представляют муниципальные образования в странах, сходных по экономико-правовым, административно-территориальным, демографическим, природно-климатическим условиям с муниципальными районами Российской Федерации.

Существенную проблему для систематизации лучших практик представляет экономико-правовой статус муниципальных образований в раз-

2 Стратегирование пространственного развития и инфраструктурного обустройства территорий. С. 42. 
ных странах, который значительно отличается как в части комбинации прав и обязанностей, так и возможностей, в особенности финансовых. Однако, с этой точки зрения, для отбора практик целесообразным видится опора на экономико-пространственную характеристику муниципальных районов, представленную выше, и характеристику сельских муниципальных образований как населенных сельских территорий с местным самоуправлением, обладающих признаками ${ }^{3}$ сельской местности (низкая плотность населения, рассредоточенность населенных пунктов, относительная удаленность от крупных городских центров, большой удельный вес сырьевых отраслей экономики, невысокая концентрация промышленности и других сфер деятельности, большой удельный вес сырьевых отраслей экономики и высокая зависимость от природно-климатических, биологических и географических факторов). Таким образом, отбор лучших практик осуществлялся на основе соответствия муниципального образования указанным характеристикам и общности проблем, с которыми сталкивались и/или сталкиваются органы местного самоуправления, например, дисперсность населенных пунктов и их удаленность как препятствие связанности экономического пространства и взаимодействию между экономическими агентами; малонаселенность, ведущая к сложностям аккумулирования ресурсов (финансовых, материальных) и т. п.

В качестве источников лучших практик в процессе их систематизации использовались эмпирические и теоретические исследования, посвященные проблемам сельских муниципальных образований, а также отдельным проблемам, с которыми сталкивается данный вид муниципалитетов, отчеты и руководство международных организаций, локальных ассоциаций сельского развития, региональных фондов содействия местному развитию, а также сайты муниципальных образований.

В исследовании применялся компаративный метод, который позволил систематизировать лучшие практики зарубежных муниципальных образований, сходных по экономико-правовым, административно-территориальным, демографическим, природно-климатическим условиям с муниципальными районами Российской Федерации.

Результаты исследования. Результаты исследования представим систематизированно по указанным четырем направлениям.

Первое направление - рост экономической активности и экономически значимых результатов с учетом центробежного характера производственных отночений на территории.

Обзор показал, что в данный момент доминирующей парадигмой развития территорий, характеризующихся центробежной природой производственных отношений и наличием соответствующих специфических ресурсов, является парадигма мультифункционального развития, поскольку ресурсы, которыми

${ }^{3}$ Киселев С. В. Сельская экономика: учеб. М.: ИНФРА-М, 2010. С. 14. 
обладает такая территория, имеют потенциал применения в разных сферах, а не только в сельском хозяйстве. Ключевые отличия парадигмы мультифункционального сельского развития представлены в таблице 1.

Т а 6 л и ц а 1. Новая парадигма сельского развития ${ }^{4}$ $\mathrm{T}$ a b l e 1 . The new paradigm of rural development

\begin{tabular}{|c|c|}
\hline $\begin{array}{l}\text { Критерий / } \\
\text { Criterion }\end{array}$ & $\begin{array}{c}\text { Старая парадигма / The } \\
\text { old paradigm }\end{array}$ \\
\hline $\begin{array}{l}\text { Цель / Objec- } \\
\text { tive }\end{array}$ & $\begin{array}{l}\text { Выравнивание и назна- } \\
\text { чение целевых показа- } \\
\text { телей, ориентированное } \\
\text { на доход фермы и еe } \\
\text { конкурентоспособность / } \\
\text { Equalization of targets } \\
\text { and their setting, focused } \\
\text { on the farm income and } \\
\text { competitiveness }\end{array}$ \\
\hline
\end{tabular}

Ключевой целевой сектор / Kеу target sector

Основные ин- Субсидии / Subsidies струменты / Main tools Ключевые участники / Key actors
Основана на одном секторе / Based on one sector

Национальные правительства, фермеры / National governments, farmers
Новая парадигма / The new paradigm

Конкурентоспособность сельских территорий, придание ценности сельским активам, вовлечение ранее неиспользуемых ресурсов / Competitiveness of rural areas, adding value to rural assets, mobilization of previously unused resources

Разные сектора сельских экономик (сельский туризм, производство, информационно-коммуникационный сектор и др.) / Various sectors of rural economies (e.g. rural tourism, manufacturing, ICT industry, etc.)

Инвестиции / Investment

Все уровни управления (наднациональный, национальный, региональный, локальный), множество локальных стейкхолдеров (общественные, частные, некоммерческие организации) / All levels of government (supranational, national, regional and local), multiple local stakeholders (public, private, nonprofit organizations)

Мультифункциональное развитие сельских территорий - концепция, которая продвигает несельскохозяйственные виды деятельности и нацелена на преодоление стереотипа о том, что внегородские территории это монофункциональные территории. «...Эта концепция является не просто попыткой увеличить занятость, она дает гораздо больший импульс развитию сельских территорий, в том числе в части улучшения условий жизни и модернизации инфраструктуры» [16, р. 13]. Данная парадигма

${ }^{4}$ New Rural Policy: Linking up for Growth. Paris: OECD Publication, 2015. P. 7. 
формирует отправную точку в поиске способов решения экономических проблем территории: через раскрытие потенциала территории, поиск неиспользуемых ресурсов, диверсификацию сельской экономики, повышение инвестиционной привлекательности, активное использование международного, межрегионального, межмуниципального опыта [17] и знаний.

В части роста экономической активности и экономически значимых результатов можно выделить два блока: меры, направленные на поддержку производства, и меры, направленные на улучшение предоставления услуг.

Основные проблемы, связанные с производством на данной территории, - конкуренция с городскими территориями за человеческие, финансовые, материальные и другие виды ресурсов, а также низкая производительность. Препятствиями на пути повышения производительности являются большое расстояние до рынков реализации готовой продукции и рынков материалов (ведут к высоким издержкам), небольшой размер локального рынка (необходимость продажи на другие территории), ограниченность рабочей силы, компетенций (результат - низкая конкурентоспособность товара по цене и ограниченность объема производства), старение и снижение численности населения. Таким образом, усилия органов местного самоуправления могут касаться данных направлений.

Возможности для повышения уровня экономической деятельности на сельских территориях несет в себе социальное предпринимательство. Такая характеристика социальных предпринимателей, как связанность с местным сообществом и вовлеченность в жизнь муниципалитета, означает, что они мобилизуют большое разнообразие локальных ресурсов и активов для достижения локально привязанных результатов, включая развитие социального капитала [18].

Несомненно, эффективность сельского хозяйства повышает развитие точечного земледелия или «умных» ферм. Появившись благодаря удешевлению интернет-технологий и сотовой связи, они дают производителям сельскохозяйственной продукции возможности применять точечный мониторинг локального климата, почвы, растений, животных, передвижения техники. Это вносит свой вклад в сокращение затрат на горючее, семена, воду, удобрения, средства защиты растений, корма. Накопление больших объемов данных позволяет составлять карты урожайности и делать севооборот более гибким [19]. Данная практика уже активно заимствуется российскими предприятиями и приносит положительные результаты, что подтверждают обзоры, опубликованные в журнале «Эксперт» ${ }^{5}$, поэтому подробно останавливаться на ней мы не будем.

Другой эффективной практикой может быть издольное сельское хозяйство (англ. share farming) - способ ведения сельскохозяйственной

5 Лабыкин А. АПК уходит в «цифру» // Эксперт. 2018. № 25. С. 18-21; Инкинжинова С. Зерно хотят оцифровать // Эксперт. 2018. № 25. С. 22-24. 
деятельности, при котором фермеры пользуются различными сельскохозяйственными активами в обмен на часть дохода с урожая или часть урожая, но не владеют ими. С одной стороны, такой способ ведения сельского хозяйства известен давно и ранее воспринимался скорее как негативное явление, так как получил распространение в феодальном обществе, в бедных странах Африки, в Индии. С другой стороны, сегодня издольное сельское хозяйство применяется в развитых странах, поскольку дает возможность фермерам снять часть ответственности с себя, уменьшить риски и увеличить доход. Издольное сельское хозяйство также позволяет снизить барьеры входа в отрасль и привлечь в нее инвестиции, балансировать возрастную структуру занятых 6 . Такое сельское хозяйство отличается от сельскохозяйственного производства по контракту (англ. contract farming), поскольку риски в нем разделены более пропорционально. Характеристика издольного сельского хозяйства с точки зрения разделения ответственности между его участниками представлена в таблице 2.

Т а б л и ц а 2. Разделение ответственности в издольном сельском хозяйстве ${ }^{7}$ $\mathrm{T}$ a $\mathrm{b}$ l e 2. Allocation of responsibilities in share farming

\begin{tabular}{|c|c|c|}
\hline Актив / Asset & $\begin{array}{l}\text { Владелец / } \\
\text { Owner }\end{array}$ & $\begin{array}{l}\text { Oператор/ } \\
\text { фермер / } \\
\text { Operator / } \\
\text { farmer }\end{array}$ \\
\hline Экспертные знания / Expertise & + & + \\
\hline Сельскохозяйственные постройки / Farm buildings & + & - \\
\hline Сельскохозяйственная земля / Farmland & + & - \\
\hline $\begin{array}{l}\text { Полевые машины и мобильная техника / Field } \\
\text { machines and mobile machinery }\end{array}$ & - & + \\
\hline Стационарное оборудование / Fixed equipment & + & - \\
\hline Труд / Labor & - & + \\
\hline $\begin{array}{l}\text { Долгосрочный уход за землей / Long term handling } \\
\text { of land }\end{array}$ & + & - \\
\hline $\begin{array}{l}\text { Капитальный ремонт строений / Major repairs of } \\
\text { buildings }\end{array}$ & + & - \\
\hline $\begin{array}{l}\text { Часть оборотного капитала в виде доли фактических } \\
\text { затрат / Part of the working capital as a share of ac- } \\
\text { tual costs }\end{array}$ & + & + \\
\hline $\begin{array}{l}\text { Доля в собственности на домашний скот / Share in } \\
\text { the ownership of livestock }\end{array}$ & + & + \\
\hline
\end{tabular}

${ }^{6}$ Sharefarming: How it works and why it could reshape farming // Farmers Weekly. 2018. August 24. URLS: https://www.fwi.co.uk/business/business-management/partnerships/ share-farming-how-it-works-and-why-it-could-reshape-farming (дата обращения: 11.07.2019).

7 Там же. 
Второй блок практик связан с улучшением предоставления услуг населению. В сельской местности действует ряд специфических факторов, влияющих на стоимость услуг. Кроме ранее перечисленных он включает также растущее разнообразие потребностей жителей и ограниченное количество организаций, предоставляющих услуги. Среди практик, позволяющих улучшить предоставление услуг населению и повысить их экономическую эффективность, можно назвать ${ }^{8}$ : альтернативные способы доставки услуг (например, передвижные стоматологические пункты, библиотеки); помощь муниципальных предприятий в оказании услуг, отсутствующих на территории; использование альтернативных источников электроэнергии, которые позволяют обеспечивать бесперебойное электроснабжение поставщиков услуг. Дополнительные возможности в этом направлении возникают благодаря современным цифровым технологиям и телекоммуникационной связи.

Европейская сеть развития сельского хозяйства (European Network for Rural Development) проанализировала разнообразный опыт внедрения концепции «Smart Village» («,УМная“ деревня») для улучшения качества и объема предоставления услуг на удаленных и малонаселенных территориях. Был сделан вывод о том, что цифровые технологии позволяют не только повысить разнообразие предоставляемых услуг, но и сделать процесс более гибким и настроенным на требования потребителя, при этом сами потребители участвуют в выборе проектов цифровизации населенного пункта [20]. Среди примеров, решением которых стали цифровые технологии, можно назвать создание коворкингов в Испании (которые обеспечили не только рабочие места находящимся на территории муниципалитета путешественникам, но и приток новых жителей, стремящихся поменять образ жизни), предоставление услуг химчистки, ремонта, ухода за садом для старшего населения в Испании, онлайнобучение фермеров в Австрии и многое другое 9 .

Второе направление - сохранение и повышение качественных характеристик физического базиса, а также степени его освоенности.

Поддержание степени освоенности территории, улучшение качественных характеристик физического базиса критическим образом зависит от плотности экономических агентов. Падение численности населения приводит к снижению контроля над территорией, обезлюдению и в конечном счете исчезновению поселений. В связи с этим интересны выводы Дж. Сисснер, анализировавшей нормативные документы шведских муниципальных образований относительно отражения в них

${ }^{8}$ New Rural Policy: Linking up for Growth. Paris: OECD Publication, 2015. Pp. 29-30.

9 Digital and Social Innovation in Rural Services / The European Agricultural Fund for Rural Development. Luxembourg: Publications Office of the European Union, 2018. URL: https://enrd.ec.europa.eu/sites/enrd/files/enrd_publications/publi-eafrd-brochure-07-en_2018-0. pdf (дата обращения: 11.07.2019). 
вопросов демографического сжатия [12]. Хотя исследование было направлено на изучение ответа местного самоуправления на вызов сокращения населения (и его старения) в целом, а не только в сельской местности, оно проводилось на материалах пяти муниципалитетов сельскохозяйственной провинции Эстергетланд, которые попадают по классификации Ассоциации местных органов власти и регионов Швеции в категорию C - маленькие города / городские территории и сельские муниципалитеты ${ }^{10}$. Автор исследования отмечает, что шведские муниципалитеты не отличаются большой численностью населения (самый большой муниципалитет - Стокгольм, население которого составляет 890 тыс. чел., при этом средняя численность населения муниципалитета в Швеции - 15,5 тыс. чел.); меньше всего человек проживают в самых маленьких поселениях, расположенных в сельской местности [12, p. 8]. Таким образом, рассмотрение данного опыта представляется целесообразным ввиду соответствия основных экономико-пространственных характеристик муниципалитетов.

Три вывода, к которым приходит Дж. Сисснер, заключаются в следующем. Во-первых, изменение демографической ситуации рассматривается муниципалитетами как важный фактор муниципального развития, так как ведет к дефициту компетенций и рабочей силы, финансовых ресурсов (налогов и субсидий), необходимости повышать эффективность социального обеспечения, прекращать или объединять предоставление существующих государственных услуг или перераспределять средства между ними (например, часть расходов на школы перенаправлять на уход за пожилым населением), в связи с чем возрастает роль межмуниципального сотрудничества и объединения ресурсов. Во-вторых, в документах муниципальных образований представлены два варианта реагирования на проблему демографического сжатия принятие мер, направленных на стимулирование роста численности населения и повышение привлекательности территории для бизнеса и инвестиций, и мер по адаптации к данному изменению, оптимизации его последствий (например, управление основными средствами (жилым фондом, общественными зданиями и инженерной инфраструктурой [10])), хотя последний тип не оказывается в приоритете. Кроме перечисленных вариантов существуют еще два - игнорирование статистических данных и рассмотрение складывающейся демографической ситуации как возможности для нового витка в муниципальном развитии $[16 ; 21]$. В-третьих, по мнению исследователя, небольшие муниципалитеты, которые больше всего нуждаются в выработке стратегий для ответа на вызовы

${ }^{10}$ Classification of Swedish Municipalities 2017 / Swedish Association of Local Authorities and Regions. URL: https://skl.se/download/18.6b78741215a632d39cbcc85/1487772640274/ Classification+of+Swedish+Municipalities+2017.pdf (дата обращения: 11.07.2019). 
демографического сжатия, имеют меньше всего возможностей для этого, поэтому возрастает роль региональных и национальных органов власти в обеспечении информацией и лучшими практиками муниципалитетов и поддержке развития их нормативно-правовой базы.

В качестве способа, позволяющего сглаживать отрицательные последствия демографического сжатия, Дж. Сисснер и ее коллега М. Мейер рассматривают неформальные практики пространственного планирования [13]. Словенский ученый С. Кузар определяет их как попытки жителей адаптировать пространство в соответствии со своими потребностями, предпринимаемые вне официальной (формальной) системы планирования [22, р. 159]. Интересно, что С. Кузар не говорит о неформальных практиках пространственного планирования только как о положительном явлении - они могут также включать и незаконные способы отстаивания интересов (например, коррупцию, лоббизм [22, p. 162]), однако мы в дальнейшем будем иметь в виду те практики, которые соответствуют нормам закона и приводят к конструктивному диалогу между жителями и муниципалитетом. Согласно словенскому исследователю, существуют три случая возникновения неформальных практик: 1) формальная система планирования не работает или дает неудовлетворительный результат (в силу временных затрат, противоречивости норм или отсутствия гибкости); 2) есть несоответствия между нормативным актом и практическим внедрением новых формальных институтов; 3) система планирования недостаточно легитимна («привязана» к реальной ситуации и не учитывает интересов стейкхолдеров). В этих случаях использование неформальных практик позволяет компенсировать недостатки системы планирования, предусмотренной законодательством.

Дж. Сисснер и М. Мейер предлагают развивать неформальные практики на основе ресурсного подхода. Анализ неформальных практик пространственного планирования (являющихся результатом коллективного принятия решений и генерирующих пространственный эффект), проведенный учеными на материалах провинции Эстергетланд (Швеция) и Ахтерхук (часть провинции Гелдерланд, Нидерланды), позволил выявить четыре вида ресурсов, «приобретаемых» муниципалитетами благодаря инициативам жителей. Данные ресурсы компенсируют сокращение ресурсной базы из-за падения численности населения и позволяют поддерживать привлекательность территории и качество жизни.

Во-первых, это финансовые ресурсы, приток которых обеспечивается несколькими способами: запросом и получением общеевропейских субсидий (например, программа EU Leader), неоплачиваемой работой волонтеров, а также передачей операционных издержек под ответственность инициаторов проекта после завершения капитальных затрат (например, поддержание местной библиотеки или ледовой арены). 
Во-вторых, материальные ресурсы, такие как техника и оборудование. Примером служит проведение широкополосного доступа к сети Интернет в Швеции. Для телекоммуникационных компаний невыгодно проведение оптоволокна на малонаселенных территориях, поэтому в Швеции государство предоставляет оборудование и материалы, а органы местного самоуправления и жители организуют и контролируют процесс прокладки кабеля. Другим примером может служить использование пустующих зданий, принадлежащих муниципалитету, когда жители предлагают идеи их использования или снижения издержек их эксплуатации.

B-третьих, человеческие ресурсы (знания, умения, компетенции, опыт, здравый смысл и интуиция). На территориях, где отмечается демографическое сжатие, в органах власти и общественных организациях происходит сокращение рабочих мест, увольнение сотрудников или выход на пенсию, в связи с чем качество человеческого капитала падает, хотя является важным фактором в управлении такими территориями. Знание местных особенностей, которым могут поделиться жители, помогает улучшать процесс формального пространственного планирования. Для использования этих знаний, интеллектуального капитала, физических навыков жителей, а также достижения общественного консенсуса по вопросам использования территории муниципалитетов в изучаемой провинции Нидерландов организован и функционирует фонд Gelderse Federatie voor Dorpshuizen en Kleine Kernen (Региональный фонд для общинных центров и малых общин Гелдерланда). Использование знаний осуществляется и в обратном направлении. Шведский аналог этого фонда Hela Sverige Ska Leva («Вся Швеция будет жить») разработал свою методику локального экономического анализа, которая может применяться местными жителями для анализа данных государственной статистики с целью дальнейшего выдвижения инициатив. Методика аналогична разработкам, сделанным для городских экономик, таким как «Understanding Your Local Economy: A Resource Guide for Cities» ${ }^{11}$, и включает широкий набор инструментов (анализ временных рядов, темпов роста и прироста, сложных индексов, бенчмаркинг, ГИС-картирование, PEST-анализ, анализ добавочной стоимости, коэффициентов локализации, компетентностный аудит и другие с пояснениями и примерами). Разработка шведского фонда, по мнению еще одной группы ученых, не только позволяет выявлять активы, которыми обладает территория, но и избегать излишнего пессимизма [23]. Оба фонда являются площадкой для обмена опытом и интерпретации новых нормативно-правовых актов.

В-четвертых, организационные ресурсы (структуры планирования и координирования и социальный капитал). В этом случае муници-

${ }^{11}$ Understanding Your Local Economy. A Resource Guide for Cities. Washington, DC: The Cities Alliance, 2007. 
палитеты получают легитимность, признание принимаемых решений и возможность общей ответственности между активными жителями и представителями органов власти. Из активных жителей создаются работающие структуры, способные решать вопросы местного значения. Происходит делегирование ответственности в таких областях, как образование и здравоохранение, создание спортивных сооружений, озеленение общественного пространства.

Таким образом, неформальные практики позволяют расширять ресурсную базу «сжимающихся» муниципалитетов и тем самым поддерживать освоенность территории, сохранять ее привлекательность.

Исследование сельских территорий Латвии подтверждает, что разработка пространственной политики в муниципальных образованиях, испытывающих демографическое сжатие, связана с поиском баланса между оптимизацией издержек на выполнение обязательств социального обеспечения, предоставление государственных услуг, содержание муниципальной собственности и инфраструктуры (англ. shrink to survive уменьшиться, чтобы выжить) и сохранением потенциала территории, еe привлекательности для населения и бизнеса, поскольку часто сокращение издержек (закрытие школ, учреждений здравоохранения и др.) приводит к значительному оттоку населения на более перспективные территории [11]. Такая миграция особенно характерна для территорий, граничащих с развивающимися центрами с высокой транспортной доступностью для населения из «сжимающихся» территорий. Необходимо отметить, что эффект конкуренции муниципалитетов в российских регионах нарастает. Кроме того, муниципальные образования могут намеренно привлекать внутренних мигрантов [24], поскольку такой инструмент увеличения численности населения более доступен на муниципальном уровне.

Сохранение и улучшение освоенности территории возможно и в случае создания в ее пределах объекта, повышающего ее привлекательность для проживания. Примером такого объекта служит Научный институт Гран-Сacco (Gran Sasso Science Institute, GSSI) в регионе Абруццо (Италия $)^{12}$. На момент создания Института регион переживал длительную историю масштабной эмиграции за пределы своей территории. В основном население эмигрировало из небольших сельских муниципалитетов. В 2000-2015 гг. регион потерял более 60 тыс. чел. в возрастной группе 15-34 лет (-17,5\%), а доля людей в возрасте старше 65 лет превысила среднее значение по Италии и Европейскому союзу. В связи с этим осуществлялись различные программы по восстановлению социально-экономического состояния территории, направленные на усиление

${ }^{12}$ Shrinking Rural Regions in Europe: Policy Brief. Luxembourg: European Spatial Planning Observation Network, 2017. URL: https://www.espon.eu/rural-shrinking (дата обращения: 11.07.2019). 
экономики знаний и ориентированные на развитие внутренних ресурсов региона, инноваций и конкурентоспособности. Однако эта структура не выдержала испытания экономическим кризисом 2008-2009 гг. В 2009 г. произошло землетрясение, вызвавшее масштабные разрушения. Научный институт Гран-Сассо был создан в 2012 г., чтобы предложить другой вариант программы социально-экономического восстановления. Фокус исследования Института сосредоточился на «чрезвычайном» событии землетрясении - и уникальных ресурсах и опыте территории, т. е. на поле исследований естественных наук. Целью стало развитие центра международного уровня в области геологии и физики для привлечения международных высококвалифицированных исследователей. До 2016 г. Институт находился в ведении Национального института ядерных исследований, однако позднее Министерство образования признало автономию GSSI как университета. GSSI почти полностью финансируется на общественные средства. Он оказался успешным в привлечении человеческих ресурсов из-за рубежа и таким образом стимулировал восстановление человеческого капитала территории. Вероятно, еще рано делать окончательные выводы, но по наблюдениям на территории возрастает экономическая деятельность. Второй результат - создание новых стартапов и предприятий, связанных с Институтом.

Третье направление - рост интегрированности муниципального района в экономическое пространство региона и связанности экономического пространства внутри муниципального района.

Вопросы развития транспортной инфраструктуры относятся к числу наиболее острых в развитии сельских муниципальных образований в силу их малонаселенности и, следовательно, низкого спроса на транспортные услуги и удаленности, приводящей к высоким издержкам. Уровень транспортной доступности имеет также принципиальное значение при разработке стратегий экономического развития такого муниципального образования. Как формулируют это Д. Хьюстон, С. Маккей и М. Мюррей, «категорию, ,сельское“ можно рассматривать в двух плоскостях: доступные сельские районы, отличающиеся ростом и связанностью; и периферийные сельские районы, часто характеризующиеся неопределенностью и удаленностью» [25, p. 44].

В. Канцлер на VI Конференции по транспортным исследованиям в Швейцарии подчеркивал важность полноценного использования существующей инфраструктуры, поскольку ресурсная база малонаселенных муниципалитетов невелика [8]. Решением, по его мнению, может стать гибкий подход к обеспечению транспортной доступности населенных пунктов, включающий:

- вовлечение граждан: перевозки небольшими автобусами, водителями которых являются местные жители (Bürgerbus); 
- совместное или поочередное использование личных и общественных автомобилей (private and public car pooling);

- альтернативы классическому общественному транспорту: гибкие транспортные услуги, такие как вызов автобуса по телефону при необходимости (Rufbus) - в остальное время автобус не курсирует, вызов такси по телефону (Anruftaxi). Такие услуги предоставляет компания Verkehrsverbund Schwarzwald-Baar $\mathrm{GmbH}^{13}$ в земельном районе Шварцвальд-Баар. Тарифы автобуса и такси не отличаются от тарифов обычного общественного транспорта данной транспортной компании.

Другим аспектом повышения связанности экономического пространства внутри сельских муниципальных образований является обеспечение коммуникационного взаимодействия экономических агентов, в том числе для решения вопросов пространственного планирования. Для России проблема представляется более чем актуальной ввиду больших расстояний как между населенными пунктами, так и между муниципальными образованиями (сельские поселения внутри муниципальных районов), поскольку принцип пешеходной доступности административного центра муниципального образования соблюдается далеко не всегда.

В этом контексте полезен опыт Финляндии, добившейся существенных успехов в привлечении жителей к участию в пространственном планировании на уровне муниципального образования, рассмотренный С. И. Федуловой ${ }^{14}$ [26]. Опыт, изученный исследователем, касается разработки Городского плана Хельсинки и интересен с точки зрения применения современных практик и цифровых технологий. Особую ценность, по мнению С. И. Федуловой, представляет масштабный онлайнопрос населения, проведенный на этапе разработки Плана: «В короткие сроки были охвачены разные возрастные категории населения, в том числе молодежь и люди трудоспособного возраста, разные группы по ценностям и интересам, например автолюбители и собаководы... Жителям предлагалось в течение месяца отмечать на интерактивной карте конкретные площадки и маршруты в соответствии со специально разработанными вопросами, такими как возможность строительства нового жилья и офисов, обязательное сохранение территорий в текущем виде, улучшение состояния рекреационных территорий, разработка пешеходных и велосипедных маршрутов» [26, с. 108]. Форма опроса позволила значительно увеличить количество участников процесса пространственного планирования по сравнению с традиционными способами вовлечения

13 RufBus and Anruf-Sammel-Taxi. URL: http://www.v-s-b.de/en/service/rufbus-und-ast. html (дата обращения: 11.07.2019).

14 Федулова С. И. Пространственное планирование в странах Европейского союза и Российской Федерации: географические особенности, лучшие практики: автореф. дис. ... канд. геогр. наук: 25.00.24. М., 2017. 22 с. 
населения, что дало возможность изучить ожидания людей, снизить вероятность конфликтов, собрать большой массив данных о муниципалитете.

В России уже есть опыт адаптации модели северных стран для проведения голосований по вопросам жизнедеятельности городов, поселков, в том числе планирования, обустройства и развития городской среды. Порталы «Активный гражданин» созданы и функционируют в Калининградской области ${ }^{15}$ и в г. Москве ${ }^{16}$.

Четвертое направление - сбалансированное развитие сельско-городских отношений.

Близость к развитой городской территории и интеграция в глобальный цикл «производство - потребление» часто оказывается критичным фактором развития муниципальных районов как муниципальных образований, концентрирующих преимущественно сельские поселения. В Повестке территориального развития Европейского союза ${ }^{17}$ на основе взаимозависимости между сельскими и городскими территориями утверждается необходимость их широкого партнерства: во-первых, важно улучшать доступ к городским территориям из близлежащих сельских для поддержания уровня занятости и обеспечения необходимыми услугами; во-вторых, у городских территорий возникает ответственность за развитие окрестных территорий.

Документ «Перспектива европейского пространственного развития» $(\mathrm{ESDP})^{18}$ в качестве одной из целей пространственного развития территории Европейского союза, которые должны приниматься во внимание при разработке документов на разных уровнях, называет необходимость полицентричного и гармоничного пространственного развития. Для этого требуется развитие партнерства между сельскими и городскими территориями в таких областях, как местный транспорт, управление отходами, разграничение жилых и промышленных территорий.

Словенский исследователь М. Дивьяк рассматривает случай стратегического пространственного планирования для двух городов - Любляны и Копера с точки зрения гармоничного развития города и близлежащих территорий [27]. Проблема, с которой столкнулась Словения, - демографическое сжатие в крупных городах (Любляне, Мариборе, Целе,

15 Проект «Активный гражданин» (Калининградская область). URL: https://ag.gov39. ru (дата обращения: 11.07.2019).

${ }^{16}$ Проект «Активный гражданин» (Москва). URL: https://ag.mos.ru/site/index (дата обращения: 11.07.2019).

17 Territorial Agenda of the European Union 2020. Towards an Inclusive, Smart and Sustainable Europe of Diverse Regions. URL: http://ec.europa.eu/regional_policy/sources/policy/ what/territorial-cohesion/territorial_agenda_2020.pdf (дата обращения: 11.07.2019).

${ }^{18}$ European Spatial Development Perspective: Towards Balanced and Sustainable Development of the Territory of the European Union. Potsdam: ESDP, 1999. URLS: https://ec.europa.eu/ regional_policy/sources/docoffic/official/reports/pdf/sum_en.pdf (дата обращения: 11.07.2019). 
Копере) с параллельным рассредоточенным ростом населения пригородов. В целом пространственная организация страны характеризуется полицентричностью, поскольку исторически Словения находилась на пересечении крупных транспортных путей, а ее регионы существенно различаются по природно-климатическим условиям. В 1960-1970-е гг. в Словении наблюдалась ускоренная урбанизация, однако после 1981 г. население двинулось в противоположном направлении: все больше жителей переезжали из центра города ближе к окраинам и в пригороды, при этом расселение происходило неравномерно. К началу 1990-х гг. около трети населения Словении проживали в пригородах. В результате экстенсивные процессы субурбанизации с достаточно низкой плотностью во вновь формируемых поселениях снизили эффективность землепользования, ухудшили состояние окружающей среды и локальных экономик.

Для того чтобы направить процесс расселения в русло устойчивого развития, был разработан и осуществлен план децентрализованной концентрации поселений для Любляны и Копера с небольшими вариациями. Он включает три общих блока: 1) развитие центральных застроенных территорий города и его исторического центра; 2) обновление, возрождение и трансформацию центральных мест города для улучшения городской среды и повышения привлекательности города для нынешних и потенциальных жителей; 3) развитие небольших центров концентрации в пригородных и сельских территориях и создание сетевых связей между ними. Важный принцип децентрализованной модели - связь региональных очагов городского роста с маршрутами общественного транспорта. Это позволяет оживить инвестиционный процесс и тем самым восстанавливать эти территории на основе реструктуризации экономики и делегирования им новых городских функций. Основной целью в развитии внутренних районов страны является концентрация расселения, снижение «расползания» городов, а также переключение жителей на использование общественного транспорта, а не личных автомобилей.

В отношении Любляны эта модель направлена прежде всего на снижение транспортного давления на центр города и формирование нескольких центров городского роста в пригородах таким образом, чтобы рассеянный жилой фонд из отдельно стоящих домов в пригородах концентрировался вдоль транспортных осей. При этом улучшится снабжение населения товарами и услугами, а поселения смогут функционировать почти независимо.

Что касается Копера, то город, будучи важным административным, экономическим и образовательным центром, окажется более тесно связанным с пригородами и сельскими поселениям с помощью автомобильной и автобусной инфраструктуры. Планы по развитию инфраструктуры включают расширение порта (постройка третьего причала), замену ны- 
нешнего шоссе Копер - Изола, которое идет по побережью, на новое шоссе, которое проложат по внутренним районам через тоннель. При этом прибрежное шоссе будет больше использоваться для развития рекреационных проектов и местных автобусных маршрутов.

Таким образом, стратегии для пригородных территорий связаны с созданием децентрализованной концентрации на субурбанизированных территориях, объединенных маршрутами общественного транспорта. Применение предложенных для городов моделей позволит улучшить следующие аспекты пространственного развития: концентрацию расселения и землепользование; качество городской среды новых городских центров и их функции; возможности по трудоустройству; коммунальную и другую инфраструктуру; концентрацию населения вблизи транспортных остановок; экологическую составляющую общественного транспорта.

На основе изученного опыта можно дать несколько рекомендаций в отношении обеспечения сбалансированного развития сельско-городских отношений.

Во-первых, ввиду малой населенности сельских и небольших муниципалитетов важно не только вписывать их в общую транспортную инфраструктуру, но и определять локальные центры городского роста, которые смогут заменить и выполнить часть функций крупного городского поселения.

Во-вторых, планирование городских территорий обязательно должно учитывать уровень развития, потребности и ресурсы близлежащих сельских территорий. Необходимо использовать положительные стороны сельской местности, такие как более низкая стоимость земли (жилья) и хорошие экологические условия, в особенности подкрепленные хорошей транспортной доступностью [28, р. 179].

В-третьих, большое значение для выстраивания сельско-городских отношений имеет текущее расположение сельских территорий по отношению к городским. С этой точки зрения ОЭСР выделяет три типа сельских территорий ${ }^{19}$ : сельские территории, расположенные внутри функциональных городских территорий; сельские территории, расположенные близко к ним, и удаленные сельские регионы. В зависимости от типа смещается фокус выстраивания отношений. В первом случае, например, основные сложности развития сельской территории будут связаны с «доставкой» местному населению услуг, потому что последние сконцентрированы в городском ядре; с соизмерением компетенций и навыков с требованиями локального рынка труда и управлением землепользованием под давлением со стороны городской территории. Во втором случае сельская территория достаточно интегрирована с го-

${ }^{19}$ New Rural Policy: Linking up for Growth. Paris: OECD Publication, 2015. 
родской экономикой, а ее экономика включает и некоторые городские сектора экономики; она в состоянии конкурировать с городом за бизнес и жителей, поэтому могут возникать конфликты землепользования, а также между потребностями новых и коренных жителей. В третьем случае территории вынуждены работать над своими конкурентными преимуществами (абсолютными и сравнительными), улучшать доступ к рынкам поставки произведенных на территории товаров, развивать трудовые навыки, компетенции населения в направлении поддержки сравнительного преимущества и улучшать предоставление услуг населению. Однако выстраивание отношений тем сложнее, чем больше разница между городским центром и сельской территорией.

Обсуждение и заключение. В целом проведенный обзор лучших практик позволил сделать и подтвердить ряд общих выводов:

- развитие муниципального образования необязательно должно быть направлено на рост экономических и других показателей через привлечение инвестиций, богатого населения и другого рода стимулирование; альтернативными целями пространственного развития могут быть сохранение текущих показателей, территориальной идентичности муниципального образования, снижение его отрицательного влияния на экологическую ситуацию;

- пространственное развитие должно принимать во внимание множество разнонаправленных трендов, очерчивающих контекст развития региональных экономик и муниципальных районов как их части;

- значительное влияние на причины, следствия, способы противодействия сельскому сжатию как в чисто демографическом, так и в экономико-пространственном понимании оказывает экономико-правовой статус муниципальных образований. В случае Швеции, например, автономность муниципалитета и существенный объем ответственности не только оговорены в Конституции, но и финансово обеспечены, а сами муниципальные образования составляют заметную долю публичного сектора (83 \% сотрудников сектора [12, p. 9]);

- рассогласованность стратегических и программных документов пространственного развития разного уровня (международного (в рамках интеграционных объединений), национального, регионального, муниципального) является существенным препятствием в их реализации и снижает эффективность мероприятий. Причины рассогласованности могут носить политический характер или быть связанными с недостатком информации и ресурсов при разработке документов.

Выводы и описание лучших практик, полученные в результате проведенного исследования, позволяют обозначить теоретическую значимость в контексте осмысления экономико-пространственного развития на муниципальном уровне, а также могут быть полезны в практике 
регионального и муниципального управления для разработки и реализации документов стратегического планирования. В настоящий момент существуют лакуны, связанные с осознанием значимости экономикопространственного развития для муниципальных образований, а также непосредственным воплощением его целей и задач на муниципальном уровне с использованием конкретных инструментов. Систематизация лучших практик по направлениям экономико-пространственного развития дает возможность муниципальным районам и регионам использовать их в четком соответствии со своими индивидуальными потребностями: потребностью в росте экономической активности и экономически значимых результатов на территории; сохранении и повышении качественных характеристик территории и ее освоенности; росте интегрированности муниципальных районов в экономическое пространство региона и связанности экономического пространства внутри муниципального района; в сбалансированном развитии сельско-городских отношений (городские и сельские поселения в пределах муниципального района; муниципальные районы и городские округа в пределах региона).

\section{СПИСОК ИСПОЛЬЗОВАННЫХ ИСТОЧНИКОВ}

1. Минакир П. А. Национальная стратегия пространственного развития: добросовестные заблуждения или намеренные упрощения? // Пространственная экономика. 2016. № 3. C. 7-15. DOI: https://doi.org/10.14530/se.2016.3.007-015

2. Dvoryadkina E., Karkh D., Belousova E. Digital Agriculture in Improving Spatial Economic Development of Rural Municipalities in Russia // International Scientific and Practical Conference "Digital Agriculture - Development Strategy" (ISPC 2019). Atlantis Press, June 2019. Pp. 426-430. DOI: https://doi.org/10.2991/ispc-19.2019.95

3. Белоусова Е. А. Сельские поселения как объект исследования в концепциях экономического пространства // Управленец. 2016. № 6 (64). С. 42-47. URL: http://upravlenets.usue.ru/ru/-2016/389 (дата обращения: 11.07.2019).

4. Dvoryadkina E. B., Belousova E. A. Municipal Districts in Economic Space of a Region: Constructive and Destructive Trends // Известия Уральского государственного экономического университета. 2018. Т. 19, № 5. С. 84-106. DOI: https://doi.org/10.29141/2073-1019-2018-19-5-7

5. Колмакова Е. М. Социально-экономический анализ муниципальных образований по критерию их устойчивого территориального развития // Вестник Челябинского государственного университета. 2014. № 2 (331). С. 17-19. URL: http://www.lib.csu.ru/elbibl/vestn_arh.shtml (дата обращения: 11.07.2019).

6. Киселева Н. Н., Браткова В. В. Управление пространственным ростом // Вестник Санкт-Петербургского государственного университета технологии и дизайна. Сер. 3: Экономические, гуманитарные и общественные науки. 2018. № 1. C. 31-37. URL: https://elibrary.ru/item.asp?id=36346748 (дата обращения: 11.07.2019). 
7. Суворова А. В. Пространственное развитие: содержание и особенности // Journal of New Economy. 2019. Т. 20, № 3. С. 51-64. DOI: https://doi. org/10.29141/2658-5081-2019-20-3-4

8. Canzler W. Infrastructure Investments in a Shrinking Society // 6th STRC Swiss Transport Research Conference. Monte Verità, 2017. URL: http://www.strc. ch/2006/Canzler_STRC 2006.pdf (дата обращения: 11.07.2019).

9. Hospers G.-J., Reverda N. Managing Population Decline in Europe's Urban and Rural Areas. London: Springer, 2015. 81 p. DOI: https://doi.org/10.1007/9783-319-12412-4

10. Jonsson R., Syssner J. New Demography, Old Infrastructure: The Management of Fixed Assets in Shrinking Municipalities in Sweden // Dealing with Urban and Rural Shrinkage. Formal and Informal Strategies / ed. by G.-J. Hospers, J. Syssner. Zurich: LIT VERLAG GmbH\&Co. KG Wien, 2018. URL: http://www.diva-portal.org/ smash/record.jsf?pid=diva2\%3A1179127\&dswid=-5770 (дата обращения: 11.07.2019).

11. Pužulis, A., Kūle L. Shrinking of Rural Territories in Latvia // European Integration Studies. 2016. No. 10. Pp. 90-105. DOI: https://doi.org/10.5755/j01. eis. 0.10 .14988

12. Syssner J. Planning for Shrinkage? Policy Implications of Demographic Decline in Swedish Municipalities // Revista de extudios sobre despoblación y desarollo rural. 2016. Vol. 20. Pp. 7-31. DOI: https://doi.org/10.4422/ager.2015.14

13. Syssner J., Meijer M. Informal Planning in Depopulating Rural Areas: A Resource-Based View of Informal Planning Practices // European Countryside. 2017. Vol. 9, no. 3. Pp. 458-472. URL: https://ideas.repec.org/a/vrs/eurcou/v9y2017i3p458472n4.html (дата обращения: 11.07.2019).

14. Thellbro C. Spatial Planning for Sustainable Rural Municipalities. Umeå, Sweden: Sveriges lantbruksuniv., Acta Universitatis agriculturae Sueciae, 2017. 142 p. URL: https://pub.epsilon.slu.se/14734/1/thellbro_a_171117.pdf (дата обращения: 11.07.2019).

15. Антипин И. А., Казакова Н. В. Концептуальные основы разработки стратегии пространственного развития в муниципальном образовании // Российское предпринимательство. 2016. T. 17, № 8. DOI: https://doi.org/10.18334/rp.17.8.35119

16. Multifunctional Development of Rural Areas. International Experience / ed. by P. Bórawski. Ostrołęka: Wydawnictwo Wyższej Szkoły Ekonomiczno-Społecznej w Ostrołęce, 2012. URL: https://ideas.repec.org/b/ags/agsaem/208117.html (дата обращения: 11.07.2019).

17. Зырянов С. Г., Иванов О. П., Гордеев С. С. Устойчивость регионального развития и практика межмуниципального взаимодействия // Научный ежегодник Центра анализа и прогнозирования. 2017. № 1. C. 10-19. URL: http://www.chel. ranepa.ru/nauka/nauchnyy-ezhegodnik-tsentra-analiza-i-prognozirovaniya.php (дата обращения: 11.07.2019).

18. Eversole R., Barraket J., Luke B. Social Enterprises in Rural Community Development // Community Development Journal. 2014. Vol. 49, issue 2. Pp. 245-261. DOI: https://doi.org/10.1093/cdj/bst030

19. Степных Н. В., Заргарян А. М., Нестерова Е. В. Электронная база данных состояния и функционирования агроландшафтов // Известия Уральского 
государственного экономического университета. 2018. Т. 19, № 4. С. 136-146. DOI: https://doi.org/10.29141/2073-1019-2018-19-4-10

20. Smart Villages: Revitalising Rural Services. EU Rural Review. 2018. No. 26. URL: https://enrd.ec.europa.eu/sites/enrd/files/enrd_publications/publi-enrd-rr-26-2018en.pdf (дата обращения: 11.07.2019).

21. Shrinking Cities: Urban Challenges of Globalisation / C. Martinez-Fernandez [et al.] // International Journal of Urban and Regional Research. 2012. Vol. 36, issue 2. Pp. 213-225. DOI: https://doi.org/10.1111/j.1468-2427.2011.01092.x

22. Kušar S. Landscape Studies Informal Planning Practices: Some Evidence from Slovenia // Journal of Landscape Studies. 2010. No. 3. Pp. 159-165. URL: http://www.centrumprokrajinu.cz/files/JLS_Volume\%203_pp\%20159-165.pdf (дата обращения: 11.07.2019).

23. Hutlman M., Rydstrom C., Tingvall P. Localizing the Economy: Rural Development in Ostergotland // Dealing with Urban and Rural Shrinkage. Formal and Informal Strategies / G.-J. Hospers, J. Syssner, eds. Zurich: LIT VERLAG GmbH\&Co. KG Wien, 2018. 144 p. DOI: https://doi.org/10.1111/tesg.12317

24. Martinez-Fernandez C., Weyman T. The Crossroads of Demographic Change and Local Development // Demographic Change and Local Development: Shrinkage, Regeneration and Social Dynamics / C. Martinez-Fernandez, N. Kubo, A. Noya, T. Weyman, eds. Paris: OECD, 2012. Pp. 15-36. DOI: https://doi. org/10.1787/9789264180468-en

25. Houston D., McKay S., Murray M. Civic Engagement and Development Strategies Learning from the Experience of Participatory Rural Redevelopment // Future Directions for the European Shrinking City / W. Neill, H. Schlappa, eds. New York: Routledge, 2016. Pp. 44-54. DOI: https://doi.org/10.4324/9781315747286

26. Федулова С. И. Опыт Финляндии в вовлечении населения в городское планирование // Общество. Среда. Развитие. 2016. № 1. С. 106-110. URL: http:// www.terrahumana.ru/index.html (дата обращения: 11.07.2019).

27. Divjak M. S. Urban Planning Strategies for Dealing with Shrinkage and Suburbanisation in Slovene Cities // Demographic Change and Local Development: Shrinkage, Regeneration and Social Dynamics / C. Martinez-Fernandez, N. Kubo, A. Noya, T. Weyman, eds. Paris: OECD, 2012. Pp. 159-166. DOI: https://doi. org/10.1787/9789264180468-en

28. Schenkel W. Regeneration Strategies in Shrinking Urban Neighbourhoods: Dimensions of Interventions in Theory and Practice (Switzerland) // Demographic Change and Local Development: Shrinkage, Regeneration and Social Dynamics / C. Martinez-Fernandez, N. Kubo, A. Noya, T. Weyman, eds. Paris: OECD, 2012. Pp. 179-186. DOI: https://doi.org/10.1787/9789264180468-en

Поступила 21.07.2019; принята к публикации 29.08.2019; опубликована онлайн 30.12.2019.

\section{Об авторах:}

Дворядкина Елена Борисовна, проректор по научной работе, профессор кафедры региональной, муниципальной экономики и управления ФГБОУ ВО «Уральский государственный экономический университет» (620144, Россия, 
г. Екатеринбург, ул. 8 Марта, д. 62/45), доктор экономических наук, ORCID: https:// orcid.org/0000-0001-5163-0334, Researcher ID: B-3564-2017, dvoryadkina@usue.ru

Белоусова Елизавета Александровна, главный специалист управления по научно-исследовательской работе, ассистент кафедры региональной, муниципальной экономики и управления ФГБОУ ВО «Уральский государственный экономический университет» (620144, Россия, г. Екатеринбург, ул. 8 Марта, д. 62/45), кандидат экономических наук, ORCID: https://orcid.org/0000-0001-5355-5243, Researcher ID: W-2254-2019, belousova-unir@usue.ru

\section{Заявленный вклад авторов:}

Дворядкина Елена Борисовна - научное руководство; критический анализ и доработка текста; изучение концепции.

Белоусова Елизавета Александровна - сбор, обработка и анализ информации; подготовка первоначального варианта текста и его последующая доработка.

\section{Для изитирования:}

Дворядкина Е. Б., Белоусова Е. А. Лучшие практики пространственного развития: возможность адаптации в отношении муниципальных районов // Регионология. 2019. Т. 27, № 4. С. 633-660. DOI: https://doi.org/10.15507/24131407.109.027.201904.633-660

Все авторы прочитали и одобрили окончательный вариант рукописи.

\section{REFERENCES}

1. Minakir P.A. The National Strategy of Spatial Development: Is It the Conscientious Delusion or Deliberate Simplification? Prostranstvennaya ehkonomika = Spatial Economics. 2016; (3):7-15. (In Russ., abstract in Eng.) DOI: https://doi. org/10.14530/se.2016.3.007-015

2. Dvoryadkina E., Karkh D., Belousova E. Digital Agriculture in Improving Spatial Economic Development of Rural Municipalities in Russia. In: International Scientific and Practical Conference "Digital agriculture - Development Strategy" (ISPC 2019). Atlantis Press, June 2019. p. 426-430. DOI: https://doi.org/10.2991/ ispc-19.2019.95

3. Belousova E.A. Rural Settlements as an Object of Research in the Concepts of Economic Space. Upravlenets = The Manager. 2016; (6):42-47. Available at: http:// upravlenets.usue.ru/ru/-2016/389 (accessed 11.07.2019). (In Russ., abstract in Eng.)

4. Dvoryadkina E.B., Belousova E.A. Municipal Districts in Economic Space of a Region: Constructive and Destructive Trends. Izvestiya Uralskogo gosudarstvennogo ehkonomicheskogo universiteta $=$ Journal of the Ural State University of Economics. 2018; 19(5):84-106. (In Eng.) DOI: https://doi.org/10.29141/2073-1019-2018-19-5-7

5. Kolmakova E.M. Need for Socio-Economic Analysis of Municipalities in Terms of Their Sustainable Territorial Development. Vestnik Chelyabinskogo gosudarst- 
vennogo universiteta $=$ Bulletin of Chelyabinsk State University. 2014; (2):17-19. Available at: http://www.lib.csu.ru/elbibl/vestn_arh.shtml (accessed 11.07.2019). (In Russ., abstract in Eng.)

6. Kiseleva N.N., Bratkova V.V. Management of Spatial Growth. Vestnik SanktPeterburgskogo gosudarstvennogo universiteta tekhnologii i dizajna. Seriya 3: Ehkonomicheskie, gumanitarnye $i$ obshchestvennye nauki = Vestnik of St. Petersburg State University of Technology and Design. Series 3. Economic, Humanitarian and Social Sciences. 2018; (1):31-37. Available at: https://elibrary.ru/item.asp?id=36346748 (accessed 11.07.2019). (In Russ., abstract in Eng.)

7. Suvorova A.V. Spatial Development: Essence and Specifics. Journal of New Economy. 2019; 20(3):51-64. (In Russ., abstract in Eng.) DOI: https://doi. org/10.29141/2658-5081-2019-20-3-4

8. Canzler W. Infrastructure Investments in a Shrinking Society. In: 6th STRC Swiss Transport Research Conference. Monte Verità. 2017. Available at: http://www. strc.ch/2006/Canzler_STRC_2006.pdf (accessed 11.07.2019). (In Eng.)

9. Hospers G.-J., Reverda N. Managing Population Decline in Europe's Urban and Rural Areas. London: Springer; 2015. (In Eng.) DOI: https://doi.org/10.1007/9783-319-12412-4

10. Jonsson R., Syssner J. New Demography, Old Infrastructure: The Management of Fixed Assets in Shrinking Municipalities in Sweden. In: Dealing with Urban and Rural Shrinkage. Formal and Informal Strategies. Zurich: LIT VERLAG GmbH\&Co. KG Wien; 2018. Available at: http://www.diva-portal.org/smash/record.jsf?pid=diva 2\%3A1179127\&dswid=-5770 (accessed 11.07.2019). (In Eng.)

11. Pužulis A., Kūle L. Shrinking of Rural Territories in Latvia. European Integration Studies. 2016; (10):90-105. (In Eng.) DOI: https://doi.org/10.5755/j01. eis.0.10.14988

12. Syssner J. Planning for Shrinkage? Policy Implications of Demographic Decline in Swedish Municipalities. Revista de extudios sobre despoblación y desarollo rural. 2016; 20:7-31. (In Eng.) DOI: https://doi.org/10.4422/ager.2015.14

13. Syssner J., Meijer M. Informal Planning in Depopulating Rural Areas: A Resource-Based View of Informal Planning Practices. European Countryside. 2017; 9(3):458-472. Available at: https://ideas.repec.org/a/vrs/eurcou/v9y2017i3p458-472n4. html (accessed 11.07.2019). (In Eng.)

14. Thellbro C. Spatial Planning for Sustainable Rural Municipalities. Umeå, Sweden: Sveriges lantbruksuniv., Acta Universitatis agriculturae Sueciae; 2017. Available at: https://pub.epsilon.slu.se/14734/1/thellbro_a_171117.pdf (accessed 11.07.2019). (In Eng.)

15. Antipin I.A., Kazakova N.V. The Conceptual Base of the Spatial Development Strategy of a Municipal Unit. Rossiyskoe predprinimatelstvo = Russian Journal of Entrepreneurship. 2016; 17(8):1011-1026. (In Russ., abstract in Eng.) DOI: https:// doi.org/10.18334/rp.17.8.35119

16. Bórawski P., editor. Multifunctional Development of Rural Areas. International Experience. Ostrołęka: Wydawnictwo Wyższej Szkoły Ekonomiczno-Społecznej w Ostrołęce; 2012. Available at: https://ideas.repec.org/b/ags/agsaem/208117.html (accessed 11.07.2019). (In Eng.) 
17. Zyryanov S.G., Ivanov O.P., Gordeev S.S. Sustainability of Regional Development and the Practice of Inter-Municipal Cooperation. Nauchnyj ezhegodnik Tsentra analiza i prognozirovaniya $=$ Scientific Annual Publication of the Analysis and Forecast Centre. 2017; (1):10-19. Available at: http://www.chel.ranepa.ru/nauka/ nauchnyy-ezhegodnik-tsentra-analiza-i-prognozirovaniya.php (accessed 11.07.2019). (In Russ., abstract in Eng.)

18. Eversole R., Barraket J., Luke B. Social Enterprises in Rural Community Development. Community Development Journal. 2014; 49(2):245-261. (In Eng.) DOI: https://doi.org/10.1093/cdj/bst030

19. Stepnykh N.V., Zargaryan A.M., Nesterova E.V. Electronic Database of the State and Functioning of Agricultural Landscapes. Izvestiya Uralskogo gosudarstvennogo ehkonomicheskogo universiteta $=$ Journal of the Ural State University of Economics. 2018; 19(4):136-146. (In Russ., abstract in Eng.) DOI: https://doi. org/10.29141/2073-1019-2018-19-4-10

20. Smart Villages: Revitalising Rural Services. EU Rural Review. 2018; (26). Available at: https://enrd.ec.europa.eu/sites/enrd/files/enrd_publications/publi-enrd-rr26-2018-en.pdf (accessed 11.07.2019). (In Eng.)

21. Martinez-Fernandez C., Audirac I., Fol S., Cunningham-Sabot E. Shrinking Cities: Urban Challenges of Globalisation. International Journal of Urban and Regional Research. 2012; 36(2):213-225. (In Eng.) DOI: https://doi.org/10.1111/j.14682427.2011.01092.x

22. Kušar S. Landscape Studies Informal Planning Practices: Some Evidence from Slovenia. Journal of Landscape Studies. 2010; (3):159-165. Available at: http:// www.centrumprokrajinu.cz/files/JLS_Volume\%203_pp\%20159-165.pdf (accessed 11.07.2019). (In Eng.)

23. Hutlman M., Rydstrom C., Tingvall P. Localizing the Economy: Rural Development in Ostergotland. In: Dealing with Urban and Rural Shrinkage. Formal and Informal Strategies. Zurich: LIT VERLAG GmbH\&Co. KG Wien; 2018. (In Eng.) DOI: https://doi.org/10.1111/tesg. 12317

24. Martinez-Fernandez C., Weyman T. The Crossroads of Demographic Change And Local Development. In: Demographic Change and Local Development: Shrinkage, Regeneration and Social Dynamics. Paris: OECD; 2012. p. 15-36. (In Eng.) DOI: https://doi.org/10.1787/9789264180468-en

25. Houston D., McKay S., Murray M. Civic Engagement and Development Strategies Learning from the Experience of Participatory Rural Redevelopment. In: Future Directions for the European Shrinking City. New York: Routledge; 2016. p. 44-54. (In Eng.) DOI: https://doi.org/10.4324/9781315747286

26. Fedulova S.I. Finnish Experience in Citizen Involvement in Urban Planning. Obshchestvo. Sreda. Razvitie = Society. Environment. Development. 2016; (1):106-110. Available at: http://www.terrahumana.ru/index.html (accessed 11.07.2019). (In Russ.)

27. Divjak M.S. Urban Planning Strategies for Dealing with Shrinkage and Suburbanisation in Slovene Cities. In: Demographic Change and Local Development: Shrinkage, Regeneration and Social Dynamics. Paris: OECD; 2012. p. 159-166. (In Eng.) DOI: https://doi.org/10.1787/9789264180468-en 
28. Schenkel W. Regeneration Strategies in Shrinking Urban Neighbourhoods: Dimensions of Interventions in Theory and Practice (Switzerland). In: Demographic Change and Local Development: Shrinkage, Regeneration and Social Dynamics. Paris: OECD; 2012. p. 179-186. (In Eng.) DOI: https://doi.org/10.1787/9789264180468-en

Submitted 21.07.2019; accepted for publication 29.08.2019; published online 30.12.2019.

About the authors:

Elena B. Dvoryadkina, Professor, Department of Regional and Municipal Economics and Management; Vice-Rector for Scientific Work, Ural State University of Economics (62/45 8 Marta St., Ekaterinburg 620144, Russia), Dr. Sci. (Economics), ORCID: https://orcid.org/0000-0001-5163-0334, Researcher ID: B-3564-2017, dvoryadkina@usue.ru

Elizaveta A. Belousova, Chief Specialist, Research Office; Assistant Lecturer, Department of Regional and Municipal Economics and Management, Ural State University of Economics (62/45 8 Marta St., Ekaterinburg 620144, Russia), Ph. D. (Economics), ORCID: https://orcid.org/0000-0001-5355-5243, Researcher ID: W-2254-2019, belousova-unir@usue.ru

Contribution of the authors:

Elena B. Dvoryadkina - academic supervision; critical analysis and revision of the text; exploration of the concept.

Elizaveta A. Belousova - collection, processing and analysis of information; writing the initial text of the article and its subsequent revision.

For citation:

Dvoryadkina E.B., Belousova E.A. Best Practices of Spatial Development: Possibility of Using Them in the Municipal Districts of Russia. Regionology = Russian Journal of Regional Studies. 2019; 27(4):633-660. DOI: https://doi.org/10.15507/24131407.109.027.201904.633-660

The authors have read and approved the final version of the manuscript. 


\title{
Факторы инновационного развития региона
}

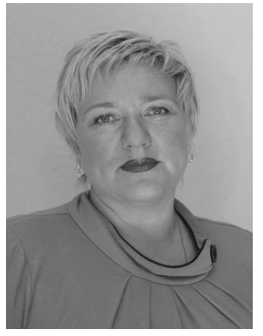

\author{
И. Б. Юленкова \\ ФГБОУ ВО «МГУ им. Н. П. Огарёва» (г. Саранск, Россия), \\ yulenkova.irina@yandex.ru
}

Введение. Инновации - одно из значимых условий экономического роста и развития общества. В зависимости от уровня инновационных процессов определяются направления и темпы развития регионов с позиции качественных преобразований и увеличения основных экономических показателей. К необходимым условиям инновационного развития и устойчивого экономического роста региона относится определение факторов, влияющих на инновационную деятельность. В связи с этим изучение инновационного развития регионов приобретает большое значение и является актуальным. Цель исследования обоснование системного подхода к классификации факторов инновационного развития регионов в контексте их влияния на устойчивое социально-экономическое развитие территорий.

Материалы и методы. В качестве объекта исследования рассматриваются инновационное развитие региона на примере Республики Мордовия. Информационной базой для исследования послужила региональная статистика. Применяются методы факторного и системного анализа, экспертного опроса, планирования и прогнозирования, сравнения.

Результаты исследования. Определены особенности инновационного развития региона. Проведена классификация факторов, влияющих на инновационное развитие региона. С помощью обозначенных факторов, по мнению автора, можно выработать стратегию роста инновационной активности региона. Дан анализ факторов, доказано их влияние на уровень региональных инновационных процессов.

Обсуждение и заключение. Определение институциональных условий и воздействия внутренних и внешних факторов, выявление оптимального уровня соотношения максимального дохода и минимальных затрат приведет к расширению инновационной активности предприятий региона, что обеспечит инновационное и социально-экономическое развитие региона. Полученные результаты служат основой для оценки привлекательности региона с точки зрения инвестиционных вложений, прогнозируют влияние инноваций на региональный рост. Результаты научного исследования обладают практической значимостью и могут быть использованы в практике стимулирования инновационной активности регионов.

Ключевые слова: регион, региональное развитие, стратегия, факторы, инновации, инновационное развитие, инфраструктура, инновационная активность

(C) Юленкова И. Б., 2019

Контент доступен под лицензией Creative Commons Attribution 4.0 License. This work is licensed under a Creative Commons Attribution 4.0 License. 
Финансирование. Статья подготовлена при финансовой поддержке РФФИ и Правительства РМ (проект № 18-410-130004 p_a «Развитие методологии формирования финансово-экономического климата для устойчивого инновационного предпринимательства в регионе»).

\title{
Factors in Innovative Development of a Region
}

\author{
I. B. Yulenkova \\ National Research Mordovia State University \\ (Saransk, Russia), \\ yulenkova.irina@yandex.ru
}

Introduction. Innovation is one of the necessary conditions for economic growth and development of society. Depending on the level of processes of innovation, directions and pace of development of regions are determined in terms of qualitative transformations and the increase in basic economic indicators. The necessary conditions for innovative development and sustainable economic growth in a region include identification of factors affecting innovative activities. In this regard, the study of innovative development of regions is of particular importance and relevance. The purpose of this research is to substantiate the systematic approach to the classification of factors in innovative development of regions in the context of their influence on sustainable socio-economic development of territories.

Materials and Methods. The object of this research was innovative development of a region exemplified by the case of the Republic of Mordovia. Regional statistics was used as the information base for the research. The study employed the methods of factor and system analysis, expert survey, planning, forecasting and comparison. Results. The features of the innovative development of a region have been determined. The factors affecting the innovative development of a region have been classified. According to the author, using the indicated factors makes it possible to develop a strategy for the growth of innovative activities in a region. The factors have been analyzed and it has been proved that they affect the level of regional innovation processes.

Discussion and Conclusion. Determination of the institutional conditions and the impact of internal and external factors, identifying the optimal level of correlation of maximum income and minimum costs will lead to the expansion of innovative activities of enterprises in a region, which will ensure the innovative and socioeconomic development of the region. The results obtained serve as the basis for assessing the attractiveness of a region in terms of investment and provide a forecast for the impact of innovation on the regional growth. The results of this research have practical relevance and can be used in the practice of stimulating innovative activities in regions.

Keywords: region, regional development, innovation, strategy, factors, innovative development, infrastructure, innovative activities

Funding. This article was prepared with the financial support from the Russian Foundation for Basic Research and the Government of the Republic of Mordovia (project No. 18-410-130004 r_a "Development of a methodology for the creation of an economic and financial climate for sustainable innovative entrepreneurship in a region"). 
Введение. В настоящее время на развитие социально-экономической сферы региона большое влияние оказывают инновации. Внедрение инноваций во все сферы жизни обеспечит регионам выход на траекторию устойчивого развития, основанного на инновационном потенциале территорий. С теоретической точки зрения инновации - это фактор экономического роста. Развитие новых технологий, производств, выпуск новых видов продукции и услуг определяют перспективы долгосрочного экономического роста. Действующая практика и труды отечественных и зарубежных ученых доказывают зависимость экономического роста от темпов развития научно-технического прогресса (исследования Н. Я. Тинергена, Р. Солоу, Дж. Хикса и др.).

В последнее время в региональной инновационной политике наблюдается заметная активность дискуссий о направлениях поддержки инноваций, повышается восприимчивость к механизмам стимулирования инноваций, развиваются инструменты поддержки.

Проводимые мероприятия направлены на достижение высоких результатов функционирования инновационной сферы, и еще нет общих подходов к определению их эффективности.

Без учета особенностей и тенденций развития регионов и исследования факторов, степени их влияния на инновационную деятельность невозможно определить условия развития социально-экономических систем с позиции инновационного подхода. Цель данного исследования определение классификации и степени воздействия факторов на инновационную деятельность как важного условия инновационного развития и устойчивого экономического роста региона. Для этого необходимо решить следующие задачи: выявить особенности функционирования региональных систем, определить институциональные аспекты инновационного развития региона, выявить факторы и их влияние на инновационное развитие региона, определить критерии выгодного соотношения максимального результата и минимальных затрат.

Обзор литературы. Большинство современных научных исследований делают упор на развитии инноваций в отдельных странах и регионах, так как в разделении труда и достижении лидирующих позиций в глобальной конкуренции инновационные товары определяют положение страны и региона. Исследуются факторы, которые оказывают влияние на инновационную активность, обосновывается необходимость вмешательства в инновационную сферу ${ }^{1}$.

Отечественными учеными-экономистами разработаны концепции, основу которых составляет системный подход к инновациям, исследо-

1 Рейтинг инновационного развития субъектов Российской Федерации / науч. ред. Л. М. Гохберг. М.: НИУ ВШЭ, 2017. Вып. 5. 257 с. 
ваны влияющие на инновационную активность факторы ${ }^{2}$ Л. И. Абалкин изучил факторы обеспечения экономического развития страны и отметил оригинальность отечественной модели рыночной экономики, где на первое место ставится роль человека, инновационный подход к решению актуальных экономических проблем ${ }^{3}$.

В современной литературе рассматриваются создание новой модели в аспекте инвестиционной экономики ${ }^{4}$, направления управления инновационными проектами ${ }^{5}$, международный аспект внедрения инноваций и возможности использования передового опыта [1], инновационные процессы в мезоэкономике ${ }^{6}$, основы инновационного менеджмента в АПК 7 , инновационные подходы к экономическому развитию на региональном уровне [2], методики оценки инновационного потенциала региона [3].

Ряд исследователей изучают факторы инновационного развития регионов и больших городов [4; 5], подсистемы региональной инновационной системы и условия их функционирования ${ }^{8}[6 ; 7]$, проблемы разработки концептуальных основ инновационной стратегии регионов ${ }^{9}$, профили инновационного развития регионов Российской Федерации [8].

А. В. Горбачев, А. А. Старостина полагают, что инновационное развитие регионов связано с двумя инновационными условиями: экономическим развитием организаций в регионе, передачей полномочий от национального к региональному уровням управления ${ }^{10}$. А. М. Носонов на разных уровнях (федеральные округа, регионы) рассмотрел факторы,

${ }^{2}$ Глазьев С. Ю., Львов Д. С., Фетисов Г. Г. Эволюция технико-экономических систем: возможности и границы централизованного регулирования. М.: Наука, 1992. 207 с.; Системный подход к управлению инновациями на промышленных предприятиях: моногр. / О. Н. Герасина [и др.]. Казань: Изд-во КНИТУ, 2013. 268 с.

3 Абалкин Л. И. Стратегический ответ России на вызовы нового века. М.: Экзамен, 2004. 605 c.

${ }^{4}$ Гончаренко Л. П. Расширенное воспроизводство инновационной сферы экономики и стимулирование спроса на инновации: теория и методология: моногр. М.: Русайнс, 2016. $287 \mathrm{c}$.

${ }^{5}$ Егоров А. Ю. Рынок инновационных проектов: методология формирования, управления и развития. М.: Палеотип, 2007. 236 с.

6 Ардашева Е. П. Отраслевая политика как система управления инвестициями и инновациями в мезоэкономике. Казань, 2007. 266 с.

7 Пилюгин Р. А. Организационно-экономические основы развития инновационной деятельности в АПК: автореф. дис. ... канд. экон. наук. М., 2005. 26 с.

8 Кулапина Г. М., Маркова О. В. Факторы и необходимые условия управления инновационным развитием экономики региона // Экономика и управление: новые вызовы и перспективы. 2013. № 4. С. 28-31.

${ }_{9}^{9}$ Гуриева Л. К. Концептуальные основы инновационной стратегии регионального развития // Наука и инновационные технологии для регионального развития: сб. ст. Всерос. науч.-практ. конф., г. Пенза, июнь 2003 г. Пенза, 2003. С. 21-23.

${ }^{10}$ Горбачев А. В., Старостина А. А. Управление проектами как эффективный способ обеспечения устойчивого развития региона // Регион в условиях перехода к устойчивой модели развития современного российского общества: материалы межрегион. науч.-практ. конф. (апрель 2004 г.). Брянск, 2004. Ч. 1. С. 160-161. 
характеризующие неравномерность инновационной деятельности на территории России [9]. В. Л. Бабурин, С. П. Земцов первостепенным значением в инновационном развитии определяют наличие инновационного потенциала региона и способность территорий воспринимать инновации $^{11}[10 ; 11]$.

Зарубежные ученые-экономисты рассматривают инновационную деятельность как основной фактор экономического роста [12; 13]. Заметное внимание обращается на развитие инновационных процессов в конкретных странах и их регионах: изучаются актуальные проблемы инновационных процессов в регионах, например, в сфере развития человеческого капитала, стимулирования роста экономики и т. д. [14-16]. Исходя из значения инноваций как фактора эффективного развития производства, П. Дракер рассматривал их как один из инструментов активного развития бизнеса [17]. Основоположник теории инноваций Й. А. Шумпетер оказал влияние на современную эволюционную теорию, которая расширяет общепринятую картину, дополняет рыночные взаимоотношения, подчеркивает воздействие на них более крупных институциональных и социальных структур ${ }^{12}$. Л. Занг, Ф. Хьенг, Х. Лао, Е. Гао считают, что различные факторы влияют на национальный инновационный потенциал стран и их регионов [18]. М. Джанг полагает, что достойный уровень жизни в регионе напрямую связан с накоплением человеческого капитала [19]. По мнению П. Ромера, возрастающая общественная отдача наблюдается по расходам на научно-исследовательские и опытно-конструкторские работы ${ }^{13}$, а А. Джаффе, Я. Лернер, С. Штерн обосновали роль информационной инфраструктуры в региональной инновационной системе [20]. Необходимо отметить научное направление, отличительной особенностью которого является использование методов, направленных на выявление закономерностей и факторов создания новых технологий и продуктов, выбора территориальных приоритетов и определения эффективных инструментов региональной политики. Наиболее яркими его представителями являются Д. Аудретш (Одрич) [21], Ц. Грилихес, П. Кругман, М. Фишер, М. Фельдман, С. Фриман ${ }^{14}$.

${ }^{11}$ Бабурин В. Л., Земцов С. П. Инновационный потенциал регионов России. М.: КДУ, 2017. 358 c.

${ }^{12}$ Schumpeter J. A. Capitalism, Socialism and Democracy. L.: Allen Unwin, 1943. 437 p.; Schumpeter J. A. Theoretical Problems of Economic Growth // The Journal of Economic History. 1947. No. 7 (S1). Pp. 1-9.

${ }^{13}$ Romer P. M. Endogenous Technological Change // Journal of Political Economy. 1990. Vol. 98, no. 5. Pp. S71-S102.

${ }_{14}$ Griliches Z., Lichtenberg F. R. R\&D and Productivity Growth at the Industry Level: Is there Still a Relationship? // R\&D, Patents, and Productivity. University of Chicago Press, 1984. Pp. 465-502; Krugman P. Increasing Returns and Economic Geography // Journal of Political Economy. 1991. No. 99. Pp. 483-499; Feldman M. The Geography of Innovation. 1994. Pp. 37-49; Freeman C. Networks of Innovators: A Synthesis of Research Issues // Research Policy. 1991. Vol. 20, no. 5. Pp. 499-514. 
Проведенный выше обзор свидетельствует о значимости факторов инновационного развития. Данные вопросы изучаются достаточно долго и раскрыты с точки зрения различных аспектов. Однако, по нашему мнению, для эффективного решения проблем инновационного развития регионов, кардинального улучшения данного процесса с учетом быстрого научно-технического прогресса необходима актуализация комплексного подхода к систематизации факторов при разработке стратегий регионального развития

Кроме того, существующие исследования и публикации не в полной мере соответствуют нашей цели. Необходим инструментарий, адаптированный для конкретного российского региона, - Республики Мордовия, а также выработка факторов, подходящих для его дальнейшего развития.

Материалы и методы. Объект исследования - Республика Мордовия. Информационной базой служат региональная статистика по теме исследования, законодательные и нормативные акты.

Методы анализа в статье подразумевают обобщение оцениваемых явлений, их разделение на составные части для изучения свойств и их описание с точки зрения взаимосвязи и взаимозависимости. Применение графических и сравнительных методов анализа позволяет наглядно представить количественные результаты исследования.

Методы планирования в рамках заявленного исследования способствуют обоснованию основных направлений и пропорций инновационной деятельности в соответствии с прогнозом и целями развития, ресурсным обеспечением и спросом на рынке. Эти методы тесно связаны с методами прогнозирования, которые направлены на разработку прогнозов инновационного развития на долгосрочной основе. Методы прогнозирования основываются на анализе тенденций.

Системный анализ использовался в исследовании с целью оценки возможности достижения цели с учетом влияния внутренних и внешних факторов. В рамках факторного анализа изучалось развитие науки и техники в инновационной экономике, инновационный потенциал отраслей и предприятий, проводился анализ прироста научно-технического потенциала. Функционально-стоимостной анализ позволил выявить баланс между вложенными средствами в разработку и внедрение инноваций и их полезностью.

Результаты исследования. На современном этапе развития общества инновационные процессы являются главным фактором повышения эффективности производства и решения основных социально-экономических задач. Инновационное развитие становится доминирующим направлением в государственной политике и экономике. Как фактор экономического роста инновации особенно важны для регионов России, которые обладают достаточно высоким промышленным и интеллек- 
туальным потенциалом. Однако развитие регионов связано не только с использованием достижений научно-технического прогресса и передовых технологий, но и с определенными возможностями самостоятельного их создания и освоения.

Факторы инновационного развития - это экономические ресурсы регионов, являющиеся структурными элементами региональной экономики. Исследование факторов инновационного развития позволяет определить направления эффективного функционирования региональных систем. В связи с этим становится перспективным обоснование факторов инновационного развития с позиции их воздействия на имеющийся инновационный потенциал и стимулирование инновационной активности регионов.

В Республике Мордовия, несмотря на незначительное снижение количества предприятий, функционирующих в инновационной сфере (рис. 1, 2), научно-исследовательская деятельность организаций способствует ускоренному развитию и внедрению в производство новых поколений высокоэффективной техники, которая в свою очередь должна повысить темпы роста и обновления выпускаемой продукции (табл. 1, 2). Имеются технические базы экономических систем, которые основываются на использовании новейших достижений в области нанотехнологий, биотехнологии, информатики.

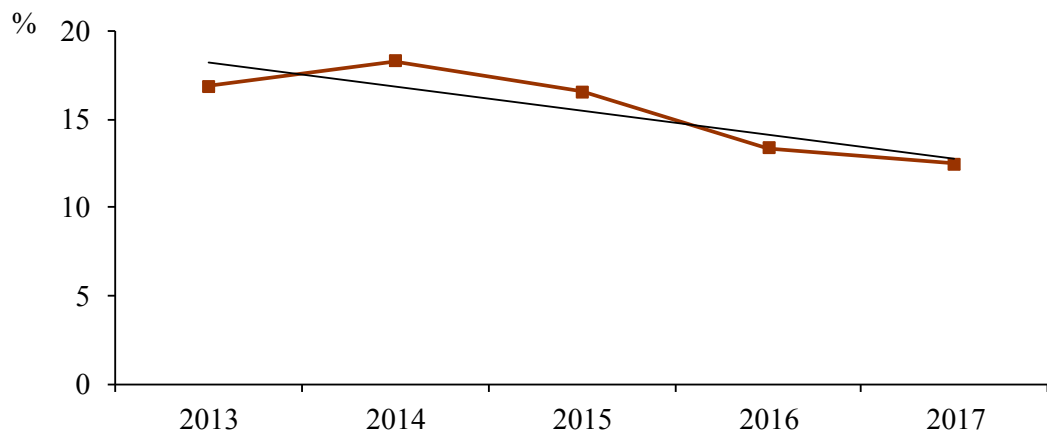

Р и с. 1. Количество предприятий, функционирующих в инновационной сфере Республики Мордовия с 2013 по 2017 г., \%

F i g. 1. Number of enterprises operating in the field of innovation in the Republic of Mordovia from 2013 to $2017, \%$

Проведенный анализ научно-инновационного потенциала свидетельствует о том, что Мордовия находится на пути научно-инновационного развития. Это связано с применением передовых производственных технологий, расширением научных исследований и улучшением их качества, внедрением результатов интеллектуального труда в производство (табл. 3). 


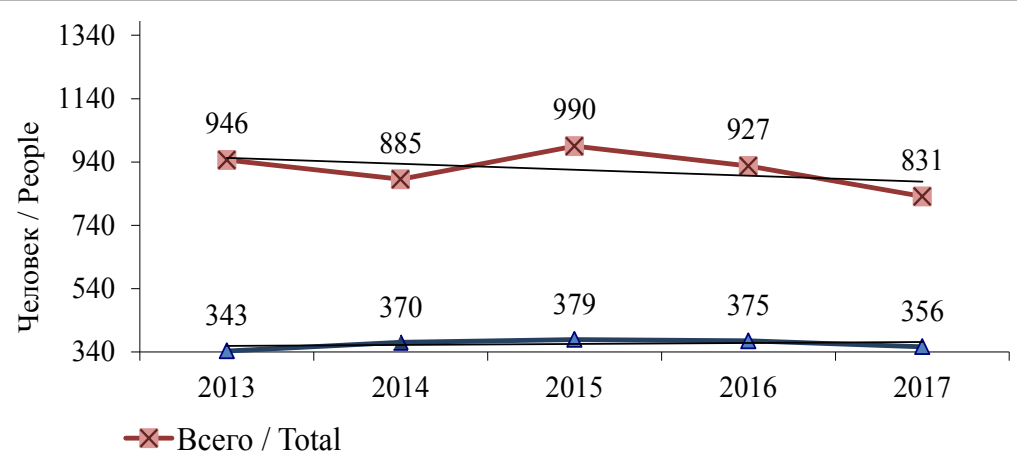

$\rightarrow$ В том числе по виду деятельности «Научные исследования и разработки» / Including the type of activity "Research and Development"

Р и с. 2. Численность персонала в сфере научных исследований и разработок в Республике Мордовия с 2013 по 2017 г., \%

F i g. 2. Number of personnel in the field of research and development in the Republic of Mordovia from 2013 to 2017, \%

Т а б л и ц а 1. Объем научно-технических работ в Республике Мордовия с 2013 по 2017 г., млн руб. ${ }^{15}$

$\mathrm{T}$ a $\mathrm{b} 1$ e 1 . Volume of scientific and technical work in the Republic of Mordovia from 2013 to 2017 , million rubles

\begin{tabular}{|c|c|c|c|c|c|}
\hline \multirow{2}{*}{ Показатель / Indicator } & \multicolumn{5}{|c|}{ Годы / Year } \\
\hline & 2013 & 2014 & 2015 & 2016 & 2017 \\
\hline Всего / Total & 993,8 & 1202,6 & 1052,9 & 1074,2 & 989,3 \\
\hline $\begin{array}{l}\text { Из них / Of which: } \\
\text { научные исследования } \\
\text { и разработки / research and } \\
\text { development }\end{array}$ & 920,3 & 1121,2 & 959,4 & 955,9 & 987,7 \\
\hline $\begin{array}{l}\text { научно-технические услуги / } \\
\text { scientific and techniological } \\
\text { services }\end{array}$ & 1,2 & 1,8 & 1,8 & 1,8 & - \\
\hline $\begin{array}{l}\text { прочие работы (услуги) / } \\
\text { other works (services) }\end{array}$ & 72,3 & 79,6 & 91,7 & 116,5 & 1,6 \\
\hline
\end{tabular}

15 Таблица составлена по данным Территориального органа Федеральной службы Государственной статистики по Республике Мордовия. URL: http://mrd.gks.ru/ (дата обращения: 15.01.2019). 
Т а 6 л и ц а 2. Затраты на выполнение научных исследований и разработок в Республике Мордовия с 2013 по 2017 г., млн руб. ${ }^{16}$

$\mathrm{T}$ a b l e 2. Costs of research and development in the Republic of Mordovia from 2013 to 2017 , million rubles

\begin{tabular}{|c|c|c|c|c|c|}
\hline \multirow{2}{*}{ Показатель / Indicator } & \multicolumn{5}{|c|}{ Годы / Year } \\
\hline & 2013 & 2014 & 2015 & 2016 & 2017 \\
\hline Всего / Total & 919,8 & 996,5 & 888,9 & 842,7 & 926,1 \\
\hline $\begin{array}{l}\text { Из них / Of which: } \\
\text { внутренние затраты / } \\
\text { internal costs }\end{array}$ & 906,9 & 969,1 & 823,1 & 798,8 & 828,8 \\
\hline $\begin{array}{l}\text { в том числе / including: } \\
\text { текущие / recurrent costs }\end{array}$ & 789,6 & 830,5 & 818,5 & 775,5 & 785,8 \\
\hline капитальные / capital costs & 117,3 & 138,6 & 4,6 & 23,3 & 43,0 \\
\hline $\begin{array}{l}\text { внешние затраты / } \\
\text { external costs }\end{array}$ & 12,9 & 27,4 & 65,8 & 43,9 & 97,3 \\
\hline
\end{tabular}

Т а б л и ц а 3 . Показатели инновационного развития Республики Мордовия с 2013 по 2017 г. $^{17}$

$\mathrm{T}$ a $\mathrm{b} 1$ e 3 . Indicators of innovative development of the Republic of Mordovia from 2013 to 2017

\begin{tabular}{|c|c|c|c|c|c|}
\hline \multirow{2}{*}{ Показатель / Indicator } & \multicolumn{5}{|c|}{ Годы / Year } \\
\hline & 2013 & 2014 & 2015 & 2016 & 2017 \\
\hline 1 & 2 & 3 & 4 & 5 & 6 \\
\hline $\begin{array}{l}\text { Внутренние затраты на научные иссле- } \\
\text { дования и разработки, \% к ВРП / Internal } \\
\text { research and development costs, \% of GRP }\end{array}$ & 1,04 & 1,05 & 1,10 & 1,20 & 1,3 \\
\hline $\begin{array}{l}\text { Удельный вес внебюджетных средств } \\
\text { во внутренних затратах на научные } \\
\text { исследования и разработки, \% / Share } \\
\text { of extra-budgetary funds in the internal } \\
\text { research and development costs, \% }\end{array}$ & 46,0 & 46,2 & 45,4 & 43,3 & 41,5 \\
\hline $\begin{array}{l}\text { Удельный вес вузовского сектора науки } \\
\text { во внутренних затратах на научные } \\
\text { исследования и разработки, \% / Share of } \\
\text { the university science sector in the internal } \\
\text { research and development costs, \% }\end{array}$ & 4,1 & 4,6 & 5,0 & 5,5 & 5,7 \\
\hline
\end{tabular}

16 Таблица составлена по данным Территориального органа Федеральной службы Государственной статистики по Республике Мордовия. URL: http://mrd.gks.ru/ (дата обращения: 15.01.2019).

${ }_{17}$ Таблица составлена по: Рейтинг инновационного развития субъектов Российской Федерации. 
Окончание табл. 3 / End of table 3

\begin{tabular}{l} 
1 \\
\hline Удельный вес исследователей в воз- \\
расте до 39 лет в общей численности \\
исследователей, \% / Share of researchers \\
under the age of 39 in the total number of \\
researchers, \%
\end{tabular}

Удельный вес предприятий, осуществляющих инновационную деятельность, \% / Share of enterprises engaged in innovative activities, \%

Коэффициент исследовательской активности (количество заявок и патентов на 10 тыс. чел. населения), \% / Coefficient of research activity (number of applications and patents per 10,000 population), \%

Удельный вес передовых технологий интеллектуальной формы собственности, \%/ Share of advanced technologies of intellectual property, $\%$

Удельный вес инновационной продукции, \% / Share of innovative products, \%

Количество передовых производственных технологий, ед. / Number of advanced production technologies, units

Предприятия в сфере научных исследований и разработок, ед. / Enterprises in the field of research and development, units

Численность персонала в сфере научных исследований и разработок, чел. / Number of personnel in the field of research and development, persons

Инвестиции по научным исследованиям и разработкам, млн руб. / Investment in research and development, million rubles

Доля капитальных вложений в науку в общем объеме инвестиций, \% / Share of capital investment in science in the total volume of investment, $\%$

Финансирование науки за счет средств федерального бюджета, млн руб. / Financing of science from the federal budget, million rubles

Внутренние затраты на научные исследования и разработки, млн руб. / Internal $16,9 \quad 18,3 \quad 16,6 \quad 13,4 \quad 12,5$

$1,6 \quad 1,97 \quad 1,93 \quad 1,4 \quad 1,7$

$1,5 \quad 1,7 \quad 1,6 \quad 1,2 \quad 1,0$

$4,1 \quad 4,5 \quad 4,6 \quad 4,4 \quad 4,4$

$\begin{array}{lllll}6 & 7 & 6 & 8 & 10\end{array}$

$\begin{array}{lllll}16 & 17 & 26 & 25 & 17\end{array}$

$\begin{array}{lllll}946 & 885 & 990 & 927 & 831\end{array}$

$18,1 \quad 15,3 \quad 56,2 \quad 16,3 \quad 17,4$

$0,05 \quad 0,01 \quad 0,1 \quad 0,02 \quad 0,04$

$12,7 \quad 26,4 \quad 63,8 \quad 41,9 \quad 95,3$

$906,9 \quad 969,1 \quad 823,1 \quad 798,8 \quad 828,8$ research and development costs, million rubles 
Развитие инновационной деятельности с использованием имеющегося потенциала может решить очень важные задачи, такие как решение проблем социально-экономического развития региона на современном уровне с наименьшими временными и материальными затратами; создание новых и сохранение имеющихся рабочих мест в научно-технической сфере. Для инновационного развития региона необходимо наличие благоприятного инновационного климата, систематизация влияющих на инновационное развитие факторов.

Мы выделили следующие факторы инновационного развития региона (рис. 3).

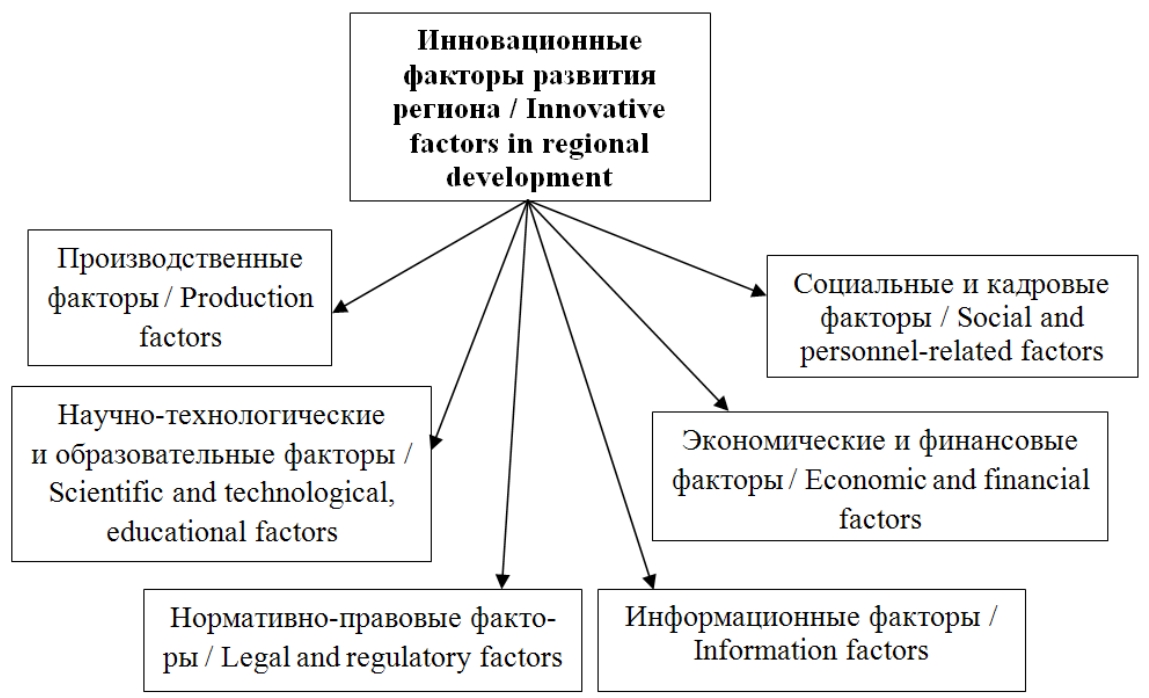

Р и с. 3. Инновационные факторы развития региона

$\mathrm{F}$ i g. 3. Innovative factors in the development of a region

Рассмотрим их подробнее.

1. Производственные факторы: тий;

- функциональная производственно-технологическая база предприя-

- развитая инфраструктура промышленных предприятий;

- основные фонды и уровень их износа;

- положительная тенденция в динамике объемов производства;

- численность рабочих мест на предприятии;

- модернизация производства, освоение новых технологий. 
2. Нормативно-правовые факторы:

- законодательная база инновационной деятельности, наличие стратегии развития региона, отдельных отраслей, наличие программ развития инновационной активности предприятий;

- улучшение управления интеллектуальной собственностью;

- наличие эффективного механизма государственно-частного партнерства и программ.

3. Научно-технологические и образовательные факторы:

- развитая сеть национальных научно-исследовательских учреждений, учебно-научных лабораторий, исследовательских центров;

- кадровый персонал высокой квалификации;

- малые инновационные предприятия при вузах;

- инновационный потенциал вузов, высокая публикационная активность;

- профессиональные контакты образовательных учреждений с профильными предприятиями с целью практико-ориентированного обучения.

4. Экономические и финансовые факторы:

- система финансовой поддержки инноваций за счет средств бюджетов различных уровней и средств внебюджетных фондов содействия инновационного развития;

- ликвидное и устойчивое финансовое состояние предприятий;

- положительная тенденция изменения объемов реализации продукции;

- частно-государственное партнерство;

- государственный заказ;

- развитие системы лизинга для малых и средних предприятий;

- конкурентоспособность и инвестиционная привлекательность предприятий и региона.

5. Сочиильные и кадровые факторы:

- возрастной состав работников, снижение оттока молодых специалистов;

- численность занятых на предприятии;

- численность населения;

- дифференцированный уровень образования и квалификации кадров;

- система социальной защиты и мотивации труда работников предприятий.

6. Информационные факторы:

- доступность информации по объектам инновационной инфраструктуры;

- внедрение информационных технологий;

- развитие сети информационных коммуникаций.

Сочетание этих факторов обусловливает привлекательность регионов с точки зрения инновационного развития. Эффективность управления 
данными факторами зависит от особенностей современного развития России, зарубежного опыта и в большей степени от стратегических основ инновационного развития регионов.

Обсуждение и заключение. В результате исследования нами выделены факторы, влияющие на уровень инновационного развития региона производственные, нормативно-правовые, научно-технологические и образовательные, экономические и финансовые, информационные. Все они будут способствовать созданию благоприятного финансово-экономического климата инновационного развития, что в свою очередь повысит инвестиционную привлекательность территорий. Систематизированные факторы оказывают значительное воздействие на инновационную активность предприятий, повышают конкурентоспособность выпускаемой продукции и оказываемых услуг. Для разработки методики инновационного развития регионов необходимо, на наш взгляд, учитывать имеющиеся факторы, способствующие инновационному прорыву с учетом региональных и отраслевых особенностей.

Практическая значимость данного исследования заключается в систематизации факторов, которая позволит выстроить эффективную стратегию роста инновационной активности и достичь в итоге качественного экономического роста региона в целом.

\section{СПИСОК ИСПОЛЬЗОВАННЫХ ИСТОЧНИКОВ}

1. Мясникович М. В. О роли государства в обеспечении инновационного процесса // Проблемы управления. 2007. № 1. C. 15-19. URL: https://elibrary.ru/ item.asp?id=35255173 (дата обращения: 27.04.2019).

2. Кильдюшкина И. Г. Инновационные подходы к развитию экономики на региональном уровне // Известия высших учебных заведений. Поволжский регион. Общественные науки. 2011. № 1. С. 116-124. URL: https://izvuz_on.pnzgu. ru/on15111 (дата обращения: 27.04.2019).

3. Меньщикова В. И., Ермаков А. И. Методики оценки инновационного потенциала региона: сущность, особенности применения, недостатки // Социально-экономические явления и процессы. 2011. № 10. C. 127-136. URL: https:// elibrary.ru/item.asp?id=17692518 (дата обращения: 27.04.2019).

4. Лукашева Н. Е. Приоритеты стратегического планирования в вопросах инновационного развития мегаполиса // Креативная экономика. 2011. № 8. C. 77-81. URL: https://creativeconomy.ru/lib/4444 (дата обращения: 27.04.2019).

5. Петрухина Е. В. Основные факторы инновационного развития регионов // Научные ведомости Белгородского государственного университета. Сер.: Экономика. Информатика. 2012. Т. 22. № 7-1. C. 56-65. URL: https://www.bsu.edu. $\mathrm{ru} / \mathrm{bsu} /$ science/public/bsu-science-journal/detail.php?IBLOCK_ID=106\&SECTION_ ID=6463\&ELEMENT_ID=204789 (дата обращения: 27.04.2019). 
6. Лошакова И. М. Оценка факторов, препятствующих развитию инновационного потенциала региона // Наука и экономика. 2011. № 2. С. 9-11. URL: https://elibrary.ru/item.asp?id=16532579 (дата обращения: 27.04.2019).

7. Загидуллина Г. М., Сиразетдинов Р. М. Основные факторы, способствующие развитию инновационной системы региона // Общественные науки. 2011. № 7. C. 493-496.

8. Фокеев М. А. Ключевые факторы инновационного развития регионов России // Финансы и кредит. 2017. Т. 23, № 15. С. 900-912. DOI: https://doi. org $/ 10.24891 /$ fc. 23.15 .900

9. Носонов А. М. Особенности инновационного развития регионов России // Регионология. 2014. № 4. С. 22-31. URL: http://regionsar.ru/ru/node/1318 (дата обращения: 27.04.2019).

10. Zemtsov S., Baburin V. Does Economic-Geographical Position Affect Innovation Processes in Russian Regions? // Geography, Environment, Sustainability. 2016. No. 4 (9). Pp. 14-33. DOI: https://doi.org/10.24057/2071-9388-2016-9-4-14-32

11. Determinants of Regional Innovation in Russia: Are People or Capital More Important? / S. Zemtsov [et al.] // Foresight-Russia. 2016. No. 2. Pp. $29-42$. DOI: https://doi.org/10.17323/1995-459X.2016.2.29.42

12. Porter M. E. The Economic Performance of Regions // Regional Studies. 2003. No. 37. Pp. 549-578. DOI: https://doi.org/10.1080/0034340032000108688

13. Vasilevska D., Rivza B. Green Entrepreneurship as a Factor of Sustainable Economic Development in Baltic States // International Multidisciplinary Scientific GeoConference Surveying Geology and Mining Ecology Management, SGEM. 2018. Vol. 18, issue 5.3. Pp. 423-430. DOI: https://doi.org/10.5593/ sgem $2018 / 5.3 /$ S28.054

14. Multifunctional Econometrics Models of Turnover Dynamics of Using Primary Factors of the Economic Process / V. Bendic [et al.] // Proceedings of the 28th International Business Information Management Association Conference - Vision 2020: Innovation Management, Development Sustainability, and Competitive Economic Growth. 2016. Pp. 3395-3414. URL: https://ibima.org/accepted-paper/multifunctional-econometrics-models-turnover-dynamics-using-primary-factors-economic-process/ (дата обращения: 27.04.2019).

15. Zhang Y., Hu P. Analysis on the Overall Level of Regional Innovation Environment in China // ACM International Conference Proceeding Series. 2018. Pp. 159-164. DOI: https://doi.org/10.1145/3241748.3241771

16. Hovgaard A., Hansen E., Roos J. Innovation in the Forest Products Industry: An Analysis of Companies in Alaska and Oregon // USDA Forest Service - General Technical Report PNW(629). 2005. Pp. 1-48. DOI: https://doi.org/10.2737/PNW-GTR-629

17. Drucker P. F. Innovation and Entrepreneurship: Practice and Principles. HarperBusiness, 2006. 277 p. URL: https://www.amazon.com/Innovation-Entrepreneurship-Peter-F-Drucker/dp/0060851139 (дата обращения: 27.04.2019).

18. Does governance Efficiency Matter for National Innovative Capacity? One Tale From Different Countries / L. Zang [et al.] // Technology Analysis and Strategic Management. 2019. Vol. 31, issue 2. Pp. 239-252. DOI: https://doi.org/10.1080/09 537325.2018 .1493450 
19. Junge M., Severgnini B., Srensen A. Evidence on the Impact of Education on Innovation and Productivity // Working Papers from Copenhagen Business School. 2012. No. 2. Pp. 1-31. URL: https://ideas.repec.org/p/hhs/cbsnow/2012_002.html (дата обращения: 27.04.2019).

20. Jaffe A. B., Lerner J., Stern S. Innovation Policy and the Economy. National Bureau of Economic Research. The MIT Press, Cambridge, Massachusetts, 2005. Vol. 5. 184 p. URL: https://mitpress.mit.edu/books/innovation-policy-and-economy-volume-5 (дата обращения: 27.04.2019).

21. Audretsch D., Keilbach M. Entrepreneurship Capital and Economic Performance // Regional Studies. 2004. Vol. 38, no. 8. Pp. 949-959. DOI: https://doi. org/10.1080/0034340042000280956

Поступила 29.04.2019; принята к публикации 15.07.2019; опубликована онлайн 30.12.2019.

\section{Об авторе:}

Юленкова Ирина Борисовна, доцент кафедры финансов и кредита ФГБОУ ВО «МГУ им. Н. П. Огарёва» (430005, Россия, г. Саранск, ул. Большевистская, д. 68/1), кандидат экономических наук, ORCID: https:/orcid.org/0000-0003-0705-1284, yulenkova.irina@yandex.ru

Благодарности. Автор выражает признательность рецензенту, чьи ценные замечания позволили улучшить качество текста.

Для циитирования:

Юленкова И. Б. Факторы инновационного развития региона // Регионология. 2019. Т. 27, № 4. С. 661-677. DOI: https://doi.org/10.15507/24131407.109.027.201904.661-677

Автор прочитал и одобрил окончательный вариант рукописи.

\section{REFERENCES}

1. Myasnikovich M.V. The Role of the State in Proving of The Innovate Process. Problemy upravleniya = Public Administration Issues. 2007; (1):15-19. Available at: https://elibrary.ru/item.asp?id=35255173 (accessed 27.04.2019). (In Russ., abstract in Eng.)

2. Kildyushkina I.G. [Innovative Approaches to Economic Development at the Regional Level]. Izvestiya vysshikh uchebnykh zavedenij. Povolzhskij region. Obshhestvennye nauki = University Proceedings. Volga Region. Social Sciences. 2011; (1):116-124. Available at: https://izvuz_on.pnzgu.ru/on15111 (accessed 27.04.2019). (In Russ.)

3. Menshchikova V.I., Ermakov A.I. Techniques of the Estimation of Innovative Potential of Region: Essence, Features of Application, Lacks. Sotsialno-ehkonomicheskie yavleniya $i$ protsessy $=$ Social and Economic Phenomena and Processes. 
2011; (10):127-136. Available at: https://elibrary.ru/item.asp?id=17692518 (accessed 27.04.2019). (In Russ., abstract in Eng.)

4. Lukasheva N.E. Priorities of Strategic Planning in Questions of Innovative Development of Megalopolis. Kreativnaya ehkonomika = Creative Economy. 2011; (8):77-81. Available at: https://creativeconomy.ru/lib/4444 (accessed 27.04.2019). (In Russ., abstract in Eng.)

5. Petrukhina E.V. Major Factors of Innovative Development of Regions. Nauchnye vedomosti Belgorodskogo gosudarstvennogo universiteta. Seriya: Ehkonomika. Informatika = Belgorod State University Scientific Bulletin. Series "Economics. Computer Science". 2012; 22(7-1):56-65. Available at: https://www.bsu.edu.ru/bsu/science/public/ bsu-science-journal/detail.php?IBLOCK_ID=106\&SECTION_ID=6463\&ELEMENT_ ID=204789 (accessed 27.04.2019). (In Russ., abstract in Eng.)

6. Loshakova I.M. Estimation of the Factors Impending Innovations and Innovative Potential Development of the Region. Nauka $i$ ehkonomika $=$ Science and Economics. 2011; (2):9-11. Available at: https://elibrary.ru/item.asp?id=16532579 (accessed 27.04.2019). (In Russ., abstract in Eng.)

7. Zagidullina G.M., Sirazetdinov R.M. [Main Factors Contributing to the Development of the Innovation System of a Region]. Obshhestvennye nauki = Social Sciences. 2011; (7):493-496. Available at: https://elibrary.ru/item.asp?id=21610610 (accessed 27.04.2019). (In Russ.)

8. Fokeev M.A. Key Factors of Innovative Development of Russian Regions. Finansy $i$ kredit $=$ Finance and Credit. 2017; 23(15):900-912. DOI: https://doi. org/10.24891/fc. 23.15 .900

9. Nosonov A.M. Features of Innovative Development of Russia's Regions. Regionologiya $=$ Regionology. 2014; (4):22-31. Available at: http://regionsar.ru/ru/ node/1318 (accessed 27.04.2019). (In Russ., abstract in Eng.)

10. Zemtsov S., Baburin V. Does Economic-Geographical Position Affect Innovation Processes in Russian Regions? Geography, Environment, Sustainability. 2016; (4):14-33. (In Eng.) DOI: https://doi.org/10.24057/2071-9388-2016-9-4-14-32

11. Zemtsov S., Muradov A., Wade I., Barinova V. Determinants of Regional Innovation in Russia: Are People or Capital More Important? Foresight-Russia. 2016; (2):29-42. (In Eng.) DOI: https://doi.org/10.17323/1995-459X.2016.2.29.42

12. Porter M.E. The Economic Performance of Regions. Regional Studies. 2003; (37):549-578. (In Eng.) DOI: https://doi.org/10.1080/0034340032000108688

13. Vasilevska D., Rivza B. Green Entrepreneurship as a Factor of Sustainable Economic Development in Baltic States. In: International Multidisciplinary Scientific GeoConference Surveying Geology and Mining Ecology Management, SGEM. 2018; 18(5.3):423-430. (In Eng.) DOI: https://doi.org/10.5593/sgem2018/5.3/S28.054

14. Bendic V., Mohora C., Tilină D., Turcu E., Niţă A. Multifunctional Econometrics Models of Turnover Dynamics of Using Primary Factors of the Economic Process. In: Proceedings of the 28th International Business Information Management Association Conference - Vision 2020: Innovation Management, Development Sustainability, and Competitive Economic Growth. 2016. p. 3395-3414. Available at: https://ibima.org/accepted-paper/multifunctional-econometrics-models-turnoverdynamics-using-primary-factors-economic-process/ (accessed 27.04.2019). (In Eng.) 
15. Zhang Y., Hu P. Analysis on the Overall Level of Regional Innovation Environment in China. In: ACM International Conference Proceeding Series. 2018. p. 159-164. (In Eng.) DOI: https://doi.org/10.1145/3241748.3241771

16. Hovgaard A., Hansen E., Roos J. Innovation in the Forest Products Industry: An Analysis of Companies in Alaska and Oregon. In: USDA Forest Service - General Technical Report PNW(629). 2005. p. 1-48. (In Eng.) DOI: https://doi.org/10.2737/ PNW-GTR-629

17. Drucker P.F. Innovation and Entrepreneurship: Practice and Principles. HarperBusiness; 2006. Available at: https://www.amazon.com/Innovation-EntrepreneurshipPeter-F-Drucker/dp/0060851139 (accessed 27.04.2019). (In Eng.)

18. Zang L., Xiong F., Lao X., Gao Y. Does Governance Efficiency Matter for National Innovative Capacity? One Tale from Different Countries. Technology Analysis and Strategic Management. 2019; 31(2):239-252. (In Eng.) DOI: https:// doi.org/10.1080/09537325.2018.1493450

19. Junge M., Severgnini B., Srensen A. Evidence on the Impact of Education on Innovation and Productivity. Working Papers from Copenhagen Business School. 2012; (2):1-31. Available at: https://ideas.repec.org/p/hhs/cbsnow/2012_002.html (accessed 27.04.2019). (In Eng.)

20. Jaffe A.B., Lerner J., Stern S. Innovation Policy and the Economy. National Bureau of Economic Research. The MIT Press, Cambridge, Massachusetts; 2005. 5. Available at: https://mitpress.mit.edu/books/innovation-policy-and-economy-volume-5 (accessed 27.04.2019). (In Eng.)

21. Audretsch D., Keilbach M. Entrepreneurship Capital and Economic Performance. Regional Studies. 2004; 38(8):949-959. (In Eng.) DOI: https://doi. org $/ 10.1080 / 0034340042000280956$

Submitted 29.04.2019; accepted for publication 15.07.2019; published online 30.12.2019.

About the author:

Irina B. Yulenkova, Associate Professor, Department of Finance and Credit, National Research Mordovia State University (68/1 Bolshevistskaya St., Saransk 430005, Russia), Ph. D. (Economics), ORCID: https://orcid.org/0000-0003-0705-1284, yulenkova.irina@yandex.ru

Acknowledgements. The author is grateful to the reviewer, whose valuable comments made it possible to improve the quality of the text.

\section{For citation:}

Yulenkova I.B. Factors in Innovative Development of a Region. Regionology = Russian Journal of Regional Studies. 2019; 27(4):661-677. DOI: https://doi. org/10.15507/2413-1407.109.027.201904.661-677

The author has read and approved the final version of the manuscript. 


\section{Анализ правовой и инфраструктурной основы научно-технологической сферы в регионах России: потенциал и перспективы формирования связности территорий страны}

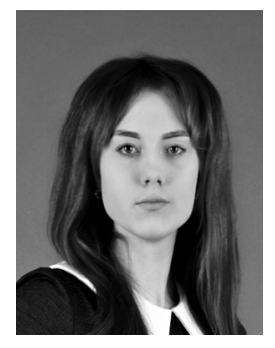

А. В. Смирнова*

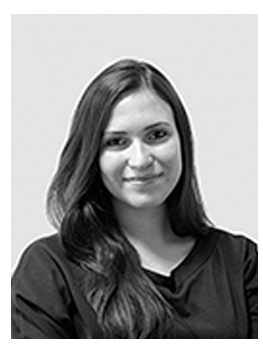

М. О. Дашкова

ФГБУ «Российский научно-исследовательский институт экономики, политики и права в научно-технической сфере» (2. Москва, Россия), *a.smirnova@riep.ru

Введение. Формирование региональной дифференциации ослабляет единство и устойчивость развития страны в целом, что сдерживает ее переход к инновационной модели экономики и выход в число передовых мировых технологических держав. Целью настоящей статьи стал комплексный анализ состояния региональной научно-технической сферы 11 субъектов Российской Федерации и оценка имеющегося у них задела и существующего потенциала для формирования единого научно-технологического пространства.

Материалы и методы. Исследование реализовано в два этапа посредством применения системного и сравнительного анализа. Использованы данные системы КонсультантПлюс и ежегодного мониторинга Министерства науки и высшего образования России, проводимого через интернет-портал «Научно-технологическая инфраструктура Российской Федерации: центры коллективного пользования и уникальные научные установки».

Результаты исследования. Исследована оснащенность законодательной базы нормативно-правовыми актами в сфере регулирования науки, проанализирована научно-инфраструктурная оснащенность 11 регионов. Выявлено и доказано существование сильной дифференциации изученных территорий. Определены регионы, выступающие лидерами и аутсайдерами по степени развитости правовой и инфраструктурной компонент научно-технологической отрасли.

(C) Смирнова А. В., Дашкова М. О., 2019 Контент доступен под лицензией Creative Commons Attribution 4.0 License. This work is licensed under a Creative Commons Attribution 4.0 License. 
Обсуждение и заключение. В настоящей статье представлены результаты первого этапа комплексного исследования, в ходе которого планируется построить и описать модели научно-технологической кооперации территорий России на примере 11 регионов. Результаты работы могут быть полезны исследователям и специалистам в области регионального развития и управления в научно-технической сфере, а также в области развития научно-технологической кооперации и связанности территорий.

Ключевые слова: связность территорий, научно-технологическая кооперация, Стратегия научно-технологического развития Российской Федерации, объекты научной инфраструктуры

Финансирование. Исследование выполнено в рамках государственного задания РИЭПП «Мониторинг и экспертно-аналитическое сопровождение реализации государственной политики в области научно-технологической связности территории Российской Федерации» (проект № 26.13358.2019/13.1).

\title{
Analysis of the Legal and Infrastructural Basis for the Scientific and Technological Sphere in the Regions of Russia: Potential and Prospects for the Formation of Connectedness of the Country's Territories
}

\author{
A. V. Smirnova", M. O. Dashkova \\ Russian Research Institute of Economics, Politics and Law in Science \\ and Technology (Moscow, Russia), \\ *a.smirnova@riep.ru
}

Introduction. The formation of regional differentiation weakens the unity and sustainability of the country's development as a whole, which hinders its transition to an innovative economic model and joining the ranks of the of the world's leading technological powers. The objective of this paper is to give a comprehensive analysis of the state of the regional scientific and technological sphere of eleven constituent entities of the Russian Federation and to assess the existing groundwork and potential for the formation of a single scientific and technological space.

Materials and Methods. The study has been implemented in two stages and has employed the methods of induction and deduction, as well as those of systemic and comparative analysis. The study has examined data from the Consultant Plus system and the annual monitoring survey conducted by the Ministry of Education and Science of Russia through the internet portal 'Scientific and Technological Infrastructure of the Russian FederationCenters for Collective use of Scientific Equipment and Unique Scientific Installations'. Results. The equipment of the legislative framework with legal and regulatory instruments in the field of science regulation has been examined; the scientific and infrastructural equipment of 11 regions has been analyzed. The existence of a strong differentiation between the studied territories has been revealed and proved. The regions that are the leaders and laggards in terms of the degree of development of the legal and infrastructural components of the scientific and technological industry have been identified.

Discussion and Conclusion. This article presents the results of the first stage of a comprehensive study which is supposed to make an attempt to build and describe a model of scientific and technological cooperation of the territories of Russia based 
on the case study of 11 regions. The results of the work can be useful to researchers and specialists in the field of regional development and management in the scientific and technological sphere, as well as in the field of development of scientific and technological cooperation and connectedness of territories.

Keywords: connectedness of territories, scientific and technological cooperation, Strategy for Scientific and Technological Development of the Russian Federation, scientific infrastructure facilities

Funding. The study was carried out as part of the RIEPL's state assignment 'Monitoring and expert and analytical support for the implementation of the state policy in the field of scientific and technological connectedness of the territory of the Russian Federation' (project No. 26.13358.2019/13.1).

Введение. В целях обеспечения конкурентоспособности и укрепления суверенитета страны необходимо нейтрализовать факторы, создающие риск отставания Российской Федерации от мировых научно-технологических лидеров. Данные факторы были обозначены Указом Президента Российской Федерации от 01.12.2016 № 642 «О Стратегии научно-технологического развития Российской Федерации» ${ }^{1}$.

В начале 2019 г. распоряжением Правительства Российской Федерации ${ }^{2}$ были выделены геостратегические территории, имеющие существенное значение для обеспечения устойчивого социально-экономического развития, территориальной целостности и безопасности Российской Федерации. Они были разделены на две группы - приоритетные и приграничные. К приоритетным геостратегическим территориям отнесены:

- субъекты Российской Федерации, характеризующиеся эксклавным положением (Республика Крым, город федерального значения Севастополь, Калининградская область);

- субъекты Российской Федерации, расположенные на Дальнем Востоке (Республика (Саха) Якутия, Приморский, Хабаровский края).

Приграничные геостратегические территории Российской Федерации включают:

- субъекты Российской Федерации, граничащие со странами, входящими в Евразийский экономический союз (Новосибирская область);

- субъекты Российской Федерации, граничащие с другими странами (Белгородская область).

${ }^{1}$ О Стратегии научно-технологического развития Российской Федерации: Указ Президента Российской Федерации от 01.12.2016 № 642 // Электронный фонд правовой и нормативно-технической документации. URL: http://docs.cntd.ru/document/420384257 (дата обращения: 12.02.2019).

2 Об утверждении Стратегии пространственного развития Российской Федерации на период до 2025 года: Распоряжение Правительства РФ от 13.02.2019 № 207-р. 
Цель настоящей статьи заключена в исследовании стратегического развития научной и технической сферы в отдельных субъектах Российской Федерации и в последующей оценке имеющегося у них задела и существующего потенциала для участия в теме территориальной связности.

Обзор литературы. Научно-технологическая связность изучается учеными с разных позиций. По мнению Е. П. Кузнецовой, она может представлять собой кооперацию научных организаций, вузов и промышленных предприятий в рамках создания и осуществления совместного проекта, целью которого должно стать создание инновационного продукта или технологии $[1 ; 2]$. Важно понимать, что модели научно-технологической кооперации разнятся в зависимости от областей научных исследований и отраслей рынка [3]. Партнерские связи между наукой и бизнесом создаются в наукоемких областях, в частности в сфере биотехнологии (особенно фармацевтической), химии, IT-технологий и машиностроения [4].

В настоящее время осуществляется субсидирование научно-исследовательских и опытно-конструкторских работ (НИОКР), реализуемых в кооперации с вузами, научными организациями и промышленными предприятиями в целях создания высокотехнологичной продукции [1].

Рядом авторов кластеризация рассматривается как форма проявления научной и производственной связанности территорий [5-10]. Кластерная кооперация выступает в качестве модели, востребованной более чем на $2 / 3$ производств, формирующих высокотехнологичный сектор экономики стран Европейского союза [6]. Л. Г. Газман среди основных субъектов мирового инновационного процесса выделяет стратегические альянсы, инновационные консорциумы и кластеры [7]. Оптимальным путем интеграции России во всемирные инновационные процессы может стать создание глобально-ориентированных региональных инновационных систем кластерной структуры [8]. Б. Асхайм и М. Гертлер доказали, что чем более наукоемкой является экономическая деятельность, тем более свойственно ей стремление быть географически кластеризованной [11].

Многие авторы исследуют связность в качестве свойства социально-экономического пространства агломерации, считая ее одной из характеристик территориального единства, выступающего инструментом комплексного социально-экономического развития поселений в составе агломерации [12;13].

В целях увеличения внутренних расходов на НИОКР при невозможности использования средств государственного бюджета существует необходимость активного привлечения внебюджетных средств [14], вследствие чего в качестве основных субъектов развития научно-технической деятельности в России выступает национальный предпринимательский сектор $[15 ; 16]$. По доле частных капиталовложений в реализацию 
НИОКР в настоящем периоде Россия отстает от среднемирового уровня [17], участие бизнеса в сфере финансового обеспечения науки - $40 \%$ [2]. Так, в странах Европейского союза финансирование экономики знаний частным сектором по данным 2016 г. составляло $60 \%$, а в США и Китае - 70 и 77 \% соответственно.

В условиях излишней централизации, применения жестких подходов в налогообложении и ограниченности инвестиций (бюджетных и финансовых) в инновационное развитие регионов главным ресурсом и ключом к развитию выступает, как отмечает Л. О. Житинская, внутренний потенциал территорий России [9]. Госпрограммы, комплексные научно-технические программы и проекты полного инновационного цикла являются ключевым инструментом реализации Стратегии научно-технологического развития России $[18 ; 19]$. Стратегия научно-технологического развития России в своей реализации требует кардинальных изменений от субъектов Федерации как в плане производственной модернизации, так и в сфере управления научно-техническим развитием. Вследствие чего коллективом ученых разработана и апробирована методика оценки уровня готовности регионов к реализации приоритетных направлений научно-технического развития страны, основанная на расчете интегрального показателя [20]. Трансформация приоритетов инновационной деятельности регионов с учетом современных мировых тенденций является жизнеспособным механизмом повышения конкурентоспособности регионов. Известен методологический подход к выбору приоритетов инновационного экономического развития в регионах [21]. При разработке национальных приоритетов важно понимать, что определяющими критериями заинтересованности мирового сообщества результатами исследований и разработок служат технологическая изощренность и масштабность исследования, в то время как национальный подтекст и уклон в сторону прикладных исследований и разработок снижает востребованность в целом [22].

Достижение заявленных Россией в Стратегии научно-технологического развития целей возможно через стремительную адаптацию передового опыта зарубежных стран и реализацию совместных международных проектов и программ [23]. Вследствие грамотной реализации международного научно-технического сотрудничества возможно решение социальноэкономических проблем Российской Федерации [24]. Целесообразно развитие российско-германской кооперации с участием малых инновационных предприятий при условии создания для них государством на территории России благоприятной среды и инфраструктуры [23].

Существует мнение о зарождении в России зачатков проявления всемирных инновационных процессов и возможности интенсификации их посредством использования перспективных форм научно-технической ко- 
операции, первостепенно со странами СНГ [7]. С. М. Гоннова и соавторы предприняли попытку разработки модели электронной аналитической системы - инструмента мониторинга и управления процессами, связанными с разработкой и реализацией совместных научно-технических проектов государствами, входящими в состав СНГ [25]. Помимо кооперации со странами СНГ, России выгодно сотрудничество со странами - партнерами БРИКС в областях, в которых объединение усилий потенциально может привести к синергизму [26; 27]. М. Костемир и соавторы утверждают, что в число долгосрочных целей стран-партнеров входит трансформация БРИКС в единую платформу для решения ключевых вопросов науки и техники в рамках стратегического партнерства [28]. Создание единой сетевой платформы BRICS-TTN рассматривается М. В. Балашовой как один из важнейших механизмов поддержки инфраструктурной интеграции стран [29].

Среди инструментов интенсификации развития экономики отдельных регионов эффективна также поддержка межвузовской кооперации и формирование опорных вузов ${ }^{3}[30 ; 31]$.

Концепция создания региональной инновационной системы (Regional Innovative System, RIS) зарекомендовала себя как одна из наиболее влиятельных в сфере разработки политики межрегионального взаимодействия на территории Европейского союза [32]. Под инновационной системой, согласно П. П. Савиотти, понимается совокупность всех действующих лиц и их взаимодействий, целью которых является генерирование и внедрение инноваций [33]. Концепция гласит, что инновации генерируются не столько обособленно отдельными лицами и организациями, сколько вследствие реализации сложных моделей взаимодействия между ними [34]. Ключевая компонента в концепции RIS - регион, который представляет собой политическую единицу, соединяющую между собой региональный и федеральный (национальный) уровни управления в сфере инновационного развития [35]. Однако, как пишет Ч. Эдквист, существует ряд трудностей по применению концепции RIS к построению региональной инновационной политики ввиду неопределенности границ, существующих между национальными и региональными системами [36]. Европейский союз в целях обеспечения устойчивого территориального развития передает ряд полномочий в отношении формирования политики в области НИОКР местным/региональным органам власти. Сугубо политической задачей на уровне региона становится налаживание научных связей путем образования новых и/или укрепления существующих научных сетей, в целях чего существуют связующие организации - звенья

${ }^{3}$ В рамках государственного проекта «Опорные университеты региональных экономических систем». 
(брокерские конторы, компании по взаимодействию промышленности и науки, элементы научной инфраструктуры, технологические платформы) [37].

Для начала активного развития небольшого научного региона, расположенного на территории какой-либо крупной страны, рентабельнее (с точки зрения координации) выстраивать кооперационные связи внутри национальной системы, чем ориентироваться на развитие международного научно-технического сотрудничества. Для развития небольшого научного региона, расположенного внутри какой-либо небольшой страны, целесообразна стратегия активной международной коммуникации и взаимодействия (особенно с Европейским союзом) ввиду того, что национальный научно-технологический и инновационный потенциал данных стран слаб, а международные коллаборации открывают доступ к ранее недоступным ценным ресурсам других стран (в том числе инфраструктурным) [38]. Крупные научные регионы любых по размерам стран практикуют гибридные стратегии - глобально-локальные, нацеленные как на активное международное, так и национальное сотрудничество. Страны с автаркической экономической системой обособленны в сфере мировой науки, притом их местное (межрегиональное) сотрудничество малоэффективно часто ввиду отсутствия интегрированной RIS. Для такого рода стран должна проводиться политика по наращиванию и укреплению национального научного потенциала через поощрение избирательного международного партнерства [38].

Завершая обзор литературы, хочется заключить, что вопросы научно-технологической связности территорий как основы устойчивого развития регионов России в последнее время активно изучаются в российском научном сообществе. Связность рассматривается как кооперация образовательной, научной и производственной систем, заложенных в потенциал субъектов Российской Федерации. Такого рода кооперация способна обеспечить переход экономики России на инновационный уровень, преддверием которого должно быть создание элементов научной инфраструктуры - кластеров, технопарков и индустриальных парков, технологических платформ (в том числе сетевых) и бизнес-инкубаторов. Регион должен выступить в роли элементарной единицы инновационной системы страны. Совокупность таких элементов (регионов) и субэлементов (научных организаций, вузов, промышленных предприятий и организаций, нацеленных на их кооперацию) в своих статических и динамических связях должны стать базисом инновационной экономики. В зарубежной литературе также активно рассматриваются модели межрегиональных научно-технологических связей. Концепция RSI стала одной из ключевых в процессе укрепления межрегиональных связей и становления единого научно-технологического и инновационного пространства на территории Европейского союза. 
Материалы и методы. Проведенное исследование было реализовано последовательно в два этапа. На первом этапе проводился анализ существующей нормативно-правовой базы, регулирующей научную и техническую деятельность в рассматриваемых регионах. На втором этапе в рамках ежегодного мониторинга ${ }^{4}$ посредством интерактивных форм, размещенных на интернет-портале «Научно-технологическая инфраструктура Российской Федерации: центры коллективного пользования и уникальные научные установки» (http://ckp-rf.ru), были собраны сведения об оснащенности выбранных территорий объектами научной инфраструктуры - центрами коллективного пользования научным оборудованием и уникальными научными установками. Сбор данных в рамках ежегодного мониторинга осуществлялся в течение первого квартала года, следующего за отчетным. На момент написания статьи верифицированные данные были доступны за 2017 г. Вследствие сбора статистических данных была проведена обработка и анализ полученной информации посредством программных средств MS Excel.

В ходе исследования применен метод системного анализа, с помощью которого регионы рассмотрены как территориально обособленные и строго дифференцированные уникальные блоки (элементы), однако существующие и функционирующие внутри единой системы (страны) и подчиняющиеся закономерностям ее функционирования. С помощью сравнительного анализа регионы были ранжированы в зависимости от оснащенности их законодательной базы нормативно-правовыми актами и в зависимости от их инфраструктурной оснащенности, что позволило сформировать условный рейтинг, отметив лидеров и аутсайдеров научно-технологического и инновационного развития.

Результаты исследования. Анализ региональной нормативно-правовой базы развития научной и технической деятельности в отдельных регионах Российской Федерации.

В контексте разработки темы научно-технологической связности территорий важно отметить существование документов по государственному стратегическому планированию и регулированию пространственного развития страны - Стратегии пространственного развития России до 2025 года и Федерального закона от 28.06.2014 № 172-Ф3 «О стратегическом планировании в Российской Федерации» ${ }^{5}$ [39]. Залогом устойчивого экономического роста страны является формирование

${ }^{4}$ Ежегодный мониторинг осуществляется Министерством науки и высшего образования Российской Федерации в соответствии с Поручением Президента и Правительства Российской Федерации, оператором выступает Российский научно-исследовательский институт экономики, политики и права в научно-технической сфере.

5 О стратегическом планировании в Российской Федерации: Федеральный закон от 28.06.2014 № 172-Ф3. URL: http://www.consultant.ru/document/consdocLAW164841 (дата обращения: 10.01.2018). 
на уровне государства условий, являющихся стимулом для развития научно-технического потенциала, ввиду чего существует ряд документов, регулирующих данную сферу и носящих статус нормативно-правовых актов федерального уровня ${ }^{6}$.

Научно-технологическая деятельность комплексно определяется в п. 10 ст. 2. Федерального закона от 29.07.2017 № 216-Ф3 «Об инновационных научно-технологических центрах и о внесении изменений в отдельные законодательные акты Российской Федерации» ${ }^{7}$.

В гл. 4 Федерального закона от 23.08.1996 № 127-Ф3 «О науке и государственной научно-технической политике» ${ }^{8}$ раскрывается тема государственной поддержки инновационной деятельности, в том числе и в регионах России. Например, к одному из принципов такой поддержки относится «обеспечение эффективности государственной поддержки инновационной деятельности для целей социально-экономического развития Российской Федерации и субъектов Российской Федерации» (абз. 8 ч. 3 ст. 16.1), а к субъектам государственной поддержки (ч. 1 ст. 16.2) - субъекты Российской Федерации.

Таким образом, на федеральном уровне заложены основы для формирования нормативной правовой базы в регионах России для развития научной и технической деятельности.

Далее рассмотрим нормативно-правовые акты в сфере развития научной и технической деятельности в обозначенных выше регионах.

Законодательная база Новосибирской области в сфере развития научной и технической деятельности представлена в таблице 1. Научнотехническая политика Новосибирской области является региональной составляющей государственной научно-технической политики Российской Федерации (предусмотренной Федеральным законом от 23.08.1996 № 127-Ф3 «О науке и государственной научно-технической политике» $\left.{ }^{9}\right)$ и составной частью социально-экономической политики Новосибирской области (предусмотренной распоряжением Правительства Российской Федерации от 05.07.2010 № 1120-p ${ }^{10}$ и постановлением Губернатора

${ }^{6}$ Барсукова Н. Е., Клюшникова Е. В., Мальцева А. А. Исследование институциональной и правовой готовности регионов России к развитию научно-технологической сферы // Россия: тенденции и перспективы развития. 2018. № 13-2. C. 739-746. URL: https://cyberleninka.ru/article/n/issledovanie-institutsionalnoy-i-pravovoy-gotovnosti-regionov-rossii-k-razvitiyu-nauchno-tehnologicheskoy-sfery (дата обращения: 25.10.2019).

7 Об инновационных научно-технологических центрах и о внесении изменений в отдельные законодательные акты Российской Федерации: Федеральный закон от 29.07.2017 № 216-Ф3.

${ }^{8}$ О науке и государственной научно-технической политике: Федеральный закон от 23.08.1996 № 127-Ф3.

9 Там же.

${ }^{10}$ Об утверждении Стратегии социально-экономического развития Сибири до 2020 года: Распоряжение Правительства РФ от 05.07.2010 № 1120-р. 
Новосибирской области от 03.12.2007 № 474), которая формируется в тесной взаимосвязи с промышленной, инвестиционной политикой Новосибирской области, а также политикой в иных сферах деятельности (ч. 1 и 2 ст. 3 Закона от 20.04.1995 № 17-О3 «О научной деятельности и научно-технической политике Новосибирской области»). Из этого следует, что указанные выше правовые акты связаны между собой единой политикой.

Т а 6 л и ц а 1. Законодательная база Новосибирской области в сфере регулирования научной и технической деятельности

$\mathrm{T}$ a b l e 1. Legislative framework of the Novosibirsk Region in the field of regulation of scientific and technological activities

\begin{tabular}{|c|}
\hline $\begin{array}{c}\text { Нормативный правовой акт / } \\
\text { Normative legal act }\end{array}$ \\
\hline $\begin{array}{l}\text { Устав Ново } \\
\text { of the Novo }\end{array}$ \\
\hline $\begin{array}{l}\text { Закон от } 20.04 .1995 \text { № } 17-\mathrm{O} 3 \text { «О на } \\
\text { учной деятельности и научно-тех } \\
\text { нической политике Новосибирско } \\
\text { области» / Law No. 17-OZ of } 20 \text { Apr } \\
1995 \text { 'On Scientific Activities and th } \\
\text { Scientific and Technological Policie } \\
\text { of the Novosibirsk Region' }\end{array}$ \\
\hline
\end{tabular}

Закон от 15.12.2007 № $178-\mathrm{O} 3$ «О политике Новосибирской области в сфере развития инновационной системы» / Law No. 178-OZ of 15 December 2007 'On the Policies of the Novosibirsk Region in the Sphere of the Innovation System Development'

Концепция развития инновационной деятельности в экономике и социальной сфере на территории Новосибирской области / Concept of development of innovative activities in the economy and social sphere in the territory of the Novosibirsk Region
Примечание / Note

Основополагающий документ Fundamental document

Установил основы организации научной и инновационной деятельности, основы формирования научно-технической политики Новосибирской области, условия и порядок ее реализации, виды государственной поддержки / The law established the foundations for organizing scientific and innovative activities, as well as the foundations for the formation of the scientific and technological policies in the Novosibirsk Region, the conditions and procedure for its implementation and the types of state support

Регулирует отношения по формированию и реализации политики Новосибирской области в сфере развития инновационной системы / Regulating the relations on the formation and implementation of the NSR policy in the field of development of the innovation system

Основополагающй документ / Fundamental document

В ч. 1 ст. 4 Закона от 20.04.1995 № 17-О3 «О научной деятельности и научно-технической политике Новосибирской области» обозначено, что основная цель научно-технической политики региона - достижение высокой эффективности научно-технического и кадрового обеспечения 
социально-экономического развития области. Возможность достижения указанной цели отмечается рядом предпосылок и преимуществ для развития научной и технической деятельности, отмеченных в распоряжении Правительства РФ от 17.11.2008 № 1662-p ${ }^{11}$.

В отличие от Новосибирской области в Хабаровском крае в настоящее время нормативную правовую базу, регулирующую развитие научной и технической деятельности в регионе, составляют лишь два документа - Устав Хабаровского края и Стратегия социально-экономического развития Хабаровского края на период до 2030 года, утвержденная постановлением Правительства Хабаровского края от 13.06.2018 № 215-пр. Следует отметить, что в соответствии с п. 3 ст. 2 Федерального закона от 29.12.2014 № 473-Ф3 «О территориях опережающего социальноэкономического развития в Российской Федерации» ${ }^{12}$ Хабаровск, как и Комсомольск, Николаевск и свободный порт Ванино, отнесен к территориям опережающего развития, что также играет важную роль.

Законодательная база Приморского края в области развития научной и технической деятельности приведена в таблице 2. Приморский край, как и Новосибирская область, обладает рядом ключевых нормативно-правовых актов, регулирующих научно-технологическое развитие в регионе.

Аналогичными актами обладает и Белгородская область (табл. 3). Нормативная правовая база этого региона состоит из положений Устава и Стратегии социально-экономического развития, направленных на урегулирование сферы научной и технической деятельности области, а также специализированных законов.

Республика Саха (Якутия), несмотря на ограниченность нормативноправовой базы, регулирующей научную и техническую деятельность региона, остается одним из крупнейших центров развития науки на северо-востоке России. Нормативно-правовая база республики в данной области представлена 3 документами: Конституцией Республики Саха (Якутия), Законом Республики Саха (Якутия) от 15.04.2004 № 132-3 № 267-III «O науке и государственной научно-технической политике» и Стратегией социально-экономического развития Республики Саха (Якутия) до 2032 г. с целевым видением до 2050 г., утвержденной законом Республики Саха (Якутия) от 19.12.2018 2077-3 № 45-VI.

Законодательную базу развития научной и технической деятельности Томской области составляют нормативные правовые акты, представленные в таблице 4.

${ }^{11}$ О Концепции долгосрочного социально-экономического развития Российской Федерации на период до 2020 года: Распоряжение Правительства РФ от 17.11.2008 № 1662-p (вместе с «Концепцией долгосрочного социально-экономического развития Российской Федерации на период до 2020 года»).

${ }_{12} \mathrm{O}$ территориях опережающего социально-экономического развития в Российской Федерации: Федеральный закон от 29.12.2014 № 473-Ф3. 
Т а б л и ц а 2. Законодательная база Приморского края в сфере регулирования научной и технической деятельности

$\mathrm{T}$ a b 1 e 2. Legislative framework of the Primorye Territory in the field of regulation of scientific and technological activities

Нормативный правовой акт /
Normative legal act

Закон Приморского края от 15.02.2008 № 195-КЗ «Об инновационной деятельности на территории Приморского края»/ Law of the Primorye Territory No. 195-KZ of 15 February 2008 'On Innovative Activities in the Territory of the Primorye Territory'
Примечание / Note
В ст. 68 заложены основные принципы участия органов государственной власти Приморского края в проведении единой государственной политики, в том числе в п. 4 - «государственной поддержки и развития науки и образования, культуры и искусства», в п. 6 - «содействия использованию научных достижений для развития экономики края» / Article 68 lays down the basic principles for the participation of the public authorities of the Primorye Territory in the implementation of a unified state policy, in particular in Paragraph 4: "state support and development of science and education, culture and art" and in Paragraph 6: "promoting the use of scientific achievements for the economic development of the region"

Регулирует отношения между субъектами научной и (или) научно-технической деятельности и органами государственной власти и устанавливает полномочия органов государственной власти Приморского края, цели, задачи, основные направления их деятельности в научной и (или) научно-технической сферах / The law regulates relations between subjects of scientific and (or) scientific and technological activities and public authorities, establishes the powers of the public authorities of the Primorye Territory, goals, objectives, main directions of their activities in the scientific and (or) scientific and technological fields

Регулирует отношения органов государственной власти Приморского края и субъектов инновационной деятельности для развития инновационной деятельности, создание режима максимального благоприятствования для субъектов инновационной деятельности / The law regulates relations of the public authorities of the Primorye Territory and subjects of innovative activities in order to develop innovative activities and gives subjects of innovative activities preferential treatment 
Окончание табл. 2 / End of table 2

\begin{tabular}{l|l}
\hline 1 & 2 \\
\hline Постановление Губернатора При- \\
морского края от 07.09.2018 № 48-пг \\
«О Координационном совете по во- \\
просам научной, научно-технической \\
и инновационной деятельности При- \\
морском крае»/ Decree of the Governor \\
of the Primorye Territory No. 48-pg of \\
7 September 2018 'On the Coordination \\
Council for Scientific, Scientific and \\
Technological, and Innovative Activities \\
in the Primorye Territory'
\end{tabular}

Т а б л и ц а 3. Законодательная база Белгородской области в сфере регулирования научной и технической деятельности

$\mathrm{T}$ a b 1 e 3. Legislative framework of the Belgorod Region in the field of regulation of scientific and technological activities

\begin{tabular}{|c|c|}
\hline $\begin{array}{c}\text { Нормативный правовой акт / Norma- } \\
\text { tive legal act }\end{array}$ & Примечание / Note \\
\hline 1 & 2 \\
\hline $\begin{array}{l}\text { Устав Белгородской области / Charter } \\
\text { of the Belgorod Region }\end{array}$ & $\begin{array}{l}\text { В соответствии с п. «и» ст. } 42 \text { Уста- } \\
\text { ва к обязанностям Правительства } \\
\text { Белгородской области относится ре- } \\
\text { ализация программы по развитию } \\
\text { науки / In accordance with Paragraph } \\
\text { J ('и') of Article } 42 \text { of the Charter, the } \\
\text { responsibilities of the Government of } \\
\text { the Belgorod Region include the imple- } \\
\text { mentation of the Science development } \\
\text { program }\end{array}$ \\
\hline
\end{tabular}

Закон Белгородской области от 13.11.2003 № 96 «О деятельности органов государственной власти Белгородской области в научной и (или) научно-технической сферах» / Law of the Belgorod Region No. 96 of 13 November 2003 'On the Activities of the Public Authorities of the Belgorod Region in the Scientific and (or) Scientific and Technological Spheres'
До 2015 г. назывался «О науке и научно-технической политике в Белгородской области». Устанавливает правовые основы деятельности органов государственной власти субъекта в научной и (или) научно-технической cфepax / Until 2015, the law was called 'On Science and Science and Technology Policies in the Belgorod Region.' The law establishes the legal basis for the activities of the public authorities of the region in the scientific and (or) scientific and technological spheres 
Окончание табл. 3 / End of table 3

\begin{tabular}{l}
\hline 1 \\
\hline Закон Белгородской области от \\
01.10 .2009 № 296 «Об инновацион- \\
ной деятельности и инновационной \\
политике на территории Белгородской \\
области» / Law of the Belgorod Region \\
No.296 of 1 October 2009 'On Innovative \\
Activities and Innovation Policies in the \\
Belgorod Region’
\end{tabular}

Стратегия социально-экономического развития Белгородской области на период до 2025 г., утверждена постановлением Правительства Белгородской области от 25.01.2010 № 27-пп / Strategy for Socio-Economic Development of the Belgorod Region until 2025, approved by the Decree of the Government of the Belgorod Region No. 27-pp of 25 January 2010

\section{2}

Определяет организационные, правовые и экономические условия и гарантии инновационной деятельности и основы формирования и реализации инновационной политики / The law assigns organizational, legal and economic conditions and guarantees of innovative activities and the basis for the formation and implementation of innovation policies

Одним из мероприятий по развитию указана «Инновационная система региона», где среди основных задач обозначено эффективное использование интеллектуального потенциала, генерация новых знаний, интеграция фундаментальной и прикладной науки в высокотехнологичные производства, развитие механизма государственной поддержки инновационной деятельности / 'Innovation System of the Region' is referred to as one of the development measures, where the main tasks include effective use of the intellectual potential, generation of new knowledge, integration of fundamental and applied science in high-tech industries, development of a mechanism of state support for innovative activities

На территории Московской области действует значительно большее количество нормативных правовых актов, регулирующих развитие научной и научно-технической политики. Рассмотрим их в таблице 5.

В ходе правового анализа выявилось отсутствие специальных нормативных правовых актов, регулирующих развитие научно-технической и инновационной деятельности на территории г. Севастополя и Республики Крым. Однако стоит отметить, что Законом г. Севастополя от 18.12.2015 № 219-3С «Об основах промышленной политики города Севастополя» в рамках стимулирования деятельности в сфере промышленности предусматривается поддержка осуществляемой научно-технической и инновационной деятельности субъектами рассматриваемой деятельности. Одной из стратегических задач развития Республики Крым в рамках Закона Республики Крым от 09.01.2017 № 352-3РК/2017 «О стратегии социально-экономического развития Республики Крым до 2030 года» является «развитие системы государственной поддержки научной, научно-технической и инновационной деятельности». В этих документах 
устанавливается заинтересованность в развитии и поддержке научной, научно-технический и инновационной деятельности и приоритетность таких положений.

Т а б л и ц а 4. Законодательная база Томской области в сфере регулирования научной и технической деятельности

$\mathrm{T}$ a b l e 4. Legislative framework of the Tomsk Region in the field of regulation of scientific and technological activities

\begin{tabular}{c|c}
\hline $\begin{array}{c}\text { Нормативный правовой } \\
\text { акт / Normative legal act }\end{array}$ & Примечание / Note \\
\hline 1 & 2 \\
\hline
\end{tabular}

Закон Томской области от 01.12.2000 № 56-O3 «О научной деятельности и научно-технической политике Томской области» / Law of the Tomsk Region No. 56-OZ of 1 December 2000 'On Scientific Activities and the Scientific and Technological Policies of the Tomsk Region'

Закон Томской области от 12.03.2015 № 25-О3 «Об инновационной деятельности в Томской области» / Law of the Tomsk Region No.25-OZ of

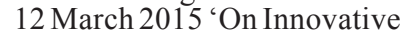
Activities in the Tomsk Region'
Устанавливает основные принципы, цели и задачи научно-технической политики и формы ее реализации в регионе; определяет круг субъектов научной и (или) научно-технической деятельности и организационно-правового обеспечения научной и (или) научно-технической деятельности, а также полномочия последних; создает дополнительные гарантии для использования результатов научно-технической деятельности в материальном производстве и социальной жизни Томской области; определяет организационные формы, механизмы управления и финансирования научно-технической деятельности на территории области / The law establishes the basic principles, goals and objectives of scientific and technological policies and the forms of its implementation in the region; the law defines the circle of subjects of scientific and (or) scientific and technological activities, organizational and legal support of scientific and (or) scientific and technological activities, as well as their powers; the law provides additional guarantees for the use of the results of scientific and technological activities in material production and social life of the Tomsk Region; the law defines the organizational forms, mechanisms for management and financing of scientific and technological activities in the region

Регулирует экономические, правовые и организационные условия развития инновационной деятельности в Томской области / The law regulates economic, legal and organizational conditions for the development of innovative activities in the Tomsk Region 
Окончание табл. 4 / End of table 4

\begin{tabular}{|c|c|}
\hline 1 & 2 \\
\hline $\begin{array}{l}\text { Закон Томской области } \\
\text { от } 13.03 .2006 \text { № 29-O3 } \\
\text { «О премиях Томской об- } \\
\text { ласти в сфере образования, } \\
\text { науки, здравоохранения } \\
\text { и культуры» / Law of the } \\
\text { Тomsk Region No. 29-OZ of } \\
13 \text { March } 2006 \text { 'On the Tomsk } \\
\text { Region's Prizes for Education, } \\
\text { Science, Health and Culture' }\end{array}$ & $\begin{array}{l}\text { Реализация закона направлена на стимулирова- } \\
\text { ние творческой инициативы работников науки, } \\
\text { образования и культуры, аспирантов, студентов } \\
\text { и учащихся, широкого привлечения их к образо- } \\
\text { вательной, научно-исследовательской, проектно- } \\
\text { конструкторской деятельности и внедрению на- } \\
\text { учных и научно-педагогических достижений } \\
\text { с учетом приоритетов социально- экономического } \\
\text { развития Tомской области / Implementation of the } \\
\text { law is aimed at stimulating the creative initiative of } \\
\text { workers in science, education and culture, post-grad- } \\
\text { uate students, university students and pupils, their } \\
\text { intense involvement in educational, research, design } \\
\text { and development activities and the implementation } \\
\text { of research, scientific and pedagogical achievements, } \\
\text { taking into account the priorities of the Tomsk Re- } \\
\text { gion's social and economic development }\end{array}$ \\
\hline
\end{tabular}

Т а б л и ц а 5. Законодательная база Московской области в сфере регулирования научной и технической деятельности

$\mathrm{T}$ a $\mathrm{b} 1 \mathrm{e}$ 5. Legislative framework of the Moscow Region in the field of regulation of scientific and technological activities

\begin{tabular}{|c|c|}
\hline $\begin{array}{c}\text { Нормативный правовой акт / Norma- } \\
\text { tive legal act }\end{array}$ & Примечание / Note \\
\hline 1 & 2 \\
\hline $\begin{array}{l}\text { Закон Московской области от 06.05.2016 } \\
\text { № 38/2016-О3 «О научно-технической } \\
\text { политике органов государственной } \\
\text { власти Московской области» / Law } \\
\text { of the Moscow Region No. 38/2016-OZ } \\
\text { of } 6 \text { May 2016 'On the Scientific and } \\
\text { Technological Policies of the Public } \\
\text { Authorities of the Moscow Region' }\end{array}$ & $\begin{array}{l}\text { Определяет основные цели, задачи } \\
\text { и принципы научно-технической дея- } \\
\text { тельности региона, раскрывает методы } \\
\text { еерегулирования, устанавливаетпорядок } \\
\text { реализации научно-технической поли- } \\
\text { тики органов государственной власти } \\
\text { Московской области/The law establishes } \\
\text { the main goals, objectives and principles } \\
\text { of the scientific and technological activi- } \\
\text { ties in the region, reveals the methods of } \\
\text { regulating them, establishes the procedure } \\
\text { for the implementation of the scientific } \\
\text { and technological policies of the public } \\
\text { authorities of the Moscow Region }\end{array}$ \\
\hline $\begin{array}{l}\text { Закон Московскойобласти от } 10.02 .2011 \\
\text { № } 15 / 2011 \text {-О3 «Об инновационной } \\
\text { политике органов государственной } \\
\text { власти Московской области» / Law } \\
\text { of the Moscow Region No. } 15 / 2011 \text {-OZ } \\
\text { of } 10 \text { February } 2011 \text { 'On the Innovation } \\
\text { Policies of the Public Authorities of the } \\
\text { Moscow Region' }\end{array}$ & $\begin{array}{l}\text { Закрепляет цели, задачи и принципы } \\
\text { инновационной политики региона, уста- } \\
\text { навливает формы и методы стимулиро-- } \\
\text { вания инновационнойдеятельности/The } \\
\text { law establishes the goals, objectives and } \\
\text { principles of the innovation policy of the } \\
\text { region, as well as the forms and methods } \\
\text { of stimulating innovative activities }\end{array}$ \\
\hline
\end{tabular}


РЕГИОНОЛОГИЯ. Том 27, № 4, 2019

Окончание табл. 5 / End of table 5

\begin{tabular}{l}
\hline 1 \\
\hline Закон Московской области от \\
03.04 .2013 № 27/2013-О3 «О грантах \\
Правительства Московской области \\
в сферах науки, технологий, техники \\
и инноваций» / Law of the Moscow \\
Region No.27/2013-OZ of 3 March 2013 \\
'On Grants from the Government of the \\
Moscow Region for Science, Technology, \\
Engineering and Innovation' \\
Рaспоряжение Правительства Москов- \\
ской области от 26.12.2016 № 446-РП \\
«O приоритетных для Московской \\
области направлениях развития науки, \\
технологий и техники» / Order of the \\
Governmеnt of the Moscow Region No. \\
446-RР of 26 December 2016 'On the \\
Priority Directions for the Development \\
of Science, Technology and Engineering \\
in the Moscow Region'
\end{tabular}

Закон Московской области от 24.11.2004 № 151/2004-О3 «О льготном налогообложении в Московской области» / Law of the Moscow Region No. 151/2004-OZ of 24 November 2004 'On Preferential Taxation in the Moscow Region'

Утверждает перечень приоритетных для Московской области направлений развития науки, технологий и техники / The order approves the list of priority areas for the development of science, technology and engineering in the Moscow region

Регулирует предоставление налоговых льгот при ведении научной и (или) научно-технической и инновационной деятельности / The law regulates the provision of tax benefits when conducting scientific and (or) scientific and technological, as well as innovative activities

В целях поддержки развития научной и технической деятельности в Калининградской области действуют нормативные правовые акты, представленные в таблице 6.

Законодательство Республики Татарстан в области развития научной и технической деятельности представлено нормативными правовыми актами, отраженными в таблице 7.

Подводя итоги анализа региональной нормативно-правовой базы поддержки и развития научной и технической деятельности в отдельных регионах Российской Федерации, можно заключить, что в целом ситуация удовлетворительная - база имеется, однако ее полноценность разнится от региона к региону, существует серьезная разрозненность. Так, в некоторых субъектах имеется обширная нормативно-правовая база (Новосибирская, Московская, Белгородская области, Приморский край, Республика Татарстан), содержащая не только общие положения, но и частные, например, вопросы финансирования. В других регионах (Республика Крым и г. Севастополь) полностью отсутствуют документы по указанной сфере, в связи с чем такие регионы нуждаются в создании базы по реализации научной и технической деятельности. 
Т а б л и ц а 6. Законодательная база Калининградской области в сфере регулирования научной и технической деятельности

$\mathrm{T}$ a b 1 e 6 . Legislative framework of the Kaliningrad Region in the field of regulation of scientific and technological activities

\begin{tabular}{|c|c|}
\hline $\begin{array}{c}\text { Нормативный правовой акт / Norma- } \\
\text { tive legal act }\end{array}$ & Примечание / Note \\
\hline $\begin{array}{l}\text { Закон Калининградской области от } \\
24.04 .2018 \text { № } 164 \text { «О разграничении } \\
\text { полномочий органов государствен- } \\
\text { ной власти Калининградской области } \\
\text { в сфере научной и научно-технической } \\
\text { деятельности и государственной под- } \\
\text { держки инновационной деятельности»/ } \\
\text { Law of the Kaliningrad Region No. } 164 \\
\text { of } 24 \text { April } 2018 \text { 'On the Delimitation } \\
\text { of Powers of Public Authorities of the } \\
\text { Kaliningrad Region in the Field of Sci- } \\
\text { entific, Scientific and Technological } \\
\text { Activities and State Support for Inno- } \\
\text { vative Activities' }\end{array}$ & $\begin{array}{l}\text { Определяет полномочия органов госу- } \\
\text { дарственной власти Калининградской } \\
\text { области в сфере научной и научно- } \\
\text { технической деятельности и государ- } \\
\text { ственной поддержки инновационной } \\
\text { деятельности, определяет формы г-- } \\
\text { сударственной поддержки инноваци- } \\
\text { онной деятельности и ее финансовое } \\
\text { обеспечение / The law determines the } \\
\text { powers of the public authorities of the } \\
\text { Kaliningrad Region in the field of sci- } \\
\text { entific, scientific and technological ac- } \\
\text { tivities and state support for innovative } \\
\text { activities; the law determines the forms } \\
\text { of state support for innovative activities } \\
\text { including financial support }\end{array}$ \\
\hline $\begin{array}{l}\text { Постановление Правительства Кали- } \\
\text { нинградской области от 06.03.2018 } \\
\text { № } 124 \text { «О комиссии по вопросам } \\
\text { реализации проектов в области ра- } \\
\text { диоэлектронной промышленности, } \\
\text { научной, научно-технической и инно- } \\
\text { вационной деятельности на территории } \\
\text { Калининградской области / Decree of } \\
\text { the Government of the Kaliningrad Re- } \\
\text { gion No. } 124 \text { of } 6 \text { March } 2018 \text { 'On the } \\
\text { Commission for the Implementation of }\end{array}$ & $\begin{array}{l}\text { Регламентирует образование идействие } \\
\text { комиссии по вопросам реализации } \\
\text { проектов в области радиоэлектрон- } \\
\text { ной промышленности, научной, на- } \\
\text { учно-технической и инновационной } \\
\text { деятельности / The decree regulates the } \\
\text { formation and operation of the commis- } \\
\text { sion for the implementation of projects } \\
\text { in the field of radio-electronic industry, } \\
\text { scientific, scientific and technological, } \\
\text { and innovative activities }\end{array}$ \\
\hline
\end{tabular}

Projects in the Field of the Radio-Electronic Industry, Scientific, Scientific and Technological, and Innovative Activities in the Kaliningrad Region'

Анализ состояния научной инфраструктуры в отдельных регионах Российской Федерациии.

Анализ объектов научной инфраструктуры (далее - НИ) выбранных регионов был проведен на основе сведений о центрах коллективного пользования научным оборудованием (далее - ЦКП) и уникальных научных установках (далее - УНУ) [40].

Согласно определению Федерального закона «О науке и государственной научно-технической политике», ЦКП представляет собой «структурное подразделение (совокупность структурных подразделений), которое создано научной организацией и (или) образовательной организацией, располагает научным и (или) технологическим оборудованием, 
Т а б л и ц а 7. Законодательная база Республики Татарстан в сфере регулирования научной и технической деятельности

$\mathrm{T}$ a b 1 e 7 . Legislative framework of the Republic of Tatarstan in the field of regulation of scientific and technological activities

$\begin{gathered}\text { Нормативный правовой акт / } \\ \text { Normative legal act }\end{gathered}$
Закон Республики Татарстан
от 18.06.1998 № 1661 «О науке
и научной деятельности»/Law
of the Republic of Tatarstan
No. 1661 of 18 June 1998 ‘On
Science and Scientific Activities’

Закон Республики Татарстан
от 02.08.2010 № 63-3РТ «Oб
инновационной деятельности
в Pеспублике Татарстан» / Law
of the Republic of Tatarstan
No. 63-ZRT of 2 August 2010
'On Innovative Activities in the
Republic of Tatarstan’

Republic of Tatarstan'

Закон Республики Татарстан от 21.04.2016 «О промышленной политике в Республике Татарстан» № 24-3PT / Law of the Republic of Tatarstan No. 24-ZRT of 21 April $2016^{\prime}$ On Industrial Policies in the Republic of Tatarstan'

Указ Президента Республики Татарстан от 16.04.1993 № УП-206 «Об учреждении Государственных премий Республики Татарстан в области науки и техники» / Decree of the President of the Republic of Tatarstan No. UP-206 of 16 April 1993 'On the Establishment of State Prizes of the Republic of Tatarstan for Science and Technology'

\author{
Примечание / Note
}

Обеспечивает правовое регулирование научной деятельности на территории Республики Татарстан, определяет круг субъектов, их права и обязанности, определяет государственную политику в сфере науки / The law provides legal regulation of scientific activities in the Republic of Tatarstan, determines the range of subjects, their rights and obligations, and the republican policies in the field of science

Определяет цели, задачи и принципы инновационной политики Республики Татарстан, регулирует отношения, возникающие в связи с установлением и реализацией мер государственной поддержки инновационной деятельности на территории Республики Татарстан / The law establishes the goals, objectives and principles of the innovation policies of the Republic of Tatarstan, regulates the relations arising in connection with the establishment and implementation of measures of state support for innovative activities in the Republic of Tatarstan

Направлен на регулирование отношений, возникающих при проведении промышленной политики и осуществлении деятельности в сфере промышленности / The law regulates relations arising from the implementation of industrial policies and activities

Цель Указа - развитие науки и техники в регионе, стимулирование научно-технического прогресса и поощрения выдающихся достижений в области науки и техники / The objective of the decree is to develop science and technology in the region, stimulate scientific and technological progress and encourage outstanding achievements in the field of science and technology

квалифицированным персоналом и обеспечивает в интересах третьих лиц выполнение работ и оказание услуг для проведения научных исследований, а также осуществления экспериментальных разработок»; 
УНУ - «комплекс научного оборудования, не имеющий аналогов в Российской Федерации, функционирующий как единое целое и созданный научной организацией и (или) образовательной организацией в целях получения научных результатов, достижение которых невозможно при использовании другого оборудования» ${ }^{13}$.

В 2017 г. в мониторинге приняли участие 402 ЦКП и 219 УНУ, а в 2018 г. - 353 ЦКП и 198 УНУ. На начало 2019 г. на портале ckp-rf.ru зарегистрированы 593 ЦКП и 350 УНУ. Замечена явная положительная динамика в течение трех анализируемых лет. Более $1 / 4$ объектов НИ страны в 2018 г. было сконцентрировано в рассматриваемых 11 регионах - 26,1\% ЦКП и 25,5\% УНУ (рисунок).

Концентрация УНУ /

Concentration of the Large-Scale

Research Facilities

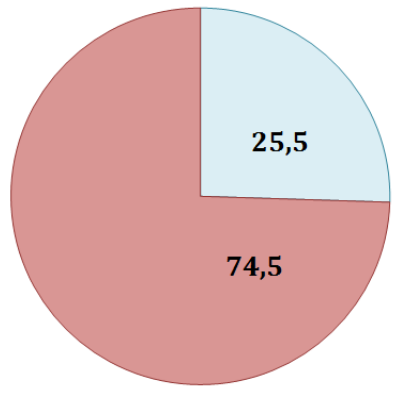

Концепция ЦКП / Concentration of the Core Shared Research Facilities

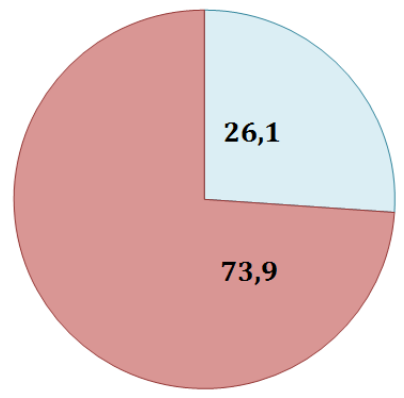

$\square$ На территории 11 регионов России / In 11 regions of the Russian Federation

$\square$ На территории других регионов России / In other regions of the Russian Federation

Р и с у н о к. Концентрация ЦКП и УНУ на территории Российской Федерации и отдельных регионов страны, 2018 г., \%

F i g u r e. Concentration of the Core Shared Research Facilities and Large-

Scale Research Facilities in the Russian Federation and in certain constituent entities of the Russian Federation in 2018, \%

Московская и Новосибирская области являются лидерами по количеству ЦКП и УНУ среди 11 выбранных для анализа субъектов Федерации. В г. Севастополь в 2018 г., как и в 2017 г., зафиксированы 3 ЦКП, но

13 О науке и государственной научно-технической политике: Федеральный закон от 23.08.1996 № 127-Ф3. 
не зафиксирована ни одна УНУ. Аналогичная ситуация наблюдается в Республике Татарстан, где, согласно анкетным данным, в 2017 и 2018 гг. были расположены 5 и 4 ЦКП соответственно, а УНУ отсутствовали (табл. 8).

Т а б л и ц а 8. Количество ЦКП и УНУ в Российской Федерации и отдельных регионах страны в 2017-2018 гг. ${ }^{14}$

$\mathrm{T}$ a b 1 e 8 . Number of the Core Shared Research Facilities and Large-Scale Research Facilities in the Russian Federation and in certain regions of the country in 2017-2018

\begin{tabular}{|c|c|c|c|c|}
\hline \multirow[t]{2}{*}{ Регион / Region } & \multicolumn{2}{|c|}{$\begin{array}{c}\text { Количество ЦКП / } \\
\text { Number of the Core } \\
\text { Shared Research Faci- } \\
\text { lities }\end{array}$} & \multicolumn{2}{|c|}{$\begin{array}{c}\text { Количество УНУ / } \\
\text { Number of the Large- } \\
\text { Scale Research Faci- } \\
\text { lities }\end{array}$} \\
\hline & 2017 & 2018 & 2017 & 2018 \\
\hline $\begin{array}{l}\text { Российская Федерация / } \\
\text { Russian Federation }\end{array}$ & 402 & 353 & 219 & 198 \\
\hline $\begin{array}{l}\text { Новосибирская область / } \\
\text { Novosibirsk Region }\end{array}$ & 32 & 27 & 15 & 12 \\
\hline $\begin{array}{l}\text { Московская область / Mos- } \\
\text { cow Region }\end{array}$ & 25 & 21 & 23 & 19 \\
\hline $\begin{array}{l}\text { Приморский край / Primo- } \\
\text { rye Territory }\end{array}$ & 16 & 14 & 5 & 5 \\
\hline $\begin{array}{l}\text { Томская область / Tomsk } \\
\text { Region }\end{array}$ & 8 & 6 & 11 & 8 \\
\hline $\begin{array}{l}\text { Республика Крым / Repub- } \\
\text { lic of Crimea }\end{array}$ & 3 & 5 & 3 & 2 \\
\hline $\begin{array}{l}\text { Белгородская область / } \\
\text { Belgorod Region }\end{array}$ & 3 & 3 & 3 & 3 \\
\hline $\begin{array}{l}\text { Республика Саха (Яку- } \\
\text { } \\
\text { (Yakutia) }\end{array}$ & 3 & 3 & 2 & 1 \\
\hline $\begin{array}{l}\text { Хабаровский край } \\
\text { Khabarovsk Territory }\end{array}$ & 8 & 6 & - & - \\
\hline $\begin{array}{l}\text { Республика Татарстан / } \\
\text { Republic of Tatarstan }\end{array}$ & 5 & 4 & - & - \\
\hline г. Севастополь / Sevastopol & 3 & 3 & - & - \\
\hline $\begin{array}{l}\text { Калининградская область/ } \\
\text { Kaliningrad Region }\end{array}$ & - & - & 1 & - \\
\hline $\begin{array}{l}\text { Итого по } 11 \text { регионам / } \\
\text { Total for } 11 \text { regions }\end{array}$ & 106 & 92 & 63 & 50 \\
\hline
\end{tabular}

14 Таблица составлена на основе данных ежегодного мониторинга Министерства науки и высшего образования России. 
Показатели результативности объектов НИ приведены в таблицах 9 и 10. Тройку регионов-лидеров по объему выполненных работ и оказанных услуг составляют Московская, Белгородская и Новосибирская области. Этот результат стал логичным следствием активного привлечения внешних пользователей: по доле работ (услуг) в интересах внешних пользователей эти три региона также занимают первые три места. Белгородская область значительно опережает остальные субъекты по количеству заявок на результаты интеллектуальной деятельности и патентов, полученных благодаря использованию оборудования ЦКП. При этом количество ЦКП в Белгородской области в 9 раз меньше, чем в Новосибирской, которую ей удалось опередить. По числу организаций внешних пользователей Белгородская область также входит в топ-3.

Т а б л и ц а 9. Показатели результативности деятельности ЦКП в отдельных регионах Российской Федерации, 2018 г. ${ }^{15}$

$\mathrm{T}$ a b 1 e 9. Indicators of performance of the Core Shared Research Facilities in certain regions of the Russian Federation in 2018

\begin{tabular}{|c|c|c|c|c|}
\hline Регион / Region & $\begin{array}{c}\text { Объем вы- } \\
\text { полненных } \\
\text { работ (услуг), } \\
\text { млн руб./ } \\
\text { Volume of } \\
\text { work (ser- } \\
\text { vices), million } \\
\text { rubles }\end{array}$ & $\begin{array}{c}\text { Доля работ } \\
\text { (услуг) в ин- } \\
\text { тересах внеш- } \\
\text { них пользо-- } \\
\text { вателей, \%/ } \\
\text { Share of work } \\
\text { (services) for } \\
\text { external } \\
\text { users, \% }\end{array}$ & \begin{tabular}{|} 
Количество \\
организаций- \\
пользовате- \\
лей / \\
Number of \\
user organiza- \\
tions
\end{tabular} & $\begin{array}{c}\text { Количество } \\
\text { РИД }{ }^{16} \text { и за- } \\
\text { явок на РИД / } \\
\text { Number of } \\
\text { patents and } \\
\text { patent applica- } \\
\text { tions }\end{array}$ \\
\hline 1 & 2 & 3 & 4 & 5 \\
\hline $\begin{array}{l}\text { Московскаяобласть/ } \\
\text { Moscow Region }\end{array}$ & 750,7 & 85,9 & 387 & 36 \\
\hline $\begin{array}{l}\text { Белгородская об- } \\
\text { ласть / Belgorod } \\
\text { Region }\end{array}$ & 299,5 & 78,7 & 224 & 121 \\
\hline $\begin{array}{l}\text { Новосибирская об- } \\
\text { ласть / Novosibirsk } \\
\text { Region }\end{array}$ & 273,5 & 67,6 & 344 & 44 \\
\hline $\begin{array}{l}\text { Tомская область / } \\
\text { Tomsk Region }\end{array}$ & 174,2 & 60,1 & 145 & 0 \\
\hline $\begin{array}{l}\text { Приморский край / } \\
\text { Primorye Territory }\end{array}$ & 71,0 & 66,2 & 108 & 14 \\
\hline $\begin{array}{l}\text { Республика Caxa } \\
\text { (Якутия)/Republic } \\
\text { of Sakha (Yakutia) }\end{array}$ & 29,2 & 41,0 & 56 & 2 \\
\hline
\end{tabular}

15 Таблица составлена на основе данных ежегодного мониторинга Министерства науки и высшего образования России.

${ }^{16}$ РИД - результаты интеллектуальной деятельности. 
Окончание табл. 9 / End of table 9

\begin{tabular}{lc|c|c|c}
\hline 1 & 2 & 3 & 4 & 5 \\
\hline $\begin{array}{l}\text { Республика Татар- } \\
\text { стан / Republic of }\end{array}$ & 22,3 & 78,3 & 94 & 3 \\
$\begin{array}{l}\text { Tatarstan } \\
\text { Хабаровский край / }\end{array}$ & 17,1 & 75,5 & 66 & 13 \\
$\begin{array}{l}\text { Khabarovsk Territory } \\
\text { Peспублика Крым / }\end{array}$ & 2,4 & 28,7 & 29 & 5 \\
$\begin{array}{l}\text { Republic of Crimea } \\
\text { г. Севастополь/Sev- } \\
\text { astopol }\end{array}$ & 1,5 & 49,8 & 23 & 2
\end{tabular}

Важно отметить последнее место Томской области по количеству результатов интеллектуальной деятельности, однако это обусловлено тем, что за 2018 г. ни один из шести ЦКП региона не отчитался информацией о поданных заявках или полученных патентах.

Т а б л и ц а 10. Показатели результативности деятельности УНУ в отдельных регионах Российской Федерации, 2018 г. ${ }^{17}$

$\mathrm{T}$ a $\mathrm{b} 1$ e 10. Indicators of performance of the Large-Scale Research Facilities in certain regions of the Russian Federation in 2018

\begin{tabular}{|c|c|c|c|c|c|}
\hline Регион / Region & $\begin{array}{c}\text { Общий } \\
\text { объем вы- } \\
\text { полненных } \\
\text { HИР, млн } \\
\text { руб. / Total } \\
\text { amount } \\
\text { of R\&D } \\
\text { performed, } \\
\text { million } \\
\text { rubles }\end{array}$ & $\begin{array}{c}\text { Общий } \\
\text { объем } \\
\text { оказанных } \\
\text { услуг, млн } \\
\text { руб./Total } \\
\text { amount of } \\
\text { services } \\
\text { provided, } \\
\text { million } \\
\text { rubles }\end{array}$ & \begin{tabular}{|} 
Количество \\
пользо- \\
вателей, \\
чел. / \\
Number \\
of users, \\
person
\end{tabular} & $\begin{array}{c}\text { Количество } \\
\text { РИД (па- } \\
\text { тентов)/ } \\
\text { Number of } \\
\text { patents }\end{array}$ & $\begin{array}{c}\text { Количе- } \\
\text { ство заявок } \\
\text { на РИД / } \\
\text { Number of } \\
\text { patent ap- } \\
\text { plications }\end{array}$ \\
\hline 1 & 2 & 3 & 4 & 5 & 6 \\
\hline $\begin{array}{l}\text { Московская об- } \\
\text { ласть / Moscow } \\
\text { Region }\end{array}$ & 1314,2 & 638,8 & 277 & 13 & 11 \\
\hline $\begin{array}{l}\text { Новосибирская об- } \\
\text { ласть / Novosibirsk } \\
\text { Region }\end{array}$ & 438,5 & 56,9 & 138 & 5 & 0 \\
\hline $\begin{array}{l}\text { Томская область / } \\
\text { Tomsk Region }\end{array}$ & 146,6 & 44,5 & 34 & 6 & 2 \\
\hline $\begin{array}{l}\text { Приморский край / } \\
\text { Primorye Territory }\end{array}$ & 119,3 & - & 23 & 1 & 0 \\
\hline
\end{tabular}

${ }^{17}$ Таблица составлена на основе данных ежегодного мониторинга Министерства науки и высшего образования России. 
Окончание табл. 10 / End of table 10

\begin{tabular}{c|c|c|c|c|c}
\hline 1 & 2 & 3 & 4 & 5 & 6 \\
\hline $\begin{array}{l}\text { Республика Крым/ } \\
\text { Republic of Crimea }\end{array}$ & 46,7 & - & 1 & 1 & 0 \\
$\begin{array}{l}\text { Республика Caxa } \\
\text { (Якутия)/Republic } \\
\text { of Sakha (Yakutia) }\end{array}$ & 32,5 & 0,0 & 1 & 0 & 0 \\
$\begin{array}{l}\text { Белгородская об- } \\
\text { ласть / Belgorod } \\
\text { Region }\end{array}$ & 24,3 & 10,4 & 27 & 0 & 0 \\
\end{tabular}

По другим показателям в числе аутсайдеров постоянно присутствуют Республика Крым и г. Севастополь. Низкие показатели результативности республики во многом определены спецификой НИ, в которой превалируют научные коллекции. По финансовым показателям деятельности УНУ Московская и Новосибирская области с большим отрывом опережают идущие следом в рейтинге Томскую и Белгородскую области и Приморский край.

Обсуждение и заключение. В статье был приведен сравнительный анализ и оценка регионального потенциала (нормативно-правового, материально-технического, инфраструктурного), который имеется на сегодняшний день на территории России. Таким образом, настоящая статья включила результаты первых этапов исследования, нацеленного на рассмотрение возможностей и путей создания научно-технологической и промышленной связности территорий в России. В дальнейшем планируется провести анализ существующих на территории России, кооперационных, производственных и научно-технологических цепочек, осветить вопрос вовлеченности в них рассматриваемых в настоящей статье территорий. Целесообразно изучить и ряд других вопросов, в числе которых экономический климат внутри регионов, уровень социально-экономического развития, эффективность функционирования существующих в России кооперационных цепочек; направленность и механизмы их деятельности; специфика, функциональность и статус (для внутреннего/мирового рынка) продуктов, выпускаемых вследствие кооперации.

Настоящая статья может быть полезна широкому кругу лиц, интересующихся вопросами пространственного развития и инновационной трансформации территорий, вопросами промышленной и научно-технологической связности и вопросами смежных областей. 


\section{СПИСОК ИСПОЛЬЗОВАННЫХ ИСТОЧНИКОВ}

1. Кузнецова Е. П. Эффективность реализации государственной поддержки развития научно-технологической кооперации // Вестник Владимирского государственного университета имени Александра Григорьевича и Николая Григорьевича Столетовых. Сер.: Экономические науки. 2018. № 3 (17). C. 167-173. URL: http:// vestnik-es.vlsu.ru/fileadmin/No17/Vestnik_No_17.pdf (дата обращения: 25.07.2019).

2. Кузнецова Е. П. Научно-технологическая кооперация в России: современное состояние, проблемы и инструменты государственной поддержки // Вопросы территориального развития. 2019. № 1 (46). С. 1-12. DOI: http://doi. org/10.15838/tdi.2019.1.46.4

3. Hedge D., Hicks D. The Maturation of Global Corporate R\&D: Evidence from the Activity of U.S. Foreign Subsidiaries // Research Policy. 2008. Vol. 37. Pp. 390-406. DOI: https://doi.org/10.1016/j.respol.2007.12.004

4. Jones Ch. I. R\&D-Based Models of Economic Growth // Journal of Political Economy. 1995. Vol. 103, issue 4. Pp. 759-784. URL: https://www.jstor.org/ stable/2138581?seq=1\#metadata_info_tab_contents (дата обращения: 25.07.2019).

5. Резанов К. В. Связанность и стратегический синергизм как основа комплексообразования: качественный анализ кластеризации // Власть и управление на Востоке России. 2015. № 1 (70). C. 60-66. URL: http://vlastdviu.ru/index. php?page $=$ rio4-2015(1-70)\&rc=rio (дата обращения: 25.07.2019).

6. Матюкин С. В., Фокин А. Е. Анализ развития кластеров высокотехнологичных секторов: адаптация зарубежного опыта для модернизации экономики региона // Фундаментальные исследования. 2019. № 1. С. 33-39. DOI: http://doi. org/10.17513/fr.42401

7. Глазман Г. Л. Формы проявления глобализации инновационных процессов // Известия высших учебных заведений. Поволжский регион. Общественные науки. 2013. № 3 (27). С. 180-188. URL: https://izvuz_on.pnzgu.ru/on20313 (дата обращения: 25.07.2019).

8. Миэринь Л. А., Глазман Г. Л. Интеграция России в глобальное инновационное пространство: концептуально-управленческий подход // Теория и практика сервиса: экономика, социальная сфера, технологии. 2015. № 1 (23). C. 10-14. URL: https://unecon.ru/izdaniya/teoriya-i-praktika-servisa/arhiv (дата обращения: 25.07.2019).

9. Житинская Л. О. О перспективах становления конкурентоспособной и инновационной региональной экономики // Вестник Воронежского государственного университета инженерных технологий. 2017. Т. 79, № 1. С. 392-400. DOI: http://doi.org/10.20914/2310-1202-2017-1-392-400

10. Куценко Е. Пилотные инновационные территориальные кластеры России: модель устойчивого развития // Форсайт. 2015. Т. 9, № 1. C. 32-55. DOI: http:// doi.org/10.17323/1995-459X.2015.1.32.55

11. Asheim B., Gertler M. The Geography of Innovation // The Oxford Handbook of Innovation / J. Fagerberg, D. C. Mowery, R. R. Nelson (eds). 2005. Pp. 291-317. DOI: http://doi.org/10.1093/oxfordhb/9780199286805.003.0011 
12. Оценка интенсивности социально-экономических взаимодействий на территории агломерации в аспекте связанности социально-экономического пространства / И. В. Волчкова [и др.] // Вопросы управления. 2016. № 4 (41). C. 182-195. URL: http://vestnik.uapa.ru/ru/issue/2016/04/25/ (дата обращения: 25.10.2019).

13. Положенцева Ю. С. Количественная оценка уровня развития межрегиональной связанности экономического пространства // Инновационная экономика: перспективы развития и совершенствования. 2018. № 3 (29). С. 116-128. URL: https://elibrary.ru/item.asp?id=35039976 (дата обращения: 25.10.2019).

14. Юсупов Р. М., Соколов Б. В. Стратегии научно-технологического развития Российской Федерации на долгосрочный период // Инновации. 2016. № 7 (213). C. 30-32. URL: https://maginnov.ru/ru/zhurnal/arhiv/2016/innovacii-n7-2016/ strategii-nauchno-tehnologicheskogo-razvitiya-rossijskoj-federacii-na-dolgosrochnyjperiod (дата обращения: 25.07.2019).

15. Starodubov V. I., Kurakova N. G. Identifying the Subject in the Strategy for Scientific and Technological Development of the Russian Federation // Herald of the Russian Academy of Sciences. 2016. Vol. 86, issue 6. Pp. 441-447. DOI: http://doi. org/10.1134/S1019331616060150

16. Kurakova N. G., Zinov V. G., Tsvetkova L. A. The System of Measurable Indicators for Scientific and Technological Development of the Russian Federation: Methodology and Design // Scientific and Technical Information Processing. 2017. Vol. 44, issue 3. Pp. 184-195. DOI: http://doi.org/10.3103/S0147688217030054

17. What Impedes Universities from Creating Dual-Purpose Technologies? / M. Kuzyk [et al.] // Форсайт. 2017. Т. 11, № 4. C. 84-95. DOI: http://doi. org/10.17323/2500-2597.2017.4.84.95

18. Дементьев В. В., Слободяник С. Н. Государственные программы как инструмент реализации Стратегии научно-технологического развития Российской Федерации // Научные труды: Институт народнохозяйственного прогнозирования PAH. 2017. № 15. C. 316-335. URL: https://cyberleninka.ru/article/n/gosudarstvennyeprogrammy-kak-instrument-realizatsii-strategii-nauchno-tehnologicheskogo-razvitiyarossiyskoy-federatsii (дата обращения: 25.07.2019).

19. Pogosyan M. A., Strelets D. Y., Vladimirova V. G. Territorial Connectivity of the Russian Federation: From the Statement of Complex Problems to Drawing up Integrated Scientific and Technical Projects // Herald of the Russian Academy of Sciences. 2019. Vol. 89, issue 2. Pp. 179-184. DOI: http://doi.org/10.1134/ S1019331619020175

20. Integral Express Analysis of Institutional and Legal Readiness of the Russian Federation' Subjects to Implement the Priorities of Scientific and Technological Development / A. Maltseva [et al.] // Amazonia Investiga. 2019. Vol. 8, no. 19. Pp. 72-82. URL: https://amazoniainvestiga.info/index.php/amazonia/article/view/201 (дата обращения: 25.07.2019).

21. Суховей А. Ф., Голова И. М. Обоснование трансформации приоритетов инновационно-технологического развития регионов РФ в условиях глобального кризиса // Экономика региона. 2016. Т. 12, вып. 3. С. 911-923. DOI: http://doi. org/10.17059/2016-3-25 
22. Azagra-Caro J. M., Consoli D. Knowledge Flows, the Influence of National R\&D Structure and the Moderating Role of Public-Private Cooperation // Journal of Technology Transfer. 2016. Vol. 41, issue 1. Pp. 152-172. DOI: http://doi. org/10.1007/s10961-014-9382-7

23. Гершман М. А., Кузнецова Т. Е. Особенности участия малых предприятий в международной научно-технической кооперации: опыт российско-германских контактов // Форсайт. 2012. Т. 6, № 3. C. 51-61. URL: https://foresight-journal. hse.ru/2012-6-3/62922199.html (дата обращения: 25.07.2019).

24. Позиционирование международного научно-технического сотрудничества в правовых документах стран - участников научной глобализации / А. А. Балякин [и др.] // Вестник Российского университета дружбы народов. Сер.: Социология. 2018. Т. 18, №. 4. C. 651-667. DOI: http://doi.org/10.22363/23132272-2018-18-4-651-667

25. Adapting the CIS Cooperation Formats to the Modern Context Based on Scientific and Technological Policy Coordination / S. M. Gonnova [et al.] // Scientific and Technical Information Processing. 2017. Vol. 44, issue 3. Pp. 236-246. DOI: http://doi.org/10.3103/S0147688217040025

26. Сидорова Е. А. Инновационное развитие стран БРИКС, предпосылки и перспективы сотрудничества // Вестник международных организаций: образование, наука, новая экономика. 2018. № 1. C. 34-50. DOI: http://doi.org/10.17323/19967845-2018-01-02

27. Powell W.W., Snellman K. The Knowledge Economy // Annual Review of Sociology. 2004. Vol. 30, issue 1. Pp. 199-220. DOI: http://doi.org/10.1146/annurev. soc.29.010202.100037

28. Identifying Directions for Russia's Science and Technology Cooperation / M. Kotsemir [et al.] // Foresight and STI Governance. 2015. Vol. 9, issue 4. Pp. 54-72. DOI: http://doi.org/10.17323/1995-459x.2015.4.54.72

29. Mechanisms for Supporting Scientific and Technological Cooperation Between the BRICS States: Multilateral Calls and Networking Platform for Knowledge and Technology Transfer / M. V. Balashova [et al.] // Research Journal of Pharmaceutical Biological and Chemical Sciences. 2016. Vol. 7, no. 5. Pp. 2777-2786. URL: https:// www.rjpbcs.com/2016_7.5.html (дата обращения: 25.07.2019).

30. Иванов С. А., Сокол-Номоконов Э. Н. Феномен опорных университетов региональной экономики в современной России // Высшее образование в России. 2018. T. 27, № 1. C. 19-30. URL: http://vovr.ru/upload/1-18.pdf (дата обращения: 25.07.2019).

31. Гафуров И. Р., Сафиуллин М. Р., Ельшин Л. А. Механизмы и направления развития высшей школы в системе инновационно-технологического развития национальной экономики // Alma Mater (Вестник высшей школы). 2017. № 11. C. 5-10. DOI: http://doi.org/10.20339/AM.11-17.005

32. National Systems of Production, Innovation and Competence Building / B. A. Lundvall [et al.] // Research Policy. 2002. Vol. 31, issue 2. Pp. 213-231. DOI: https://doi.org/10.1016/S0048-7333(01)00137-8

33. Saviotti P. P. Innovation Systems and Evolutionary Theories // Systems of Innovation - Technologies, Institutions and Organizations. London, Pinter Publishers/ 
Cassell Academic, 1997. Pp. 180-199. URL: https://charlesedquist.com/books/ systems-of-innovation-technologies-institutions-and-organizations/ (дата обращения: 25.07.2019).

34. Almeida A., Figueiredo A., Rui Silva M. From Concept to Policy: Building Regional Innovation Systems in Follower Regions // European Planning Studies. 2011. Vol. 19, issue 7. Pp. 1331-1356 DOI: https://doi.org/10.1080/09654313.2011.573140

35. Cooke P. Regional Innovation Systems, Clusters, and the Knowledge Economy // Industrial and Corporate Change. 2001. Vol. 10, issue 4. Pp. 945-974. DOI: https:// doi.org/10.1093/icc/10.4.945

36. Edquist Ch. Systems of Innovation: Perspectives and Challenges // The Oxford Handbook of Innovation / J. Fagerberg, Mowery D., Nelson R., eds. London: Oxford University Press, 2005. Pp. 181-208. DOI: https://doi.org/10.1093/oxford$\mathrm{hb} / 9780199286805.003 .0007$

37. Nuur C., Gustavsson L., Laestadius S. Promoting Regional Innovation Systems in a Global Context // Industry and Innovation. 2009. Vol. 16, issue 1. Pp. 123-139. DOI: https://doi.org/10.1080/13662710902728142

38. Kratke S., Brandt A. Knowledge Networks as a Regional Development Resource: A Network Analysis of the Interlinks between Scientific Institutions and Regional Firms in the Metropolitan Region of Hannover, Germany // European Planning Studies. 2009. Vol. 17, issue 1. Pp. 43-63. DOI: https://doi.org/10.1080/09654310802513930

39. Spatial Development Strategy of Russia: Expectations and Realities / V. E. Seliverstov [et al.] // Regional Research of Russia. 2019. Vol. 9, issue 2. Pp. 155-163. DOI: http://doi.org/10.1134/S2079970519020114

40. Калюжный К. А. Итоги мониторинга деятельности центров коллективного пользования научным оборудованием и уникальных научных установок за 2017 год // Наука. Инновации. Образование. 2018. № 4 (30). С. 40-78. URL: http://sie-journal.ru/itogi-monitoringa-deyatelnosti-rossijskih-czentrovkollektivnogo-polzovaniya-nauchnyim-oborudovaniem-i-unikalnyih-nauchnyihustanovok-za-2017-god (дата обращения: 25.07.2019).

Поступила 08.08.2019; принята к публикации 20.09.2019; опубликована онлайн 30.12.2019.

\section{Об авторах:}

Смирнова Анастасия Вадимовна, лаборант-исследователь Центра международного научно-технического сотрудничества ФГБУ «Российский научно-исследовательский институт экономики, политики и права в научно-технической сфере» (127254, Россия, г. Москва, ул. Добролюбова, д. 20A), ORCID: https:// orcid.org/0000-0003-1668-1149, a.smirnova@riep.ru

Дашкова Мария Олеговна, младший научный сотрудник Центра правовых исследований ФГБУ «Российский научно-исследовательский институт экономики, политики и права в научно-технической сфере» (127254, Россия, г. Москва, ул. Добролюбова, д. 20A), ORCID: https://orcid.org/0000-0002-1469-0343, m.dashkova@riep.ru 
Заявленный вклад авторов:

Смирнова Анастасия Вадимовна - обзор литературы; проведение анализа состояния научной инфраструктуры в отдельных регионах Российской Федерации.

Дашкова Мария Олеговна - проведение анализа региональной нормативной правовой базы развития научной и технической деятельности в отдельных регионах Российской Федерации.

Для ичтирования:

Смирнова А. В., Дашкова М. О. Анализ правовой и инфраструктурной основы научно-технологической сферы в регионах России: потенциал и перспективы формирования связности территорий страны // Регионология. 2019. Т. 27, № 4. C. 678-710. DOI: https://doi.org/10.15507/2413-1407.109.027.201904.678-710

Все авторы прочитали и одобрили окончательный вариант рукописи.

\section{REFERENCES}

1. Kuznetsova E.P. Efficiency of Implementation of State Support of Development of Scientific and Technological Cooperation. Vestnik Vladimirskogo gosudarstvennogo universiteta imeni Aleksandra Grigoryevicha i Nikolaya Grigoryevicha Stoletovykh (Seriya: Ehkonomicheskiye nauki) = Bulletin of the Vladimir State University named after Alexander G. and Nicholas G. Stoletovs. Series: Economics. 2018; (3):167-173. Available at: http://vestnik-es.vlsu.ru/fileadmin/No17/Vestnik_No_17.pdf (accessed 25.07.2019). (In Russ., abstract in Eng.)

2. Kuznetsova E.P. Scientific and Technological Cooperation in Russia: Current State, Problems and Instruments of Government Support. Voprosy territorialnogo razvitiya $=$ Territorial Development Issues. 2019; (1):1-12. (In Russ., abstract in Eng.) DOI: http://doi.org/10.15838/tdi.2019.1.46.4

3. Hedge D., Hicks D. The Maturation of Global Corporate R\&D: Evidence from the Activity of U.S. Foreign Subsidiaries. Research Policy. 2008; 37:390-406. (In Eng.) DOI: https://doi.org/10.1016/j.respol.2007.12.004

4. Jones Ch.I. R\&D-Based Models of Economic Growth. Journal of Political Economy. 1995. 103(4):759-784. Available at: https://www.jstor.org/ stable/2138581?seq=1\#metadata_info_tab_contents (accessed 25.07.2019). (In Eng.)

5. Rezanov K.V. Coherence and Strategic Sinergizm as the Basis of Complex Formations: Qualitative Analysis of Clustering. Vlast i upravleniye na Vostoke Rossii = Power and Administration in the East of Russia. 2015; (1):60-66. Available at: http://vlastdviu.ru/index.php?page $=$ rio4-2015(1-70)\& $\mathrm{rc}=$ rio (accessed 25.07.2019). (In Russ., abstract in Eng.)

6. Matyukin S.V. Fokin A.E. Analysis of Cluster Development in High-Tech Sectors: Adaptation of International Experience for Modernization of the Regional Economy. Fundamentalnye issledovaniya = Fundamental Research. 2019; (1):33-39. (In Russ., abstract in Eng.) DOI: http://doi.org/10.17513/fr.42401 
7. Glazman G.L. The Forms of Globalization of Innovative Processes. Izvestiya vysshikh uchebnykh zavedeniy. Povolzhskiy region. Obschestvennyye nauki = University Proceedings. Volga Region. Social Sciences. 2013; (3):180-188. Available at: https://izvuz_on.pnzgu.ru/on20313 (accessed 25.07.2019). (In Russ., abstract in Eng.)

8. Mierin L.A., Glazman G.L. Russia's Integration into Global Innovation Space: Conceptual and Managerial Approach. Teoriya i praktika servisa: ehkonomika, sotsialnaya sfera, tekhnologii = Theory and Practice of Service: Economics, Social Sphere, Technology. 2015; (1):10-14. Available at: https://unecon.ru/izdaniya/teoriyai-praktika-servisa/arhiv (accessed 25.07.2019). (In Russ., abstract in Eng.)

9. Zhitinskaya L.O. On the Prospects of Formation of Competitive and Innovative Regional Economy. Vestnik Voronezhskogo gosudarstvennogo universita inzhenernykh tekhnologiy $=$ Proceedings of the Voronezh State University of Engineering Technologies. 2017; 79(1):392-400. (In Russ., abstract in Eng.) DOI: http://doi. org/10.20914/2310-1202-2017-1-392-400

10. Kutsenko E. Pilot Innovative Territorial Clusters in Russia: A Sustainable Development Model. Forsajt $=$ Foresight. 2015; 9(1):32-55. (In Russ., abstract in Eng.) DOI: http://doi.org/10.17323/1995-459X.2015.1.32.55

11. Asheim B., Gertler M. The Geography of Innovation. In: Fagerberg J., Mowery D.C., Nelson R.R., eds. The Oxford Handbook of Innovation. 2005. p. 291-317. (In Eng.) DOI: http://doi.org/ 10.1093/oxfordhb/9780199286805.003.0011

12. Volchkova I.V., Danilova M.N., Podoprigora Yu.V., Seliverstov A.A., Ufimtseva T.V., Shadeiko N.R. Assessing Economic and Social Interaction Intensity within Agglomeration Territory in the Aspect of Socio-Economic Space Coherence. Voprosy upravleniya = Management Issues. 2016; (4):182-195. Available at: http:// vestnik.uapa.ru/ru/issue/2016/04/25/ (accessed 25.07.2019). (In Russ., abstract in Eng.)

13. Polozhentseva Yu.S. [Quantitative Assessment of the Development Level of Interregional Connectedness of the Economic Space]. Innovatsionnaya ehkonomika: perspektivy razvitiya $i$ sovershenstvovaniya = Innovative Economy: Prospects for Development and Improvement. 2018; (3):116-128. Available at: https://elibrary.ru/ item.asp?id=35039976 (accessed 25.10.2019). (In Russ.)

14. Yusupov R.M., Sokolov B.V. Strategy for Scientific and Technological Development of the Russian Federation for the Long Term. Innovatsii = Innovations. 2016; (7):30-32. Available at: https://maginnov.ru/ru/zhurnal/arhiv/2016/innovacii-n7-2016/ strategii-nauchno-tehnologicheskogo-razvitiya-rossijskoj-federacii-na-dolgosrochnyjperiod (accessed 25.07.2019). (In Russ., abstract in Eng.)

15. Starodubov V.I., Kurakova N.G. Identifying the Subject in the Strategy for Scientific and Technological Development of the Russian Federation. Herald of the Russian Academy of Sciences. 2016; 86(6):441-447. (In Eng.) DOI: http://doi. org/10.1134/S1019331616060150

16. Kurakova N.G., Zinov V.G., Tsvetkova L.A. The System of Measurable Indicators for Scientific and Technological Development of the Russian Federation: Methodology and Design. Scientific and Technical Information Processing. 2017; 44(3):184-195. (In Eng.) DOI: http://doi.org/10.3103/S0147688217030054

17. Kuzyk M., Grebenyuk A., Kakaeva E., Manchenko E., Dovgiy V. What Impedes Universities from Creating Dual-Purpose Technologies? Forsajt $=$ Foresight 
and STI Governance. 2017; 11(4):84-95. (In Eng.) DOI: http://doi.org/10.17323/25002597.2017.4.84.95

18. Dementiev V.V., Slobodyanik S.N. Government Programs as a Tool for the Implementation of the Strategy of Scientific and Technological Development of the Russian Federation. Nauchnyye trudy: Institut narodokhozyaystvennogo prognozirovaniya $R A N=$ Scientific Articles-Institute of Economic Forecasting Russian Academy of Sciences. 2017; (15):316-335. Available at: https://cyberleninka.ru/ article/n/gosudarstvennye-programmy-kak-instrument-realizatsii-strategii-nauchnotehnologicheskogo-razvitiya-rossiyskoy-federatsii (accessed 25.07.2019). (In Russ., abstract in Eng.)

19. Pogosyan M.A., Strelets D.Y., Vladimirova V.G. Territorial Connectivity of the Russian Federation: From the Statement of Complex Problems to Drawing up Integrated Scientific and Technical Projects. Herald of the Russian Academy of Sciences. 2019; 89(2):179-184. (In Eng.) DOI: http://doi.org/10.1134/S1019331619020175

20. Maltseva A., Klyushnikova E., Barsukova N., Gridchina A., Guseva M. Integral Express Analysis of Institutional and Legal Readiness of the Russian Federation' Subjects to Implement the Priorities of Scientific and Technological Development. Amazonia Investiga. 2019; 8(19):72-82. Available at: https://amazoniainvestiga.info/ index.php/amazonia/article/view/201 (accessed 25.07.2019). (In Eng.)

21. Sukhovey A.F., Golova I.M. Substantiation of the Transformation of the Priorities of Innovation and Technological Development of Russian Regions in the Global Crisis. Ehkonomika regiona = Economy of Region. 2016; 12(3):911-923. (In Russ., abstract in Eng.) DOI: http://doi.org/10.17059/2016-3-25

22. Azagra-Caro J.M., Consoli D. Knowledge Flows, the Influence of National R\&D Structure and the Moderating Role of Public-Private Cooperation. Journal of Technology Transfer. 2016; 41(1):152-172. (In Eng.) DOI: http://doi.org/10.1007/ s10961-014-9382-7

23. Gershman M., Kuznetsova T. Specificities of Involving Small Enterprises into International S\&T Cooperation: Evidence from the Linkages between Russia and Germany. Forsajt = Foresight-Russia. 2012; 6(3):51-61. Available at: https:// foresight-journal.hse.ru/2012-6-3/62922199.html (accessed 25.07.2019). (In Russ., abstract in Eng.)

24. Balyakin A.A., Zadorina A.K., Kuklina I.R., Malyshev A.S., Taranenko S.B. Positioning of International Scientific-Technical Cooperation in the Legal Documents of the Countries Participating in Scientific Globalization. Vestnik Rossijskogo universiteta druzhby narodov. Seriya: Sotsiologiya = RUDN Journal of Sociology. 2018; 18(4):651-667. (In Russ., abstract in Eng.) DOI: http://doi.org/10.22363/23132272-2018-18-4-651-667

25. Gonnova S.M., Sheremet Yu.E., Razuvaeva E.Yu., Rebkovets M.Yu. Adapting the CIS Cooperation Formats to the Modern Context Based on Scientific and Technological Policy Coordination. Scientific and Technical Information Processing. 2017; 44(3):236-246. (In Eng.) DOI: http://doi.org/10.3103/S0147688217040025

26. Sidorova E.A. The Innovation Development of the BRICS Countries: Preconditions and Prospects for Cooperation. Vestnik mezhdunarodnykh organizatsiy: obrazovaniye, nauka, novaya ehkonomika = International Organisations Research 
Journal. 2018; (1):34-50. (In Russ., abstract in Eng.) DOI: http://doi.org/10.17323/19967845-2018-01-02

27. Powell W.W., Snellman K. The Knowledge Economy. Annual Review of Sociology. 2004; 30(1):199-220. (In Eng.) DOI: http://doi.org/10.1146/annurev. soc.29.010202.100037

28. Kotsemir M., Kuznetsova T., Nasybulina E., Pikalova A. Identifying Directions for Russia's Science and Technology Cooperation. Foresight and STI Governance. 2015; 9(4):54-72. (In Eng.) DOI: http://doi.org/10.17323/1995-459x.2015.4.54.72

29. Balashova M.V., Bukhaeva E.E., Kuklina E.R., Luksha O.P., Yanovsky A.E. Mechanisms for Supporting Scientific and Technological Cooperation between the BRICS States: Multilateral Calls and Networking Platform for Knowledge and Technology Transfer. Research Journal of Pharmaceutical Biological and Chemical Sciences. 2016; 7(5):2777-2786. Available at: https://www.rjpbcs.com/2016_7.5.html (accessed 25.07.2019). (In Eng.)

30. Ivanov S.A., Sokol-Nomokonov E.N. The Phenomenon of Flagship Universities of Regional Economy in Modern Russia. Vysshee obrazovanie $v$ Rossii $=$ Higher Education in Russia. 2018; 27(1):19-30. Available at: http://vovr.ru/upload/1-18.pdf (accessed 25.07.2019). (In Russ., abstract in Eng.)

31. Gafurov I.R., Safiullin M.R., Elshin L.A. Mechanisms and Directions of Development of Higher School in the System of Innovative Technological Development of National Economy. Alma Mater (Vestnik Vysshey Shkoly) = Alma Mater (Higher School Herald). 2017; (11):5-10. (In Russ., abstract in Eng.) DOI: http:// doi.org/10.20339/AM.11-17.005

32. Lundvall B.A., Johnson B., Andersen E.S., Dalum B. National Systems of Production, Innovation and Competence Building. Research Policy. 2002; 3(2):213-231. (In Eng.) DOI: https://doi.org/10.1016/S0048-7333(01)00137-8

33. Saviotti P.P. Innovation Systems and Evolutionary Theories. In: Systems of Innovation - Technologies, Institutions and Organizations. London, Pinter Publishers/ Cassell Academic; 1997. p. 180-199. URL: https://charlesedquist.com/books/systemsof-innovation-technologies-institutions-and-organizations/ (accessed 25.07.2019). (In Eng.)

34. Almeida A., Figueiredo A., Rui Silva M. From Concept to Policy: Building Regional Innovation Systems in Follower Regions. European Planning Studies. 2011; 19(7):1331-1356. (In Eng.) DOI: https://doi.org/10.1080/09654313.2011.573140

35. Cooke P. Regional Innovation Systems, Clusters, and the Knowledge Economy. Industrial and Corporate Change. 2001; 10(4):945-974. (In Eng.) DOI: https://doi. org/10.1093/icc/10.4.945

36. Edquist Ch. Systems of Innovation: Perspectives and Challenges. In: Fagerberg J., Mowery D., Nelson R., eds. The Oxford Handbook of Innovation. London: Oxford University Press; 2005. p. 181-208. (In Eng.) DOI: https://doi.org/10.1093/ oxfordhb/9780199286805.003.0007

37. Nuur C., Gustavsson L., Laestadius S. Promoting Regional Innovation Systems in a Global Context. Industry and Innovation. 2009; 16(1):123-139. (In Eng.) DOI: https://doi.org/10.1080/13662710902728142 
38. Kratke S., Brandt A. Knowledge Networks as a Regional Development Resource: A Network Analysis of the Interlinks between Scientific Institutions and Regional Firms in the Metropolitan Region of Hannover, Germany. European Planning Studies. 2009; 17(1):43-63. (In Eng.) DOI: https://doi.org/10.1080/09654310802513930

39. Seliverstov V.E., Melnikova L.V., Kolomak E.A., Kryukov V.A., Suslov V.I., Suslov N.I. Spatial Development Strategy of Russia: Expectations and Realities. Regional Research of Russia. 2019; 9(2):155-163. (In Eng.) DOI: http://doi.org/10.1134/ S2079970519020114

40. Kalyuzhniy K.A. The Results of the Monitoring of Russian Core Shared Research Facilities and Unique Scientific Installations for 2017. Nauka. Innovatsii. Obrazovanie $=$ Science. Innovation. Education. 2018; (4):40-78. Available at: http:// sie-journal.ru/itogi-monitoringa-deyatelnosti-rossijskih-czentrov-kollektivnogo-polzovaniya-nauchnyim-oborudovaniem-i-unikalnyih-nauchnyih-ustanovok-za-2017-god (accessed 25.07.2019). (In Russ., abstract in Eng.)

Submitted 08.08.2019; accepted for publication 20.09.2019; published online 30.12.2019.

About the authors:

Anastasia V. Smirnova, Laboratory Researcher, Center for International Scientific and Technological Cooperation, Russian Research Institute of Economics, Politics and Law in Science and Technology (20A, Dobrolubova St., Moscow 127254, Russia), ORCID: https://orcid.org/0000-0003-1668-1149, a.smirnova@riep.ru

Maria O. Dashkova, Junior Researcher, Center for Legal Studies, Russian Research Institute of Economics, Politics and Law in Science and Technology (20A, Dobrolubova St., Moscow 127254, Russia), ORCID: https://orcid.org/0000-00021469-0343,m.dashkova@riep.ru

Contribution of the authors:

Anastasia V. Smirnova - literature review; analysis of the state of scientific infrastructure in certain regions of the Russian Federation.

Maria O. Dashkova - analysis of the regional regulatory framework for the development of scientific and technological activities in certain regions of the Russian Federation.

For citation:

Smirnova A.V., Dashkova M.O. Analysis of the Legal and Infrastructural Basis for the Scientific and Technological Sphere in the Regions of Russia: Potential and Prospects for the Formation of Connectedness of the Country's Territories. Regiono$\log y=$ Russian Journal of Regional Studies. 2019; 27(4):678-710. DOI: https://doi. org/10.15507/2413-1407.109.027.201904.678-710

The authors have read and approved the final version of the manuscript. 
ПОЛИТИЧЕСКАЯ РЕГИОНАЛИСТИКА. ЭТНОПОЛИТИКА / POLITICAL REGIONAL STUDIES. ETHNOPOLITICS

УдК 323.174(4)

DOI: $10.15507 / 2413-1407.109 .027 .201904 .711-733$ http://regionsar.ru

ISSN 2587-8549 (Print)

ISSN 2413-1407 (Online)

\title{
Проблемы и перспективы приграничного сотрудничества еврорегионов с участием России
}

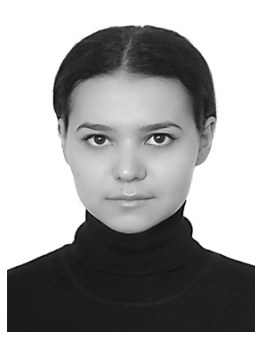

\author{
Л. Р. Рустамова \\ ФГАОУ ВО «Московский государственный институт \\ международных отношений (университет) \\ Министерства иностранных дел Российской Федерации» \\ (2. Москва, Россия), \\ leili-rustamova@yandex.ru
}

Введение. Еврорегионы с участием субъектов Российской Федерации стали активно создаваться с 1998 г. и до сих пор остаются востребованной формой развития приграничного сотрудничества с соседними странами. Кооперация в формате еврорегионов призвана решать социально-экономические проблемы приграничных регионов, однако каждый отдельный проект еврорегиона имеет свою специфику. Цель данной статьи состоит в анализе текущего состояния сотрудничества в формате еврорегионов европейского и постсоветского типов, а также возможностей экстраполирования опыта еврорегионов с членством России.

Материалы и методы. В качестве материалов были использованы уже имеющиеся исследования по теме еврорегионов, а также материалы официальных сайтов Министерства иностранных дел России и еврорегионов. Методологическую базу составили сравнительный анализ и SWOT-анализ, которые позволили выделить сильные и слабые стороны моделей еврорегионов европейского типа и постсоветского типа.

Результаты исследования. Автором были проанализированы все основные результаты деятельности еврорегионов европейского и постсоветского типов. Сделаны выводы относительно слабых и сильных сторон каждого вида еврорегионов. Возможности экстраполирования европейского опыта строительства еврорегионов на евразийском пространстве рассмотрены на примере двух проектов еврорегионов «Наш общий дом - Алтай» и «Приднестровье». В работе были сделаны выводы относительно интересов местных властей и политической элиты федерального центра в развитии программ приграничного сотрудничества, что является важным фактором успешности функционирования еврорегионов с участием субъектов Российской Федерации.

Обсуждение и заключение. Анализ текущего состояния еврорегионов с участием России позволяет сделать вывод об эффективности самого формата еврорегиона как формы приграничного сотрудничества. На основе анализа сильных

(C) Рустамова Л. Р., 2019

Контент доступен под лицензией Creative Commons Attribution 4.0 License.

This work is licensed under a Creative Commons Attribution 4.0 License. 
и слабых сторон еврорегионов даются рекомендации по организации приграничного сотрудничества в формате еврорегионов в наиболее выгодном для России направлении - евразийском пространстве, которые могут иметь практическую значимость для укрепления двусторонних международных отношений.

Ключевые слова: внутриполитический регион, внешние связи регионов, трансграничные связи, еврорегион, международные организации, евразийский регион, идентичность

Финансирование. Статья подготовлена в рамках гранта МГИМО МИД России на выполнение научных работ молодыми исследователями КМУ-IX.

\title{
Problems and Prospects of Cross-Border Cooperation in Euroregions with Russian Participation
}

\author{
L. R. Rustamova \\ Moscow State Institute of International Relations (University) of the Ministry \\ of Foreign Affairs of the Russian Federation (Moscow, Russia), \\ leili-rustamova@yandex.ru
}

Introduction. Euroregions with the participation of constituent entities of the Russian Federation have been actively created since 1998 and still remain a popular form of developing cross-border cooperation with neighboring countries. Cooperation in the format of Euroregions has been aimed at solving the socio-economic problems of the border regions. However, each individual project of a Euroregion has its specific features. The purpose of this paper is to analyze the current state of cooperation in the format of Euroregions of the European and post-Soviet types, as well as the possibilities of extrapolating the experience of Euroregions with Russian participation. Materials and Methods. The available studies on Euroregions, as well as materials from the official website of the Ministry of Foreign Affairs of the Russian Federation and those of the Euroregions, were used as materials for this research. The comparative analysis as well as SWOT analysis made it possible to highlight the strengths and weaknesses of the European-type and post-Soviet-type models of Euroregions and formed the methodological basis of the study.

Results. The author has analyzed all the main results of the activities of the Euroregions of the European and post-Soviet types. Conclusions regarding the strengths and weaknesses of each type of the Euroregions have been made. In order to consider the possibility of extrapolating the European experience in establishing Euroregions in the Eurasian space, the cases of two projects of Euroregions, 'Our Common Home - Altai' and 'Transnistria', have been studied. The conclusions were drawn regarding the interests of both the local authorities and the political elite of the federal center in the development of cross-border cooperation programs, which is an important factor in the successful functioning of the Euroregions with the participation of constituent entities of the Russian Federation.

Discussion and Conclusion. Analysis of the current state of the Euroregions with Russian participation made it possible to conclude that the format of the Euroregion itself is an effective form of cross-border cooperation. Based on the analysis of the strengths and weaknesses of the Euroregions, recommendations have been produced on organizing cross-border cooperation in the format of Euroregions in the Eurasian 
space, the most advantageous area for Russia; this can be of practical importance for strengthening bilateral international relations.

Keywords: domestic political region, external relations of regions, cross-border relations, Euroregion, international organizations, Eurasian region, identity

Funding. This article was prepared under the grant KMU-IX from MGIMO University for implementation of scientific work by young researchers.

Введение. Еврорегионами называются объединения двух и более приграничных регионов соседствующих европейских стран с целью углубления межгосударственного сотрудничества европейских государств и процессов европейской интеграции. Наличие сухопутных и морских границ со странами Европейского союза позволило распространить эту модель межгосударственного сотрудничества и на Россию, которая впервые подключилась к процессу создания еврорегионов в 1998 г., когда в состав еврорегиона «Балтика» вошла Калининградская область. Позднее область вошла в состав еще 4 еврорегионов, что сделало ее наиболее включенным в процессы интеграции и сотрудничества с Европой регионом России.

Процесс включения российских регионов можно разделить на два периода: этап активного включения в европейские форматы еврорегионов и этап создания еврорегионов на постсоветском пространстве. На данный момент субъекты Российской Федерации входят в 6 еврорегионов европейского формата: «Неман», «Псков - Ливония», «Карелия», «Балтика», «Сауле», «Лына - Лава», «Шешупе», и 4 еврорегиона, объединяющих страны постсоветского пространства: «Слобожанщина», «Донбас», «Днепр», «Ярославна». Участие российских регионов в каждом формате имеет важное политическое и экономическое значение. Возможность выхода на международную арену для российских регионов означало и включенность в общемировой тренд по усилению роли внутригосударственных регионов в мировой политике.

Цель данной статьи состоит в анализе текущего состояния сотрудничества в формате еврорегионов европейского и постсоветского типов, а также возможностей экстраполирования опыта участия в еврорегионах на евразийском пространстве.

Обзор литературы. Проблематика сотрудничества в рамках еврорегионов - довольно популярное исследовательское поле в зарубежной политологической науке. Зарубежные исследователи особое внимание уделяют институционализации приграничного сотрудничества в формате еврорегионов [1], негосударственным участникам международных отношений в проектах приграничного сотрудничества [2], значению еврорегионов для продвижения процессов европейской интеграции [3], 
критериям эффективности еврорегионов как форм приграничного сотрудничества [4] и интересам регионов в развитии приграничного сотрудничества [5]. Часть работ посвящена конкретным кейсам функционирования еврорегионов. К ним относится, например, исследование Й. Фратчек-Мюллер, А. Милзрек-Зеймо по еврорегиону «Шпрее-Нейсе Бобер» [6], работа Дж. Скотта по еврорегиону с российским участием «Карелия» [7], исследование Б. Мирсея по проблемам приграничного сотрудничества на румыно-украинской границе [8] и К. Сабау по еврорегиону «Бихор - Хайду-Бихар» [9].

В целом подход зарубежных авторов можно назвать институциональным, поскольку еврорегионы и приграничное сотрудничество рассматриваются как дополнительные положительные механизмы по устранению барьеров, ограничивающих движение людей, товаров и услуг, по замене принципа суверенитета институциональными структурами, действующими на основе общеевропейских интересов. В то же время есть ряд скептических работ, в частности таких авторов, как Э. Дековиль и Ф. Дурнд, которые рассматривали влияние приграничного сотрудничества на изменение категории доверия в отношениях близлежащих государств [10].

Первоначально сотрудничество в формате еврорегионов с большим энтузиазмом воспринималось как в политических, так и в экспертных кругах России, поскольку предполагалось, что оно позволит не только сблизиться с европейскими странами в политическом плане, но и решить вполне конкретные проблемы российских приграничных регионов: ликвидацию экономического отставания от материковой части, улучшение инфраструктуры, повышение качества жизни населения. О важности сотрудничества в формате еврорегионов для привлечений инвестиций из Европейского союза и экономического сотрудничества писали А. В. Кузнецов [11], Г. М. Федоров и В. С. Корнеевец ${ }^{1}$, на необходимость учета европейского опыта межгосударственного сотрудничества в формате еврорегионов для решения экологических и иных проблем Калининградской области указывала А. Е. Василенко ${ }^{2}$.

С этапом создания еврорегионов на постсоветском пространстве с участием Украины и Белоруссии стали появляться публикации, посвященные изучению «российской модели трансрегионализма». Одним из первых эту модель выделил Н. А. Синяускас [12].

${ }^{1}$ Федоров Г. М., Корнеевец В. С. Регионализация и формирование трансграничных регионов // Социально-экономическая география - 2011: теория и практика: материалы междунар. науч. конф. / Ассоциация российских географов-обществоведов; Балт. федерал. ун-т им. И. Канта. 2011. С. 285-292.

2 Василенко А. Е. Еврорегионы с участием Калининградской области как пилотная модель использования европейского опыта трансграничного сотрудничества в России // Дневник Алтайской школы политических исследований. 2004. № 19-20. С. 92-95. 
Изучением функционирования еврорегионов постсоветского пространства без выделения некой «российской модели» занимались Л. Н. Кулябина, А. Ш. Ногмова [13], А. В. Бредихин [14], А. М. Анисимов, Л. Б. Вардомский, В. А. Колосов, А. А. Герцен, А. А. Гриценко, М. В. Зотова, А. Б. Себенцов [15], Т. Журженко [16]. В отличие от западных исследователей российские ученые придерживаются самых разных подходов и теорий: от реализма до функционализма, и ранжировать российских исследователей по определенным подходам довольно сложно, более целесообразно классифицировать их с точки зрения оценки эффективности функционирования еврорегионов.

По прошествии 20 лет с момента вхождения российских регионов в еврорегионы европейского и постсоветского типа исследователями был накоплен эмпирический материал, который позволил сделать выводы о продуктивности такой формы приграничного сотрудничества и целесообразности дальнейшего участия субъектов Российской Федерации в еврорегионах. Е. А. Шлапенко выделяла такие проблемы сотрудничества, как дисбаланс в вопросах занятости, производства и торговли, визовый режим, а также проблемы социокультурного характера, которые помешали российским приграничным регионам углубить интеграцию с европейскими странами [17]. И. М. Бусыгина в качестве сдерживающих факторов развития трансграничных связей субъектов Российской Федерации обозначила усиление политической и экономической централизации, а также факт того, что соседями российских регионов являются (за исключением Северо-Запада) такие же периферийные и слаборазвитые регионы ${ }^{3}$.

Относительно способности приграничного сотрудничества в формате еврорегионов в нынешних условиях служить фактором налаживания межгосударственных отношений исследователи разделились на два лагеря. О. В. Цветкова в своих работах пишет о том, что «в настоящее время происходит переоценка программы сотрудничества “Европейский союз - Россия" в целях приостановки внедрения Евросоюзом программы двухстороннего регионального трансграничного сотрудничества» [18, c. 100]. Один из крупнейших исследователей внешних связей регионов Н. Б. Кондратьева отмечала, что основным препятствием для развития еврорегионов с российским участием является как раз отсутствие заинтересованности в углублении сотрудничества вследствие зависимости от общеевропейской линии поведения в отношении России ${ }^{4}$. В работах

${ }^{3}$ Метаморфозы мировой политики: коллектив. моногр. / под общ. ред. М. М. Лебедевой; Моск. гос. ин-т междунар. отношений (ун-т) МИД России. М.: МГИМО-Университет, 2012. 506 c.

${ }^{4}$ Кондратьева Н. Б. Регионы России и Европейского союза на пути к строительству Общего экономического пространства. М.: Ин-т Европы РАН; Рус. сувенир, 2008. 112 с. 
А. М. Красовского [19], А. В. Одинцовой [20] превалируют противоположные точки зрения, согласно которым приграничное сотрудничество остается одной из немногих сфер, не затронутых экономическими санкциями.

Практически все исследователи отмечали, что наиболее эффективно действующим еврорегионом, как в досанкционный период, так и в настоящее время, остается «Карелия». Существенным фактором, объединяющим Финляндию и Республику Карелия является общее культурное наследие [21], на основе которого обе стороны намерены углублять дальнейшее сотрудничество в формате еврорегиона.

Большинство авторов отмечали, что для еврорегионов постсоветского пространства характерны те же проблемы, что и для регионов европейского формата. Однако специфика функционирования «Слобожанщины», «Днепра», «Ярославны» и «Донбасса» заключается в том, что они еще в большей степени зависят от политической конъюнктуры. С другой стороны, ни в одной работе не делается попытка изучить практические интересы федерального центра от участия в формате еврорегионов на постсоветском пространстве.

В последнее время появляются исследования, посвященные изучению еврорегионов на евразийском пространстве: работы И. Н. Ротановой ${ }^{5}$, Б. Н. Ларина ${ }^{6}$. Однако и в них не исследуются интересы федерального центра в поддержке процессов строительства еврорегионов. Изучение же преимуществ приграничного сотрудничества в формате еврорегионов с позиции федеральных властей представляется целесообразным, поскольку их эффективность во многом зависит от того, что от такой формы сотрудничества ожидают центральные власти. Отчасти эту исследовательскую лакуну призвана заполнить данная работа.

Материалы и методы. Выход внутригосударственных регионов на международную арену, усиление их роли в принятии решений на национальном и глобальном уровнях как объективный процесс развития мировой политики обычно рассматривается в рамках неолиберального подхода, который постулирует о все меньшей роли государства и перераспределении властных полномочий между другими акторами. Несмотря на то, что федеральная модель политического устройства России в настоящий момент развивается в сторону централизации, наше исследование выполнено в рамках неолиберального подхода, поскольку именно в форме еврорегионов местные органы власти имеют

5 Ротанова И. Н., Иванов А. В. Укрепление взаимосвязей в алтайском приграничье в контексте деятельности международного координационного совета «Наш общий дом Алтай» // Востоковедные исследования на Алтае. 2014. № 8. С. 32-37.

6 Ларин Б. В. Международный координационный совет «Наш общий дом - Алтай». Практический опыт межрегионального сотрудничества в Евразии // Евразийство: теоретический потенциал и практические приложения. 2014. № 7. С. 9-16. 
возможность выступить с широким кругом инициатив, в том числе и на площадке международных межправительственных организаций (например, в Ассамблее европейских регионов), а также вследствие того, что реализация проектов приграничного сотрудничества в большей степени зависит от инициативы и участия местных властей.

При написании статьи автор опирался преимущественно на качественные методы анализа. Количественные методы касались сопоставления различных статистических данных. Решение задачи по выявлению факторов, способствующих и препятствующих международному сотрудничеству российских регионов в формате еврорегионов, потребовало обращения к сравнительному методу анализа. Результаты анализа слабых и сильных сторон конкретных еврорегионов представлены в форме SWOT-анализа.

В качестве материалов в данной работе использовались исследования ведущих российских и зарубежных авторов по теме еврорегионов и приграничного сотрудничества. Источниками послжили статистические данные с сайтов Министерства иностранных дел России и исследуемых еврорегионов.

Результаты исследования. Создание еврорегионов как форм объединения двух и более приграничных регионов соседствующих европейских стран имело своей целью углубление межгосударственного сотрудничества европейских государств и процессов европейской интеграции через реализацию совместных проектов по сооружению мостов, строительству дорог, развитию межуниверситетских контактов, проведению мероприятий по снятию языковых и культурных барьеров. Затем к созданию еврорегионов подключились и соседние страны, не входящие в Европейский союз, поскольку, решая задачи по улучшению инфраструктуры и выравниванию социально-экономического положения регионов соседних стран, Европейский союз создавал вокруг европейских стран пояс стабильности.

Первым еврорегионом, к участию в котором была приглашена Калининградская область, стал еврорегион «Балтика», объединяющий регионы Швеции, Литвы, Дании и Польши. Затем Калининградская область стала членом еще четырех еврорегионов: «Сауле» (с 1999 г. объединяет регионы России, Швеции, Латвии и Литвы), «Немана» (с 2002 г. объединяет регионы Белоруссии, Польши, Литвы и России), «Лына - Лавы» (с 2003 г. объединяет регионы Польши и России), «Шешупе» (с 2004 г. объединяет регионы России, Польши, Литвы). Создание еврорегионов с участием России ставило своей целью повышение уровня жизни людей, проживающих на территории еврорегиона; выравнивание социальноэкономического развития территорий; искоренение исторических предрассудков. Последнее до сих пор остается одной из ключевых проблем в отношениях России с Польшей и Литвой - активными участниками еврорегионов. Несмотря на то, что участие в еврорегионах дает массу 
возможностей для организации культурных мероприятий, реализации программ студенческого обмена и через них преодоления негативной исторической памяти, участие Калининградской области в этих еврорегионах не привело к кардинальным переменам в сфере российско-польских и российско-литовских отношений. Россия не раз предпринимала попытку внести позитивную для себя повестку дня в периоды своего председательствования в еврорегионах по всем возможным направлениям сотрудничества, однако самые важные из них реализованы не были. Так, не упрочился политический вес Калининградской области. С 2011 г. в организационных структурах еврорегиона «Балтика» русский язык был отменен в качестве официального языка общения. Несмотря на введение в 2011 г. режима местного приграничного передвижения с Калининградской областью, Польша в одностороннем порядке прекратила его в 2016 г., а власти Литвы объявили о начале строительства на сухопутном участке границы с Калининградской областью проволочного забора высотой два метра с дополнительными средствами электронного контроля ${ }^{7}$.

Последствием большей открытости Калининградской области к сотрудничеству в рамках проектов еврорегионов с Польшей и Литвой стало усиление их политики по формированию европейской идентичности в Калининграде. Польша через польское экспертное сообщество и общественных деятелей не раз высказывалась о большей близости Калининграда к Европе, чем к России. Эту идею содержит и концепция «Калининградского треугольника», в котором российский регион представлен как несущая конструкция Средней Европы. Свое влияние в регионе Польша проводит и через католическую общину, поскольку именно в Калининградской области сконцентрировано наибольшее количество католиков.

Та же тактика используется и в отношении бывших советских республик, участвующих в европейских форматах еврорегионов: Украины и Белоруссии. Не предлагая существенных экономически выгодных проектов, Литва и Польша активизируют работу с гражданским обществом этих стран. Так, в рамках еврорегиона «Озерный край», который объединяет регионы Белоруссии, Литвы и Латвии, самым серьезным проектом на сумму более 1 млн евро стало строительство велодорожек. В то же время финансирование Литвой проектов по формированию белорусской идентичности во много раз превышает финансирование проектов в рамках еврорегионов. К их числу можно отнести поддержку Литвой Европейского гуманитарного университета в Вильнюсе, который предлагает для белорусов обучение на белорусском языке.

7 Лавров назвал русофобскими действия Польши и Литвы в отношении Калининградской области // ТФСС. 06.06.2017. URL: https://tass.ru/politika/4315983 (дата обращения: 27.08.2019). 
В рамках еврорегиона «Неман», единственного еврорегиона европейского формата с участием и России, и Польши, также встает вопрос об экономической целесообразности такого формата сотрудничества. Анализ активности еврорегиона позволяет сделать вывод о том, что регионы Польши и Литвы сотрудничают скорее друг с другом, а не с Россией и Белоруссией. Положительным аспектом участия России в регионе «Неман» можно назвать ежегодную ярмарку, которая организовывается белорусской стороной и собирает представителей бизнеса, дипломатических миссий, руководителей регионов. Она представляет в том числе и диалоговую площадку для России, что особенно актуально для выстраивания отношений с Белоруссией.

Значительных проектов, представляющих экономическую выгоду, России не было предложено и в рамках еврорегиона «Сауле», в котором все проекты по строительству общей инфраструктуры проводились вне территории России. По мнению ряда экспертов, другие еврорегионы («Лына - Лава» и «Шешупе») не работают и за все время своего существования не отличились выгодными для России проектами ${ }^{8}$. В рамках региона «Лына - Лава» самым значительным проектом стал ежегодный сплав на байдарках, в рамках «Шешупе» - турнир по рыбной ловле. Незначительными мероприятиями культурного характера ознаменована деятельность еврорегиона, представленного Псковской областью России, а также регионами Эстонии и Литвы «Псков - Ливония», в рамках которого были организованы Дни Псковской области в Латвии.

Среди причин того, что еврорегионы с участием Польши и Литвы практически не реализуют масштабных экономических проектов, представляющих выгоду и для России, и для европейских стран, можно назвать следующие: 1) Польша и Литва граничат с Россией только по территории Калининградской области; 2) для них пока не ясны перспективы дальнейшей европеизации области. В 2015 г. во время VI Ежегодного форума заинтересованных сторон еврорегиона «Балтика» польская сторона на повестку дня вынесла изменение организационно-правовой формы еврорегиона на европейское объединение территориального сотрудничества - Международную ассоциацию местных и региональных органов власти «Еврорегион Балтика», что фактически означало бы, что Калининградская область присоединялась к данной ассоциации под польской юрисдикцией ${ }^{9}$. Отказ от изменения организационной формы еврорегиона, размещение на территории Калининграда российского во-

${ }^{8}$ Кондратьева Н. Б. Регионы России и Европейского Союза на пути к строительству Общего экономического пространства.

${ }_{9}^{9} \mathrm{O}$ некоторых актуальных вопросах сотрудничества России и Евросоюза на калининградском направлении // Официальный сайт МИД России. 13.02.2017. URL: http://www. mid.ru/web/guest/vnesneekonomiceskie-svazi-sub-ektov-rossijskoj-federacii/-/asset_publisher/ ykggrK2nCl8c/content/id/2638781 (дата обращения: 27.08.2019). 
оружения в 2016 г. $^{10}$ привели к снижению интереса польской стороны к участию в работе еврорегионов с Россией.

Однако входить в состав еврорегионов России в целом выгодно, так как еврорегионы представляют собой формат сотрудничества с Европейский союзом, который им активно поддерживается финансово. Россия благодаря участию в еврорегионах имеет возможность получения финансирования от европейских структур на реализацию проектов в сферах, не являющихся приоритетными для федеральных властей. Эти возможности она активно использует в единственном наиболее эффективно работающем еврорегионе «Карелия», объединяющем Республику Карелия и три финские губернии. В рамках этого еврорегиона российской стороне удалось получить финансирование от Европейского союза на проекты по развитию лесного хозяйства и приграничной инфраструктуры. За 2000-2012 гг. в рамках программ Европейского союза на территории еврорегиона «Карелия» профинансирован 501 проект на общую сумму 132 млн евро ${ }^{11}$. Среди наиболее значимых отметим обустройство пропускного пункта на границе и ремонт соответствующих участков дороги, строительство очистных сооружений в карельском городе Сортавала. В рамках данного еврорегиона предпринимаются усилия по созданию общего культурного пространства: проекты «Еврорегион Карелия: музейный гипертекст», «Электронная Карелия», «Открытая Карелия» [20].

Еще одним несомненным плюсом участия в еврорегионах остается членство в европейской независимой организации регионов «Ассамблея европейских регионов». Организация, объединяющая все еврорегионы с целью консолидации их усилий по продвижению своей политической повестки дня, представляет из себя структуру, в которой регионы борются за повышение своего политического влияния в европейских институтах власти. Для России она имеет большое значение: не являясь членом Европейского союза, Россия через свои регионы может выступать с политическими и экономическими инициативами, лоббируя их в европейских структурах. Кроме того, Ассамблея представляет из себя и дипломатическую площадку, на которой российские регионы наравне с другими могут проводить свою повестку дня вне зависимости от международной конъюнктуры, складывающейся вокруг России. В разные периоды времени на площадке Ассамблеи обсуждались вопросы Чеченской войны ${ }^{12}$, будущего Арктики, защиты прав человека в России.

10 Президент Польши обеспокоен размещением вооружений под Калининградом // РИА-новости. 29.11.2016. URL: https://ria.ru/20161129/1482371688.html?in=t (дата обращения: 27.08.2019).

${ }^{11}$ Официальный сайт еврорегиона «Карелия». URL: http://www.euregiokarelia.com/ru/ toiminta (дата обращения: 27.08.2019).

${ }_{12}$ Сайт Ассамблеи европейских регионов. URL: https://aer.eu/chechnyan-crisis-aer-expresses-concern-confirms-wish-contribute-political-solution-respects-principles-regionalism/ (дата обращения: 27.08.2019). 
Отсутствие возможности выступить по данным вопросам с разъяснением нашей позиции было бы для России дипломатическим упущением.

В таблице 1 представлены наиболее сильные и слабые стороны участия России в еврорегионах европейского формата. На данном этапе недостатки организационного и структурного характера явно перевешивают преимущества. Однако несмотря на их слабые стороны и тенденцию снижения заинтересованности приграничных европейских регионов к сотрудничеству с Россией, взаимодействие с регионами России все равно продолжается именно благодаря тому, что оно финансируется не бюджетами этих стран, а общеевропейскими структурами, для которых, в отличие от Польши и Литвы, решение приграничных проблем остается приоритетным направлением. По этой причине Европейский союз выделил из своего бюджета финансирование на реализацию программ приграничного сотрудничества «Польша - Россия» и «Литва - Россия», рассчитанных до 2020 г. $^{13}$.

С большой долей вероятности можно утверждать, что программы будут продлены по истечении срока действия, поскольку обеспечение стабильной транспортной инфраструктуры по периметру Европейского союза, выравнивание социально-экономического уровня жизни в приграничных регионах находятся в непосредственных интересах европейских структур.

С 2000-х гг. Россия начала процесс создания еврорегионов, в которых субъекты Федерации объединились с русскоязычными регионами бывших постсоветских стран: Украины и Белоруссии. Процесс строительства еврорегионов на постсоветском пространстве шел параллельно развитию отношений с европейскими странами в формате еврорегионов. Европейская институциональная структура «Ассамблея европейских регионов» включила все еврорегионы с участием России и постсоветских стран: «Днепр» (2003 г.), «Слобожанщину» (2003г.), «Ярославну» (2007 г.) и «Донбасс» $(2010$ г.). В 2012 г. в Крыму озвучили предложение создать еврорегион «Крым - Кубань», однако после событий 2014 г. такая инициатива перестала быть актуальной. Необходимость создания еврорегионов была обусловлена наличием общей советской инфраструктуры, которая требовала совместных усилий по модернизации, особенно это касалось транспортных магистралей, через которые осуществляли грузовые поездки обе стороны, а также возникшими после распада СССР сложностями передвижения населения, проживающего на границах новообразовавшихся республик.

Объединение российских, украинских и белорусских регионов, с политической точки зрения, было важным в первую очередь для политического руководства России. Однако инициатива об их организации не

13 От строительства дорог до восстановления туристических объектов // Коммерсант. URL: http://eu.kommersant.ru/prigranichnoe-sotrudnichestvo.html (дата обращения: 27.08.2019). 
Т а 6 л и ц а 1. SWOT-анализ еврорегионов европейского типа ${ }^{14}$ T a b l e 1. SWOT analysis of the European-type Euroregions

\begin{tabular}{c|c|c|c}
\hline $\begin{array}{c}\text { S (Сильные } \\
\text { стороны) } \\
\begin{array}{c}\text { Strengths } \\
\hline\end{array}\end{array}$ & $\begin{array}{c}\text { W (Слабые } \\
\text { стороны) }\end{array}$ & $\begin{array}{c}\text { О (Возмож- } \\
\text { Ности)/ } \\
\text { Opportunities }\end{array}$ & $\begin{array}{c}\text { T (Угрозы) } \\
\text { Threats }\end{array}$ \\
\hline
\end{tabular}

Еврорегионы европейского типа / Euroregions of the European type

Наличие институциональных струкTyp / Presence of institutional structures

Востребованность и актуальность предлагаемых инфраструктурных проектов в рамках еврорегионов / Demand for and relevance of the proposed infrastructure projects within the framework of Euroregions

Прямой диа лог гражданских структур / Direct dialogue of civic structures
Объединяют слаборазвитые регионы как России, так и стран Европейского союза / Include poorly developed regions of both Russia and the EU countries

Представлены всего несколькими регионами России: Калининградской и Псковской областями / Are represented by only a few regions of Russia: the Kaliningrad Region and the Pskov Region

Слабые финансовые возможности российских регионов / Weak financial opportunities of Russian regions

Отсутствие серьезных экономически выгодных предложений со стороны западных партнеров / Lack of serious cost-effective offers from Western partners
Углубление сотрудничества в сфере культуры/Deepening c u $1 \mathrm{t}$ u r a 1 cooperation

3 а и н те ре сованность общеевропейских структур к развитию пригранич ного сотрудничества по всему периметру Европейского союза / Interest of pan-European structures in the development of cross-border cooperation throughout the EU
Анти россий ская риторика политическо го руководства Польши и Литвы / Anti-Russian rhetoric of the political leadership of Poland and Lithuania

Распространение своего культурного влияния / Extension of cultural influence

исходила исключительно от России. Еврорегион «Слобожанщина» был организован по инициативе Харьковской (Украина) и Белгородской областей из-за острой необходимости в установлении облегченного режима пересечения границы. Благодаря усилиям приграничных регионов было

${ }^{14}$ Составлено автором на основе анализа 7 еврорегионов с участием России и стран Европейского союза. 
подписано соглашение между Правительством Российской Федерации и Кабинетом Министров Украины о порядке пересечения российскоукраинской государственной границы жителями приграничных регионов России и Украины. Однако основное отличие российских еврорегионов от западных состоит в том, что их финансирование идет не от общего фонда, образованного правительствами Украины, Белоруссии и России, или структур СНГ, а из бюджета областей, большая часть из которых в России являются дотационными. Следовательно, реализуемые проекты по масштабам значительно меньше и сконцентрированы либо на мероприятиях в сфере культуры, науки и образования, либо инфраструктурных проектах, представляющих для всех сторон жизненную необходимость. Финансирование тех или иных проектов из федерального бюджета сильно зависит от текущей политической ситуации и тона межгосударственных отношений России, Украины и Белоруссии.

Так, создание еврорегиона «Донбасс», включающего в себя Ростовскую и Воронежскую области Российской Федерации, Луганскую и Донецкую области Украины сначала способствовало решению важных проблем регионов. Возобновилась работа крупных предприятий, ранее находящихся на грани упадка (например, «Лугансктепловоз»), была построена транспортная инфраструктура для облегчения пересечения границ двух государств. Однако помимо еврорегионов на постсоветском пространстве украинские власти еще раньше стали активно вовлекаться в еврорегионы с участием стран Европейского союза: «Буг», «Карпаты», «Нижний Дунай», «Верхний Прут». Именно участие в разнонаправленных процессах у западных и восточных границ при отсутствии установок на укрепление своей украинской идентичности, по мнению Л. Н. Кулябиной и А. Ш. Ногмовой, и привело к развалу национальногосударственного образования в Украине, а также отказу от развития отношений с Россией в пользу ассоциации с Европейским союзом [13]. После событий Евромайдана и прихода прозападной администрации работа еврорегиона фактически прекратилась по инициативе украинской стороны, нереализованным остался важнейший проект по улучшению экологической ситуации в районе р. Северный Донецк, дальнейшее сотрудничество этих областей усиливало конфликтогенность отношений России и Украины, а также конфликт центра и периферии Украины. Действующая программа трансграничного сотрудничества Украины до 2020 г. исключает развитие всех приграничных регионов с Россией, на них не распространяются транспортные проекты, финансирование в сфере жилищного строительства ${ }^{15}$. Таким образом перестали работать и другие

15 Трансграничное сотрудничество Украины с РФ: ломать - не строить // Ритм Евразии. 03.09.2016. URL: https://www.ritmeurasia.org/news--2016-09-03--transgranichnoe-sotrudnichestvo-ukrainy-s-rf-lomat-ne-stroit-25550 (дата обращения: 27.08.2019). 
более ранние по своему учреждению еврорегионы с участием Украины: «Слобожанщина», «Ярославна». В еврорегионе «Слобожанщина» остались нерелизованными планы по созданию технопарка «Слобожанщина», в еврорегионе «Ярославна», который за время существования реализовал больше 20 совместных программ трансграничного сотрудничества в сфере энергосбережения, экологии, демографии, культуры, информации, также все проекты оказались замороженными. Работа еврорегиона «Днепр», объединяющего также и Белоруссию, осталась только в двустороннем формате. Сложности функционирования этого региона заключаются в том, что оно также серьезно зависит от уровня российско-белорусских отношений, поскольку Белоруссия как унитарное государство выделяет средства на реализацию программ приграничного сотрудничества из федерального бюджета.

С окончанием украинского участия в еврорегионе «Днепр» активизировались торговые отношения Брянской области с регионами Белоруссии. В 2018 г. Белоруссия как и прежде числилась основным торговым партнером Брянской области (48,4 \% от всего товарооборота). На политическом уровне проводятся мероприятия, посвященные дням единения славянских народов, молодежному сотрудничеству. Однако нынешний этап российско-белорусских отношений, характеризующийся достаточно жесткой критикой политических лидеров стран, не позволяет говорить о том, что федеральные власти с обеих сторон проявят заинтересованность в реализации масштабных экономических проектов в областях, входящих в еврорегион «Днепр».

Несмотря на то, что Украина заморозила свое членство в еврорегионах, все они остались членами Ассамблеи европейских регионов, а «Ярославна» по-прежнему состоит в Конгрессе местных и региональных властей Совета Европы. Членство в данных организациях для России важно, так как они являются дипломатическими площадками, позволяющими представить интересы российских регионов, наладить перспективное сотрудничество с другими европейскими регионами, облегчить возможность установления двусторонних контактов с представителями европейского бизнеса по вопросам реализации инвестиционных проектов.

B таблице 2 представлены результаты SWOT-анализа еврорегионов постсоветского типа. Основное отличие от еврорегионов европейского формата заключается в том, что интеграция происходит на уровне властей и это затрудняет сотрудничество в период конфликтов. Фактически изза такой формы организации еврорегионов с постсоветскими странами перестал действовать формат всех еврорегионов с участием Украины, несмотря на наличие таких сильных сторон еврорегионов, как разнонаправленность проектов, востребованность проектов приграничного сотрудничества у населения обеих стран и их относительная однородность. 
Т а 6 л и ц а 2. SWOT-анализ еврорегионов постсоветского типа ${ }^{16}$ $\mathrm{T}$ a b l e 2. SWOT analysis of the post-Soviet type Euroregions

\begin{tabular}{c|c|c|c}
\hline $\begin{array}{c}\text { S (Сильные } \\
\text { cтороны) } \\
\text { Strengths }\end{array}$ & $\begin{array}{c}\text { W (Слабые } \\
\text { стороны) } \\
\text { Weaknesses }\end{array}$ & $\begin{array}{c}\text { O (Возможно- } \\
\text { сти) } / \\
\text { Opportunities }\end{array}$ & $\begin{array}{c}\text { T (Угрозы) } / \\
\text { Threats }\end{array}$ \\
\hline
\end{tabular}

Еврорегионы постсоветского типа / Euroregions of the post-Soviet type

Наличие институцион а льных структур / Presence of institutional structures

Востребованность и актуальность возможностей облегченного режима пересечения и экономических проектов у населения / Demand for and relevance of a facilitated crossing regime and economic projects among the population

Разнонаправленность проектов сотрудничества (от экономики до культуры)/ Diversity of cooperation projects (ranging from economy to culture)
Слабые финан совые возможности российских и постсовет ских регионов / Weak financial opportunities of Russian and post-Soviet regions

Сильная зависимость от уровня двухсторонних отношений и позиции федерального центра / Strong dependence on the level of bilateral relations and the standpoint of the federal center
Углубление сотрудни честв а в сферекультуры/ Deepening cultural cooperation
Антироссийская риторика / AntiRussian rhetoric

Наличие территориальных споров с Украиной / Territorial disputes with Ukraine

Для того чтобы наладить эффективное сотрудничество с постсоветскими странами в формате еврорегионов, необходимо изменить механизм финансирования проектов по типу Европейского союза. Создание структуры, занимающейся финансированием проектов по приграничному сотрудничеству, пополняемой в равной степени всеми участниками еврорегионов на постсоветском пространстве, позволило бы избежать зависимости приграничных проектов от текущей обстановки в двусторонних отношениях, а также поставило регионы в равное друг с другом

\footnotetext{
${ }^{16}$ Составлено автором на основе анализа 4 еврорегионов с участием России и стран СНГ.
} 
положение в плане возможностей финансирования. О необходимости внедрения специализированных институтов поддержки в рамках программно-проектного метода реализации приграничных инициатив говорят, в частности, и такие исследователи, как Е. А. Шлапенко [17].

Неудачный пока опыт по налаживанию сотрудничества в формате еврорегионов с Украиной и Белоруссией для России не стал фактором отказа от участия в них. В настоящий момент, пока проекты с Украиной остаются замороженными, а характер риторики белорусского политического руководства в значительной степени влияет на весь комплекс российско-белорусских отношений, Россия вводит понятие «Евразиярегион», которое распространяет идеологию и практику приграничного сотрудничества европейского формата еврорегионов на территории, расположенные в азиатской части страны. Новые форматы трансграничного сотрудничества должны были вобрать в себя позитивный опыт Европейского союза в решении проблем приграничного сотрудничества и в то же время избежать таких проблем участия России в еврорегионах, как диспропорции в территориальном развитии и возможностях финансирования, малая заинтересованность, несоответствие нормативно-правовой базы и т. д.

Первым подобным регионом можно назвать «Наш общий дом - Алтай», который был основан в 2004 г. регионами России, Казахстана, Монголии, Китая. В его основу легла Декларация о развитии трансграничного сотрудничества в Алтайском регионе. Однако почти сразу в его работе проявились старые проблемы зависимости регионов от средств федерального бюджета и отличие правового регулирования. В то же время при создании этого еврорегиона учитывался опыт европейских еврорегионов, где помимо решения конкретных приграничных проблем также организовываются проекты, нацеленные на воспитание будущего поколения в духе добрососедства. На площадке данной ассоциации на регулярной основе проводятся мероприятия, направленные на воспитание молодежи: Международная летняя школа студентов «Наш общий дом - Алтай», Детская общественная экологическая экспедиция «Начни с дома своего», Международная конференция по научно-техническому сотрудничеству, Международная летняя школа аспирантов и молодых ученых, Совет ректоров вузов Большого Алтая, Туристско-спортивный фестиваль «Большой Алтай» ${ }^{17}$. Часть мероприятий приурочена к проектам по решению более глобальных проблем, требующих в то же время активных усилий на уровне местных властей и гражданского общества: деятельности Шанхайской организации сотрудничества. Активное во-

${ }^{17}$ Ротанова И. Н., Иванов А. В. Укрепление взаимосвязей в алтайском приграничье в контексте деятельности международного координационного совета «Наш общий дом Алтай». 
влечение молодежи в проект приграничного сотрудничества в формате «Евразии-региона» говорит о том, что он нацелен на долгосрочную перспективу и его результаты можно будет оценить в полной мере по прошествии нескольких десятилетий.

С 2013 г. стали появляться идеи о возможности создания еще одного евразийского региона - «Приднестровье», который не имеет общих границ с Россией, но представляется интересным с точки зрения решения экономических проблем и выстраивания общего поля идентичности. Востребованность данного объединения, с одной стороны, обусловлена и интересом гражданских структур непризнанной республики к сотрудничеству с Россией, с другой - заинтересованностью России. Формат еврорегиона обычно воспринимается на общеевропейском уровне как процесс сближения на уровне гражданских структур, внутригосударственные регионы относятся к негосударственным акторам мировой политики и их деятельность на международной арене не ассоциируется однозначно с прогосударственной политикой. На фоне напряженных отношений со странами Европейского союза такой формат сближения с Приднестровьем представляется как наиболее безопасный с точки зрения восприятия этой инициативы ближайшими соседями непризнанной республики.

Основной проблемой при строительстве этого евразийского региона выступает не географический фактор, а фактор конкуренции. В апреле 2013 г. параллельно с инициативой создания региона «Приднестровье» с Россией, двум регионам непризнанной республики предложили вступить в украино-молдавский еврорегион «Днестр». Объявленной целью приглашения выступает комплексное развитие прилегающих территорий через культурное, научное, образовательное и экологическое сотрудничество.

Как представляется, формат «Евразии-региона» было бы целесообразно развивать внутри Евразийского экономического союза (ЕАЭС), в рамках которого уже пройдены важнейшие этапы экономической интеграции и созданы структуры, способные финансировать проекты приграничного сотрудничества наиболее эффективным способом. О готовности к проектам сотрудничества на уровне местных властей говорит и положительное отношение к углублению интеграции граждан стран - участниц ЕАЭС [17]. Сближение приграничных регионов стран ЕАЭС способствовало бы выработке территориальной идентичности, поиск концептуальных основ которой в рамках ЕАЭС пока только обсуждается.

Обсуждение и заключение. Изучение еврорегионов продолжает оставаться актуальной темой, поскольку, несмотря на ухудшение международной ситуации вокруг России, еврорегионы являются формой сотрудничества властей на местном уровне, в задачи которого входит улучшение положения местного населения. Однако не все еврорегионы с участием России в одинаковой степени нацелены на решение проблем 
приграничного сотрудничества. Часть из них носит скорее характер культурного обмена: «Шешупе», «Лына - Лава», «Псков - Ливония». В то же время практически все еврорегионы европейского типа включают в себя мероприятия, направленные на формирование определенной территориальной идентичности. Основная проблема при этом состоит в том, что в рамках еврорегионов европейского типа сложно говорить о какой-то территориальной идентичности, поскольку Россия не входит в Европейский союз и ее не объединяют с европейскими странами общеевропейские ценности и стремление к регионализации. Сотрудничество в этом типе еврорегионов должно основываться на решении первоочередных задач: улучшении социально-экономического положения и реализации инфраструктурных проектов, а затем уже культурных. Именно по причине того, что отсутствуют проекты по созданию общей инфраструктуры, поддержки бизнеса, нет видимого эффекта от существования еврорегионов «Шешупе» и «Псков - Ливония». Культурные проекты без построения общей инфраструктуры приводят к тому, что у сторон не вырабатываются чувства сплоченности и ответственности перед населением прилегающих территорий, пропадает интерес к углублению сотрудничества.

Еврорегионы постсоветского пространства («Слобожанщина», «Ярославна», «Донбасс» и «Днепр») имеют все основания к углублению сотрудничества на основе построения идентичности. Проблема заключается в том, что они становятся полем боя европейского и российского проектов. Ограниченность возможностей российских и постсоветских регионов по реализации проектов приграничного сотрудничества на фоне европейских возможностей финансирования стала одной из причин того, что выгоды от пребывания в рамках еврорегионов постсоветского типа на данном этапе политическим руководством Украины не принимаются во внимание.

Неоднозначные результаты их функционирования все же не ведут к свертыванию сотрудничества в формате еврорегионов в целом. Приграничное сотрудничество с Россией останется неизбежной формой сотрудничества как для европейских стран, так и для постсоветских в силу трансграничного характера проблем приграничных территорий. По этой причине неизбежным является и реанимирование еврорегионов с участием Украины, поскольку даже в случае перехода к полной ассоциации с Европейским союзом ей придется следовать в фарватере общеевропейской политики по поддержке процессов регионализации. Для российской политической элиты участие российских субъектов в еврорегионах европейского и постсоветского типов также безальтернативно, поскольку они позволяют российским регионам оставаться членами международных организаций (Ассамблеи европейских регионов, 
Ассоциации европейских приграничных регионов). Это дает возможность российским регионам выдвигать в них свою повестку дня и тем самым решать внешнеполитические задачи России.

На данном этапе идет процесс распространения опыта участия в еврорегионах и на евразийском пространстве. Этого требует общемировая тенденция расширения участия регионов в мировых политических процессах. С другой стороны, объединение людей в рамках определенных сообществ, мобилизация ресурсов для решения общих проблем должны способствовать углублению евразийской интеграции. Выводы автора о причинах неэффективного функционирования некоторых еврорегионов с участием России, а также конкретные предложения по устранению проблем имеют практическую значимость для государственных структур, занимающихся реализацией проектов по углублению интеграции на евразийском пространстве.

В силу того, что процесс строительства уже существующих еврорегионов продолжает оставаться на начальной стадии, в ближайшее время планируются к пересмотру соглашения о приграничном сотрудничестве между Россией и Польшей, Россией и Литвой; многие вопросы, поднятые автором в данном исследовании, потребуют дополнительного изучения. Данное исследование может быть использовано в качестве основы для последующего изучения, например, будущего еврорегионов с участием России и Украины после нормализации двусторонних отношений, влияния приграничного сотрудничества в формате еврорегионов на санкционный режим и других вопросов, касающихся внешних связей приграничных территорий в формате еврорегионов.

\section{СПИСОК ИСПОЛЬЗОВАННЫХ ИСТОЧНИКОВ}

1. Cross-Border Cooperation in the EU: Euroregions Amid Multilevel Governance and Reterritorialization / A. Noferini [et al.] // European Planning Studies. 2019. DOI: https://doi.org/10.1080/09654313.2019.1623973

2. The Catalysts of Cross-Border Cooperation Development in Euroregions / J. Kurowska-Pysz [et al.] // Polish Journal of Management Studies. 2018. Vol. 18, issue 1. Pp. 180-193. DOI: https://doi.org/10.17512/pjms.2018.18.1.14

3. Telle S. Euroregions as Soft Spaces: Between Consolidation and Transformation // European Spatial Research and Policy. 2017. No. 24. Pp. 93-110. DOI: https://doi. org/10.1515/esrp-2017-0011

4. Lawrence R. Deriving Collaborative Aims and Outcomes: A Case-Study of Cross-Border Cooperation in Central and Eastern Europe // Evaluation. 2011. Vol. 17. Pp. 365-382. DOI: https://doi.org/10.1177/1356389011421927

5. De Sousa L. Understanding European Cross-Border Cooperation: A Framework for Analysis // Journal of European Integration. 2013. Vol. 35, issue 6. Pp. 669-687. DOI: https://doi.org/10.1080/07036337.2012.711827 
6. Frątczak-Müller J., Mielczarek-Żejmo A. Cross-Border Partnership - the Impact of Institutions on Creating the Borderland Communities (The Case of Spree-NeisseBober Euroregion) // Innovation The European Journal of Social Science Research. 2016. Vol. 29, issue 1. Pp. 1-21. DOI: https://doi.org/10.1080/13511610.2015.1098523

7. Scott J. W. Constructing Familiarity in Finnish-Russian Karelia: Shifting Uses of History and the Re-Interpretation of Regions // European Planning Studies. 2012. Vol. 21, issue 1. Pp. 75-92. DOI: https://doi.org/10.1080/09654313.2012.716240

8. Brie M. European Instruments of Cross-Border Cooperation. Case Study: The Romanian-Ukrainian Border // Identités, citoyennetés et démocratie, 20 ans après / sous la direction de Fabienne Maron, Grzegorz Pozarlik. Bruxelles, 2010. Pp. 265-280. URL: https://papers.ssrn.com/sol3/papers.cfm?abstract_id=2221175 (дата обращения: 27.08.2019).

9. Cismas L. M., Sabau C. Cross-Border Cooperation in Europe: The Case of Bihor-Hajdu Bihar Euroregion // International Business Research. 2012. Vol. 5, no. 3. Pp. 91-99. DOI: https://doi.org/10.5539/ibr.v5n3p91

10. Decoville A., Durand F. Exploring Cross-Border Integration in Europe: How do Populations Cross Borders and Perceive their Neighbours? // European Urban and Regional Studies. 2018. No. 26 (2). Pp. 134-157. DOI: https://doi. org/10.1177/0969776418756934

11. Kuznetsov A. Perspectives of Euroregions with Russian Participation in Terms of Changes in the EU Regional Policy // Baltic Region. 2009. No. 2. Pp. 39-45. DOI: https://doi.org/10.5922/2079-8555-2009-2-5

12. Синяускас Н. А. Особенности российского трансграничного регионализма // Terra Economicus. 2013. T. 11, № 3.3. C. 145-150. URL: https://te.sfedu.ru/ arkhiv-nomerov/2013/83-nomer-3-3/1130-osobennosti-rossijskogo-transgranichnogo-regionalizma.html (дата обращения: 27.08.2019).

13. Кулябина Л. Н., Ногмова А. Ш. Динамика сотрудничества России со странами Европы в рамках еврорегионов // Вестник Дипломатической академии МИД России. Россия и мир. 2018. № 4 (18). С. 56-68. URL: https://elibrary.ru/ item.asp?id=36527006 (дата обращения: 27.08.2019). (In Russ., abstract in Eng.)

14. Бредихин А. В. Роль еврорегионов в наднациональной интеграции (на примере еврорегиона «Донбасс») // Россия и современный мир. 2013. № 3 (80). C. 90-101. URL: http://rossovmir.ru/issue.php?id=40 (дата обращения: 27.08.2019).

15. Приграничное сотрудничество регионов России, Беларуси и Украины: состояние и перспективы / А. М. Анисимов [и др.] // Евразийская экономическая интеграция. 2013. № 4 (21). C. 77-96. URL: https://eabr.org/analytics/archive-edb-editions/eurasian-economic-integration/592/ (дата обращения: 27.08.2019).

16. Zhurzhenko T. Cross-Border Cooperation and Transformation of Regional Identities in the Ukrainian-Russian Borderlands: Towards a Euroregion "Slobozhanshchyna"? Part 1 // Nationalities Papers. 2004. Vol. 32, issue 1. Pp. 207-232. DOI: https://doi.org/10.1080/0090599042000230296

17. Шлапеко Е. А. Модели приграничного сотрудничества регионов России // Общество. Среда. Развитие. 2018. № 1. С. 20-24. URL: http://www.terrahumana. ru/index.html (дата обращения: 27.08.2019). 
18. Цветкова О. В. Трансграничное сотрудничество приграничных субъектов Российской Федерации // PolitBook. 2016. № 4. C. 96-107. URL: http://politbook. online/index.php/archiv/68-pb-2016-4 (дата обращения: 27.08.2019).

19. Красовский А. М. Направления совершенствования сотрудничества России и Евросоюза в Калининградской области // Власть. 2015. № 10. С. 89-91. URL: https://www.jour.isras.ru/index.php/vlast/article/view/3041 (дата обращения: 27.08.2019).

20. Одинцова А. В. Опыт и проблемы приграничного сотрудничества // Федерализм. 2015. № 4 (80). C. 97-110. URL: https://elibrary.ru/item.asp?id=25322378 (дата обращения: 27.08.2019).

21. Корчагина Н. А. Еврорегионы как модель сотрудничества приграничных регионов // Каспийский регион: политика, экономика, культура. 2004. № 1 . C. 12-19. URL: http://kaspy.asu.edu.ru/?articleId=1498 (дата обращения: 27.08.2019).

Поступила 04.09.2019; принята к публикации 16.10.2019; опубликована онлайн 30.12.2019.

\section{Об авторе:}

Рустамова Лейли Рустамовна, преподаватель кафедры мировых политических процессов ФГАОУ ВО «Московский государственный институт международных отношений (университет) Министерства иностранных дел Российской Федерации» (119454, Россия, г. Москва, пр. Вернадского, д. 76); научный сотрудник ФГБНУ «Национальный исследовательский институт мировой экономики и международных отношений имени Е. М. Примакова Российской академии наук (117997, Россия, г. Москва, ул. Профсоюзная, д. 23), кандидат политических наук, ORCID: https:/orcid.org/0000-0001-9803-9904, leili-rustamova@yandex.ru

\section{Для циитирования:}

Рустамова Л. Р. Проблемы и перспективы приграничного сотрудничества еврорегионов с участием России // Регионология. 2019. Т. 27, № 4. С. 711-733. DOI: https://doi.org/10.15507/2413-1407.109.027.201904.711-733

Автор прочитал и одобрил окончательный вариант рукописи.

\section{REFERENCES}

1. Noferini A., Berzi M., Camonita F., Durà A. Cross-Border Cooperation in the EU: Euroregions amid Multilevel Governance and Reterritorialization. European Planning Studies. 2019. (In Eng.) DOI: https://doi.org/10.1080/09654313.2019.1623973

2. Kurowska-Pysz J., Szczepanska-Woszczyna K., Stverkova H. The Catalysts of Cross-Border Cooperation Development in Euroregions. Polish Journal of Management Studies. 2018; 18(1):180-193. (In Eng.) DOI: https://doi.org/10.17512/ pjms.2018.18.1.14 
3. Telle S. Euroregions as Soft Spaces: Between Consolidation and Transformation. European Spatial Research and Policy. 2017; (24):93-110. (In Eng.) DOI: https:// doi.org/10.1515/esrp-2017-0011

4. Lawrence R. Deriving Collaborative Aims and Outcomes: A Case-Study of CrossBorder Cooperation in Central and Eastern Europe. Evaluation. 2011; 17:365-382. (In Eng.) DOI: https://doi.org/10.1177/1356389011421927

5. De Sousa L. Understanding European Cross-border Cooperation: A Framework for Analysis. Journal of European Integration. 2013; 35(6):669-687. (In Eng.) DOI: https://doi.org/10.1080/07036337.2012.711827

6. Frątczak-Müller J., Mielczarek-Żejmo A. Cross-Border Partnership - the Impact of Institutions on Creating the Borderland Communities (The Case of Spree-NeisseBober Euroregion). Innovation The European Journal of Social Science Research. 2016; 29(1):1-21. (In Eng.) DOI: https://doi.org/10.1080/13511610.2015.1098523

7. Scott J.W. Constructing Familiarity in Finnish-Russian Karelia: Shifting Uses of History and the Re-Interpretation of Regions. European Planning Studies. 2012; 21(1):75-92. (In Eng.) DOI: https://doi.org/10.1080/09654313.2012.716240

8. Brie M. European Instruments of Cross-Border Cooperation. Case Study: The Romanian-Ukrainian Border. In: Identités, citoyennetés et démocratie, 20 ans après / sous la direction de Fabienne Maron, Grzegorz Pozarlik. Bruxelles; 2010. p. 265-280. Available at: https://papers.ssrn.com/sol3/papers.cfm?abstract id=2221175 (accessed 27.08.2019). (In Eng.)

9. Cismas L. M., Sabau C. Cross-Border Cooperation in Europe: The Case of Bihor-Hajdu Bihar Euroregion. International Business Research. 2012; 5(3):91-99. (In Eng.) DOI: https://doi.org/10.5539/ibr.v5n3p91

10. Decoville A., Durand F. Exploring Cross-Border Integration in Europe: How do Populations Cross Borders and Perceive their Neighbours? European Urban and Regional Studies. 2018; (26):134-157. (In Eng.) DOI: https://doi. org/10.1177/0969776418756934

11. Kuznetsov A. Perspectives of Euroregions with Russian Participation in Terms of Changes in the EU Regional Policy. Baltic Region. 2009; (2):39-45. (In Eng.) DOI: https://doi.org/10.5922/2079-8555-2009-2-5

12. Siniauskas N.A. Features of the Russian Transboundary Regionalism. Terra Economicus. 2013; 11(3.3):145-150. Available at: https://te.sfedu.ru/arkhivnomerov/2013/83-nomer-3-3/1130-osobennosti-rossijskogo-transgranichnogo-regionalizma.html (accessed 27.08.2019). (In Russ., abstract in Eng.)

13. Kulyabina L.N., Nogmova A.Sh. Dynamics of Russia's Cooperation with European Countries in Euroregions. Vestnik Diplomaticheskoj akademii MID Rossii. Rossija $i$ mir = Bulletin of the Diplomatic Academy of the Russian Ministry of Foreign Affairs. Russia and the World. 2018; (4):56-68. Available at: https://elibrary.ru/ item.asp?id=36527006 (accessed 27.08.2019). (In Russ., abstract in Eng.)

14. Bredikhin A.V. The Role of Euroregions in the Supranational Integration (A Case Study of the "Donbass" Euroregion). Rossiya i sovremennyj mir = Russia and the Contemporary World. 2013; (3):90-101. Available at: http://rossovmir.ru/ issue.php?id=40 (accessed 27.08.2019). (In Russ., abstract in Eng.)

15. Anisimov A.M., Vardomskiy L.B., Vertinskaya T.S., et al. Trans-Border Cooperation in the Regions of Russia, Belarus and Ukraine: Its Status and Future 
Outlook. Evrazijskaya ehkonomicheskaya integratsiya = Eurasian Economic Integration. 2013; (4):77-96. Available at: https://eabr.org/analytics/archive-edb-editions/ eurasian-economic-integration/592/ (accessed 27.08.2019). (In Russ., abstract in Eng.)

16. Zhurzhenko T. Cross-Border Cooperation and Transformation of Regional Identities in the Ukrainian-Russian Borderlands: Towards a Euroregion "Slobozhanshchyna"? Part 1. Nationalities Papers. 2004; 32(1):207-232. DOI: https://doi. org/10.1080/0090599042000230296

17. Shlapeko E.A. Models of Cross-Border Cooperation of the Russian Regions. Obshhestvo. Sreda. Razvitie = Society. Environment. Development. 2018; (1):20-24. Available at: http://www.terrahumana.ru/index.html (accessed 27.08.2019). (In Russ., abstract in Eng.)

18. Tsvetkova O.V. Cross-Border Cooperation of Border Regions of the Russian Federation. PolitBook. 2016; 4:96-107. Available at: http://politbook.online/index.php/ archiv/68-pb-2016-4 (accessed 27.08.2019). (In Russ., abstract in Eng.)

19. Krasovskiy A.M. The Directions of Improvement of Cooperation Between Russia and the European Union in the Kaliningrad Region Vlast = Power. 2015; (10):89-91. Available at: https://www.jour.isras.ru/index.php/vlast/article/view/3041 (accessed 27.08.2019). (In Russ., abstract in Eng.)

20. Odintsova A.V. Experience and Problems of Cross-Border Cooperation. Federalizm = Federalism. 2015; (4):97-110. Available at: https://elibrary.ru/item. asp?id=25322378 (accessed 27.08.2019). (In Russ., abstract in Eng.)

21. Korchagina N.A. Euro-Regions as a Model of Transfrontier Cooperation. Kaspijskij region: politika, ehkonomika, kultura = Caspian Region: Politics, Economics, Culture. 2004; (1):12-19. Available at: http://kaspy.asu.edu.ru/?articleId=1498 (accessed 27.08.2019). (In Russ.)

Submitted 04.09.2019; accepted for publication 16.10.2019; published online 30.12.2019.

\section{About the author:}

Leili R. Rustamova, Lecturer, Department of World Politics, Moscow State Institute of International Relations (University) of the Ministry of Foreign Affairs of the Russian Federation (76 Prospect Vernadskogo, Moscow 119454, Russia); Researcher, Primakov Institute of World Economy and International Relations (23 Profsoyuznaya St., Moscow 117997, Russia), Ph. D. (Political Science), ORCID: https://orcid.org/0000-0001-9803-9904, leili-rustamova@yandex.ru

\section{For citation:}

Rustamova L.R. Problems and Prospects of Cross-Border Cooperation in Euroregions with Russian Participation. Regionology $=$ Russian Journal of Regional Studies. 2019; 27(4):711-733. DOI: https://doi.org/10.15507/2413-1407.109.027.201904.711-733

The author has read and approved the final version of the manuscript. 


\section{Специфика развития этнонационального пространства современной России как фактор нациестроительства: стратегический ситуационный анализ}

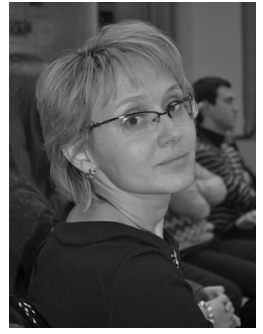

И. Г. Напалкова*

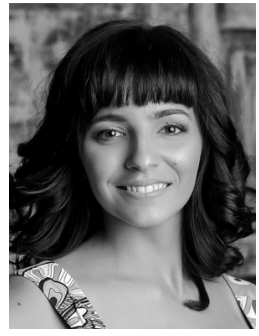

А. С. Солдатова

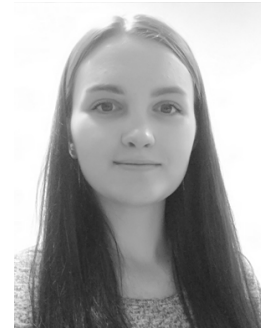

К. В. Курочкина

ФГБОУ ВО «МГУ им. Н. П. Огарёва» (г. Саранск, Россия), zamisi@yandex.ru

Введение. Для России традиционной считается проблема взаимодействия и поиска баланса в системе «центр - периферия», являющаяся импульсом к социально-экономической дифференциации. Однако не менее значимой референцией выступает многонациональность, которая конфигурирует российское пространство, как совокупность отдельных этнических локумов, связанных между собой. Особенности этнонационального пространства во многом определяют стабильность/нестабильность развития государства, что актуализирует исследования в данной области. Цель данной публикации - проанализировать специфику развития и потенциал этнонационального пространства современной России как фактора нациестроительства.

Материалы и методы. В качестве основного метода выступил стратегический ситуационный анализ (методика SWOT), дающий возможность рассмотреть предметное поле, опираясь на факторы, фиксирующие динамику сложившейся ситуации.

Результаты исследования. Выявлены историко-генетические, юридические, институциональные, управленческие, программные, этноментальные и другие факторы, комплексно характеризующие современное этнонациональное пространство России как сложную систему, транслирующую сущность и характер взаимоотношений этносов внутри государства. Произведена их оценка с позиций «сильный - слабый», «возможность - угроза». Составлена SWOT-матрица, констатирующая превальвацию слабых сторон и угроз, в соответствии с которой определены риски развития, способные усилить негативные этнонациональные процессы.

(C) Напалкова И. Г., Солдатова А. С., Курочкина К. В., 2019 Контент доступен под лицензией Creative Commons Attribution 4.0 License. This work is licensed under a Creative Commons Attribution 4.0 License. 
Обсуждение и заключение. В целом развитие этнонационального пространства России имеет контрастный характер: некоторые факторы одновременно относятся и к сильному, и к слабому полю SWOT-матрицы. Отмечается снижение остроты этнонациональной проблематики в обществе, уменьшение степени конфликтности и межнациональных разногласий. Основные конфликты и протесты локализуются в рамках социально-политической сферы, катализатором которых в настоящее время является избирательная тематика. Результаты исследования могут быть использованы органами государственной власти и управления для совершенствования этнонациональной сферы, коррегирования отдельных направлений национальной политики и пространственного развития в контексте нациестроительства.

Ключевые слова: этнонациональное пространство, Россия, нациестроительство, соционации, межнациональная интеграция, межнациональный конфликт, государственно-гражданская идентичность, SWOT-анализ

Финансирование. Исследование выполнено при финансовой поддержке РФФИ, проект «Пространственное развитие России как фактор нациестроительства и формирования национальной идеи» № 18-011-00364 А.

\title{
Specifics of the Development of the Ethno-National Space of Modern Russia as a Factor in Nation Building: A Strategic Situational Analysis
}

\author{
I. G. Napalkova*, A. S. Soldatova, K. V. Kurochkina \\ National Research Mordovia State University (Saransk, Russia), \\ zamisi@yandex.ru
}

Introduction. In Russia, the problem of interaction and search for balance in the 'center - periphery' system is considered to be common and is an impulse to socioeconomic differentiation. However, no less important is the factor in multi-ethnicity, which organizes the space of Russia into a set of interconnected individual locations associated with certain ethnic groups. Features of the ethno-national space largely determine the (in)stability of the development of the state, which increases relevance of research in this field. The objective of this piece of research is to analyze the specifics of development and the potential of the ethno-national space of modern Russia as a factor in nation building.

Materials and Methods. Strategic situational analysis (the SWOT analysis technique) was used as the main method, which makes it possible to consider the subject field, relying on factors that capture the dynamics of the current situation.

Results. The authors have identified the historical and genetic, legal, institutional, managerial, programmatic, ethno-mental and other factors that comprehensively characterize the modern ethno-national space of Russia as a complex system that translates the essence and nature of the relationship between ethnic groups within the state. The identified factors have been evaluated in terms of strengths or weaknesses, opportunities or threats. A SWOT matrix has been developed, stating the prevalence of weaknesses and threats; in accordance with this matrix, development risks that can accelerate negative ethno-national processes have been identified. 
Discussion and Conclusion. On the whole, the ethno-national space of Russia has a contrasting nature: some factors simultaneously relate to both the strengths and weaknesses of the SWOT matrix. There has been a decrease in the acuteness of ethnonational problems in society as well as a reduction in the proneness to conflict and interethnic discord. The main conflicts and protests have been localized within the socio-political sphere, the electoral issues being their catalyst currently. The results of the study can be used by state executive and administrative bodies to improve the ethno-national sphere, to adjust certain areas of ethno-national policies and spatial development in the context of nation building.

Keywords: ethno-national space, Russia, nation building, socio-nations, interethnic integration, ethnic conflict, national and civil identity, SWOT analysis

Funding. The study was carried out with the financial support from the Russian Foundation for Basic Research, project "Spatial Development of Russia as a Factor in Nation Building and the Formation of the National Idea", No. 18-011-00364 A.

Введение. Национальное пространство, будучи одним из измерений социального пространства, циркулирует и транслирует сущность и характер взаимоотношений этносов внутри государства, происходящие процессы, явления, события, конфликты в межнациональной сфере, репрезентирует степень сформированности соционации, ее социокультурную зрелость и т. д. Особенности национального пространства России активно влияют на ее геополитическое, экономическое, социальное положение, уровень конкурентоспособности на международных рынках, степень национальной безопасности и пр. Ситуация осложняется социально-политическими событиями, происходящими на международной арене. Обострением проблем национальной идентичности вследствие проникновения глобализации в национальную культуру (особенно остро переживается в полиэтничных государствах, которым является и Россия).

В нашем государстве в качестве ответа глобальным вызовам и угрозам стал утвержденный вектор развития, направленный на формирование и укрепление общероссийской гражданской нации. Однако этот выбор вызывает споры и дискуссии: начиная с определения понятия «нация», «гражданская нация», какова степень сформированности общероссийской гражданской нации, национально-государственная идея мобилизует народ или индокринирует, до обвинений в инициации политической элитой процесса нациестроительства и желании управлять и контролировать этот процесс «сверху», что серьезно нарушает естественно-исторические механизмы. Поэтому исследование специфики пространственного функционирования имеет важное значение как для нивелирования негативных трендов и деструктивных межнациональных практик, так и для выработки возможных сценарных вариантов дальнейшего развития государства и общества. 
Основная цель публикации - анализ специфики развития этнонационального пространства современной России как фактора нациестроительства средствами стратегического ситуационного анализа.

Реализация цели предполагает решение ряда задач: выделить сильные и слабые стороны развития этнонационального пространства; определить возможности и угрозы из числа общесистемных факторов развития государства и общества; детерминировать способы нивелирования негативных факторов этнонационального пространства и нейтрализовать угрозы его развитию.

Данная научная работа стала определенным лонгитюдом исследования 2014 г. «Этнонациональное пространство современной России: специфика развития и управленческий потенциал» [1], что позволяет проследить траекторию изменений этнопространственных предикторов.

Обзор литературы. В рамках объектно-предметного поля данной работы условно можно выделить несколько больших тематических блоков в степени изученности проблемы. Первый - собственно проблематика нациестроительства и вопросы, его эксплицирующие. Широкий спектр проблем нациестроительства рассматривается в работах В. А. Тишкова, в том числе «роль языковых проблем в современном нациестроительстве» [2]. Этнометодология в изучении культур актуализируется в публикациях таких авторов, как К. Майер и М. Дж. Тезич [3; 4].

Национальную идею как смысл существования и стратегию развития этноса анализирует В. А. Тураев, подчеркивая существенные различия между понятием «национально-государственная идея», которое рассматривается как продукт творчества политической элиты, и «национальная идея народа» - как продукт народной культуры [5].

Эмпирическая проверка наиболее известных модернистских теорий национализма, рассматривающих нациестроительство как «результат перехода от традиционных к современным обществам», была проведена М. С. Фабрикант [6].

Спектр стратегий, используемых в процессе нациестроительства на постсоветском пространстве, анализирует Д. Э. Летняков; он также отмечает сложности, с которыми сталкиваются постсоветские общества в ходе осуществления политики нациестроительства [7]. Особенности межэтнических взаимодействий и проблемы толерантности исследуют Е. Нымм, Ф. Коста Буранелли ${ }^{1}[8]$ и др.

Попытку пересмотреть методологию сравнительного анализа стратегий построения государства-нации на постсоветском пространстве

${ }^{1}$ Nõmm J. Back to Square One: Fostering a Culture of Tolerance as a Way of Modern Society's Development // IMCIC 2019 - 10 $0^{\text {th }}$ International Multi-Conference on Complexity, Informatics and Cybernetics, Proceedings. 2019. No. 2. Pp. 147-152. 
предпринимает и В. В. Лапкин, констатируя, что «крушение имперской государственности в 1991 г. спустя десятилетие привело... к бифуркации путей национально-государственного строительства» [9, с. 54].

И. В. Бахлов и О. В. Бахлова рассматривают позиции политических партий Российской Федерации по вопросам идеологического обоснования нациестроительства в России и отмечают отсутствие у них инициирующего начала [10]. Роль религии в нациестроительстве современной России, в частности необходимость использования потенциала религиозных объединений в решении вопросов различных социальных конфликтов на основе уважения к специфике и независимости религиозных институтов, акцентирует О. В. Куропаткина [11].

Второй блок работ - особенности, характеристики, потенциал этнонационального пространства России.

Этничность в социально-политическом пространстве России изучается Л. М. Дробижевой и В. А. Мансуровым². На основе данных социологических опросов авторы отмечают, что при общем тренде снижения межэтнической напряженности переоценивать улучшение межэтнических отношений в настоящий момент времени в России нельзя. О различных трансформациях, в рамках которых социально-политическое пространство разграничивается по этническому принципу, рассуждает О. Н. Максимова [12].

Положительные и негативные факторы этнонационального пространства России периода 2000-2012 гг. в контексте собственно этнонационального и общесистемного территориального развития рассматривают И. Г. Напалкова и А. С. Солдатова [1], которыми констатируется его двойственность и полярность. Проблемы этничности и межэтнических отношений в рамках национального государства, размывание основ социального пространства, а также этнополитическую конфликтность через призму социально-экономических факторов анализирует Е. С. Садовая [13].

Третье направление исследований - идентичность как основа консолидации нации. Спектр изучаемых вопросов очень широк: гражданская идентичность как ресурс сплоченности полиэтнического пространства (Л. М. Дробижева ${ }^{3}$, А. Г. Ткаченко [14] и др. ), синтез этнонационального и государственно-гражданского как основа идентичности (М. К. Горшков, И. О. Тюрина [15], Е. И. Долгаева [16] и др.) ценности, идеи, символы,

2 Дробижева Л. М., Мансуров В. А. Этничность в социально-политическом пространстве России весной 2018 г. // Степная цивилизация - 2018 г. Земля предков: традиции и новации в социально-культурном развитии общества / отв. ред. В. А. Мансуров. М.; Кызыл: ОО РОС, 2018. С. 29-36.

${ }^{3}$ Дробижева Л. М. Гражданская идентичность: динамика и потенциал в консолидации полиэтнического общества // Этническое и религиозное многообразие России: моногр. / Под ред. В. А. Тишкова, В. В. Степанова. Изд. 2-е, исправ. и доп. М.: ИЭА РАН, 2018. C. $107-118$. 
мифы и конструирование их средствами национальной идентичности (Г. В. Пушкарева [17], А. С. Солдатова, Е. В. Ширманов [18] и др.).

Четвертый блок - изучение особенностей этнонациональной политики и регулирования этнополитических отношений в Российской Федерации, в том числе основы этнонациональной политики государства, ее специфика в России (К. С. Зайков, А. М. Тамицкий, М. Ю. Задорин [19]); «роль этнополитики в конструировании новой российской гражданской нации» (Н. С. Толкунов [20]); «национальная политика в оценке и восприятии населения» (О. Ю. Посухова, А. В. Сериков [21]); региональные особенности этнонациональной политики (О. В. Минчук [22], С. А. Мадюкова, А. А. Персидская [23], Ю. В. Попков [24] и др.).

Несмотря на значительный тематический спектр и разнообразие научных подходов к исследуемой теме дискуссионными остаются вопросы необходимости активного участия государства в процессе нациестроительства, используемых средств и методов данного процесса, поиска путей и способов разрешения конфликта идентичностей и др. Также можно констатировать отсутствие комплексных работ, системно характеризующих этнонациональное пространство России, базирующихся на комплексе прикладных методов, что актуализирует изучение заявленного предметного поля.

Материалы и методы. В качестве специальных методов и подходов выступили: сравнительный анализ, аналитический метод, системный и концептуальный подходы, позволившие раскрыть общую направленность исследования, его архитектонику и преемственность.

В числе прикладных использовался метод ситуационного анализа, в частности SWOT-анализ, характеризующий предметное поле, базируясь на факторах, определяющих динамику сложившейся ситуации.

Ключевыми направлениями каротажа стали два типа факторов: собственно этнонационального развития и общесистемные пространственного развития (исторические предпосылки; законодательство в сфере национальной политики и политико-правовая среда его реализации; развитие межнациональных отношений; государственная национальная политика; программный подход в сфере нациестроительства; компетентность и качество государственного управления в сфере этнонационального развития; экономическое развитие; социально-демографические показатели; государственно-гражданское взаимодействие; информационные кампании и медийные проекты; международная среда и др.).

Выявленные процессы, события, факторы были включены в матрицу SWOT-анализа в оценочные области «Strengths» (сильные стороны), «Weaknesses» (слабые стороны), «Opportunities» (возможности), «Threats» (угрозы), которая позволяет не только де факто характеризовать национально-политическую ситуацию в государстве, но и оказывать зна- 
чительную помощь в построении стратегических планов дальнейшего развития национальных отношений, включая принятие законодательных решений в области национальной политики, мер по урегулированию межэтнических противоречий, разработку площадок для межнационального взаимодействия и т. д.

Результаты исследования. В числе положительных факторов развития этнонационального пространства (поле «Strengths») современной России по-прежнему остаются позиции, выделенные нами ранее в рамках исследования 2014 г.:

- исторически сложившаяся вариативность управленческих практик в отношениях «центр - национальная периферия»;

- совершенствование отечественного законодательства в сфере реализации государственной национальной политики;

- проведение информационных кампаний и реализация медийных проектов по укреплению общероссийской идентичности и межэтнической толерантности;

- проведение мониторингов в сфере межнациональных отношений;

- формирование связей российских регионов с зарубежными странами по линии «родственных народов»;

- использование подходов разработки стратегий развития межнациональных отношений, основанных на оценке опыта, уже накопленного многими национальными регионами [1, с. 49-52].

Также к позиции «Strengths» в настоящее время относятся:

- историческая преемственность как символический базис «новой России»;

- применение программно-целевого подхода в национальной политике, в том числе поддержка этнического меньшинства через механизм государственных программ;

- активное вертикальное взаимодействие федеральных, региональных органов государственной власти, органов местного самоуправления, некоммерческих организаций (НКО), научно-исследовательских и иных организаций по вопросам разработки, реализации и оценки эффективности национальной политики;

- развитие системы адаптации и интеграции иностранных мигрантов в российский социум;

- усиление роли некоммерческих организаций в российском обществе в целом и в инициации и реализации проектов этнонациональной направленности в частности;

- выделение Президентских грантов для НКО по этнонациональной тематике;

- инициативная деятельность национально-культурных автономий (НКА), национально-культурных организаций; 
- активное формирование общероссийской гражданской нации;

- превальвация государственно-гражданской идентичности;

- кронверк патриотизма как центральной оси государственно-гражданской идентичности;

- проведение информационных кампаний и мероприятий по укреплению патриотического сознания россиян;

- достаточно высокий уровень национальной терпимости и веротерпимости;

- укрепление русского языка как государственного при обеспечении условий для изучения и сохранения языков народов России;

- трансформация внешнеполитического имиджа России.

К числу негативных факторов (поле «Weaknesses»), определенных в рамках предыдущего исследования и до сих пор сохраняющих свою значимость, относятся:

- несовпадение административно-политических, экономических, этнолингвистических, культурных и прочих границ советского пространства;

- этнический принцип структурирования территорий как основа советского федерализма;

- полисубъектность этнополитики;

- проблемы институционального наполнения национальной политики;

- постоянное реформирование уполномоченных органов в сфере регулирования национальной политики Российской Федерации и перераспределение функций);

- несовершенство финансовых рычагов реализации государственной национальной политики;

- дискомфортная политическая атмосфера национальностей в столичном регионе;

- несформированность общероссийской гражданской нации [1, с. 53-57].

К слабым сторонам развития этнонационального пространства также были отнесены:

- реминисценция советской системы мифологизации мышления;

- отказ представителей власти постсоветской России от советского прошлого;

- высокая социально-экономическая дифференциация в регионах с разным национальным составом населения (экономическое неравенство, соотношение богатых и бедных);

- применение программно-целевого подхода в национальной политике;

- наложение локальных этнопространств на национально-государственное пространство;

- отсутствие унифицированности органов исполнительной власти субъектов Федерации в сфере национальной политики;

- недостаточность ресурсной обеспеченности на локальном уровне; 
- полярность взглядов в общеполитическом и научном дискурсе на само понятие «российская гражданская нация»: от полного отрицания до сформированности и устойчивого характера развития;

- активное формирование общероссийской гражданской нации «сверху»;

- продвижение патриотизма как национальной идеи административными ресурсами;

- неоднозначное отношение россиян к патриотизму как национальной идее;

- добровольно-принудительное изучение национальных государственных языков;

- низкий уровень конструктивной политической и общественной активности россиян;

- наличие стереотипов и мифов о России;

- укорененность отрицательных гетеростереотипов об отдельных этносах и их проявление в межкультурных коммуникациях;

- декларативный статус национально-культурных автономий;

- непроработанность информационных кампаний и информационных поводов;

- деструктивная деятельность отдельных региональных организаций по развитию этносепаратизма.

Помимо внутренних факторов на развитие этнонационального пространства оказывают воздействие внешние коэффициенты (распределяемые в областях «Opportunities»/ «Threats»), прежде всего системные факторы внешнего влияния, среди которых общеэкономические, общеполитические, научно-технические, природно-экологические, демографические и др. Их воздействие дает возможность или же составляет угрозу и усиливает негативные тенденции.

К полю возможностей можно отнести: социальную ориентированность российского государства; реализацию госпрограмм в области нового качества жизни, в том числе развитие здравоохранения, образования, доступной среды, культуры и туризма, физкультуры и спорта, охрану окружающей среды и др.; создание и продвижение площадок для активного взаимодействия разноуровневых акторов по вопросам, связанным с реализацией государственной политики Российской Федерации; активную поддержку федеральным центром гражданских инициатив; сформированность общеразделяемых российским обществом ценностей; достаточно высокий уровень доверия к власти, прежде всего к Президенту РФ и др.

Среди угроз общесистемного характера можно выделить:

- асимметричность отношений центра с регионами;

- дефицит горизонтального взаимодействия; 
- безынициативность и неспособность регионов правильно формировать свои запросы;

- высокий уровень коррупции; «фаворитизм» в системе отношений «центр - регион»;

- «замораживание» сильной государственной региональной политики;

- избыточность субъектного состава федерации;

- преобладание внешнеполитической проблематики над внутриполитической;

- отсутствие в ролевой структуре политической культуры России конструктивной оппозиции;

- наличие сложносоставных субъектов Федерации;

- концентрация бюджетных ресурсов на федеральном уровне;

- неоднородность, контрастность, диспропорции в социально-экономическом положении регионов;

- разделение по темпам социально-экономического развития не только в рамках административных границ, но и внутри них;

- уплотнение экономического пространства России, особенно на ограниченной территории макрозоны «Центр и Северо-Запад России»;

- отсутствие свободной межрегиональной конкуренции;

- слабая инфраструктурная освоенность, слабая заселенность отдельных территорий, недостаточная развитость транспортных путей, что не позволяет в полной мере реализовать в ряде регионов значимые направления в экономике;

- низкий агломерационный эффект; разница в демографическом потенциале субъектов Федерации;

- углубление социального расслоения и экономической дифференциации населения;

- пространственная неравномерность распространения мирохозяйственных связей;

- активные миграционные приросты;

- сохраняющиеся ориентации части населения на западные гражданские общества с их системой либерально-демократических ценностей и традиций, неподходящие нашим народам из-за ментальных, национальных обычаев и ценностей, духовного уклада;

- попытки фальсификации истории и мифотворчество в ущерб интересам России, активная информационная антироссийская пропаганда в зарубежных СМИ;

- не в полном объеме используются средства социально-политических технологий для продвижения и реализации социально значимых проектов и инициатив и др.

Тенденции, происходящие в нашей стране, усугубляются процессами глобализации, которая, с одной стороны, размывает принципы нацио- 
нального самоопределения, а с другой - ведет к процессам регионализации, когда отдельные регионы стремятся сохранить и укрепить свою идентичность в современных условиях. Накаляется военно-политическая обстановка, наблюдается отвержение элементарных правил приличия, не говоря уже о нормах международного права.

Таким образом, в матрице SWOT-анализа поле «Strengths» характеризуется 20 позициями, «Weaknesses»-26, «Opportunities»-6, «Threaths»-22.

Обсуждение и заключение. Можно сделать следующие выводы о характере исследуемой сферы.

1. Комбинация факторов SWOT-анализа свидетельствует об ограничении стратегического развития, так как угрозы и слабые стороны превалируют над сильными сторонами и возможностями. Ситуация осложняется тем, что отрицательные характеристики развития этнонационального пространства не всегда нивелируются другими группами факторов.

2. Все позиции в полях «Strengths» и «Weaknesses» можно разделить на две группы: 1 - инварианты, являющиеся исторически сложившейся данностью; 2 - вариативные динамично меняющиеся характеристики, зависящие от управленческих решений и определенные текущим хронотопом.

3. Для этнонационального пространства современной России характерна контрадикторность, т. е. достаточно высокая степень насыщенности как матрицы «Strengths», так и «Weakness», что при наполненности «Threats» приводит к диссонансу и снижению эффективности его развития.

4. В целом факторы, характеризующие этнонациональное пространство России, полярны, так как некоторые из них одновременно относятся как к сильным, так и к слабым сторонам. Например, использование программно-целевого подхода в национальной политике, с одной стороны, позволяет системно решать проблемы, концентрируя ресурсы на актуальные направления, корректировать индикаторы и мероприятия на основе мониторинга эффективности, инициировать общественный контроль и др. С другой стороны, эксперты отмечают несоответствие ряда программ требованиям, предъявляемым к ним, слабое ресурсное сопровождение, включающее недостаточность внебюджетного финансирования, несовершенство технологий реализации и др.

5. Значимость целого ряда положительных характеристик снижается за счет отрицательных референций, свойственных одной и той же области. Например, «Кронверк патриотизма как центральной оси государственно-гражданской идентичности» (+) нивелируется за счет неоднозначного отношения россиян к патриотизму как национальной идее (-) и ее продвижения административными ресурсами (-). С одной стороны, патриотические чувства рассматриваются как «важная основа сильного государства», «наша связь с героическим прошлым» и др. 
Так, по данным опроса, проводимого фондом «Общественное мнение» ${ }^{4}$ летом 2019 г., на вопрос «Считаете ли вы себя патриотом страны»?» 73 \% россиян ответили положительно (что на $4 \%$ меньше, чем в 2018 г.), из них $84 \%$ граждан среднего возраста (31-35 лет) с высшим образованием и $80 \%$ жителей Москвы. При этом $21 \%$ не считают себя патриотами, в основном это люди со средним общим образованием и ниже $(31$ \%), жители Северо-Западного федерального округа (29 \%) и Дальневосточного федерального округа (29 \%). С другой стороны, многие респонденты подчеркивали негативные моменты восприятия, связанные с дисбалансом между чувством гордости за страну через призму ее истории, ее побед и проблемами современности, волнующими и возмущающими граждан - рост коррупции, бюрократия, произвол правоохранительных органов, низкий уровень жизни части россиян и т. п. Часть населения начинает градировать понятия «государство» и «страна». Символом данного процесса стали строчки Е. Евтушенко «Я Родину люблю свою, но государство - ненавижу!».

Сильные стороны «Проведение информационных кампаний и мероприятий по укреплению патриотического сознания россиян» $(+)$ и «Проведение информационных кампаний и реализация медийных проектов по укреплению общероссийской идентичности и межэтнической толерантности» $(+)$ ослабляются за счет усиливающегося противоборства в глобальном информационном пространстве (-), непроработанности информационных кампаний и информационных поводов, особенно на региональном уровне (-), недостаточной развитости и активности использования средств социально-политических технологий (PR, брендинг, медиарилейшинз и др.) для оптимизации взаимоотношения этносов и личностей в национальном пространстве (-).

Информационный повод является одним из главных средств в организации связей с общественностью. Из-за их непроработанности не просто понижается эффективность отдельно взятой информационной кампании, а могут возникать негативные оценочные суждения, снижающие ценность продвигаемой идеи. Так, например, в 2019 г. в Республике Мордовия на акцию «Бессмертный полк» несколько высокопоставленных чиновников пришли с портретом одного и того же ветерана, причем на портретах были указаны три разных имени. Это вызвало широкий общественный резонанс и недовольство.

«Активная деятельность национально-культурных автономий, национально-культурных организаций» (+) обесценивается за счет «Декларативного статуса НКА» (-).

${ }^{4}$ Патриотизм [Электронный ресурс] // Опрос «ФОМнибус». URL: https://bd.fom.ru/pdf/ d23pm2019.pdf (дата обращения: 10.09.2019). 
В поле «Strengths» НКА характеризуются как носители значимой роли в поддержании межнационального мира и согласия, создающие условия для интеграции различных национальных культур в единое гражданское общество, а также (согласно изменениям на 04.11.2014, внесенным в Ф3 от 17.06.1996 № 74-Ф3 «О национально-культурной автономии») участвуют в укреплении общегражданской идентичности, гармонизации межэтнических отношений, содействуют межрелигиозному диалогу, социально-культурной адаптации и интеграции мигрантов. Возможность трансформироваться в некоммерческие организации открыла автономиям дополнительные финансовые ресурсы в виде участия в Грантах Президента РФ для НКО. Данный фактор усиливается за счет повышения эффективности во взаимодействии органов власти с национально-культурными объединениями, что может быть классифицировано как отдельная сильная сторона.

Как отмечают отдельные специалисты, в международной практике НКА, являющиеся институтом, отстаивающим интересы определенного народа в парламенте, а также обеспечивающим его культурные и языковые потребности, в России представляют собой всего лишь вид общественных организаций. Термин «автономия» в названии НКА является фикцией. Для НКА, несмотря на наличие отдельного федерального закона, даже не предусмотрели самостоятельной организационно-правовой формы, как, например, для общин коренных малочисленных народов.

Позитивным фактором выступает «Достаточно высокий уровень национальной терпимости и веротерпимости» (+). Доля граждан, положительно оценивающих состояние межконфессиональных отношений, по данным «ЕМИСС. Государственная статистика» ${ }^{5}$, стабильно высока: в 2017 г. в целом по России она составляет 79 \% (в 2015 г. - 77 \%, в 2013 г. - 68,4 \%), наибольшие значения показателя зафиксированы в Ингушетии - 91,5 \%, Республике Мордовия - 91,3, Марий Эл - 91,1 \%, а наименьшие - в г. Москве $(55,9$ \%). Многие эксперты (Е. Г. Каменский, А. Ю. Огурцова, С. В. Полутин, Н. В. Шумкова, А. М. Чушкин, С. Р. Хайкин, С. Б. Бережкова, В. В. Огневая) констатируют снижение потенциального уровня межнациональной конфликтности и повышение межконфессионального согласия при сохранении бытовой ксенофобии, мигрантофобии и т. п.

Ценность фактора уменьшается за счет укорененности отрицательных гетеростереотипов об отдельных этносах и их проявлении в межкультурных коммуникациях (-). Ряд экспертов и исследователей этнонацио-

5 Доля граждан, положительно оценивающих состояние межконфессиональных отношений [Электронный ресурс] // ЕМИСС. Государственная статистика. URL: https://www. fedstat.ru/indicator/50995 (дата обращения: 27.05.2019). 
нальной проблематики констатируют, что усиление установок на межнациональную толерантность не снижает превальвацию отрицательных гетеростереотипов, переводящих бытовые конфликты в этническую плоскость и способствующих развитию ксенофобии.

В информационном поле присутствует достаточно много бытовых происшествий и преступлений, муссирующих принадлежность их участников к той или иной национальности: «Конфликт в Чемодановке» (русские/цыгане), «Убийство Расулом Мирзаевым Ивана Агафонова» (дагестанцы/русские), «Дело в станице Марьинской (Ставрополье)» (кавказцы/русские) и др.

По данным «Левада-Центра» ${ }^{6}$, рейтинг этнической антипатии в 2018 г. возглавляли цыгане и китайцы, первые устойчиво ассоциируются с этнической преступностью, вторые - с конкуренцией на рынке труда, несколько улучшилось отношение к выходцам с Кавказа.

6. Роль отдельных положительных факторов в контексте этнонациональной проблематики также нивелируется за счет неблагоприятных тенденций, характерных для их общего развития. Например, действие сильной стороны «Усиление роли некоммерческих организаций в инициации и реализации этнонациональной проектной практике» снижено за счет собственных проблем деятельности НКО. К ним относятся: отсутствие стабильных источников финансирования и, как следствие, преобладание краткосрочных проектов и разовых инициатив, невысокая гражданская активность в ряде регионов, зависимость от административных ресурсов, что ограничивает гибкость и самостоятельность организаций.

К сильным сторонам, как и в предыдущем исследовании 2014 г. [1], относится локальная динамика: частные мероприятия, события, отдельные управленческие практики. Слабые стороны и угрозы часто носят системный характер. Например, фиксируемая положительная динамика отдельных экономических показателей в «слабых» национальных субъектах не свидетельствует в целом об улучшении их экономического положения. Так, Мордовия при положительной динамике промышленного производства, формировании уникального кластера инновационного развития, ведущих позициях по объему валовой продукции сельского хозяйства лидирует в рейтинге самых закредитованных регионов России, а показатель ВРП (63 место) в 73,72 раза меньше относительно первой позиции (г. Москва).

7. Как сильные, так и слабые стороны способны провоцировать риски развития этнонационального пространства. В частности, активное

${ }^{6}$ Цыгане и китайцы возглавили рейтинг этнической неприязни в России [Электронный ресурс] // RFI. URL: http://ru.rfi.fr/rossiya/20180827-tsygane-i-kitaitsy-vozglavili-reitingetnicheskoi-nepriyazni-v-rossii (дата обращения: 01.06.2019). 
использование административного ресурса в системе государственной политики и управления, несмотря на сложившуюся в сознании россиян традицию властвования, основанную на централизации, снижает уровень общественного доверия властным институтам, ослабляет солидарные связи, ведет к разобщенности и дезинтеграции, в то же время стимулируя у части населения склонность к государственному патернализму. Отсутствие унифицированной системы управления национальной политикой в субъектах РФ иногда становится причиной дублирования мероприятий или их слабой проработанности, снижению оперативности реагирования на возникающие конфликтные ситуации в сфере межнациональных и межрелигиозных отношений. Рост патриотизма может провоцировать межнациональную нетерпимость. Этнические стереотипы, несмотря на улучшение национальных установок, продолжают сохранять укорененность в сознании большинства российских граждан, что ведет к повышению агрессивности, прежде всего в крупных городах, и, как следствие, к росту ксенофобии, кавказофобии, антисемитизма и т. п. Неоднородность, контрастность, диспропорции в социально-экономическом положении регионов в совокупности с «фаворитизмом» в системе отношений «центр регионы» может стать пусковым механизмом для этнонациональной тематики и спровоцировать рост межнациональной конфликтности и др.

8. По сравнению с исследованием 2014 г. можно отметить снижение остроты этнонациональной тематики в обществе, степени конфликтности и межнациональных разногласий, хотя проблемные зоны остаются. Основные конфликты и протесты локализуются в рамках социально-политической проблематики, катализатором которой в настоящее время выступает избирательный процесс.

Устойчивость развития этнонационального пространства России является основанием стабильного развития государства, что актуализирует его изучение и анализ.

Проведенное исследование позволило выделить и описать факторы развития этнонационального пространства, оценить в позициях «сильный - слабый», «возможность - угроза», рассмотреть комбинацию и оценить стратегическое развитие анализируемой сферы как ограничение развития, что связано с преобладанием характеристик в матрицах «Weaknesses» и «Threats».

Сравнение матриц SWOT-анализа 2014 и 2019 гг. позволяет констатировать численное факторное увеличение в поле «сильные стороны» и сделать вывод, что период 2000-2012 гг. в плане управления национальным пространством можно было назвать этапом системных преобразований, а современный этап (2012-2019 гг.) - укреплением государственно-гражданских начал. 
Для эффективного развития полиэтничного российского государства необходима сильная государственная этнонациональная политика, базирующаяся на принципах системности, комплексности, гармоничности, стабильности при активном участии различных институтов и структур, выступающих ее субъектами. Также для усиления результативности государственной политики необходимо совершенствовать механизмы принятия управленческих решений, использовать передовые методы и технологии ее реализации, способные нивелировать негативные факторы, риски и угрозы, активнее привлекать ведущие исследовательские коллективы к мониторингу этнонациональной сферы.

Также следует подчеркнуть, что слабые стороны пространственного развития не должны игнорироваться, информацию не следует демонстрировать только в положительном разрезе путем манипуляционных приемов, это может привести к дисгармонии, недовольству населения и росту протестных настроений.

Теоретическая и практическая значимость данной работы заключается в разработке матрицы SWOT-анализа, поля которой характеризуют этнонациональное пространство современной России. Оперативная аналитика и комплексный анализ необходимы также для принятия своевременных управленческих решений в плане координации и корригирования пространственного развития, вариативность процессов внутри которого может варьироваться от интеграции до дифференциации и конфликта, а также оперативного решения возникающих проблем и снижения воздействия негативных факторов и рисков, что в целом влияет на национальную безопасность и обеспечение национальных интересов России.

Результаты исследования могут быть использованы органами государственной власти и управления для совершенствования этнонациональной сферы, коррегирования отдельных направлений национальной политики и пространственного развития в контексте нациестроительства, так как полученные данные служат базисными элементами при разработке стратегических целей и задач управления.

\section{СПИСОК ИСПОЛЬЗОВАННЫХ ИСТОЧНИКОВ}

1. Напалкова И. Г., Солдатова А. С. Этнонациональное пространство современной России: специфика развития и управленческий потенциал // ARS ADMINISTRANDI. 2014. № 1. C. 48-60. URL: http://ars-administrandi.com/article/ Napalkova_Soldatova_2014_1.pdf (дата обращения: 05.05.2019).

2. Тишков В. А. Языковая ситуация и языковая политика в России (ревизия категорий и практик) // Полис. Политические исследования. 2019. № 3 . C. 127-144. DOI: https://doi.org/10.17976/jpps/2019.03.08 
3. Meyer C. Ethnomethodology's Culture // Human Studies. 2019. Vol. 42, issue 2. Pp. 281-303. DOI: https://doi.org/10.1007/s10746-019-09515-5

4. Тезич М. Дж. Концепции этноса, этничности и Ethnicity в научных традициях России и Запада // Новые исследования Тувы. 2016. № 2. С. 199-210. URL: https://www.tuva.asia/journal/issue_30/8682-tezich.html (дата обращения: 10.09.2019).

5. Тураев В. А. Национальная идея как смысл существования и стратегия развития этноса // Россия и АTP. 2010. № 2. С. 154-160. URL: https://elibrary. ru/item.asp?id=15219223 (дата обращения: 10.09.2019).

6. Fabrykant M. S. Value of (Expla) Nation: Testing Modernist Theories of Nationalism // Журнал Сибирского федерального университета. Гуманитарные науки. 2013. Т. 6, № 11. С. 1656-1672. URL: http://journal.sfu-kras.ru/article/10106 (дата обращения: 10.09.2019).

7. Летняков Д. Э. Создавая нацию: политика идентичности в постсоветских государствах // Мир России. Социология. Этнология. 2016. Т. 25, № 2. С. 144-167. URL: https://elibrary.ru/item.asp?id=26283969 (дата обращения: 10.09.2019).

8. Costa Buranelli F. World Society as a Shared Ethnos and the Limits of World Society in Central Asia // International Politics. 2018. Vol. 55. Pp. 57-72. DOI: https://doi.org/10.1057/s41311-017-0064-6

9. Лапкин В. В. Проблемы национального строительства в полиэтнических постсоветских обществах: украинский казус в сравнительной перспективе // Полис. Политические исследования. 2016. № 4. С. 54-64. DOI: https://doi. org/10.17976/jpps/2016.04.06

10. Бахлов И. В., Бахлова О. В. Основы идеологии нациестроительства в современной России: подходы политических партий // Известия Саратовского университета. Новая серия. Сер.: Социология. Политология. 2018. Т. 18, вып. 3. C. 354-362. DOI: https://doi.org/10.18500/1818-9601-2018-18-3-354-362

11. Куропаткина О. В. Роль религии в нациестроительстве современной России // Проблемный анализ и государственно-управленческое проектирование. 2014. T. 7, вып. 1. С. 26-38. URL: https://elibrary.ru/item.asp?id=21480166 (дата обращения: 10.09.2019).

12. Максимова О. Н. Этническая идентичность как демаркация социальнополитического пространства // Современное общество и власть. 2018. № 3 (17). C. 46-57. URL: https://elibrary.ru/item.asp?id=36511880 (дата обращения: 10.09.2019).

13. Садовая Е. С. Социально-экономические факторы этнополитической конфликтности // Полис. Политические исследования. 2016. № 4. С. 41-53. DOI: https://doi.org/10.17976/jpps/2016.04.05

14. Ткаченко А. Г. Укрепление российской национальной идентичности как противодействие радикальному национализму // Вестник Академии экономической безопасности МВД России. 2015. № 6. С. 70-74. URL: https://elibrary.ru/ item.asp?id=24211106 (accessed 05.05.2019).

15. Горшков М. К., Тюрина И. О. Синтез этнонационального и государственно-гражданского как основа идентичности // Вестник РУДН. Сер.: Социология. 2018. № 1 (18). C. 44-57. DOI: http://dx.doi.org/10.22363/2313-2272-2018-18-1-44-57 
16. Долгаева Е. И. Факторы общероссийской национально-гражданской идентичности в интерпретации жителей полиэтнического региона // Регионология. 2018. Т. 26. № 1 (102). С. 123-140. DOI: https://doi.org/10.15507/24131407.102.026.201801.123-140

17. Пушкарева Г. В. Идеи и ценности как способ конструирования символического пространства национальной идентичности // Полис. Политические исследования. 2017. № 5. С. 156-173. DOI: https://doi.org/10.17976/jpps/2017.05.11

18. Солдатова А. С., Ширманов Е. В. Соотношение общенационального, этнического и регионального в идентичности жителей Мордовии (по материалам прикладного исследования) // Ars Administrandi. 2015. № 1. С. 51-60. URL: http://ars-administrandi.com/abstracts.php?id=441 (дата обращения: 10.09.2019).

19. Зайков К. С., Тамицкий А. М., Задорин М. Ю. Основы этнонациональной политики государства на примере Российской Федерации // Федерализм. 2016. № 3 (83). C. 145-158. URL: https://elibrary.ru/item.asp?id=27339772 (дата обращения: 10.09.2019).

20. Толкунов Н. С. Роль этнополитики в формировании российской гражданской нации // Известия Саратовского университета. Новая серия. Сер.: Социология. Политология. 2018. Т. 18, вып. 4. С. 474-478. DOI: https://doi. org/10.18500/1818-9601-2018-18-4-474-478

21. Посухова О. Ю., Сериков А. В. Национальная политика РФ в оценке и восприятии населения Южно-российского региона // Власть. 2017. № 8. C. 143-150. URL: https://www.jour.isras.ru/index.php/vlast/article/view/5339 (дата обращения: 10.09.2019).

22. Минчук О. В. Этнонациональная политика Республики Коми: нормативное и инфраструктурное обеспечение // Арктика и Север. 2016. № 25. С. 134-147. DOI: https://doi.org/10.17238/issn2221-2698.2016.25.137

23. Мадюкова С. А., Персидская О. А. Этнонациональная политика в Республике Алтай // Сибирский философский журнал. 2016. № 1 (14). С. 120-134. URL: https://nsu.ru/sibphil/2016.1 (дата обращения: 10.09.2019).

24. Попков Ю. В. Региональные особенности этнонациональной политики // Новые исследования Тувы. 2013 № 4. C. 9-28. URL: https://nit.tuva.asia/nit/article/ view/195 (дата обращения: 10.09.2019).

Поступила 10.09.2019; принята к публикации 18.10.2019; опубликована онлайн 30.12.2019.

\section{Об авторах:}

Напалкова Ирина Геннадьевна, доцент кафедры всеобщей истории, политологии и регионоведения ФГБОУ ВО «МГУ им. Н. П. Огарёва» (430005, Россия, г. Саранск, ул. Большевистская, д. 68/1), кандидат исторических наук, ORCID: https://orcid.org/0000-0003-3896-1600, zamisi@yandex.ru

Солдатова Анна Сергеевна, младший научный сотрудник Научно-образовательного центра «Политический анализ территориальных систем» ФГБОУ ВО «МГУ им. Н. П. Огарёва» (430005, Россия, г. Саранск, ул. Большевистская, д. 68/1), ORCID: https://orcid.org/0000-0003-0247-1917, anasoldatova@mail.ru 
Курочкина Ксения Вячеславовна, политолог, магистрант кафедры всеобщей истории, политологии и регионоведения, научный сотрудник Научно-образовательного центра «Политический анализ территориальных систем» ФГБОУ ВО «МГУ им. Н. П. Огарёва» (430005, Россия, г. Саранск, ул. Большевистская, д. 68/1), ORCID: https://orcid.org/0000-0001-6993-4766, ksen.kurochckina2017@yandex.ru

\section{Заявленный вклад авторов:}

Напалкова Ирина Геннадьевна - научное руководство; основная идея исследования; определение теоретико-методологических основ исследования; критический анализ; формулирование выводов; написание статьи.

Солдатова Анна Сергеевна - разработка теоретико-методологических основ исследования; сбор и обработка данных; написание статьи.

Курочкина Ксения Вячеславовна - поиск аналитических материалов; анализ статистического и фактического материала; подготовка начального варианта текста.

\section{Для иитирования:}

Напалкова И. Г., Солдатова А. С., Курочкина К. В. Специфика развития этнонационального пространства современной России как фактор нациестроительства: стратегический ситуационный анализ // Регионология. 2019. Т. 27, № 4. C. 734-755. DOI: https://doi.org/10.15507/2413-1407.109.027.201904.734-755

\section{Авторы прочитали и одобрили окончательный вариант рукописи.}

\section{REFERENCES}

1. Napalkova I.G., Soldatova A.S. Ethno-National Space of Contemporary Russia: Specific Development and Management Capacity. Ars Administrandi. 2014; (1):48-60. Available at: http://ars-administrandi.com/article/Napalkova_Soldatova_2014_1.pdf (accessed 10.09.2019). (In Russ., abstract in Eng.)

2. Tishkov V.A. Language Situation and Language Policy in Russia (Revising Categories and Practices). Polis. Politicheskie issledovaniya $=$ Policy. Political Research. 2019; (3):127-144. (In Russ., abstract in Eng.) DOI: https://doi.org/10.17976/ jpps/2019.03.08

3. Meyer C. Ethnomethodology's Culture. Human Studies. 2019; 42(2):281-303. (In Eng.) DOI: https://doi.org/10.1007/s10746-019-09515-5

4. Tezic M.C. The Concepts of Ethnos, Ethnichnost' and Ethnicity in Russian and Western Scholarship. Novye issledovaniya Tuvy = New Research of Tuva. 2016; (2):199-210. Available at: https://www.tuva.asia/journal/issue_30/8682-tezich.html (accessed 10.09.2019). (In Russ., abstract in Eng.)

5. Turaev V.A. National Idea as the Meaning of Life and Strategy of Development of Ethnic Community. Rossiya i ATR = Russia and the Pacific. 2010; (2):154-160. Available at: https://elibrary.ru/item.asp?id=15219223 (accessed 10.09.2019). (In Russ., abstract in Eng.) 
6. Fabrykant M.S. Value of (Expla) Nation: Testing Modernist Theories of Nationalism. Zhurnal Sibirskogo federalnogo universiteta. Gumanitarnye nauki = Journal of Siberian Federal University. Humanities \& Social Sciences. 2013; 6(11):1656-1672. Available at: http://journal.sfu-kras.ru/article/10106 (accessed 10.09.2019). (In Eng.)

7. Letnyakov D.E. Nation-Building: Identity Policies in Post-Soviet States. Mir Rossii. Sotsiologiya. Ehtnologiya = Universe Of Russia. Sociology. Ethnology. 2016; 25(2):144-167. Available at: https://elibrary.ru/item.asp?id=26283969 (accessed 10.09.2019). (In Russ., abstract in Eng.)

8. Costa Buranelli F. World Society as a Shared Ethnos and the Limits of World Society in Central Asia. International Politics. 2018; 55:57-72. (In Eng.) DOI: https:// doi.org/10.1057/s41311-017-0064-6

9. Lapkin V.V. Problems of Nation Building in Multi-Ethnic Post-Soviet Societies: Ukrainian Case in Comparative Perspective. Polis. Politicheskie issledovaniya $=$ Policy. Political Research. 2016; (4):54-64. (In Russ., abstract in Eng.) DOI: https:// doi.org/10.17976/jpps/2016.04.06

10. Bakhlov I.V., Bakhlova O.V. Fundamentals of the Ideology of Nation Building in Modern Russia: The Approaches of Political Parties. Izvestiya Saratovskogo universiteta. Novaya seriya. Seriya Sotsiologiya. Politologiya $=$ Izvestia of Saratov University. New Series. Series: Sociology. Politology. 2018; 18(3):354-362. (In Russ., abstract in Eng.) DOI: https://doi.org/10.18500/1818-9601-2018-18-3354-362

11. Kuropatkina O.V. The Role of Religion in Modern Russian Nation Building. Problemnyj analiz i gosudarstvenno-upravlencheskoe proektirovanie = Problem Analysis and Public Administration Projection. 2014; 7(1):26-38. Available at: https://elibrary.ru/item.asp?id=21480166 (accessed 10.09.2019). (In Russ., abstract in Eng.)

12. Maksimova O.N. Ethnic Identity as the Demarcation of the Sociopolitical Space. Sovremennoe obshhestvo $i$ vlast = Modern Society and Power. 2018; (3):46-57. Available at: https://elibrary.ru/item.asp?id=36511880 (accessed 10.09.2019). (In Russ., abstract in Eng.)

13. Sadovaya E.S. Socio-Economic Factors of Ethnopolitical Conflict. Polis. Politicheskie issledovaniya = Policy. Political Research. 2016; (4):41-53. (In Russ., abstract in Eng.) DOI: https://doi.org/10.17976/jpps/2016.04.05

14. Tkachenko A.G. The Strengthening of Russian National Identity as a Counteraction to Radical Nationalism. Vestnik Akademii ehkonomicheskoj bezopasnosti MVD Rossii = Bulletin of the Academy of Economic Security of the Ministry of Internal Affairs of Russia. 2015; (6):70-74. Available at: https://elibrary.ru/item. asp?id=24211106 (accessed 10.09.2019). (In Russ., abstract in Eng.)

15. Gorshkov M.K., Tyurina I.O. Synthesis of Ethnic and Civil as a Basis for The Russian Identity. Vestnik RUDN. Seriya: Sotsiologiya = RUDN Journal of Sociology. 2018; (1):44-57. (In Russ., abstract in Eng.) DOI: http://dx.doi.org/10.22363/23132272-2018-18-1-44-57

16. Dolgaeva E.I. Interpretation of the Factors of the All-Russian National and Civil Identity by the Inhabitants of a Multiethnic Region. Regionologiya = Regionology. 
2018; 26(1):123-140. (In Russ., abstract in Eng.) DOI: https://doi.org/10.15507/24131407.102.026.201801.123-140

17. Pushkareva G.V. Ideas and Values as a Method of Constructing Symbolic Space of the National Identity. Polis. Politicheskie issledovaniya $=$ Policy. Political Research. 2017; (5):156-173. (In Russ., abstract in Eng.) DOI: https://doi.org/10.17976/ jpps/2017.05.11

18. Soldatova A.S., Shirmanov E.V. National, Ethnic and Regional Identities of Inhabitants of Mordovia (Based on Applied Research). Ars Administrandi. 2015; (1):51-60. Available at: http://ars-administrandi.com/abstracts.php?id=441 (accessed 10.09.2019). (In Russ., abstract in Eng.)

19. Zaykov K.S., Tamitskiy A.M., Zadorin M.Yu. The Basics of Ethno-National Policy on the Example of the Russian Federation. Federalizm $=$ Federalism. 2016; (3):145-158. Available at: https://elibrary.ru/item.asp?id=27339772 (accessed 10.09.2019). (In Russ., abstract in Eng.)

20. Tolkunov N.S. The Role of Ethno-Politics in the Formation of the Russian Civil Nation. Izvestiya Saratovskogo universiteta. Novaya seriya. Seriya Sotsiologiya. Politologiya $=$ Izvestia of Saratov University. New Series. Series: Sociology. Politology. 2018; 18(4):474-478. (In Russ., abstract in Eng.) DOI: https://doi.org/10.18500/18189601-2018-18-4-474-478

21. Posukhova O.Yu., Serikov A.V. Russian National Policy in Assessment and Perception of South-Russian Region Population. Vlast = Power. 2017; (8):143-150. Available at: https://www.jour.isras.ru/index.php/vlast/article/view/5339 (accessed 10.09.2019). (In Russ., abstract in Eng.)

22. Minchuk O.V. Ethnonational Policy of the Komi Republic: Normative and Infrastructural Support. Arktika $i$ Sever = Arctic and North. 2016; (25):134-147. DOI: https://doi.org/10.17238/issn2221-2698.2016.25.137

23. Madyukova S.A., Persidskaya O.A. Ethnonational Policy in Republic of Altai. Sibirskij filosofskij zhurnal = Siberian Journal of Philosophy. 2016; (1):120-134. Available at: https://nsu.ru/sibphil/2016.1 (accessed 10.09.2019). (In Russ., abstract in Eng.)

24. Popkov Yu.V. Regional Features of Ethnonational Policy. Novye issledovaniya Tuvy $=$ New Research of Tuva. 2013; (4):9-28. Available at: https://nit.tuva.asia/nit/ article/view/195 (accessed 10.09.2019). (In Russ., abstract in Eng.)

Submitted 10.09.2019; accepted for publication 18.10.2019; published online 30.12.2019.

About the authors:

Irina G. Napalkova, Associate Professor, Department of World History, Political Science and Regional Studies, National Research Mordovia State University (68/1 Bolshevistskaya St., Saransk 430005, Russia), Ph. D. (History), ORCID: https://orcid. org/0000-0003-3896-1600,zamisi@yandex.ru

Anna S. Soldatova, Research Assistant, Center for Science and Education 'Political Analysis of Territorial Systems', National Research Mordovia State University (68/1 Bolshevistskaya St., Saransk 430005, Russia), ORCID: https:// orcid.org/0000-0003-0247-1917, anasoldatova@mail.ru 
Ksenia V. Kurochkina, Political Scientist; Master's Degree Student, Department of World History, Political Science and Regional Studies; Research Officer, Center for Science and Education 'Political Analysis of Territorial Systems', National Research Mordovia State University (68/1 Bolshevistskaya St., Saransk 430005, Russia), ORCID: https://orcid.org/0000-0001-6993-4766, ksen.kurochckina2017@yandex.ru

Contribution of the authors:

Irina G. Napalkova - academic supervision; putting forward the basic idea of the study; substantiation of the theoretical and methodological foundations of the study; critical analysis; drawing conclusions; writing the article.

Anna S. Soldatova - development of theoretical and methodological foundations of the study; data collection and processing; writing the article.

Ksenia V. Kurochkina - search for analytical materials; analysis of statistical and factual material; preparation of the initial version of the text.

For citation:

Napalkova I.G., Soldatova A.S., Kurochkina K.V. Specifics of the Development of the Ethno-National Space of Modern Russia as a Factor in Nation Building: A Strategic Situational Analysis. Regionology = Russian Journal of Regional Studies. 2019; 27(4):734-755. DOI: https://doi.org/10.15507/2413-1407.109.027.201904.734-755

The authors have read and approved the final version of the manuscript. 


\section{СОЦИАЛЬНАЯ СТРУКТУРА, СОЦИАЛЬНЫЕ ИНСТИТУТЫ И ПРОЦЕССЫ / SOCIAL STRUCTURE, SOCIAL INSTITUTIONS AND PROCESSES}

УДК 330.43(4)

DOI: $10.15507 / 2413-1407.109 .027 .201904 .756-778$

http://regionsar.ru ISSN 2587-8549 (Print) ISSN 2413-1407 (Online)

\section{Факторы миграционной привлекательности провинциального города (на примере г. Саранска)}

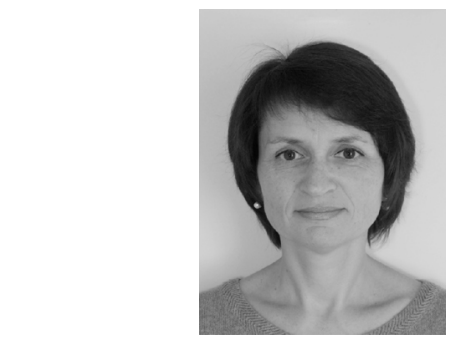

К. В. Фофанова"

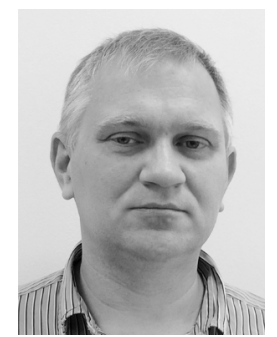

А. А. Сычев

ФГБОУ ВО «МГУ им. Н. П. Огарёва» (г. Саранск, Россия),

Введение. Народонаселение является важнейшим экономическим, социальным и культурным ресурсом, и тенденция к его сокращению выступает серьезным препятствием для развития городов. В России наблюдаются процессы сокращения населения за счет его естественной убыли, которая до недавних пор компенсировалась миграционным приростом. Однако в последние годы внешние иммиграционные потоки значительно сократились. В этих условиях актуальность приобретает задача повышения привлекательности провинциального города для мигрантов. Выявление и комплексный анализ всего многообразия факторов миграционной привлекательности городского пространства (на примере г. Саранска) является целью настоящего исследования.

Материалы и методы. В исследовании использованы качественные и количественные методы. Основным методом выступил метод полуструктурированного интервью, дополненный методом вторичного анализа статистических данных. Эмпирической базой послужили 57 полуструктурированных интервью, проведенных в 2017-2019 гг. с мигрантами, в том числе участниками Государственной программы по переселению соотечественников и иностранными студентами, обучающимися в г. Саранске.

Результаты исследования. Анализ интервью демонстрирует, что привлекательность региона обусловливается не каким-либо одним фактором, а их системной совокупностью. Определены факторы, влияющие на выбор региона для пере-

(C) Фофанова К. В., Сычев А. А., 2019 Контент доступен под лицензией Creative Commons Attribution 4.0 License. This work is licensed under a Creative Commons Attribution 4.0 License. 
езда: экономические, социальные, культурные, политические, природные. Хотя в процессе принятия решения основной удельный вес принадлежит факторам экономического характера, значимое влияние на выбор региона оказывают и наличие крепких социальных связей, отношение населения и официальных лиц, доступность образования и жилья, экологическая обстановка.

Обсуждение и заключение. При разработке миграционной политики следует учитывать все группы факторов, способствующих привлечению мигрантов в провинциальный город. Анализ этих факторов, сравнение ожиданий приезжих и реальных проблем, с которыми они сталкиваются, позволяют предметно повышать уровень миграционной привлекательности города, учитывать при планировании изменений в городском пространстве мнение мигрантов как полноправных субъектов социальных изменений. Статья может быть полезна исследователям в области социологии миграции и сотрудникам служб и организаций, занимающихся разработкой миграционной политики на региональном уровне.

Ключевые слова: миграционная привлекательность, провинциальный город, трудовые мигранты, соотечественники, иностранные студенты, переселенцы, адаптация

Финансирование. Исследование выполнено при финансовой поддержке РФФИ в рамках научного проекта № 17-03-00370-ОГН.

\title{
Factors in Migration Attractiveness of a Provincial City: The Case Study of the City of Saransk
}

\author{
K. V. Fofanova*, A. A. Sychev \\ National Research Mordovia State University (Saransk, Russia), \\ *kateri02@yandex.ru
}

Introduction. Population is one of the most important economic, social and cultural resources, and the tendency of decline in population is a serious obstacle to urban development. In Russia, the processes of decline in population have taken place due to its natural loss, which until recently has been offset by migration growth. However, in recent years, external immigration flows have reduced significantly. In these conditions, the task of increasing the attractiveness of a provincial city for migrants is of particular relevance. The objective of this study is identification and comprehensive analysis of the full diversity of factors in migration attractiveness of urban space, exemplified by the city of Saransk.

Materials and Methods. The study employed qualitative and quantitative research methods, the method of semi-structured interview, supplemented by the method of secondary analysis of statistical data, being the main one. 57 semi-structured interviews with migrants, including participants of the State Program for Resettlement of Compatriots and foreign students studying in the city of Saransk, conducted in 2017-2019, provided the empirical basis for this research.

Results. The performed analysis of the interviews has shown that attractiveness of a region is determined not by some single factor, but by a systemic combination of them. The following factors influencing the choice of a region for resettlement have been identified: economic, social, cultural, political and natural ones. Although in the decision-making process the economic factors are the most important ones, 
the presence of strong social ties, the attitude of the population and officials, the availability of education and housing, and the environmental situation also have a significant impact on the choice of the region.

Discussion and Conclusion. When developing migration policies, all groups of factors that help attract migrants to a provincial city should be taken into account. Analysis of these factors as well as comparison of the expectations of newcomers and the real problems they face, make it possible to substantively increase the migration attractiveness of a city and to take into account the opinion of migrants as full-fledged subjects of social change when planning changes in the urban space. The paper may be useful to researchers in the field of sociology of migration and employees of services and organizations involved in the development of migration policies at the regional level.

Keywords: migration attractiveness, provincial city, labor migrants, compatriots, foreign students, settlers, adaptation

Funding. The study was carried out with the financial support from the Russian Foundation for Basic Research as part of the scientific project No. 17-03-00370-OGN.

Введение. Народонаселение является важнейшим экономическим, социальным и культурным ресурсом, и тенденция к его сокращению, фиксируемая в ряде стран и регионов, выступает серьезным препятствием для их развития. Депопуляция создает или усиливает серьезные проблемы в различных сферах общественной жизни: уменьшение количества трудоспособного населения приводит к дефициту рабочей силы и спаду в экономике; быстрое старение общества усиливает нагрузку на системы здравоохранения и пенсионного обеспечения; отток населения в большие города ведет к вымиранию деревень и т. д.

В России многие десятилетия наблюдаются процессы сокращения населения за счет его естественной убыли (превышения смертности над рождаемостью), которая до недавних пор компенсировалась миграционным приростом. В первое десятилетие после развала Советского Союза важным источником этого прироста были соотечественники, массово возвращавшиеся на историческую родину из новых независимых государств, позже - трудовые мигранты из менее благополучных государств СНГ. После 2014 г. основу миграционного потока составили жители Украины, вынужденные покинуть свою страну из-за серьезных рисков для жизни и благополучия. Однако к 2018 г. эти потоки иссякли, и миграционный прирост составил всего лишь 124,9 тыс. чел., что является самым низким показателем за всю историю современной России. Соответственно, впервые за много лет общее население страны не выросло, а сократилось: общая убыль составила 99,7 тыс. чел. ${ }^{1}$. В ряду

${ }^{1}$ Федеральная служба государственной статистики. Компоненты изменения численности населения Российской Федерации [Электронный pecypc]. URL: http:/www.gks.ru/wps/wcm/ connect/rosstat_main/rosstat/ru/statistics/population/demography/\# (дата обращения: 01.06.2019). 
причин, которые привели к этой ситуации, можно назвать ухудшение экономической ситуации в России, усиление эмиграции за ее пределы, переориентацию миграционных потоков с России на другие страны (так, для Средней Азии центром притяжения мигрантов становится культурно близкий Казахстан, а Украина и Молдавия активно пользуются возможностями безвизового въезда в Европейский союз).

Региональные статистические данные последних лет демонстрируют ту же тенденцию к снижению входящих миграционных потоков. Однако в распределении миграции по регионам наблюдается заметная диспропорция: подавляющая часть мигрантов ориентированы на крупные городские агломерации, прежде всего на Москву, Санкт-Петербург, а также Московскую и Ленинградскую области. Менее экономически развитые регионы и провинциальные российские города, которые не могут предложить мигрантам сопоставимых возможностей для поиска работы, организации бизнеса и получения достойной заработной платы, остаются на периферии миграционного процесса. Соответственно, если в экономически развитых регионах еще можно надеяться на то, что внешняя миграция будет компенсировать естественную убыль, то в менее развитых регионах реализация такого сценария без эффективных федеральных и региональных программ по привлечению мигрантов представляется маловероятной.

Диспропорция между регионами усугубляется в силу внутренней миграции: трудоспособное население из менее благополучных регионов России все активнее перебирается в экономические центры в поисках работы и лучших условий для самореализации. В итоге значительно ослабляется хозяйственный и культурный потенциал регионов-доноров, что в долгосрочной перспективе может привести к экономическому расслоению населения по региональному признаку и усилению социальных противоречий между центром и периферией внутри страны.

В то же время переезд большого количества внешних и внутренних мигрантов в экономические центры России нельзя однозначно назвать благом для принимающих регионов. С одной стороны, они действительно усиливают экономический и креативный потенциал крупных городов, с другой - рост этнического и культурного разнообразия все чаще вызывает опасения не готового к таким изменениям принимающего сообщества. Некоторые исследователи предполагают, что неконтролируемая миграция в большие города способна привести к возникновению закрытых национальных анклавов, появлению этнической преступности, обострению межнациональных отношений и т. д. Если сейчас эта проблема не кажется серьезной, то в будущем отсутствие эффективных программ интеграции мигрантов в крупных мегаполисах способно привести к возникновению серьезной напряженности между коренным населением 
и мигрантами, а также к конфликтам за сферы влияния между разными этническими группами [1].

Таким образом, диспропорциональное распределение миграционных потоков способно породить проблемы как для тех регионов, куда они почти не попадают, так и для экономически благополучных регионов. В подобных условиях важной задачей государства и общества становится сглаживание усиливающихся дисбалансов [2, с. 640], в том числе равномерное распределение потоков миграции, предполагающее повышение миграционной привлекательности провинции.

Достаточно типична в этом аспекте ситуация в Республике Мордовия. Население республики стабильно сокращается с 1970-х гг. Среди регионов Приволжского федерального округа у Мордовии один из самых высоких коэффициентов естественной убыли населения - 5,1 на 1000 чел. $^{2}$. В 2018 г. миграционная убыль составила 5,5 тыс. чел. Население региона уезжает в основном в Московскую область, Москву и Санкт-Петербург. Согласно официальным прогнозам, численность населения республики в ближайшие десятилетия будет только уменьшаться ${ }^{3}$. Уже очевидно, что программы по поощрению рождаемости не способны коренным образом преломить ситуацию, а непродуманные запретительные меры, предлагаемые в качестве решения проблемы [3, с. 145], способны только усугубить обстановку, сделав многие регионы крайне непривлекательными для жизни. Конечно, специальные программы по повышению рождаемости и меры, стимулирующие трудоустройство молодежи в регионе, необходимы. Однако следует признать, что на сегодняшний день единственным реально функционирующим каналом восполнения убыли населения в регионе является внешняя миграция.

Республика в последние годы вызывает интерес, по большей части, у трудовых мигрантов из стран Средней Азии - Узбекистана, Таджикистана, Туркменистана, т. е. тех стран, где экономическая обстановка менее благополучна, чем в России ${ }^{4}$. Однако поток мигрантов даже из этих стран слишком мал для того, чтобы оказать заметное влияние на ситуацию в регионе. Для решения демографических и экономических проблем необходимы не абстрактные мигранты, а люди, успешно интегрированные в экономику, общество, культуру принимающего региона.

2 Коэффициенты рождаемости, смертности и естественного прироста населения // Социально-экономическое положение России. 2019. № 1. С. 387.

3 Территориальный орган Федеральной службы государственной статистики по Республике Мордовия. Прогноз численности населения РМ до 2035 года [Электронный peсурс]. URL: http://mrd.gks.ru/wps/wcm/connect/rosstat_ts/mrd/ru/statistics/population/ (дата обращения: 01.06.2019).

${ }^{4}$ Территориальный орган Федеральной службы государственной статистики по Республике Мордовия. Общие итоги миграции населения в Республике Мордовия [Электронный pecypc]. URL: https://mrd.gks.ru/folder/27964 (дата обращения: 01.06.2019). 
В этой связи важной задачей для властей на региональном уровне становится привлечение на постоянное место жительства в регион тех лиц, которые могут успешно интегрироваться в принимающее общество и стать полноправными жителями страны. Для этого необходима комплексная концепция региональной миграционной политики, которая рассматривала бы привлечение мигрантов и их адаптацию к жизни в республике в качестве важного условия развития территории. Разработка такой концепции предполагает постоянный мониторинг миграционных процессов, выявление основных барьеров, препятствующих интеграции мигрантов, а также учет региональных особенностей при анализе факторов, влияющих на выбор территории вселения и закрепление мигрантов в регионе.

Основной поток мигрантов в Республику Мордовия направлен в ее экономический центр - город Саранск. Очевидно, что он, подобно многим другим провинциальным городам России, не может предложить столь же широких возможностей в сфере занятости и оплаты труда, как крупные мегаполисы. Поэтому можно предположить, что для привлечения мигрантов городские и республиканские власти должны мобилизовать ресурсы не только экономического, но и социального, культурного, политического, экологического характера. Соответственно, цель настоящего исследования можно обозначить как выявление и комплексный анализ всего многообразия факторов привлекательности провинциального городского пространства для мигрантов.

Обзор литературы. Теоретические подходы к научному изучению миграции населения были обозначены еще в конце XIX в. британским ученым Э. Равенштайном, провозгласившим, что одним из базовых законов миграции является ее экономическая обусловленность ${ }^{5}$. Эти идеи заложили основной вектор изучения миграции. Так, Б. Томас считает, что направленность миграции определяется разницей экономических потенциалов разных стран и чередованием циклов их экономического развития ${ }^{6}$ О. Старк полагает, что для человека с недостаточным доходом миграция выступает инструментом решения конкретных экономических вопросов, например, преодоления проблем с нехваткой кредита или капитала [4].

Одну из первых теорий, объясняющих миграцию с позиции многофакторного подхода, предложил Э. Ли. По его мнению, решение о миграции принимается под воздействием разновекторных (экономических, политических, культурных и т. д.) сил, воздействующих на мигранта,

${ }^{5}$ Ravenstein E. G. The Laws of Migration // Journal of the Statistical Society of London. 1885. Vol. 48, no. 2. Pp. 167-235.

${ }^{6}$ Thomas B. Migration and Economic Growth: The Study of Great Britain and Atlantic Economy. Cambridge: Cambridge University Press, 1973. 498 p. 
как в месте исхода, так и в месте прибытия. При этом одни факторы отталкивают его от переезда, а другие - принуждают к нему. К базовым притягивающим факторам, считает Э. Ли, следует отнести более высокий уровень экономического развития, высокую заработную плату, доступ на официальный или неофициальный рынок труда и т. д. ${ }^{7}$.

На основе этих разработок в Европейском союзе проводятся исследования по сравнению миграционной привлекательности европейских стран [5], ведется изучение привлекательности городов [6].

В контексте настоящего исследования определенный интерес представляет научная работа Дж. Хиндмана, Н. Шуурман и Р. Файдлера о привлекательности малых городов для мигрантов, выполненная на примере Канады. Авторы акцентируют внимание на важности перенаправления потока мигрантов в малые города. В качестве основных факторов привлекательности малых городов они учитывают перспективы получения работы и ведения бизнеса (удельный вес этого фактора составляет 41,5 \%), наличие семьи и друзей $(39,1 \%)$, образование $(13,3 \%)$ и образ жизни $(6,1$ \%), куда включаются возможности для отдыха, климат и т. д. [7].

В некоторых российских публикациях получили развитие вопросы, связанные с изучением не только экономических, но и политических, нормативно-правовых, социокультурных аспектов миграции. Так, важный теоретико-методологический и эмпирический вклад в исследование проблем миграции вносят работы А. С. Ахиезера, обратившего внимание на то, что массовые миграции могут совершаться даже в том случае, если экономический уровень жизни переселенцев в результате переезда не повышается, а падает. Ученый находит много примеров в истории России, когда люди бежали от государства, слишком бесцеремонно вмешивающегося в их жизнь и подавляющего их свободу. Он пишет: «Человеческие потребности не редуцируются к желанию следовать вектору, указывающему на более “сытую” жизнь, на ценности, которые можно свести к потребительству. Такая модель больше напоминает поведение животных, но не человека» [8, с. 149]. Учет социокультурного подхода А. С. Ахиезера позволяет выйти за рамки узкого экономического детерминизма и посмотреть на проблему миграции в более широком контексте.

В работах С. В. Рязанцева поднимается вопрос баланса интересов местного населения и мигрантов. Позиция, защищаемая ученым, строится на гуманитарном подходе, предусматривающем восприятие мигрантов не только с точки зрения экономических преимуществ [9]. С другой стороны, как замечает автор, и сам современный мигрант уже ориентируется не только на показатели высокого уровня дохода, но

${ }^{7}$ Lee E. A Theory of Migration // Demography. 1966. No. 3. Pp. 47-57. 
и на условия, обеспечивающие более высокое качество жизни в целом. Поэтому постановка проблемы о факторах привлекательности конкретных стран, регионов, городов в настоящее время предполагает выход за пределы экономической рациональности.

Среди современных отечественных исследований стоит отметить работы М. В. Драгун, А. Л. Кривовой, Г. Ю. Никипорец-Такигавы, Л. Е. Тихоновой по миграционной привлекательности различных стран ${ }^{8}$ [10], П. О. Гуршалова, Н. А. Киселева, А. И. Латышевой, Н. А. Лоскутниковой, Е. Б. Олейник по привлекательности отдельных российских регионов [11; 12], а также исследования Н. А. Петухова, Н. П. Горидько, посвященные привлекательности городов [13; 14]. В сравнении с результатами этих и других подобных им исследований четче проявляется специфика привлекательности г. Саранска для миграции.

Таким образом, в изучении проблемы привлекательности конкретных стран, регионов, городов в настоящее время проявляется тенденция к выходу за пределы экономической рациональности и систематическому учету всего многообразия факторов притяжения, прежде всего социальных и культурных.

Материалы и методы. Для решения поставленных задач использован метод полуструктурированного интервью, позволивший выявить основные мотивы, которыми руководствовались мигранты при принятии решения о переезде.

В целях изучения факторов привлекательности провинциального города (на примере г. Саранска) проведено качественное исследование, носящее разведывательный характер: не ставя своей целью достижение репрезентативной доказательности, оно наметило базовые точки координат, вокруг которых кристаллизуются зоны привлекательности для тех, кто принимает решение о переезде.

Эмпирической базой исследования выступили 57 полуструктурированных интервью. Из них 32 интервью проведены с трудовыми мигрантами и участниками Госпрограммы по переселению соотечественников, приехавшими из Таджикистана, Узбекистана, Украины, Казахстана, Молдовы, Армении, 25 - с учебными мигрантами из Таджикистана, Туркменистана, Узбекистана, Саудовской Аравии, Индии, Ирака, Марокко. У информантов различный семейный статус и разный уровень образования. Их возраст - от 20 до 60 лет.

Выбор для исследования г. Саранска обусловлен несколькими причинами. Во-первых, Саранск достаточно типичный провинциальный город Приволжского федерального округа с проблемными зонами в области

${ }^{8}$ Тихонова Л. Е., Драгун М. В. Миграционная привлекательность Республики Беларусь в структуре общемировых тенденций // Устойчивое развитие экономики: международные и национальные аспекты. Новополоцк: Изд-во ПГУ, 2018. С. 73-78. 
демографии. Во-вторых, город относится к территориям с крайне низкой миграционной привлекательностью [15]. Уровень жизни в городе выталкивает местное население в Москву и другие крупные города, и долгосрочное развитие города во многом зависит от грамотной миграционной политики. В-третьих, в регионе с 2011 г. реализуется Государственная программа по оказанию содействия добровольному переселению в Российскую Федерацию соотечественников, проживающих за рубежом, за время которой в республику (прежде всего в ее столицу) переехали более 3000 переселенцев и членов их семей.

Анализ и интерпретация результатов осуществлялись в рамках социокультурного подхода (А. С. Ахиезер), позволяющего системно исследовать многообразие факторов миграционной привлекательности.

Таким образом, на миграционную привлекательность города влияют как притягивающие, так и отталкивающие факторы, которые требуют анализа и систематизации.

В основании исследовательской гипотезы лежит предположение о том, что кажущиеся очевидно превалирующими экономические факторы выступают не единственными в процессе принятия решений. Для мигрантов, которые рассматривают провинциальный город как место переселения, крайне важно общее качество жизни, предполагающее наилучший баланс объективных и субъективных факторов.

Собранные в ходе проведения интервью материалы, дополненные вторичным анализом статистических данных, позволяют проанализировать многообразие факторов, учет которых способен сделать провинциальный город центром притяжения для мигрантов.

Результаты исследования. Высказывания мигрантов можно распределить по нескольким группам, в зависимости от акцентирования, факторов, повлиявших на выбор региона (экономических, социальных, культурных и т. д.). В данном случае следует говорить именно об акцентах, поскольку интервью демонстрируют, что привлекательность региона обусловливается не каким-либо одним фактором, а их системной совокупностью.

Описывая экономические условия, опрошенные отмечают, что ситуация в Саранске с поиском работы далека от идеальной: «Я через месяц нашла работу, а молодому человеку пришлось совсем туго, он вообще три месяца ее искал. Мы-то сюда в ноябре приехали, вот так сложно начать работать, может быть и не сезон был»; «Очень долго искала, полгода найти не могла эту работу»; «Некоторые вообще ищут полгода работу, тут трудно что-то найти».

Нередко отмечается, что работодатели при наличии выбора предпочитают брать на работу лиц с гражданством, видимо, опасаясь дополнительного внимания и проверок контролирующих органов: «После 
стройки звонил, искал работу, я сварщик, сразу гражданство спрашивают. Без гражданства - ты здесь никто»; «Ой, не сразу [нашел работу], я как понял, у вас тут все туго с ней и без гражданства практически не берут никуда, я много куда ходил на собеседования, но только через полгода работу нашел, опять же друг попросил одноклассника меня взять, а даже не знаю, куда бы я пошел».

Судя по некоторым интервью с трудовыми мигрантами из Средней Азии, среди многих работодателей, которые готовы принять на работу людей без гражданства, распространены представления о том, что те должны работать за более низкую заработную плату, чем граждане России, и быть готовыми к низкоквалифицированной и неофициальной работе: «Работала, где только не работала, не особо кто берет без документов. ...С РВП очень сложно берут на работу, а если и берут, то сразу предлагают зарплату намного ниже»; «Сначала работал на стадионе поваром, готовил на 1000 человек. Зарплату не давали по 2-3 месяца. Директор столовой, они готовят на стадионе, не оформил меня официально, сказал: не буду. 4 месяца так работал, якобы нет квот. Ушел оттуда, работал где придется. А нужна мне официальная работа, никто не берет. Устроился обвальщиком, отработал месяц - заплатили 3 700».

Таким образом, нередко сама ситуация на рынке труда и отношение работодателей толкают мигрантов на осуществление трудовой деятельности без соответствующего разрешения, а значит и на нарушение режима пребывания в России. Очевидно, что действия подобного рода являются причиной самоизоляции некоторых групп мигрантов, которые стараются лишний раз не пересекаться с местным населением, и в перспективе могут стать плодотворной почвой для дальнейшей криминализации их деятельности.

Повышение привлекательности региона в этом контексте предполагает действия, как минимум, в двух направлениях: оказание помощи мигрантам в поиске соответствующей их квалификации работы и снятие барьеров, вынуждающих их соглашаться на неофициальную или низкооплачиваемую работу. Такие действия будут не только способствовать повышению миграционной привлекательности региона, но и сглаживать потенциальную напряженность между приезжими и местным населением.

Помимо сложностей с поиском работы, мигранты в качестве негативного явления отмечают невысокие заработные платы в регионе: «Я работаю без выходных и обеда вообще, очень тяжело, я очень устаю, зарплата тоже небольшая, сейчас жена вышла на работу, более менее легче стало»; «Не очень нравится заработная плата, маловата. А так все нормально»; «Зарплаты тут у всех маленькие, а цены на продукты такие же, как в крупных городах».

С другой стороны, многие мигранты готовы мириться с низкими заработными платами в регионе. Они понимают, что местные жители также 
получают немного, поэтому, за редким исключением, не считают себя дискриминируемыми. Если бы разрыв в доходах был заметнее, у них было бы больше причин оценивать свои заработные платы в контексте социальной справедливости: «С зарплатой все как у всех, хотелось бы больше, но тут у всех такие»; «Все устраивает, даже зарплата нормальная более-менее для Саранска, хотелось бы больше, конечно, но я доволен, что вообще есть работа».

Кроме того, по сравнению со сложной экономической ситуацией в странах исхода уже само наличие работы (даже и низкооплачиваемой) может быть преимуществом: «Зарплата, конечно, очень маленькая, терпимо, так сказать, но спасибо хоть вообще есть работа..»; «Там нет работы, нет законов, нет уважения друг к другу. Как можно там жить, нет работы. Что мы можем там кушать, если нет работы».

В некоторых случаях экономическая ситуация в стране исхода усугублялась военными действиями или коррупцией и беззаконием, так что переезд в любое относительно спокойное место однозначно воспринимался как благо: «Мы с семьей бежали от войны, наш дом обстреляли. Мы были в панике, собрали вещи и приехали сюда»; «Мы переждем это ужасное время, когда война шла, и обратно вернемся, потом будем жить нормально снова, но смотрите, какая обстановка и по сей день, не утихает это все, только хуже все становится»; «Есть только президент и его дочери, зятья, как они хотят, так все и делают, там нет суда и нет законов».

Однако экстремальная ситуация - скорее исключение, чем правило. В подавляющем большинстве причина переезда - экономическая. Очевидно, что в подобном случае привлекательность региона относительна: она зависит не от условий, существующих в регионе, а от внешней конъюнктуры. Как только ситуация в странах исхода улучшится (по крайней мере в Средней Азии для этого есть демографические ресурсы) и другие страны откроют свой рынок труда для мигрантов (как это сделал Европейский союз для жителей Украины и Молдавии), потоки мигрантов в Мордовию и подобные ей регионы иссякнут. В этом аспекте для привлечения и закрепления мигрантов следует искать дополнительные стимулы.

Одним из важных ресурсов развития региона, где мигранты могли бы реализовать себя, является малое предпринимательство: «Если честно, хочется что-то свое уже открывать, чтобы не зависеть ни от кого»; «Самое главное, когда дети закончат 5-6 класс, чтобы работа была, надо потом учить детей, нужны будут деньги. Надо сделать бизнес вот до этого возраста детей, для их удобства. И будем свободными людьми».

Многие опрошенные мигранты - это молодые и амбициозные люди, готовые рисковать. Их качества можно направить в общественно полезное 
русло, оказав информационную и образовательную поддержку (например, организовав курсы, посвященные правовым и экономическим аспектам организации бизнеса в России) и практическую помощь в открытии своего дела. Учитывая дефицит кадров в сельскохозяйственном секторе и наличие некоторого количества мигрантов из сельской местности, можно предположить, что одной из форм такого предпринимательства могут стать семейные фермы: «Как получу гражданство - покупаю сразу дом в деревне, без помощи чьей-то. Деньги чуть-чуть есть. Все собираем, складываем, 25 тысяч в месяц откладываем. В деревне мне нужен будет дом, земля большая, хочу маленькую ферму. Хочу 100-150 коров. У меня есть расчет уже всего. Молоко будем продавать, мясо».

Экономические факторы миграции практически всегда усиливаются факторами социального характера. На карте России можно найти города, где мигрант получит больше возможностей для трудоустройства, чем в Саранске. Однако если у него есть родственники, знакомые, друзья в Саранске, оценка ситуации кардинальным образом меняется. Подавляющее большинство опрошенных приехали в Саранск, имея в городе определенную поддержку со стороны местных жителей или ранее переехавших мигрантов: «Здесь у моей мамы живет родная сестра - моя тетя, мне нужно было приехать туда, где была бы хоть какая-то опора, ну, точка опоры, чтобы хоть остановиться на ночь где было. Может и подсказать что-то, я сам еще думал о Москве или Ростове как альтернативе, если тут не получится ничего»; «Толчком стал звонок двоюродной сестры из Саранска. Мы не общались никогда практически, и вдруг она решила нас найти и нам позвонить, вот позвонила, все расспросила и говорит приезжайте. Мы вообще потерялись с ней, 16 лет не общались»; «Я приехал сначала в Москву, там не нравится мне жить. Друзья посоветовали в Мордовию поехать. Друзья проходили по программе. Работают здесь, все хорошо»; «У моего мужа тут были знакомые таджики, которые здесь хорошо устроились, они ему сказали, что лучше сюда переехать, у нас муж глава семьи, поэтому мы все следуем его решению, решили приехать именно сюда, регион небольшой, спокойный, дружелюбный».

Можно предположить, что во многом такая ситуация связана с тем, что подавляющее большинство мигрантов - жители бывшего Советского Союза, которые после распада государства привыкли больше полагаться на социальные связи (кровнородственные отношения, знакомства, личные договоренности, сетевой ресурс), а не на работу, которую в условиях кризиса можно легко потерять, или финансовые накопления, которые могут в одночасье обесцениться.

Учитывая значение социальных связей для приезжих, городские власти могут организовывать взаимодействие с «узловыми центрами» мигрантских сетей, упорядочивая и облегчая их взаимодействие с ра- 
ботодателями, государственными органами, общественностью и т. д. В этом контексте представляется перспективной поддержка национальнокультурных автономий, диаспор и других этнически ориентированных общественных организаций [16].

Важным является вовлечение мигрантов в ассоциации гражданского общества, поддерживающие, выражаясь терминами Р. Патнэма, контактоустанавливающий (bridging), а не связывающий (bonding) тип социального капитала [17]. Такие ассоциации способствуют налаживанию и укреплению связей между представителями разных национальностей или культур, поскольку для успеха в ассоциации (например, в хоккейной команде или любительском оркестре) личные способности оказываются значимее этнических различий. Контактоустанавливающий капитал содействует распространению норм доверия на широкий круг лиц, способствуя тесной интеграции мигрантов в локальное сообщество [18].

Наконец, важной составляющей социальной группы факторов, определяющих привлекательность региона и перспективы интеграции мигрантов, является отношение к мигрантам местного населения. В целом все мигранты отмечают, что какого-либо ярко выраженного предвзятого отношения со стороны жителей Саранска они не ощущают: «Плохого человека не увидел за два года, не как в Москве, в Москве мы чурки. Здесь лучше Москвы, спокойно, там много народа»; «Общаемся с соседями, со всеми в подъезде, и со мной и с женой, все очень хорошо к нам относятся, это все без проблем, все очень хорошо. Ну и так с местными людьми общаюсь, с ребятами отдела полиции общаюсь, они уже все нас знают. Здесь в Саранске хорошо, это в Москве что только не скажут».

Особенно ярко контраст в отношениях с местным населением проявляется при сравнении с отношением жителей больших мегаполисов, а также некоторых национальных государств СНГ. Некоторые мигранты, оформляющие документы по программе возвращения соотечественников, в качестве одной из причин переезда назвали отношение к себе местных жителей в стране исхода: «Изначально чужой здесь не ощущала себя. Вот там ощущала, на работу ездила на попутке в Алма-Ату, так с меня как со светлой брали в два раз больше, там один негатив был. Здесь я не бросаюсь в глаза, вот уже два года работаю, все хорошо».

Вполне доброжелательное отношение жителей Саранска к приезжим можно объяснить тем, что Мордовия - это зона этнического контакта. На территории региона сотни лет сосуществуют разные нации, культуры и конфессии. За это время в республике накопился достаточный объем социального капитала, позволяющий поддерживать стабильность в обществе, т. е. выработалась толерантность к «чужому», уважительное отношение к другим культурам и религиям. 
На восприятие города влияет и его провинциальный характер: в отличие от постоянной суеты мегаполисов жизнь здесь движется медленнее, а социальная атмосфера отличается большим спокойствием. Если для одних мигрантов провинциальность - недостаток, другие видят в этом преимущество. Спокойную атмосферу предпочитают, например, многие мигранты, проживавшие в сельской местности или малых городах, студенты, нацеленные на учебу, вынужденные переселенцы из горячих точек: «Да уже на все сто процентов могу сказать, что Мордовия - это моя личная зона комфорта»; «Все нравится в городе, все спокойно. Не густонаселенный город, просторно, но главное - спокойно. Вот мы с вами сидим, разговариваем, видите - все спокойно»; «Нам Саранск нравится, тихо, спокойно. Ближайшие пять лет точно никуда не поедем»; «Я все время боюсь за детей, а здесь спокойно. В Таджикистане нет таких условий, та же учеба - проблема».

Третью группу факторов, влияющую на миграционную привлекательность города, определяют культурные особенности принимающей стороны.

Среди всех культурных факторов первое место безоговорочно занимает образовательный ресурс. В ряде случаев возможность получения качественного образования для мигрантов и, особенно, их детей, может компенсировать проблемы и неустроенность экономического характера.

Многие мигранты рассматривают переезд в Саранск как первый шаг к вложению ресурсов в образовательный капитал, а значит, и в обеспеченное будущее своих детей: «Переехали сюда, потому что в нашей стране не было перспектив для нас, для моих детей. Я очень хотела, чтобы они получили хорошее образование и устроились в жизни, а там нет ничего, разруха, поэтому лучше сюда было приехать и тут жить, воспитывать детей, водить их в хорошую школу, где были бы грамотные учителя»; «Хотим, чтобы в будущем дети поступили в университет, вот мне и нравится Саранск, что здесь и университет есть большой. И квартиру им купим в городе»; «Дочка вторая мечтает врачом стать, хочет в мединститут поступать. Вот в Саранске как раз и есть, где ей учиться».

Качественное и недорогое высшее образование является важным конкурентным преимуществом Саранска, благодаря которому в последние годы растет поток в город студентов из Туркмении, Таджикистана, а также стран дальнего зарубежья - Индии, Ирака, Сирии, Йемена и т. д.: «В Таджикистане российское образование более ценится, ну и потом есть всего один медицинский институт на весь Таджикистан, сложно поступить туда»; «Хотел получить высшее образование, поступить в университет и уже потом, конечно, если бы получилось, найти здесь работу. Ну... (пауза) в первую очередь - это образование. Я ведь на родине не поступил бы, система ЕГЭ для меня сложной оказалась слишком»; «По деньгам мы могли позволить себе только Китай и Россию. Но 
в Китае качество медицинского образования гораздо хуже. Российское образование у нас в Индии традиционно высоко оценивалось».

Привлечение иностранных студентов - это не только дополнительный источник финансирования для вузов города и фактор повышения их рейтинга и конкурентоспособности, но и возможность получения для страны квалифицированных специалистов, к концу обучения уже знающих язык и адаптированных к жизни в регионе. При этом (если говорить об экономической стороне вопроса) финансовое вложение в этих специалистов относительно невелико. Регион, таким образом, должен быть заинтересован в том, чтобы при помощи различных программ и мероприятий способствовать не только привлечению, но и закреплению студентов на своей территории [19].

Наличие в Саранске крупных вузов и хороших специалистов позволяет в перспективе разрабатывать и внедрять специальные программы дополнительного образования, ориентированные на мигрантов: ориентационные занятия, облегчающие адаптацию мигрантов в городе, языковые курсы, курсы повышения квалификации, переквалификации, знакомства с правовыми и экономическими особенностями организации бизнеса и т. д.

Хотя культурные аспекты миграционной привлекательности города не исчерпываются образованием, все же именно качественное образование дает возможность не только обучить мигрантов профессиональным навыкам и умениям, но и познакомить их с культурными особенностями страны, региона и города: с обычаями и традициями, искусством, правовой культурой и т. д.

Помимо перспектив, связанных с работой, образованием и социальными связями, мигранты упоминают и некоторые другие факторы, которые могли бы усилить миграционную привлекательность региона. Хотя их роль при выборе Саранска как цели для миграции пока не особенно высока, эти факторы следует учитывать, поскольку их игнорирование может привести к выстраиванию барьеров на пути дальнейшей интеграции мигрантов в регионе.

Один из факторов мы назовем политическим, предполагая, что он зависит от характера государственной политики, гарантирующей соблюдение политических прав и свобод мигрантов (свободу слова, свободу мысли и вероисповедания и др.), отсутствие репрессий по политическим убеждениям и т. п. Однако не меньшее значение для мигрантов имеют особенности региональной миграционной политики и конкретные практики ее реализации. Грамотная региональная политика способствует скорейшему решению социальных, экономических, культурных проблем.

В регионе в настоящее время реализуется программа содействия переселению соотечественников, участникам которой были заданы вопросы 
о том, какие конкретно действия государства были бы им полезны. Информанты чаще всего упоминают помощь с жильем и регистрацией, поскольку именно жилищная проблема на первых порах оказывается самой острой: «Самый проблемный вопрос - жилье, вернее регистрация. Если задуматься, нет разницы: свое или снимать, если как вот где жить, а вот регистрация, это да»; «Хотя бы частично помогали бы решать жилищный вопрос. Знаешь, что твое, а не так».

Большим преимуществом для города была бы практика временного предоставления общежития с регистрацией в нем до того момента, пока переселенец не найдет работу. Помощь в получении постоянного жилья была бы немаловажным аргументом за закрепление мигрантов в регионе: «Пока года три нам нельзя уезжать, если ипотеку возьмем, то тут засядем, если нет - уедем в крупный город»; «Выделили бы участок для строительства дома, либо квартиру бы помогли купить на льготных условиях. Я вот Вам скажу, что 80 \% из тех, кто проходит программу в Мордовии, уезжают, просто здесь легче получить гражданство, молодежь получила гражданство и сразу уехала».

Тем не менее нужно сказать, что мигранты реалистично относятся к мерам поддержки и не ожидают от государства многого: «Ответственность нельзя перекладывать на государство. Если захотел войти в программу, то должен стремиться сам себя как-то обеспечить. Конечно, хорошо бы помогли нам как-то с домом, мы же многодетная семья, может, землю какую-то дали или домик старый»; «Нам ничего не надо, мы получаем гражданство и работаем. Как получу гражданство, когда будет результат, вот хорошо бы государство меня поддержало, сделало бы скидку какую-нибудь за ИП, больше ничего не жду, главное - мой бизнес поддержать».

Хотя мигранты не ждут серьезной помощи, они все же надеются на то, что государство не будет выстраивать дополнительные финансовые и бюрократические барьеры на пути их интеграции: «Отношение работников УФМС не очень хорошее, наплевательское. Список дали, несколько пунктов просто нет, а потом говорят: где еще документы, и опять отправляют... Почему бы там компьютер не поставить, человека не посадить, чтобы помог людям?»; «Я весь этап прошел, везде требуют мзду. Вот могут взять и вернуть документы в УФМС, очень уверенно разговаривают, чуть что - сразу от ворот поворот. Часто приходится искать, через кого и как решить вопрос, а сами понимаете, везде отблагодарить надо»; «Столкнулись с подачей на РВП, нас опять проверяют, нас раз проверили по программе и еще раз проверяют. Это избыточно. В УФМС, когда пришел в 215 и 217 кабинеты, наша папка лежит в 215-м, а в 217-м - нужна новая папка, новый комплект документов, 
а это опять деньги»; «Это просто ужас! (возмущенно) Все очень, просто очень дорого, эти госпошлины, а ведь я не один, нас пятеро, мы разорились. А еще - нервы, реально чтобы получить одну бумажонку, нужно просто объехать сто пятьдесят учреждений еще».

Для мигрантов фактор уважения представляется очень важным. Поэтому следует учитывать, что без изменения отношения к мигрантам в государственных учреждениях рассчитывать на повышение миграционной привлекательности города или региона не приходится.

Отношение к мигрантам во многом зависит от приоритетов, заданных государством. Так, если концепция государственной миграционной политики Российской Федерации, принятая в 2012 г., была ориентирована на адаптацию мигрантов, то в соответствующем документе 2018 г. акценты смещены на вопросы миграционной безопасности страны. Конечно, безопасность крайне важна, но если государство в лице своих представителей видит в мигрантах угрозу или ресурс, а не конкретного человека, то отношение к мигрантам будет соответствующим.

Последняя группа факторов касается природных условий - географического положения Саранска, природного окружения, климата, экологической ситуации. Так, в качестве достоинства указывалась близость Саранска к Москве. Одни мигранты считали климат в Саранске преимуществом (по сравнению с северными городами), другие - недостатком (по сравнению с южными странами исхода). Очевидно, что у городских и региональных властей имеется не очень много возможностей для улучшения ситуации в этом направлении за исключением экологического аспекта. По сравнению со многими другими регионами в Мордовии относительно благополучная экологическая обстановка нет крупных промышленных предприятий, атомных электростанций и т. д. Саранск все еще остается зеленым городом. Если ситуация в этой сфере не изменится к худшему (а такие тенденции прослеживаются), экологическая обстановка сможет стать дополнительным преимуществом, позволяющим привлекать мигрантов и удерживать население в городе.

Наиболее прагматичные переселенцы учитывают всю совокупность факторов в системе: «В Саранске не был до этого никто, подошли поинженерному, данные климата, осадков. Считаем, что на первые годы подойдет. Мы не хотим города-миллионники, а Саранск почти как Винница, количество населения оптимальное, сами могут себя поддерживать. 90 \% украинцев реально не имеют денег. А рисковать и ехать в Европу, зачем мне это надо? Профессиональный вопрос, здесь все признается. А туда асфальтоукладчиком? И даже это круто».

Многофакторный подход с не меньшим успехом можно применять не только мигрантам, но и региональным властям для повышения привлекательности региона. 
Обсуждение и заключение. Традиционные теории, рассматривающие в качестве причин миграции исключительно рациональные экономические соображения, не способны комплексно описать процесс выбора мигрантом места вселения. Помимо экономических факторов, на этот процесс влияют потребности в безопасности, комфорте, поддержке, доверии, уважении.

Интервью показывают, что привлекательность провинциального города обусловлена сочетанием как минимум, пяти групп факторов: экономических, социальных, культурных, политических, природных. Хотя в процессе принятия решения основной удельный вес действительно принадлежит экономическим факторам (возможности найти работу, получать достойную заработную плату, организовать бизнес), прочие факторы также оказывают значимое влияние на выбор региона для переезда.

Среди социальных факторов большое значение для повышения привлекательности города может иметь поддержка диаспор, землячеств и прочих национально ориентированных общественных организаций, а также хорошее отношение местного населения.

В числе культурных факторов ключевую роль играет возможность получения недорогого и качественного образования, доступность детских садов, школ, вузов, что особо привлекательно для молодежи, которая составляет больший процент безвозвратной миграции.

В ряду политических факторов следует обратить внимание на региональную миграционную политику и конкретные меры ее реализации, в частности, на роль государства в облегчении получения регистрации в первое время после переезда и льготного ипотечного кредитования для закрепления мигранта в городе. Кроме того, немаловажное значение для успешной адаптации может иметь снятие лишних бюрократических барьеров.

Среди природных факторов городским властям необходимо сделать упор на благоприятную экологическую обстановку как на важный ресурс, способный послужить дополнительным аргументом для принятия решения о переезде.

В целом все отмеченные факторы вносят свой вклад в миграционную привлекательность. Как показывает анализ интервью, в процессе принятия решения о переезде учет социальных, культурных, политических, природных факторов привлекательности, взятых в их совокупности, способен перевесить экономические соображения.

Выявление основных причин выбора провинциального города для переселения, ожиданий приезжих и проблем, с которыми они сталкиваются, позволяет, с одной стороны, повысить уровень миграционной привлекательности города, а с другой - учитывать при планировании изменений в городском пространстве мнение мигрантов как полноправных субъектов социальных изменений. 


\section{СПИСОК ИСПОЛЬЗОВАННЫХ ИСТОЧНИКОВ}

1. Дмитриев А. В. Конфликтогенность внешней трудовой миграции (федеральные и региональные аспекты) // ПОИСК. 2018. № 4 (69). С. 13-19. URL: http://журналпоиск.pф/about/archieve.php (дата обращения: 15.05.2019).

2. Морошкина М. В. Пространственное развитие России: региональные диспропорции // Регионология. 2018. Т. 26, № 4. С. 638-657. DOI: https://doi. org/10.15507/2413-1407.105.026.201804.638-657

3. Комков Д. Е., Киричек П. Н. Регионы в зоне демографического риска: минус-тенденции миграции и урбанизации // Регионология. 2017. № 1 (98). C. 139-148. URL: http://regionsar.ru/ru/node/1578 (дата обращения: 15.05.2019).

4. Stark O. Migration Decision Making: A Review Article // Journal of Development Economics. 1984. Vol. 14, no. 1. Pp. 251-259. DOI: https://doi.org/10.1016/03043878(84)90053-1

5. Matuszczuk K. Migration Attractiveness Index 2017. Migration Attractiveness Index Bulletin. Warsaw: Kulczyk Research Institute, 2017. 20 p. URL: http:// ceedinstitute.org/attachments/420/39855ff647bf393ca4fba0ad823fce5a.pdf (дата обращения: 15.05.2019).

6. Ewers M. C., Dicce R. High-Skilled Migration and the Attractiveness of Cities // High-Skilled Migration: Drivers and Policies / Ed. by M. Czaika. Oxford, OUP, 2018. Pp. 176-194. DOI: https://doi.org/10.1093/oso/9780198815273.003.0009

7. Hyndman J., Schuurman N., Fiedler R. Size Matters: Attracting New Immigrants to Canadian Cities // Journal of International Migration and Integration / Revue de l'integration et de la migration internationale. 2006. Vol. 7. Pp. 1-25. DOI: https:// doi.org/10.1007/s12134-006-1000-6

8. Ахиезер А. С. Территориальная миграция - реализация потребности в полноте бытия // Общественные науки и современность. 2007. № 3. С. 141-149. URL: http://ecsocman.hse.ru/data/2010/12/01/1214824139/Axiezer.pdf (дата обращения: 15.05.2019).

9. Рязанцев С. В. Интеграция мигрантов в контексте внешней миграционной политики России // Социологические исследования. 2018. № 1. С. 105-111. DOI: https://doi.org/10.7868/S0132162518010117

10. Кривова А. Л., Никипорец-Такигава Г. Ю. Повышение миграционной привлекательности как программа государственной молодежной политики в Польше // Вопросы политологии. 2018. № 2 (30). C. 80-87. URL: http://voprospolitolog.ru/ index.php/ru/soderzhanie-vypuskov/2-30-2018 (дата обращения: 15.05.2019).

11. Киселев Н. А., Гуршалов П. О., Олейник Е. Б. Приморский край: экономический рост и проблемы миграционной привлекательности // Вопросы экономики и права. 2018. № 121. C. 114-118. URL: http://law-journal.ru/files/ pdf/201807/201807_114.pdf (дата обращения: 15.05.2019).

12. Латышева А. И., Лоскутникова Н. А. Анализ миграционных процессов Пермского края в контексте социально-экономической привлекательности региона // Концепт. 2018. № 10. C. 256-260. URL: https://e-koncept.ru/2018/184052.htm (дата обращения: 15.05.2019). 
13. Петухов Н. А. Миграционная привлекательность городов - административных центров Российской Федерации // Вестник ЮРГТУ. Сер.: Социально-экономические науки. 2018. № 4. C. 8-15. URL: https://elibrary.ru/contents. asp?id=36816002 (дата обращения: 15.05.2019).

14. Петухов Н. А., Горидько Н. П. Миграционная привлекательность крупных российских городов // РИСК: Ресурсы, Информация, Снабжение, Конкуренция. 2017. № 4. C. 156-165. URL: http://www.risk-online.ru/archive/ (дата обращения: 15.05.2019).

15. Самонина С. С. Анализ факторов миграционной привлекательности регионов ПФО // Известия Саратовского университета. Сер.: Науки о Земле. 2017. T. 17, вып. 4. C. 236-241. DOI: https://doi.org/10.18500/1819-7663-2017-17-4236-241

16. Фофанова К. В., Борисов Д. М. Сетевой ресурс как фактор интеграции трудовых мигрантов в региональный социум // Журнал исследований социальной политики. 2013. Т. 11, № 2. C. 189-206. URL: https://jsps.hse.ru/article/view/3438 (дата обращения: 15.05.2019).

17. Putnam R. D. Bowling Alone: The Collapse and Revival of American Community. New York: Simon \& Schuster, 2000. 544 p. URL: https://www.amazon.com/ Bowling-Alone-Collapse-American-Community/dp/0743203046 (дата обращения: 15.05.2019).

18. Сычев А. А. Межэтническое доверие // Вестник Пермского национального исследовательского политехнического университета. Культура. История. Философия. Право. 2017. № 1. С. 15-23. DOI: https://doi.org/10.15593/perm.kipf/2017.1.02

19. Фофанова К. В., Сычев А. А., Борисов Д. М. Адаптация иностранных студентов в российском регионе (на примере Республики Мордовия) // Теории и проблемы политических исследований. 2018. Т. 7, № 6А. С. 150-156. URL: http://publishing-vak.ru/archive-2018/politology-6.htm (дата обращения: 15.05.2019).

Поступила 21.05.2019; принята к публикации 24.06.2019; опубликована онлайн 30.12.2019.

\section{Об авторах:}

Фофанова Катерина Владиславовна, профессор кафедры социологии ФГБОУ ВО «МГУ им. Н. П. Огарёва» (430005, Россия, г. Саранск, ул. Большевистская, д. 68/1), доктор социологических наук, ORCID: https://orcid. org/0000-0003-2344-8986,kateri02@yandex.ru

Сычев Андрей Анатольевич, профессор кафедры философии ФГБОУ ВО «МГУ им. Н. П. Огарёва» (430005, Россия, г. Саранск, ул. Большевистская, д. 68/1), доктор философских наук, ORCID: https://orcid.org/0000-0003-3757-4457, Researcher ID: N-7591-2015, Scopus ID: 57205759512, sychevaa@mail.ru

\section{Заявленный вклад авторов:}

Фофанова Катерина Владиславовна - формулирование основной концепции исследования; определение методологии; анализ литературы; сбор информации. 
Сычев Андрей Анатольевич - анализ и интерпретация данных; подготовка начального варианта текста; доработка текста.

Для циитирования:

Фофанова К. В., Сычев А. А. Факторы миграционной привлекательности провинциального города (на примере г. Саранска) // Регионология. 2019. Т. 27, № 4. C. 756-778. DOI: https://doi.org/10.15507/2413-1407.109.027.201904.756-778

Все авторы прочитали и одобрили окончательный вариант рукописи.

\section{REFERENCES}

1. Dmitriev A.V. The Conflict Potential of External Labor Migration (Federal and Regional Aspects). POISK = P.O.I.S.K. Policy. Social Science. Art. Sociology. Culture. 2018; (4):13-19. Available at: http://журналпоиск.pф/about/archieve.php (accessed 15.05.2019). (In Russ., abstract in Eng.)

2. Moroshkina M.V. Spatial Development of Russia: Regional Disproportions. Regionologija = Regionology. 2018; 26(4):638-657. (In Russ., abstract in Eng.) DOI: https://doi.org/10.15507/2413-1407.105.026.201804.638-657

3. Komkov D.E., Kirichek P.N. Regions within the Area of Demographic Risk: Negative Migration and Urbanization Trends. Regionologija = Regionology. 2017; 98(1):139-148. Available at: http://regionsar.ru/ru/node/1578 (accessed 15.05.2019). (In Russ., abstract in Eng.)

4. Stark O. Migration Decision Making: A Review Article. Journal of Development Economics. 1984; 14(1):251-259. (In Eng.) DOI: https://doi.org/10.1016/03043878(84)90053-1

5. Matuszczuk K. Migration Attractiveness Index 2017. Migration Attractiveness Index Bulletin. Warsaw: Kulczyk Research Institute; 2017. Available at: http:// ceedinstitute.org/attachments/420/39855ff647bf393ca4fba0ad823fce5a.pdf (accessed 15.05.2019). (In Eng.)

6. Ewers M.C., Dicce R. High-Skilled Migration and the Attractiveness of Cities. In: High-Skilled Migration: Drivers and Policies. Oxford, OUP; 2018. p. 176-194. (In Eng.) DOI: https://doi.org/10.1093/oso/9780198815273.003.0009

7. Hyndman J., Schuurman N., Fiedler R. Size Matters: Attracting New Immigrants to Canadian Cities. Journal of International Migration and Integration / Revue de l'integration et de la migration internationale. 2006; 7:1-25. (In Eng.) DOI: https:// doi.org/10.1007/s12134-006-1000-6

8. Akhiezer A.S. Territorial Migration as Realization of Demand in Completeness of Life. Obshchestvennye nauki $i$ sovremennost $=$ Social Sciences and Contemporary World. 2007; (3):141-149. Available at: http://ecsocman.hse.ru/data/2010/12/01/1214824139/ Axiezer.pdf (accessed 15.05.2019). (In Russ.)

9. Ryazantsev S.V. Integration of Migrants in the Context of Russia's Foreign Migration Policy. Sotsiologicheskie issledovaniya = Sociological Studies. 2018; (1):105-111. (In Russ., abstract in Eng.) DOI: https://doi.org/10.7868/S0132162518010117 
10. Krivova A.L., Nikiporets-Takigava G.Yu. [Increasing Migration Attractiveness as a Program of the State Youth Policy in Poland]. Voprosy politologii = Political Science Issues. 2018; (2):80-87. Available at: http://voprospolitolog.ru/index.php/ru/ soderzhanie-vypuskov/2-30-2018 (accessed 15.05.2019). (In Russ.)

11. Kiselev N.A., Gurshalov P.O., Oleinik E.B. Primorye Territory: Economic Growth and Issues of Migration Attractiveness. Voprosy ehkonomiki $i$ prava = Economic and Law Issues. 2018; (121):114-118. Available at: http://law-journal.ru/ files/pdf/201807/201807_114.pdf (accessed 15.05.2019). (In Russ., abstract in Eng.)

12. Latysheva A.I., Loskutnikova N.A. Analysis of the Migration Processes in the Perm Region in the Context of the Socio-Economic Attractiveness of the Region. Kontsept $=$ Concept. 2018; (10):256-260. Available at: https://e-koncept. ru/2018/184052.htm (accessed 15.05.2019). (In Russ., abstract in Eng.)

13. Petukhov N.A. [Migration Attractiveness of Cities - the Administrative Centers of the Russian Federation]. Vestnik YRGTU = Bulletin of SRSPU. 2018; (4):8-15. Available at: https://elibrary.ru/contents.asp?id=36816002 (accessed 15.05.2019). (In Russ.)

14. Petukhov N.A., Goridko N.P. Migration Attractiveness of Russian Cities. RISK: Resursy, Informatsiya, Snabzhenie, Konkurentsiya = RISK: Resources, Information, Supply, Competition. 2017; (4):156-165. Available at: http://www.risk-online.ru/ archive/ (accessed 15.05.2019). (In Russ., abstract in Eng.)

15. Samonina S.S. Analysis of the Factors of Migration Attractiveness of the Volga Federal District Regions. Izvestiya Saratovskogo universiteta. Seriya Nauki o Zemle = Izvestiya of Saratov University. New Series. Series: Earth Sciences. 2017; 17(4):236-241. (In Russ., abstract in Eng.) DOI: https://doi.org/10.18500/1819-76632017-17-4-236-241

16. Fofanova K.V., Borisov D.M. Network Resource as the Factor of Integration of Foreign Labor Migrants to Regional Society. Zhurnal issledovanii sotsialnoi politiki= Journal of Social Policy Studies. 2013; 11(2):189-206. Available at: https://jsps.hse. $\mathrm{ru} / \mathrm{article} / \mathrm{view} / 3438$ (accessed 15.05.2019). (In Russ., abstract in Eng.)

17. Putnam R.D. Bowling Alone: The Collapse and Revival of American Community. New York: Simon \& Schuster; 2000. Available at: https://www. amazon.com/Bowling-Alone-Collapse-American-Community/dp/0743203046 (accessed 15.05.2019). (In Eng.)

18. Sychev A.A. Interethnic Trust. Vestnik Permskogo natsionalnogo issledovatelskogo politekhnicheskogo universiteta. Kultura. Istoriya. Filosofiya. Pravo= Bulletin of PNRPU. Culture. History. Philosophy. Law. 2017; (1):15-23. (In Russ., abstract in Eng.) DOI: https://doi.org/10.15593/perm.kipf/2017.1.02

19. Fofanova K.V., Sychev A.A., Borisov D.M. Adaptation of Foreign Students in the Russian Region (Example of the Republic of Mordovia). Teorii $i$ problemy politicheskikh issledovanij $=$ Theories and Problems of Political Studies. 2018; 7(6A):150-156. Available at: http://publishing-vak.ru/archive-2018/politology-6.htm (accessed 15.05.2019). (In Russ., abstract in Eng.)

Submitted 21.05.2019; accepted for publication 24.06.2019; published online 30.12.2019. 
About the authors:

Katerina V. Fofanova, Professor, Department of Sociology, National Research Mordovia State University (68/1 Bolshevistskaya St., Saransk 430005, Russia), Dr. Sci. (Sociology), ORCID: https://orcid.org/0000-0003-2344-8986, kateri02@yandex.ru

Andrey A. Sychev, Professor, Department of Philosophy, National Research Mordovia State University (68/1 Bolshevistskaya St., Saransk 430005, Russia), Dr. Sci. (Philosophy), ORCID: https://orcid.org/0000-0003-3757-4457, Researcher ID: N-7591-2015, Scopus Author ID: 57205759512, sychevaa@mail.ru

Contribution of the authors:

Katerina V. Fofanova - formulation of the basic concept of the research; development of methodology; analysis of the literature on the stated problem; data collection.

Andrey A. Sychev - analysis and interpretation of the data; writing the initial version of the text of the article; revision of the text.

For citation:

Fofanova K.V., Sychev A.A. Factors in Migration Attractiveness of a Provincial City: The Case Study of the City of Saransk. Regionology = Russian Journal of Regional Studies. 2019; 27(4):756-778. DOI: https://doi.org/10.15507/24131407.109.027.201904.756-778

The authors have read and approved the final version of the manuscript. 


\section{Вторичная занятость и самозанятость студентов вузов: масштабы, структура и функции (на примере Республики Мордовия)}

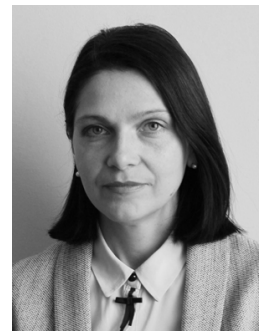

Н. П. Касаткина ${ }^{1,2}$

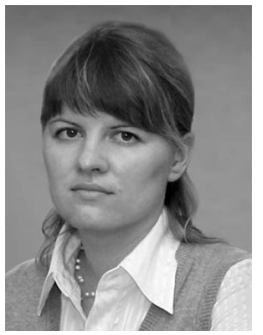

Н. В. Шумкова ${ }^{2 *}$

${ }^{1}$ ГКУ РМ «Научный ичентр социиально-экономического мониторинга»

(2. Саранск, Россия)

2 ФГБОУ ВО «МГУ им. Н. П. Огарёва» (2. Саранск, Россия),

*niiregion@mail.ru

Введение. Исследование проблематики вторичной занятости студентов как фактора интеграции молодежи в социально-профессиональную структуру общества и расширенного воспроизводства его человеческого капитала приобретает особую актуальность в контексте перспектив трансформации социального пространства современного рынка труда. Процессы дифференциации, флексибилизации, расширения нестандартных форм занятости ориентируют фокус внимания на задачи исследования особенностей структуры вторичной занятости студентов с точки зрения выявления практик самозанятости как способа реализации творческой и предпринимательской активности молодежи. Цель статьи - изучить структуру вторичной занятости студентов вузов Республики Мордовия.

Материалы и методы. Использованы материалы авторского пилотажного фокус-группового исследования и данные социологического опроса, проведенного среди студентов выпускных курсов вузов Республики Мордовия. Для анализа применялись методы расчета показателей дескриптивной статистики, оценки связи между переменными, а также многомерного статистического анализа.

Результаты исследования. Показано, что вторичная занятость студентов старших курсов вузов Республики Мордовия является распространенной практикой. Трудовая занятость студентов локализуется в основном в частном секторе и преимущественно не связана с получаемой в вузе профессией. В структуре вторичной занятости значительная доля принадлежит самозанятости, распространенность

(C) Касаткина Н. П., Шумкова Н. В., 2019 
которой составляет около $25 \%$. Сегмент студенческой самозанятости связан с предоставлением широкого спектра услуг, однако наиболее популярными являются фриланс и репетиторство. Практики самозанятости структурируются по видам деятельности в зависимости от гендерного признака, а также от новизны (традиционности) выполняемого труда.

Обсуждение и заключение. Самозанятость способствует адаптации и интеграции студентов на рынке труда и выступает фактором стимуляции миграционных настроений молодежи и неустойчивости профессиональных ориентаций. Практическая значимость исследования состоит в возможности использования его результатов органами власти Республики Мордовия при разработке молодежной политики региона и государственных программ в сфере труда и занятости, оптимизации кадровой политики организаций и ведомств.

Ключевые слова: самозанятость, вторичная занятость, трудовая занятость студентов, репетиторство, фриланс, рынок труда

Финансирование. Статья подготовлена при финансовой поддержке РФФИ и Правительства Республики Мордовия в рамках научного проекта «Социальное пространство рынка труда Республики Мордовия: самозанятость молодежи» (№ 18-411-130016 p_a).

\title{
Secondary Employment and Self-Employment of Higher Education Students: The Scale, Structure and Functions (the Case Study of the Republic of Mordovia)
}

\author{
N. P. Kasatkina ${ }^{a, b}$, N. V. Shumkova ${ }^{b^{*}}$ \\ a Scientific Center for Social and Economic Monitoring (Saransk, Russia) \\ ${ }^{b}$ National Research Mordovia State University (Saransk, Russia), \\ niiregion@mail.ru
}

Introduction. Studying the issues of secondary employment of higher education students, which is a factor in the youth integration into the social and professional structure of society and in the extended reproduction of its human capital, is of particular relevance in the context of the prospects for transformation of the social space of the modern labor market. The processes of differentiation, flexibilization, and expansion of non-standard forms of employment focus on studying the features of the structure of secondary employment of students in terms of identifying selfemployment practices as a way of implementing creative and entrepreneurial activities of the youth.

Materials and Methods. The materials of the author pilot focus group study and the data from a sociological survey conducted among final-year students of institutions of higher education in the Republic of Mordovia were used. To carry out an analysis, the methods of calculating the indicators of descriptive statistics, of assessing connections between variables, as well as that of multivariate statistical analysis were employed. Results. It has been shown that secondary employment of senior undergraduate students of institutions of higher education in the Republic of Mordovia is a common practice. The employment of students is mainly localized in the private sector and is not predominantly related to the profession the institution of higher education trains students for. Self-employment makes up a significant proportion (nearly $25 \%$ ) of secondary employment. The segment of student self-employment is associated with the provision of a wide range of services, freelance and tutoring being the most 
popular ones. Self-employment practices are structured by type of activity, depending on gender, as well as on the novelty (or traditional nature) of the work done.

Discussion and Conclusion. Self-employment contributes to students' adaptation to and integration into the labor market and is a factor in stimulating the migration attitudes of young people and instability of vocational orientations. The practical significance of the research consists in the possibility of using its results by the authorities of the Republic of Mordovia when developing the regional youth policy and state programs in labor and employment, and when optimizing the human resources policies of organizations and agencies.

Keywords: self-employment, secondary employment, employment of higher education students, tutoring, freelance, labor market

Funding. The article was done with the financial support from the Russian Foundation for Basic Research and the Government of the Republic of Mordovia as part of the scientific project 'Social Space of the Labor Market in the Republic of Mordovia: Youth Self-Employment' (No. 18-411-130016 r_a).

Введение. Направленность и содержание изменений, происходящих на рынке труда, определяются в том числе стратегиями поведения его субъектов. Наиболее проактивная позиция на рынке труда принадлежит молодежи, которая в силу специфики социального статуса формирует и реализует поливариативные стратегии интеграции в социально-профессиональную структуру общества. В результате возникают и институционализируются новые социальные практики на рынке труда, оформляются его трансформационные тренды.

Возникновение новых видов и форм трудовой деятельности и отношений, усиление флексибилизации и дифференциации рынка труда во многом обусловлены активностью молодежи в воспроизводстве соответствующих социальных практик. Многие исследования выявляют активность представителей этой социально-демографической группы в нестандартной (неполной, временной, удаленной и т. д.) занятости ${ }^{1}$.

Многочисленная часть современной молодежи - вузовское студенчество. Причем значение этой социальной группы сложно переоценить ввиду многофункциональности последствий реализации ею профессиональных и трудовых стратегий. В этом контексте одной из наиболее актуальных и в то же время дискуссионных, с исследовательской точки зрения, становится практика вторичной студенческой занятости, возрастание масштабов которой уже не требует доказательств.

В широком смысле вторичная занятость студентов - это добровольная, оплачиваемая трудовая деятельность, осуществляемая в свободное

1 Чередниченко Г. А. Образовательные траектории и профессиональные карьеры (на материалах социологических исследований молодежи). М.: ИС РАН, 2012. 332 с.; Константиновский Д. Л., Вознесенская Е. Д., Чередниченко Г. А. Молодежь России на рубеже XX-XXI веков: образование, труд, социальное самочувствие. М.: ЦСП и М, 2014. 548 с. 
от учебы время [1, с. 177]. Она выполняет ряд функций с эффектами как на микро- (индивидуально-личностном), так и на макроуровне, влияя на функционирование социальных институтов. В первую очередь, отчетливо выражены функции адаптации и интеграции молодежи на рынке труда [1], а также накопления их человеческого, социального и культурного капиталов.

Тенденции расширения масштабов вторичной занятости студентов на фоне интенсификации изменений на рынке труда, нарастания дестандартизации, плюрализации практик занятости способствуют актуализации исследования этого социального явления.

Задача исследования структуры вторичной занятости студентов еще более значима в контексте выявления практик неформальной занятости и самозанятости как проявлений творческой и предпринимательской активности молодежи, реализации ее деятельностного потенциала [1, с. 180].

Таким образом, интерес к исследованию проблематики вторичной занятости студентов вполне очевиден не только в контексте проблем интеграции молодежи в социально-профессиональную структуру общества и расширенного воспроизводства его человеческого капитала, но и перспектив трансформации социального пространства рынка труда.

Цель статьи - выявить структуру и особенности первичных практик экономической активности студенческой молодежи Республики Мордовия, изучить влияние этих практик на эффективность профессионализации в вузе, а также описать существующие стратегии их поведения на региональном рынке труда.

Обзор литературы. Тема вторичной занятости студентов популярна и у зарубежных, и у отечественных авторов. В фокусе внимания публикуемых исследований находятся масштаб распространенности, структура, детерминанты и последствия этой социальной практики.

Пристальный интерес западных социологов к проблемам совмещения работы и обучения приходится на конец 1970-х гг., когда у исследователей появляется возможность анализа результатов когортных лонгитюдных опросов, на больших массивах данных позволяющих наблюдать отсроченные эффекты индивидуальных трудовых и образовательных траекторий ${ }^{2}[2]$.

В отечественной науке актуализация проблемы вторичной занятости студентов произошла в 1990 гг., когда российские социологи зафиксировали феномен работающего студента и акцентировали внимание

${ }^{2}$ Ehrenberg R. G., Sherman D. R. Employment While in College, Academic Achievement and Post-College Outcomes: A Summary of Results // Journal of Human Resources. 1987. Vol. 22, no. 1. Pp. 1-23; San G. The Early Labor Force Experience of College Students and their Post-College Success // Economics of Education Review. 1986. Vol. 5, no. 1. Pp. 65-76. 
на анализе его детерминант, в числе которых - ухудшение социальноэкономического положения учащейся молодежи [3; 4]. Так, по данным Т. Э. Петровой, в середине 1990-х гг. в нашей стране подрабатывали более $70 \%$ студентов (на I курсе - до $40 \%$, на V курсе - 77 \% студентов) ${ }^{3}$.

Массовизация феномена работающего студента по-прежнему отмечается практически в каждой отечественной публикации. По данным многочисленных исследований, показатель вовлеченности в трудовую деятельность студентов очного отделения за последние десятилетия незначительно колеблется относительно величины, составляющей 70 \% [5-8].

Современные зарубежные авторы также единодушны в выводах касательно тенденции к возрастанию масштабов вторичной занятости студентов, которая проявляется не только в показателях доли подрабатывающих, но и в количестве времени, затрачиваемом на работу4

Рассматривая позитивные и негативные последствия трудовой занятости студентов, большинство западных публикаций актуализируют проблематику влияния вторичной занятости на их академическую успеваемость. Так, К. Каллендер, Дж. Э. Кинг, П. М. Глисон провели исследования, результаты которых показывают, что работа во время учебы отрицательно влияет на академическую успеваемость [9; 10] и повышает вероятность прерывания обучения, однако, при условии его завершения, повышает успешность на рынке труда [11].

Развернувшаяся полемика вокруг того, насколько негативным является влияние вторичной занятости на студента, - одно из существенных отличий в проблематизации рассматриваемого социального феномена в зарубежных и отечественных работах.

В российских публикациях акцент делается в первую очередь на положительных эффектах вторичной занятости студентов [12; 13$]$. В частности, влияние на профессионализацию и становление профессиональной идентичности студентов анализирует В. А. Кенинг. Согласно его выводам, неоспоримый положительный эффект совмещения учебы и работы имеет трудовая занятость студентов по получаемой специальности: «формируется тип работника, стремящегося к знаниям и проявлениям собственной полезности; трудовая деятельность студентов способствует становлению их профессиональной идентичности, профессиональной социализации и, вероятно, успешному будущему трудоустройству» $[14$, с. 72]. Его выводы о том, что подработка по специальности неполный день или неполную неделю становится дополнительным каналом

3 Петрова Т. Э. Российское студенчество и высшее образование. М.: Социум, 1995. C. $137-139$.

${ }^{4}$ Baum S. Lowering Work and Loan Burden: The Current Status of Student Reliance on Grants, Loans, and Work // Reflections on College Access and Persistence: Proceedings and Papers from a Symposium in Washington, DC. 2005. Pp. 62-74. 
профессионального обучения, находятся в согласии с результатами наблюдений других исследователей [15; 16]. С этой точки зрения, наименее удачной стратегией студента на рынке трудя является работа полный день не по специальности.

Проблематика мотивов и факторов - наиболее обширный сегмент публикаций, посвященных вторичной занятости студентов [17-19]. Детерминанты рассматриваемого социального явления, представленные в литературе, фактически дифференцируются на внутренние и внешние.

В структуре внутренних доминируют материальные мотивы студентов, которые связаны со стремлением заработать на оплату обучения в вузе и поддержание определенных стандартов потребления и качества жизни, а также с желанием получить опыт работы и конкурентные преимущества на рынке труда [7; 10; 20-22].

К внешним в первую очередь относятся макрофакторы, связанные с функционированием образования. Так, априори воспроизводимое этим институтом социальное неравенство отчетливее проявляется в условиях сокращения финансирования высшего образования. Разного рода материальные факторы выталкивают студентов из низкоресурсных социальных слоев в сферу вторичной занятости. По выводам Р. Хамфри, большинство работающих британских студентов являются выходцами из государственных школ, а не из независимых частных школ [23].

На связь вторичной занятости студентов с негативными процессами в системе высшего образования часто указывают российские исследователи. Так, А. В. Родионова в качестве фактора появления феномена работающего студента отмечает сокращение объема финансирования вузов, которое «ни сейчас, ни в дальнейшем не предполагает содержание студентов за счет государственных дотаций, кроме специально означенных в законе групп населения» [6, с. 83]. С. Ю. Рощин, В. Н. Рудаков, А. Ю. Апокин, М. М. Юдкевич основной причиной вторичной занятости студентов считают низкое качество высшего образования: поскольку «система высшего образования оказывается неспособной обеспечить студентов теми навыками и знаниями, которые являются реально востребованными рынком труда, ...многие студенты начинают строить свою карьеру задолго до окончания вуза» [цит. по: 24, с. 106].

К значимым макрофакторам, особенно в российских реалиях, следует отнести трансформацию современного рынка труда, который формирует потребность в студенческом труде и предоставляет студентам возможности для совмещения учебы и работы [7; 25].

Какова же структура вторичной занятости студенческой молодежи? Отвечая на этот вопрос, большинство российских и зарубежных исследователей берут за основу описание основных форм занятости (наемные работники или самозанятые), характера оформления трудовых отношений 
(регулируются трудовым договором (контрактом) или нет), сфер деятельности, форм собственности (государственная, частная), регулярности занятости (постоянная, временная, неполный рабочий день) и т. д.

Согласно результатам анализа зарубежных публикаций, проведенного А. Ю. Апокиным и М. М. Юдкевич, студенческая занятость в основном предполагает неквалифицированный труд и практически не связана с будущей профессией [24]. Как правило, студенты вовлечены в сферы обслуживания, туризма и общественного питания. Они подрабатывают на малых предприятиях на условиях неполной занятости.

Структура занятости российских студентов практически не отличается от зарубежной. Для нее характерны преимущественная вовлеченность в неформальные и нестандартные формы (неполный рабочий день, отсутствие трудового договора, непрозрачные условия при найме на работу и пр.), превалирование мало- или неквалифицированного труда, занятость не по специальности (в частном секторе и в сферах торговли, общественного питания, образования и культуры). Об этом свидетельствуют работы Д. Л. Константиновского, Е. Д. Вознесенской ${ }^{5}$, Г. А. Чередниченко ${ }^{6}$. Отмеченная специфика позволила Ж. Т. Тощенко рассматривать студенческую занятость в контексте процессов прекаризации труда ${ }^{7}$.

Следует отметить отдельный сегмент российских исследований, посвященный изучению неформальной самозанятости. Согласно данным, самостоятельную занятость выбирает каждый десятый российский студент [25-27]. В. С. Харченко [12; 13], Д. О. Стребков, А. В. Шевчук [28; 29] доказывают, что распространенным видом самозанятости современных российских студентов становится фриланс.

Несмотря на довольно обширный диапазон исследований, в той или иной степени освещающих структуру студенческой вторичной занятости, вопрос о масштабах вовлеченности и структуре неформальной занятости остается недостаточно изученным.

Материалы и методы. Эмпирическая база исследования включает количественные и качественные методы анализа эмпирических данных.

1. Материалы авторского пилотажного фокус-группового исследования, 2 этапа которого проведены в феврале - марте 2019 г., количество участников каждого этапа - 6 чел. Критерием отбора участников фокус-группы являлось наличие опыта самозанятости (индивидуальная самозанятость как постоянный источник дохода продолжительностью не

${ }^{5}$ Константиновский Д. Л., Чередниченко Г. А., Вознесенская Е. Д. Работающий студент: мотивы, реальность, проблемы. М., 2009. С. 38.

6 Чередниченко Г. А. Образовательные и профессиональные траектории российской молодежи (на материалах социологических исследований). М.: ЦСП и М, 2014. С. 150.

7 Тощенко Ж. Т. Прекариат: от протокласса к новому классу. М.: Наука, 2018. C. 191-201. 
менее 1 года), возраст от 18 до 35 лет. При анализе полученных данных применялся метод контент-анализа. Исследование методом фокус-групп позволило прояснить мотивацию и причины выбора стратегии самозанятости в молодежной среде.

2. Данные социологического опроса ${ }^{8}$, проведенного среди студентов выпускных курсов вузов Республики Мордовия $(\mathrm{N}=1943$, март - май 2019 г.). Сплошной опрос студентов проведен методом онлайн анкетирования посредством возможностей сервиса Google Forms. В целях обеспечения качества и достоверности результатов опрос координировался администрациями вузов. Для получения данных, репрезентирующих генеральную совокупность, проведен ремонт выборки с использованием процедуры перевзвеса. Обработка и анализ полученной информации проводились с помощью пакета SPSS. Для анализа использовались методы расчета показателей дескриптивной статистики, оценки связи между переменными, а также многомерного статистического анализа. С помощью анкетирования были выявлены масштабы распространенности и структура вторичной занятости студентов вузов Республики Мордовия.

Результаты исследования. Совмещение учебы и работы - распространенная практика среди студентов старших курсов вузов Республики Мордовия. Более половины студентов (55 \%) подрабатывали, причем большинство из них $(54 \%)$ - не по получаемой профессии. Только треть опрошенных (29 \%) работали по своей будущей специальности, $18 \%$ - как по своей, так и по другой профессии.

Источником рабочих мест для студентов в основном является частный сектор, который обеспечил занятостью 41 \% подрабатывающих студентов; почти треть опрошенных (29 \%) нашли работу на государственных предприятиях, 6 \% - заняты собственным или семейным бизнесом. Довольно масштабной является самозанятость: почти каждый четвертый работавший студент $(24 \%)$ отнес себя к этой категории.

Качество вторичной занятости оказывает существенное влияние на социально-профессиональные установки студентов, в первую очередь на степень профессиональной идентификации. В частности, чем ближе содержание труда к получаемой профессии, тем более выражена установка на трудоустройство по ней после окончания вуза. Вторичная занятость, связанная с профессией, не только позитивно влияет на формирование профессиональной идентичности, но и выступает своего рода гарантом трудоустройства, снижает неопределенность, связанную с поиском работы (табл. 1).

${ }^{8}$ Опрос проведен в рамках проекта ГКУ РМ НЦСЭМ при непосредственном участии соавтора данной статьи Н. П. Касаткиной. 


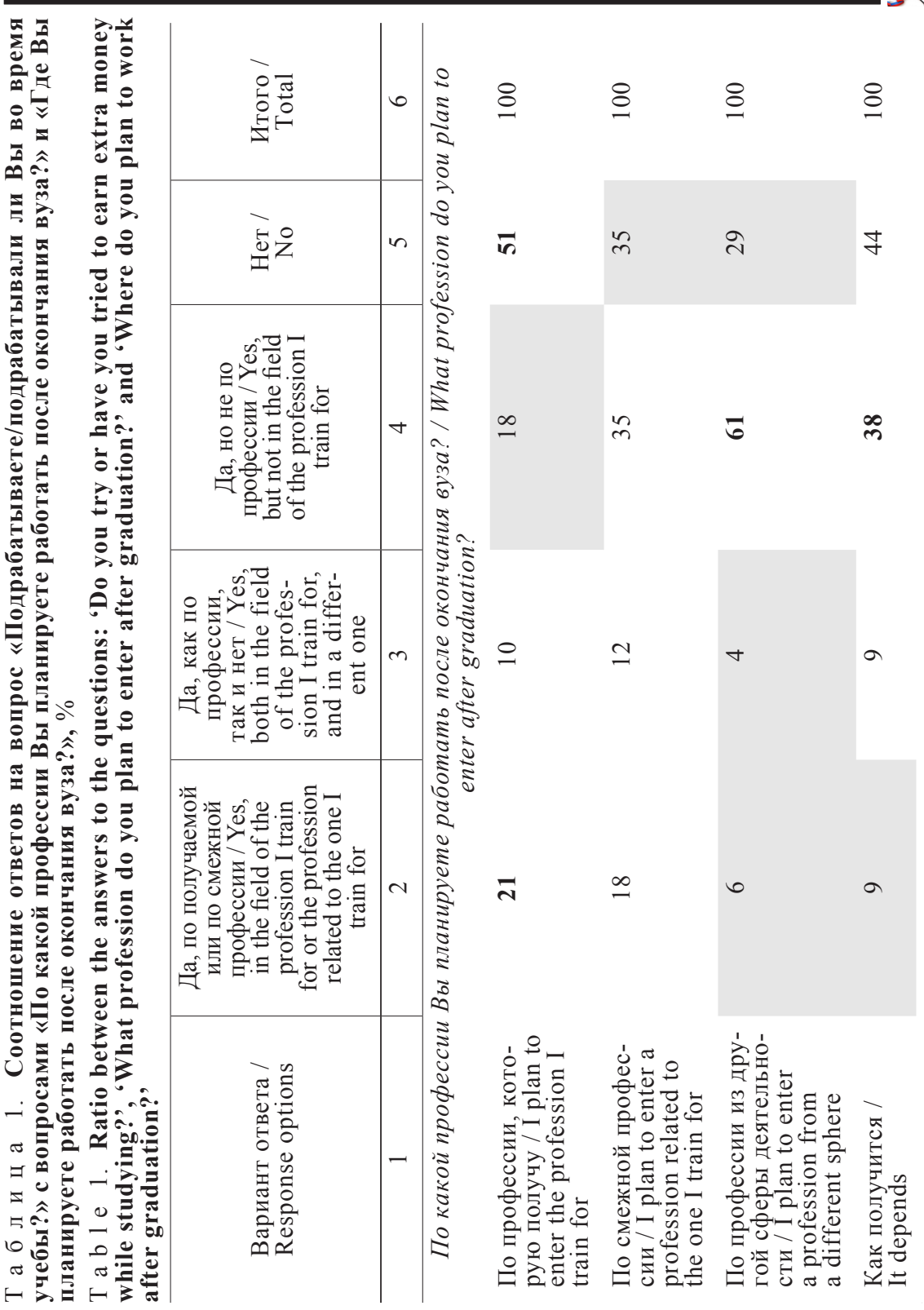




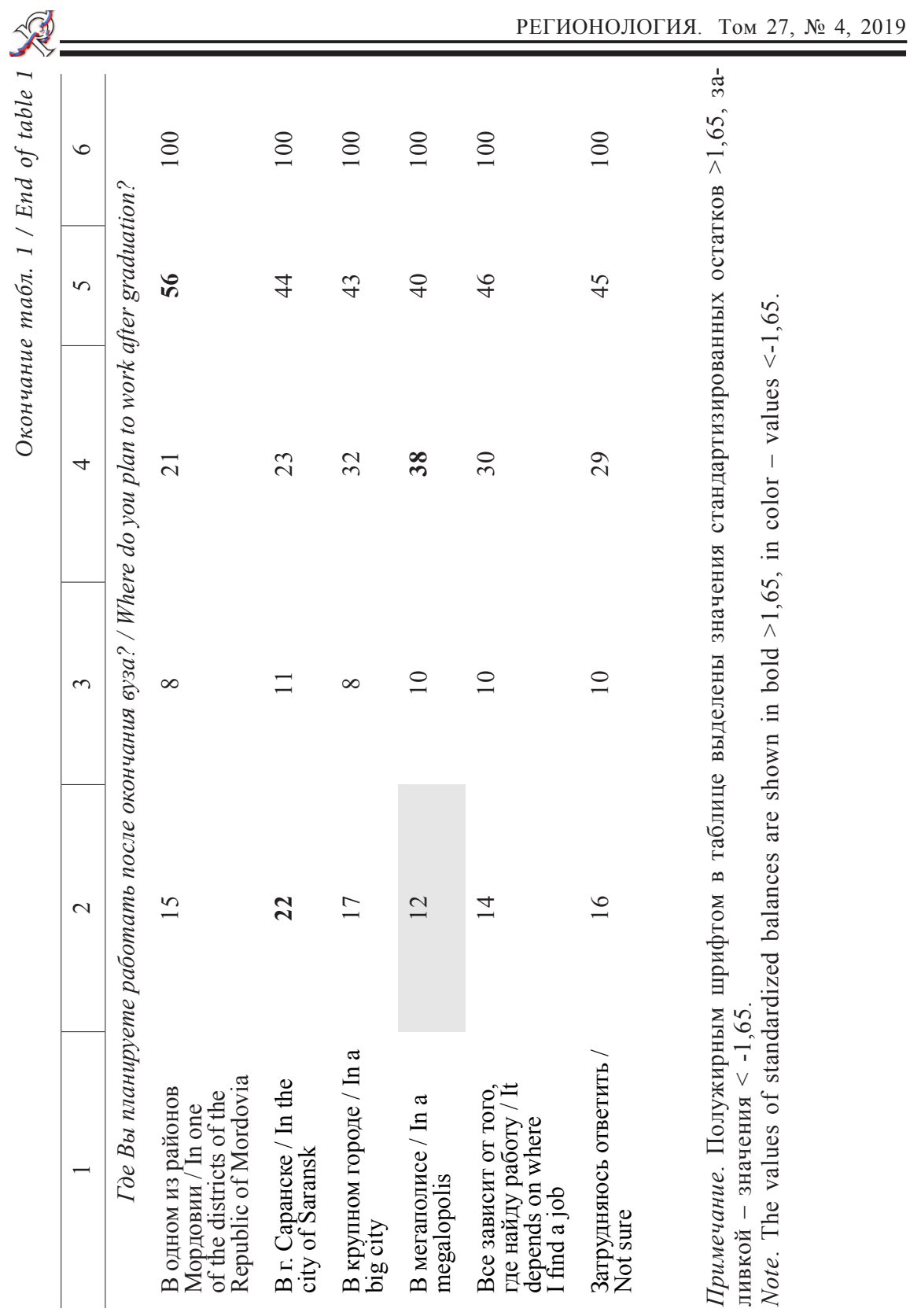


Важнейшим эффектом вторичной занятости, связанной с профессией, является закрепляемость молодежи в регионе. Подрабатывавшие по специальности более ориентированы на трудоустройство в пределах Республики Мордовия. Распространенность соответствующих установок в этой группе студентов гораздо выше, чем среди работавших не по профессии (58-77 против 5 \%). Последние более настроены на трудоустройство в мегаполисе. Таким образом, работа вне профессиональной области, с одной стороны, благоприятствует формированию у будущего выпускника вуза настроений на выезд за пределы региона, с другой способствует приобретению им социального опыта на рынке труда, накоплению человеческого капитала и повышению его адаптационных возможностей.

Следующей качественной характеристикой вторичной занятости является ее локализация в формальном или неформальном секторе занятости. В первом случае влияние трудоустройства будет иметь более очевидные позитивные результаты, поскольку регулируется институционально закрепленными нормами. Что касается неформального сектора, то последствия требуют более тщательного анализа.

Практика самозанятости, как наиболее распространенная форма неформальной занятости, является популярной среди студентов. Диапазон видов деятельности широк, однако наиболее масштабными являются заработок в интернете (фриланс) (36 \%) и репетиторство (29 \%) (табл. 2).

Т а 6 л и ц а 2. Распределение ответов на вопрос «Использовали ли Вы в период обучения следующие способы дополнительного заработка?», \% $\mathrm{T}$ a b l e 2. Distributions of answers to the question 'Did you use the following methods of making extra money during the training period?', $\%$

\begin{tabular}{l|c|c|c}
\hline \multicolumn{1}{c|}{$\begin{array}{c}\text { Практики самозанятости / } \\
\text { Self-employment practices }\end{array}$} & N & $\begin{array}{c}\text { Процент } \\
\text { ответов / } \\
\text { Responses, } \\
\%\end{array}$ & $\begin{array}{c}\text { Процент } \\
\text { наблюдений / } \\
\text { Observations, } \\
\%\end{array}$ \\
\hline 1 & 2 & 3 & 4 \\
\hline $\begin{array}{l}\text { Изготовление кондитерских изделий } \\
\text { на заказ / Маking соnfectionery to order }\end{array}$ & 13 & 1 & 2 \\
$\begin{array}{l}\text { Организация совместных закупок / } \\
\text { Оrganization of joint procurement }\end{array}$ & 30 & 3 & 6 \\
$\begin{array}{l}\text { Автомобильный сервис / Car service } \\
\text { Рукоделие: шитье, вязание / Needlework: } \\
\text { sеwing, knitting }\end{array}$ & 51 & 4 & 7 \\
$\begin{array}{l}\text { Декоративно-прикладное творчество на } \\
\text { Заказ / Arts and crafts to order }\end{array}$ & 69 & 6 & 9
\end{tabular}


Окончание табл. 2 / End of table 2

\begin{tabular}{l|c|c|c}
\hline \multicolumn{1}{c|}{1} & 2 & 3 & 4 \\
\hline Курьерские услуги / Courier services & 69 & 6 & 9 \\
Услуги такси / Тахі services & 70 & 6 & 9 \\
$\begin{array}{l}\text { Фото- и видеосъемка / Photography and } \\
\text { videography }\end{array}$ & 77 & 7 & 10 \\
$\begin{array}{l}\text { Бьюти-услуги / Beauty services } \\
\begin{array}{l}\text { Строительство и ремонт / Construction } \\
\text { and repair }\end{array}\end{array}$ & 119 & 10 & 16 \\
$\begin{array}{l}\text { Репетиторство / Tutoring } \\
\text { Заработокв Интернете(фриланс)/Earning }\end{array}$ & 213 & 11 & 17 \\
$\begin{array}{l}\text { мопеу оnline (freelance) } \\
\text { Всего / Тотаl }\end{array}$ & 1149 & 100 & 29 \\
\end{tabular}

* Сумма ответов по столбцу не равна 100 \%, так как по методике опроса можно было выбрать несколько вариантов / The sum of the responses in the column is not equal to $100 \%$, since one could select several response options according to the survey methodology.

Часто виды деятельности лежат вне профессиональной сферы, с которой связано получаемое в вузе образование, либо в смежных областях. Так, «заработок в интернете (фриланс)» практикуют не только представители обучающихся по математическим и информационно-технологическим направлениям подготовки (стандартизированный остаток $-4,7$ ), но и студенты, обучающиеся социально-гуманитарным и управленческим профессиям (2,6 и 2,5 соответственно $)^{9}$.

Однако связь с профессиональной областью все же наблюдается. Репетиторством занимаются преимущественно обучающиеся по социальногуманитарным и педагогическим направлениям (стандартизированные остатки 5,1 и 3,8 ); бьюти-услуги оказывают будущие медики и работники сферы искусства и культуры (2,0 и 1,7 соответственно). Декоративноприкладное творчество на заказ - область для учащихся по направлениям подготовки «Культура и искусство» $(5,9)$.

Таким образом, виды деятельности дифференцируются в зависимости от уровня специализированности требуемых знаний и навыков. Чем выше специализация, тем чаще она совпадает с получаемой студентом профессией.

\footnotetext{
${ }^{9}$ Стандартизованный остаток, равный по модулю 1,65 или превышающий его, указывает на значимое расхождение между наблюдаемой и ожидаемой частотами.
} 
Процедура многомерного шкалирования, проведенная с использованием возможностей программного пакета SPSS, позволила выявить особенности структуры студенческой самозанятости. Виды деятельности отчетливо подразделяются на новые и традиционные, женские и мужские (рис. 1).

Самозанятость / Self-employment

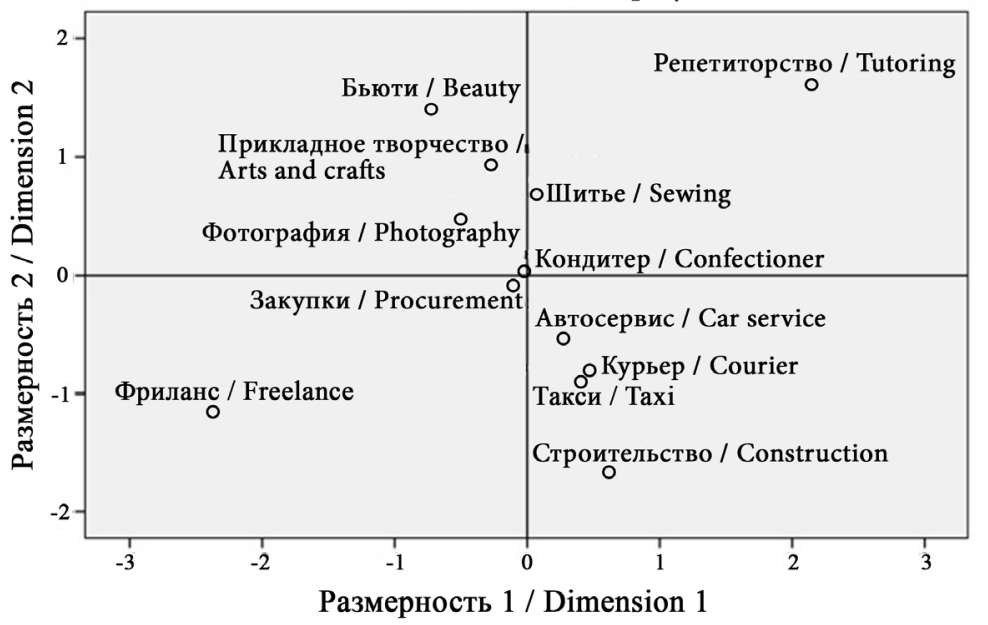

Р и с у н о к. Пространство практик самозанятости

F i g u r e. Space of self-employment practices

Новые/традиционные сферы самозанятости отчетливо дифференцировались в квадрантах, расположенных по вертикали: в правой части находятся традиционные сферы - строительство и ремонт, услуги такси, курьерские услуги, автосервис, шитье, репетиторство; новые - фриланс, бьюти услуги, декоративно-прикладное творчество на заказ, фотои видеосъемка, совместные закупки, изготовление кондитерских изделий - в левой части.

В квадрантах по горизонтали локализуются преимущественно мужские и женские виды деятельности. Содержание левого верхнего квадранта позволяет сделать вывод о том, что расширение спектра видов деятельности происходит за счет женской самозанятости - студенток, активно включающихся в практики самозанятости.

Композиция представленных на рисунке показателей, где значительно удалены фриланс и репетиторство, демонстрирует в первую очередь сосуществование на рынке труда принципиально разных по содержанию, средствам производства, условиям труда, способам поиска клиентов и коммуникации с ними видов трудовой деятельности. 
В конечном счете, это свидетельствует о существенной дифференциации неформального рынка труда, где востребованы как классические виды студенческой подработки, так и новые. Поэтому закономерен вывод о том, что самозанятость является продуктом постиндустриальной трансформации рынка труда [30], проявления которой наиболее отчетливы в его неформальной сфере.

Переходя к рассмотрению мотивационной структуры студенческой самозанятости, следует подчеркнуть, что виды деятельности самозанятых несколько отличаются по мотивации. Об этом свидетельствуют данные проведенных в феврале - марте 2019 г. фокусированных интервью с самозанятыми.

Качественное исследование позволило определить, что материальный мотив играет важную роль, однако не всегда становится первопричиной подработок. Часто истоками рассматриваемого способа заработка является хобби: «Началось с того, что мне купили фотоаппарат в 9-10 классе. Тогда он был крутой, все на него смотрели. Тогда я начала снимать... Мне подруги сказали зарабатывать на этом, потому что я и так постоянно фотографирую (студентка, естественно-научное направление подготовки, фотограф); «Люблю рисовать с детства, а фотография - это тоже рисование, но только быстрее... Начинала с пленочных фотоаппаратов, потом были цифровые и зеркальные. Сначала фотографировала животных, потом людей. Однажды друг сказал, что у меня хорошо получается, и можно начать на этом зарабатывать» (студентка, социально-гуманитарное направление, фотограф).

Доминирование материальных мотивов характерно для занимающихся репетиторством: «Стала заниматься репетиторством с конца 10 класса. ...В принципе я была еще школьником, но хотелось своих денежных средств и поэтому я решила, почему бы и нет» (студентка, социальногуманитарное направление, репетитор); «Начала заниматься репетиторством в начале 3 курса. Я не думала сначала этим заниматься, а просто хотела какой-то независимости от родителей, не сидеть на шее у них, иметь свои средства» (студентка, социально-гуманитарное направление, репетитор).

Для многих студентов самозанятость не носит жестко вынужденного характера, связанного с необходимостью оплачивать обучение или зарабатывать на самое необходимое. Как правило, студенты проявляют предприимчивость, креативность и используют возможности дополнительного заработка, которые появляются в связи с виртуализацией социальных отношений и ростом сферы услуг.

В связи с этим стоит отметить, что выраженной индивидуально-личностной характеристикой самозанятых студентов является стремление к самообразованию: «Я самоучка. Смотрела видеоролики в интернете, 
сейчас это всем доступно. Когда есть время, экспериментирую, осваиваю новые техники (студентка, естественно-научное направление, фотограф); «Как-то в инстаграме нашла аккаунт, мне очень понравились сумочки, решила, что хочу такую и могу ее сама связать. Открыла в интернете ролик, посмотрела, подумала, что все легко и понятно. Сходила за пряжей и связала» (студентка, социально-гуманитарное направление, занимается рукоделием на заказ).

Потребности в самообразовании самозанятых студентов обеспечивает интернет, постепенно демонополизирующий функции института формального образования.

Другими ключевыми характеристиками студентов, практикующих самозанятость, являются прагматичность, амбициозность и самостоятельность. Факторный анализ (SPSS, метод главных компонент) детерминант выбора профессии при поступлении в вуз показал, что будущие самозанятые отдавали предпочтенией статусным характеристикам профессии доходности и престижности (13\% объясненной дисперсии), в то время как их несамозанятые однокурсники строили свой выбор исходя из наличия бюджетных мест и величины проходного балла (12 \%). Причем последние прислушивались к рекомендациям старших членов семьи, а самозанятые действовали исходя из собственной информированности о профессии.

Сравнительный анализ студенческих установок на использование тех или иных способов поиска работы выявил принципиальные отличия самозанятых, выражающиеся в замещении ориентации на использование связей, знакомств возможностями, предоставляемыми ресурсами сети Интернет; в выстраивании стратегий организации собственного бизнеса. Спектр предполагаемых способов поиска работы у этой категории студенчества шире и многообразнее, что свидетельствует об адаптированности к реалиям современного рынка труда.

Таким образом, самозанятость как форма вторичной трудовой занятости студентов выполняет функции приспособления к условиям и потребностям (адаптационную) и встраивания в социально-профессиональную структуру регионального рынка труда (интегративную), однако не способствует повышению профессиональной ориентированности и укреплению профессиональной идентичности студентов, стимулирует их миграционные настроения. Так, большинство реализующих практики самозанятости не планируют после окончания вуза трудоустраиваться по профессии и потенциально ориентированы на выезд за пределы Республики Мордовия.

Обсуждение и заключение. Полученные результаты и выводы подтверждают тенденции, фиксируемые зарубежными и отечественными исследователями. В частности, показана масштабность вторичной за- 
нятости студентов и ее структура, воспроизводящая характерные для современного этапа свойства: преимущественно работа в частном секторе и не по специальности.

Функции вторичной занятости студентов-старшекурсников в целом характеризуются как положительные. Однозначен позитивный потенциал этой практики непосредственно на индивидуально-личностном уровне в контексте накопления человеческого капитала и формирования адаптационных стратегий на рынке труда.

На институциональном уровне проявляется амбивалентная роль вторичной занятости: ее последствия имеют позитивный эффект при условии подработок по специальности. Только в этом случае вторичная занятость способствует становлению профессиональной идентичности, и тем самым повышает эффективность института высшего образования. Занятость, не связанная с будущей профессией, напротив, негативно влияет на установку трудоустраиваться по получаемой специальности.

В структуре вторичной занятости студентов выявлен масштабный сегмент практик, лежащих в плоскости неформальной самозанятости. Расширение коммуникации посредством социальных сетей, виртуализация социальных практик стали благоприятным фактором их распространения. Структурно студенческая самозанятость отличается многообразием видов деятельности, имеет выраженные гендерные особенности и часто обусловлена накопленными знаниями, умениями, компетенциями, полученными в рамках как формального образования, так и самообразования.

Полученные результаты исследования позволяют лучше понять механизмы распространения и структуру вторичной занятости студенческой молодежи на региональном рынке труда, а соответственно - более качественно подойти к разработке программы мероприятий по сохранению человеческого капитала региона, сокращению миграционного оттока молодежи.

\section{СПИСОК ИСПОЛЬЗОВАННЫХ ИСТОЧНИКОВ}

1. Дикусарова М. Ю. Вторичная занятость студентов как способ адаптации на рынке труда // Территория новых возможностей. Вестник Владивостокского государственного университета экономики и сервиса. 2013. № 3 . C. 177-182. URL: http://science.vvsu.ru/scientific-journals/journal/current/article/ id/2145399147/2013_3_26vtorichnaia_zaniatost (дата обращения: 06.07.2019).

2. Carr R. V., Wright J. D., Brody C. J. Effects of High School Work Experience a Decade Later: Evidence From the National Longitudinal Survey // Sociology of Education. 1996. Vol. 69, no. 1. Pp. 66-81. DOI: https://doi.org/10.2307/2112724 
3. Герчиков В. И. Феномен работающего студента вуза // Социологические исследования. 1999. № 8. С. 87-94.

4. Gerchikov V. I. The Phenomenon of the Working College Student // Russian Education \& Society. 2000. Vol. 42, issue 6. Pp. 67-84. DOI: https://doi.org/10.2753/ RES1060-9393420667

5. Красова Е. В. Основные черты студенческой занятости в регионах России (на примере Владивостока и других городов) // Вестник Тюменского государственного университета. Социально-экономические и правовые исследования. 2017. T. 3, № 1. C. 266-285. DOI: https://doi.org/10.21684/2411-7897-2017-3-1-266-285

6. Родионова А. В. Трудовая занятость студентов в контексте обучения (на примере Санкт-Петербурга) // Теория и практика общественного развития. 2011. № 7. C. 80-84. URL: http://teoria-practica.ru/vipusk-7-2011/ (дата обращения: 06.07.2019).

7. Рощин С. Ю., Рудаков В. Н. Совмещение учебы и работы студентами российских вузов // Вопросы образования. 2014. № 2. C. 152-179. DOI: https:// doi.org/10.17323/1814-9545-2014-2-152-179

8. Cherednichenko G. A. The Educational and Professional Trajectories of Secondary School Graduates // Russian Education \& Society. 2011. Vol. 53, issue 8. Pp. 19-35. DOI: https://doi.org/10.2753/RES1060-9393530802

9. Callender C. The Impact of Term-Time Employment on Higher Education Students' Academic Attainment and Achievement // Journal of Education Policy. 2008. Vol. 23, issue 4. Pp. 359-377. DOI: https://doi.org/10.1080/02680930801924490

10. King J. E. Crucial Choices: How Students' Financial Decisions Affect Their Academic Success. Washington, DC: American Council on Education, 2002. 32 p. URL: https://eric.ed.gov/?id=ED469585 (дата обращения: 06.07.2019).

11. Gleason P. M. College Student Employment, Academic Progress, and Postcollege Labor Market Success // Journal of Student Financial Aid. 1993. Vol. 23, no. 2. Pp. 5-14. URL: https://eric.ed.gov/?id=EJ477819 (дата обращения: 06.07.2019).

12. Харченко В. С. Учат ли быть фрилансером в российском вузе (анализ свободной занятости в контексте образовательных стандартов ВПО нового поколения) // Педагогическое образование. 2012. № 2. С. 196-199. URL: http://journals.uspu.ru/index.php?option $=$ com_content\&view $=$ article\&id=99:innovatsii-v-praktike-obrazovaniya\&catid=96\&Itemid= $\overline{146}$ (дата обращения: 06.07.2019).

13. Харченко В. С. Совмещение работы и учебы в вузе: новые практики и новые смыслы // Вопросы образования. 2013. № 3. C. 92-104. URL: https:// vo.hse.ru/2013--3/100508673.html (дата обращения: 06.07.2019).

14. Кениг В. А. Становление профессиональной идентичности студентов, работающих по специальности // Профессиональное образование. Столица. Новые педагогические исследования. 2007. № 6. C. 64-74. URL: https://elibrary. $\mathrm{ru} / \mathrm{item} . \mathrm{asp}$ ?id=14317293 (дата обращения: 06.07.2019).

15. Янбарисова Д. М. Работа во время учебы в вузах Татарстана: влияет ли она на успеваемость? // Вопросы образования. 2014. № 1. С. 217-237. URL: https://vo.hse.ru/2014--1/117867961.html (дата обращения: 06.07.2019).

16. Yanbarisova D. Combining University Studies with Work: Influence on Academic Achievement (December 9, 2014). Higher School of Economics Research Paper No. WP BRP 21/EDU/2014. DOI: https://doi.org/10.2139/ssrn.2535776 
17. Занятость молодежи в мотивационном и структурном измерении [Электронное издание] / М. К. Горшков [и др.]; отв. редактор М. К. Горшков. М.: Институт социологии ФНИСЦ РАН, 2017. 129 с. DOI: https://doi.org/10.19181/ inab. 2017.2

18. Карпенко Е. 3. Сверхзанятость учащейся молодежи как фактор снижения качества человеческого капитала // Региональные проблемы преобразования экономики. 2015. № 8. C. 69-75. URL: http://www.rppe.ru/?p=1517 (дата обращения: 06.07.2019).

19. Drozdikova-Zaripova A. R., Kalatskaya N. N., Kostyunina N. Y. The Research of Educational Motivation of Working and Nonworking Russian Students // Review of European Studies. 2015. Vol. 7, no. 5. Pp. 108-117. DOI: https://doi. org/10.5539/res.v7n5p 108

20. Ворона М. А. Мотивы студенческой занятости // Социологические исследования. 2008. № 8. C. 106-115. URL: https://www.isras.ru/socis 2008 8.html (дата обращения: 06.07.2019).

21. Учись, студент? Влияние успеваемости в вузе на стартовую заработную плату выпускников / В. Н. Рудаков [и др.] // Вопросы экономики. 2017. № 3. C. 77-102. DOI: https://doi.org/10.32609/0042-8736-2017-3-77-102

22. Hall R. The Work-Study Relationship: Experiences of Full-Time University Students Undertaking Part-Time Employment // Journal of Education and Work. 2010. Vol. 23, issue 5. Pp. 439-449. DOI: https://doi.org/10.1080/13639080.2010.515969

23. Humphrey R. Pulling Structured Inequality Into Higher Education: The Impact of Part-Time Working on English University Students // Higher Education Quarterly. 2006. Vol. 60, issue 3. Pp. 270-286. DOI: https://doi.org/10.1111/j.14682273.2006.00317.x

24. Апокин А., Юдкевич М. Анализ студенческой занятости в контексте российского рынка труда // Вопросы экономики. 2008. № 6. С. 98-110. DOI: https://doi.org/10.32609/0042-8736-2008-6-98-110

25. Вознесенская Е. Д., Константиновский Д. Л., Чередниченко Г. А. «Кончить курс и место достать»: Исследование вторичной занятости студентов // Социологический журнал. 2001. № 3. С. 101-120. URL: https://www.jour.isras. ru/index.php/socjour/article/view/700 (дата обращения: 06.07.2019).

26. Гимпельсон В. Е., Капелюшников Р. И. Нормально ли быть неформальным? // Экономический журнал ВШЭ. 2013. № 1. С. 3-40. URL: https://ej.hse. $\mathrm{ru} / 2013-17-1 / 84540458 . \mathrm{html}$ (дата обращения: 06.07.2019).

27. Нагимова А. М., Сафиуллина Ф. Р. Совмещение обучения в вузе и трудовой занятости студентов Казани // Социологические исследования. 2014. № 4. C. 121-124. URL: http://socis.isras.ru/article/5901 (дата обращения: 06.07.2019).

28. Стребков Д. О., Шевчук А. В. Трудовые стратегии самозанятых профессионалов (фрилансеров) // Мир России. 2015. № 1. С. 72-100. URL: https:// elibrary.ru/item.asp?id=23102570 (дата обращения: 06.07.2019).

29. Davis S. N., Shevchuk A., Strebkov D. Pathways to Satisfaction with WorkLife Balance: The Case of Russian-Language Internet Freelancers // Journal of Family and Economic Issues. 2014. Vol. 35, issue 4. Pp. 542-556. DOI: https://doi. org/10.1007/s10834-013-9380-1 
30. Красильщиков В. Ориентиры грядущего? Постиндустриальное общество и парадоксы истории // Общественные науки и современность. 1993. № 2. C. $165-175$.

Поступила 15.07.2019; принята к публикации 17.09.2019; опубликована онлайн 30.12.2019.

\section{Об авторах:}

Касаткина Наталья Петровна, ведущий научный сотрудник ГКУ РМ «Научный центр социально-экономического мониторинга» (430005, Россия, г. Саранск, ул. Б. Хмельницкого, д. 39а), доцент кафедры социологии ФГБОУ ВО «МГУ им. Н. П. Огарёва» (430005, Россия, г. Саранск, ул. Большевистская, д. 68/1), кандидат социологических наук, ORCID: https://orcid.org/0000-0002-0940-2087, kasatkina-rri@mail.ru

Шумкова Наталья Викторовна, доцент кафедры социологии ФГБОУ ВО «МГУ им. Н. П. Огарёва» (430005, Россия, г. Саранск, ул. Большевистская, д. 68/1), кандидат социологических наук, ORCID: https:/orcid.org/0000-0002-2330-0028, niiregion@mail.ru

Заявленный вклад авторов:

Касаткина Наталья Петровна - научное руководство; анализ литературы по проблеме исследования; разработка методологии исследования; качественный анализ результатов; подготовка текста статьи.

Шумкова Наталья Викторовна - анализ литературы по проблеме исследования; сбор и обработка данных; первичная интерпретация статистических данных; подготовка текста статьи.

Для ичитирования:

Касаткина Н. П., Шумкова Н. В. Вторичная занятость и самозанятость студентов вузов: масштабы, структура и функции (на примере Республики Мордовия) // Регионология. 2019. Т. 27, № 4. С. 779-800. DOI: https://doi.org/10.15507/24131407.109.027.201904.779-800

Все авторы прочитали и одобрили окончательный вариант рукописи.

\section{REFERENCES}

1. Dikusarova M.Yu. Secondary Employment of Students as a Way to Adapt to the Labor Market. Territoriya novykh vozmozhnostej. Vestnik Vladivostokskogo gosudarstvennogo universiteta ehkonomiki $i$ servisa $=$ The Territory of New Opportunities. The Herald of Vladivostok State University of Economics and Service. 2013; (3):177-182. Available at: http://science.vvsu.ru/scientific-journals/journal/ current/article/id/2145399147/2013_3_26vtorichnaia_zaniatost (accessed 06.07.2019). (In Russ., abstract in Eng.) 
2. Carr R.V., Wright J.D., Brody C.J. Effects of High School Work Experience a Decade Later: Evidence from the National Longitudinal Survey. Sociology of Education. 1996; 69(1):66-81. (In Eng.) DOI: https://doi.org/10.2307/2112724

3. Gerchikov V.I. [The Phenomenon of the Working Student of an Institution of Higher Education]. Sotsiologicheskie issledovaniya = Sociological Studies. 1999; (8):87-94. (In Russ.)

4. Gerchikov V.I. The Phenomenon of the Working College Student. Russian Education \& Society. 2000; 42(6):67-84. (In Eng.) DOI: https://doi.org/10.2753/ RES1060-9393420667

5. Krasova E.V. Main Features of Students' Employment in the Regions of Russia (On Example of Vladivostok and Other Cities). Vestnik Tyumenskogo gosudarstvennogo universiteta. Sotsialno-ehkonomicheskie $i$ pravovye issledovaniya $=$ Tyumen State University Herald. Social, Economic, and Law Research. 2017; 3(1):266-285. (In Russ., abstract in Eng.) DOI: https://doi.org/10.21684/2411-7897-2017-3-1-266-285

6. Rodionova A.V. Employment of Students in Context of Learning (On the Example of Saint Petersburg). Teoriya i praktika obshhestvennogo razvitiya = Theory and Practice of Social Development. 2011; (7):80-84. Available at: http://teoria-practica. ru/vipusk-7-2011/ (accessed 06.07.2019). (In Russ., abstract in Eng.)

7. Roshchin S.Yu., Rudakov V.N. Combining Work and Study by Russian Higher Education Institution Students. Voprosy obrazovaniya = Educational Studies. 2014; (2):152-179. (In Russ., abstract in Eng.) DOI: https://doi.org/10.17323/1814-95452014-2-152-179

8. Cherednichenko G.A. The Educational and Professional Trajectories of Secondary School Graduates. Russian Education \& Society. 2011; 53(8):19-35. (In Eng.) DOI: https://doi.org/10.2753/RES1060-9393530802

9. Callender C. The Impact of Term-Time Employment on Higher Education Students' Academic Attainment and Achievement. Journal of Education Policy. 2008; 23(4):359-377. (In Eng.) DOI: https://doi.org/10.1080/02680930801924490

10. King J.E. Crucial Choices: How Students' Financial Decisions Affect their Academic Success. Washington, DC: American Council on Education; 2002. Available at: https://eric.ed.gov/?id=ED469585 (accessed 06.07.2019). (In Eng.)

11. Gleason P.M. College Student Employment, Academic Progress, and Postcollege Labor Market Success. Journal of Student Financial Aid. 1993; 23(2):5-14. Available at: https://eric.ed.gov/?id=EJ477819 (accessed 06.07.2019). (In Eng.)

12. Kharchenko V.S. Are the Students Taught to be a Freelancer in the Russian High School? Analysis of Independent Employment in the Context of Education Standards of New Generation. Pedagogicheskoe obrazovanie = Pedagogical Education in Russia. 2012; (2):196-199. Available at: http://journals.uspu.ru/index.php?option=com cont ent\&view=article\&id=99:innovatsii-v-praktike-obrazovaniya\&catid=96\&Itemid=146 (accessed 06.07.2019). (In Russ., abstract in Eng.)

13. Kharchenko V.S. Combining Work and Study in Universities: New Practices or New Implications? Voprosy obrazovaniya = Educational Studies. 2013; (3):92-104. Available at: https://vo.hse.ru/2013--3/100508673.html (accessed 06.07.2019). (In Russ., abstract in Eng.) 
14. Kenig V.A. [Establishing the Professional Identity of Students Practicing their Professions]. Professionalnoe obrazovanie. Stolitsa. Novye pedagogicheskie issledovaniya $=$ Vocational Education. The Capital. New Pedagogical Research. 2007; (6):64-74. Available at: https://elibrary.ru/item.asp?id=14317293 (accessed 06.07.2019). (In Russ.)

15. Yanbarisova D.M. Combining Work and Study in Tatarstan Higher Education Institutions: How Academic Performance Is Affected? Voprosy obrazovaniya = Educational Studies. 2014; (1):218-237. Available at: https://vo.hse.ru/2014--1/117867961. html (accessed 06.07.2019). (In Russ., abstract in Eng.)

16. Yanbarisova D. Combining University Studies with Work: Influence on Academic Achievement (December 9, 2014). Higher School of Economics Research Paper No. WP BRP 21/EDU/2014. (In Eng.) DOI: https://doi.org/10.2139/ssrn.2535776

17. Gorshkov M.K., et al. [Youth Employment in Terms of Motivation and Structure]. Moscow; 2017. (In Russ.) DOI: https://doi.org/10.19181/inab.2017.2

18. Karpenko E.Z. Overemployment of Young Students as a Factor of Reduction of the Quality of Human Capital. Regionalnye problemy preobrazovaniya ehkonomiki $=$ Regional Problems of Transforming the Economy. 2015; (8):69-75. Available at: http://www.rppe.ru/?p=1517 (accessed 06.07.2019). (In Russ., abstract in Eng.)

19. Drozdikova-Zaripova A.R., Kalatskaya N.N., Kostyunina N.Y. The Research of Educational Motivation of Working and Nonworking Russian Students. Review of European Studies. 2015; 7(5):108-117. (In Eng.) DOI: https://doi.org/10.5539/ res.v7n 5 p 108

20. Vorona M.A. Students' Employment Motives. Sotsiologicheskie issledovaniya $=$ Sociological Studies. 2008; (8):106-115. Available at: https://www.isras.ru/socis 2008 8.html (accessed 06.07.2019). (In Russ.)

21. Rudakov V.N., Chirikov I.S., Roshchin S.Yu., Drozhzhina D.S. The Impact of Academic Achievement on Starting Wages of Russian University Graduates. Voprosy ehkonomiki = Economic Issues. 2017; (3):77-102. (In Russ., abstract in Eng.) DOI: https://doi.org/10.32609/0042-8736-2017-3-77-102

22. Hall R. The Work-Study Relationship: Experiences of full-Time University Students Undertaking Part-Time Employment. Journal of Education and Work. 2010; 23(5):439-449. (In Eng.) DOI: https://doi.org/10.1080/13639080.2010.515969

23. Humphrey R. Pulling Structured Inequality into Higher Education: The Impact of Part-Time Working on English University Students. Higher Education Quarterly. 2006; 60(3):270-286. (In Eng.) DOI: https://doi.org/10.1111/j.1468-2273.2006.00317.x

24. Apokin A., Yudkevich M. Analysis of Student Employment in the Context of Russian Labor Market. Voprosy ehkonomiki= Economic Issues. 2008; (6):98-110. DOI: https://doi.org/10.32609/0042-8736-2008-6-98-110

25. Voznesenskaya E.D., Konstantinovskiy D.L., Cherednichenko G.A. 'To Complete the Course and Get a Job': A Study of Students' Secondary Employment. Sotsiologicheskij zhurnal = Sociological Journal. 2001; (3):101-120. Available at: https:// www.jour.isras.ru/index.php/socjour/article/view/700 (accessed 06.07.2019). (In Russ.)

26. Gimpelson V.E., Kapelyushnikov R.I. Is it Normal to be Informal? Ehkonomicheskij zhurnal VShEh = HSE Economic Journal. 2013; (1):3-40. Available at: https:// ej.hse.ru/2013-17-1/84540458.html (accessed 06.07.2019). (In Russ., abstract in Eng.) 
27. Nagimova A.M., Safiullina F.R. Combination of University Training with Employment among Kazan's Students. Sotsiologicheskie issledovaniya = Sociological Studies. 2014; (4):121-124. Available at: http://socis.isras.ru/article/5901 (accessed 06.07.2019). (In Russ., abstract in Eng.)

28. Strebkov D.O., Shevchuk A.V. Work Trajectories of Self-Employed Professionals. Mir Rossii = World of Russia. 2015; (1):72-100. Available at: https://elibrary. ru/item.asp?id=23102570 (accessed 06.07.2019). (In Russ., abstract in Eng.)

29. Davis S.N., Shevchuk A., Strebkov D. Pathways to Satisfaction with WorkLife Balance: The Case of Russian-Language Internet Freelancers. Journal of Family and Economic Issues. 2014; 35(4):542-556. (In Eng.) DOI: https://doi.org/10.1007/ s10834-013-9380-1

30. Krasilshchikov V. [Landmarks of the Future? Post-Industrial Society and the Paradoxes of History]. Obshhestvennye nauki $i$ sovremennost $=$ Social Sciences and Contemporary World. 1993; (2):165-175.

Submitted 15.07.2019; accepted for publication 17.09.2019; published online 30.12.2019.

About the authors:

Natalya P. Kasatkina, Leading Research Officer, Scientific Center for Social and Economic Monitoring (39a B. Khmelnitskogo St., Saransk 430005, Russia); Associate Professor, Department of Sociology, National Research Mordovia State University (68/1 Bolshevistskaya St., Saransk 430005, Russia), Ph. D. (Sociology), ORCID: https://orcid.org/0000-0002-0940-2087, kasatkina-rri@mail.ru

Natalya V. Shumkova, Associate Professor, Department of Sociology, National Research Mordovia State University (68/1 Bolshevistskaya St., Saransk 430005, Russia), Ph. D. (Sociology), ORCID: https://orcid.org/0000-0002-2330-0028, niiregion@mail.ru

Contribution of the authors:

Natalya P. Kasatkina - academic supervision; analysis of the literature on the research problem; development of research methodology; qualitative analysis of the results; writing the text of the article.

Natalya V. Shumkova - analysis of the literature on the research problem; data collection and processing; primary interpretation of statistical data; writing the text of the article.

For citation:

Kasatkina N.P., Shumkova N.V. Secondary Employment and Self-Employment of Higher Education Students: The Scale, Structure and Functions (the Case Study of the Republic of Mordovia). Regionology = Russian Journal of Regional Studies. 2019; 27(4):779-800. DOI: https://doi.org/10.15507/2413-1407.109.027.201904.779-800

The authors have read and approved the final version of the manuscript. 


\section{Диалог труда и материнства в условиях социально- экономической и территориальной дифференциации в Республике Татарстан}

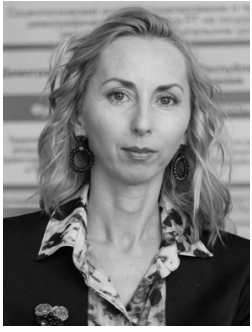

Ч. И. Ильдарханова*

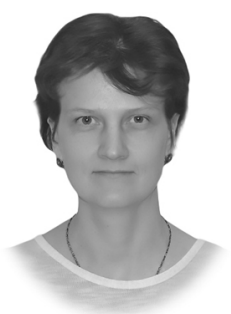

В. А. Гневашева

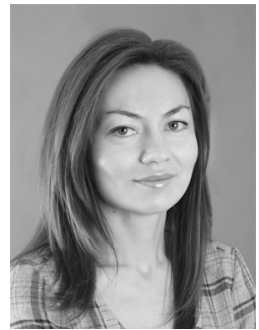

А. Ф. Валидова

Центр семьи и демографии Академии наук Республики Татарстан (2. Казань, Россия), *chulpanildusovna@gmail.com

Введение. Активность женщин на рынке труда, нежелание прерывать карьеру и сталкиваться с проблемой снижения доходов от трудовой деятельности являются теми факторами, которые препятствуют повышению рождаемости и влияют на репродуктивное поведение женщин. Под действием идеологических установок и под влиянием материальных факторов женщины сталкиваются с необходимостью брать на себя огромную долю семейных обязанностей и поддерживать баланс между работой и семьей. Целью статьи является анализ удовлетворенности и востребованности женщинами действующей государственной поддержки в Республике Татарстан в области создания условий для совмещения занятости в семье и на работе.

Материалы и методы. Основу исследования составили результаты прикладного социологического исследования «Трудовая занятость в структуре репродуктивно-родительских стратегий современной женщины в Республике Татарстан». Среди методов использовался сравнительный анализ полученных микроданных по оценке удовлетворенности женщин-матерей своим положением в контексте конфликта семьи и занятости в условиях существующей семейно-демографической политики в разрезе «город - село».

Результаты исследования. Подтверждена гипотеза о значительной роли системы дошкольных учреждений в достижении женщинами баланса между оплачиваемым трудом и материнством, при этом степень успеха реализации данной меры зависит от типа поселения. Предложены новые подходы в области поддержки семей с детьми. По мнению авторов, основные составляющие политики государства по обеспечению баланса жизни и труда для женщин-матерей должны

(c) Ильдарханова Ч. И., Гневашева В. А., Валидова А. Ф., 2019 
включать в себя практику гибких форм занятости, позволяющих сочетание участия на рынке труда с материнством, а также доступ к качественным услугам по уходу за детьми.

Обсуждение и заключение. Полученные результаты позволили сделать вывод, что вне зависимости от типа поселения финансовое состояние домохозяйств и жилищные условия, а также состояние здоровья в большей степени мешают женщинам в Республике Татарстан иметь желаемое количество детей. Материалы статьи будут полезны представителям власти для разработки программ по оптимизации регионального процесса регулирования занятости женщин.

Ключевые слова: репродуктивное поведение, рождаемость, демография, экономическая активность женщин, материнство, трудовая занятость

\title{
Dialogue of Labor and Motherhood in the Context of Socio-Economic and Territorial Differentiation in the Republic of Tatarstan
}

\author{
Ch. I. Ildarhanova*, V. A. Gnevasheva, A. F. Validova \\ Family and Demography Center, Tatarstan Academy of Sciences \\ (Kazan, Russia), \\ "chulpanildusovna@gmail.com
}

Introduction. Women's activity in the labor market, reluctance to interrupt their careers and face the problem of lowering income from work are the factors that impede the increase in birth rates and affect the reproductive behavior of women. Under the influence of ideological attitudes and material factors, women are faced with the need to assume a huge share of family responsibilities and maintain a balance between work and family. The objective of this study is to analyze women's satisfaction with and demand for the existing state support in the Republic of Tatarstan targeted at creating conditions for combining household work and paid jobs.

Materials and Methods. The study was based on the results of the applied sociological study 'Labor activity in the structure of reproductive and parental strategies of a modern woman in the Republic of Tatarstan'. The method of comparative analysis of the microdata obtained was used to assess the extent to which of women with children are satisfied with their position in the context of the conflict of family and employment in the situation of the existing family and demographic policies in the opposition of 'city - village'.

Results. The study has confirmed the hypothesis about a significant role of the system of preschool institutions in making it possible for women to achieve a balance between paid work and motherhood, while the degree of success depends on the type of settlement. New approaches to supporting families with children have been proposed. According to the authors, the main components of state policies to ensure the balance of life and work for women with children should include the practice of flexible forms of employment, making it possible to combine participation in the labor market with motherhood, as well as access to quality childcare services. Discussion and Conclusion. The results obtained made it possible to conclude that, regardless of the type of settlement, the financial position of households and the housing conditions, as well as the state of health, to a greater extent prevent women in the Republic of Tatarstan from having the desired number of children. The 
materials of the article may be useful to the authorities when developing programs to optimize the regional process of regulating employment of women.

Keywords: reproductive behavior, birth rate, demography, women's economic activity, motherhood, employment

Введение. Ведущую роль в создании благоприятного диалога по охране материнства играют правительственные структуры федерального, регионального, муниципального уровней, ключевыми партнерами которых по вопросам трудовых отношений и занятости являются работодатели и профсоюз. Построение диалога между работой и семьей включает эффективную политику охраны материнства, подразумевающую обеспечение предприятиями дружелюбной по отношению к матери и к семье среды, учитывающей потребности как работников, так и работодателей. Финансовые меры со стороны государства по облегчению стоящего перед матерями конфликта «семья - работа» сокращают расходы семей на воспитание детей и тем самым содействуют повышению рождаемости.

Согласно экономической теории, альтернативные стратегии женщин, основанные на рациональном выборе, зависят от объема потерянного дохода во время ухода за ребенком: 1) для женщин с более высоким заработком размер потерянного дохода выше, следовательно, они выберут выход на работу и оплату детского сада; 2) остаться дома предпочтут женщины с маленьким доходом и те, кто выбирает роль неработающей матери. В данном случае субсидия со стороны государства повышает объем потерянного дохода, а значит, создает стимулы для выхода на работу, в результате чего возрастает занятость женщин. С другой стороны, для работающих матерей вводимое государством пособие или субсидирование детского сада представляет собой эффект дохода и оказывает отрицательное воздействие на число рабочих часов, которое выберет женщина (она может сократить число часов рабочего времени после введения субсидии), а значит, снизится и уровень занятости женщин-матерей.

В Республике Татарстан в рамках национального проекта «Демография» ${ }^{1}$ заложены средства на финансовую поддержку семей при рождении детей, включающие различные формы поддержки в зависимости от очередности рождения детей, а также создание условий для осуществления трудовой деятельности женщин с детьми. Последнее предполагает создание в республике новых мест в организациях по уходу за детьми до трех лет и масштабную подготовку женщин в качестве работников,

${ }^{1}$ Национальный проект «Демография». URL: https://rosmintrud.ru/ministry/programms/ demography (дата обращения: 14.01.2019). 
оказывающих услуги по присмотру и уходу за детьми дошкольного возраста ${ }^{2}$.

Основной научной целью статьи является эконометрический и социологический анализ удовлетворенности и востребованности женщинами действующей государственной поддержки в Республике Татарстан в области создания условий для совмещения занятости в семье и на работе.

В соответствии с целью выдвигаются следующие задачи:

1) оценка действующих федеральных и региональных программ по повышению рождаемости и материальной поддержке семей в контексте демографических задач и задач содействия занятости женщин;

2) изучение влияния социальных программ, направленных на сокращение бедности среди семей с детьми, экономическую активность, доходы и состояние профессиональных навыков женщин-матерей;

3) проведение анализа российских и зарубежных исследований, посвященных оценке эффективности мер по поддержке женщин на положение женщин на рынке труда (доходы, профессиональные навыки и образование, гендерное неравенство);

4) по результатам анализа данных по Республике Татарстан формулирование рекомендаций по стимулированию экономической активности женщин и созданию условий для совмещения женщинами выполнения родительских обязанностей с трудовой занятостью.

Обзор литературы. В научной среде много исследований было посвящено изучению возможностей моделирования и прогнозирования занятости, ее структурных компонент, попыток системного обоснования взаимозависимости социально-экономических факторов социальной сферы в сопряжении с проблемами труда и занятости. Однако пока не сформировано направление системной и прогностической оценки взаимовлияния социально-экономических и демографических факторов, несомненно значимых для национальной безопасности государства и оказывающих ключевое влияние на развитие человеческого капитала страны.

На сегодняшний день в научной литературе нет единого мнения по поводу степени влияния семейной политики на родительские стратегии современных женщин. Согласно экономической теории репродуктивного поведения, снижение желаемого числа детей обусловлено увеличивающейся ценой времени женщины. Основоположник экономической теории фертильности Г. Беккер считает решение иметь детей сугубо рациональным, которое принимается в целях максимизации полезности и зависит от издержек и выгод, связанных с появлением ребенка, в условиях

2 Паспорт Регионального проекта «Содействие занятости женщин - создание условий дошкольного образования для детей в возрасте до трех лет». URL:http:/mert.tatarstan.ru/ rus/file/pub/pub_1767410.pdf (дата обращения: 18.03.2019). 
ограниченного дохода ${ }^{3}$. Согласно экономической модели репродуктивного поведения, перед женщиной-матерью стоит выбор между получением дохода от трудовой деятельности (в данном случае он равен разности между заработной платой и оплатой услуг по уходу за ребенком) и выполнением семейных обязанностей по уходу за ребенком [1]. Данный механизм описан в статической модели предложения рабочей силы, где спрос на свободное время снижается с повышением уровня заработной платы и наблюдается прямая положительная зависимость: рост заработной платы приводит к росту предложения на рынке труда. Однако доход от нетрудовой деятельности, в том числе пособия, субсидии и другие меры поддержки семей, посредством эффекта дохода вызывает сокращение предложений на рынке труда. Таким образом, экономическая теория не дает однозначного ответа по поводу общего эффекта мер семейной политики, направленной на повышение рождаемости и поддержку семей с детьми [2]. В частности, на решение женщины работать и совмещать материнство с формальной занятостью оказывает влияние целый ряд других факторов, таких как демографические и семейные характеристики, доход других членов домохозяйства, собственные предпочтения и т. д.

Некоторые исследования обращают внимание на то, что процесс урбанизации на уровне страны приводит к различиям в состоянии гендерного неравенства у городского и сельского населения; возрастные модели рождаемости в городах и в сельской местности также различаются. Так, российский демограф С. В. Захаров, сравнивая изменения значений среднего возраста матери для города и села, показывает, что темпы старения рождаемости в городском населении превышают этот показатель для сельского населения, и выдвигает гипотезу о формировании в России разных моделей рождаемости: «постиндустриальной городской», для которой характерна более эффективная политика планирования семьи, позднее вступление в родительство и низкие нормы детности, и «сельской, сохраняющей черты более традиционного прототипа», характеризующейся более ранним вступлением в родительство и более высокими нормами детности [3].

Д. Блум с соавторами, учитывая разную степень урбанизации в различных странах, проводит анализ влияния рождаемости на уровень экономической активности женщин и приходит к выводу о высокой отрицательной корреляции между уровнем рождаемости и занятостью женщин, что подтверждает теорию альтернативной стоимости рождения ребенка [4]. Количественный анализ, сделанный авторами, дает следующие результаты: с каждым последующим ребенком активность

${ }^{3}$ Becker G. S. A Treatise on the Family. Cambridge, MA: Harvard University Press, 1981. 304 p. 
матери на рынке труда в среднем снижается на 10-15 \% для женщин в возрасте 20-39 лет и на 5-10 \% для женщин в возрасте 40-49 лет [4]. Выводом этого подхода является положительное влияние снижения уровня рождаемости в развитых странах на трудовую активность женщин, что в свою очередь способствует росту использования человеческого капитала в экономике.

Особый интерес представляют теоретические и эмпирические работы по изучению баланса жизни и труда у женщин. В постиндустриальных странах глобализация, технологический прогресс и изменение характера занятости в сторону повышения сложности выполняемых задач на рабочем месте, рост количества профессий в сфере услуг, требующих высокого образования и умственного труда, наряду с трансформациями семейных норм, способствующих высокой вовлеченности женщин на рынке труда, привели к переходу к форме семьи, состоящей из двух работающих супругов. Таким образом, вопрос нахождения баланса между семьей и занятостью становится особенно актуальным и является объектом многих исследований [5-8]. В современных условиях с конфликтом между семьей и занятостью в большей степени сталкиваются женщины, так как именно на них ложится ноша необходимости совмещения домашних обязанностей с формальной трудовой занятостью [9; 10]. Этот процесс приводит к гендерной дискриминации на рынке труда вследствие необходимости выбора в пользу форм занятости, позволяющих совмещать их с уходом за детьми. Так, например, многие женщины вынуждены работать меньшее количество часов, делать выбор в пользу работы, не предусматривающей карьерного роста, а порой и вовсе отказываться от карьеры. Немаловажно отметить и эмоциональные проблемы, которые порождает необходимость женщинами выполнять двойную роль работающей матери. Разрываясь между уходом за детьми и рабочим графиком, многие женщины не ощущают удовлетворенности ни от одной из ролей и чувствуют, что не справляются со своими обязанностями. Таким образом, наряду с практической стороной проблемы совмещения семьи и работы эмоциональная сторона конфликта материнства и занятости также играет свою роль [11].

В несколько ином ракурсе рассмотрен вопрос участия женщинматерей в формальной занятости в публикации Л. Уаттиса и соавторов, где говорится о положительных аспектах вовлеченности матерей в работу [12]. Позитивное влияние выхода на работу и возможности включиться в профессиональную сферу, при этом выполняя роль матери, часто остается вне интереса исследований, посвященных конфликту материнства и труда. Авторы в результате проведенного анализа выделяют такие положительные факторы выхода женщин на работу, как повышение самооценки, обретение той или иной степени 
финансовой независимости, необходимости выхода из самоизоляции, которая часто возникает при непрерывном уходе за детьми и ведении домашнего хозяйства [12]. В данном случае сочетание материнства и занятости можно назвать не конфликтом, а скорее диалогом; возможность самореализации женщин, идентификация себя не исключительно в качестве матери, но и в качестве члена общества позволяют найти баланс труда и материнства.

Обзор теоретических и прикладных исследований, посвященных изучению роли государственной семейной политики, подтверждает пользу финансовых мер по поддержке рождаемости, снижающих альтернативную стоимость рождения и воспитания ребенка [13-15]. Относительно влияния материальной поддержки на уровень занятости матерей, метаанализ научно-практических исследований дает неоднозначный ответ, а некоторые работы и вовсе указывают на отрицательный эффект такой поддержки. Щедрая социальная поддержка женщин-матерей снижает вероятность выхода их на работу. Длительный отпуск по уходу может иметь негативные последствия: женщина переходит в категорию экономически неактивного населения и теряет профессиональные навыки, а также подвергается дискриминации на рынке труда.

Важной составляющей государственной семейной политики, оказывающей непосредственное влияние на вопрос достижения матерями баланса между семьей и занятостью, является доступ к системе детских садов. Проблема нахождения баланса материнства и труда усугубляется недостатком доступа к услугам по уходу за детьми дошкольного возраста. Данная проблема имеется не только в России; степень финансирования детских садов в разных странах отличается. Д. Вури подразделяет страны по типу системы институционального ухода за детьми на три основные группы: 1) страны Северной Европы, в которых действует всеобщее субсидирование государственных детских садов; 2) страны Южной Европы с системой государственных (бесплатных), но малодоступных детских садов; 3) Великобритания, США и Канада, в которых превалирует доля частных дорогостоящих детских садов, а субсидии распространяются в основном на неполные семьи [16].

Важнейшим фактором является стоимость посещения детских садов. В ряде стран она достигает половины средней заработной платы, что говорит об очень ограниченном доступе к данной услуге. Исследования, проведенные в Германии, показали, что большая доля женщин, имеющих маленьких детей, предпочли бы полную занятость, если бы они имели доступ к субсидируемым детским садам [17]. Другие исследования также подтверждают, что страны, предоставляющие доступ к бесплатным дошкольным учебным учреждениям, имеют более высокую долю матерей, участвующих на рынке труда. В этих странах большая доля детей посещает 
детские сады. Особенно высока трудовая активность женщин там, где субсидии на посещение детских образовательных учреждений предоставляются всем работающим родителям. Востребованность государственных услуг по уходу за детьми гораздо выше в странах с высоким качеством предоставляемых образовательных услуг, в случае же недостаточно хорошего качества данных услуг посещаемость детских садов низкая.

В отечественной науке анализу результативности новой семейной политики России ${ }^{4}$ с точки зрения ее влияния на рождаемость, поддержку семей с детьми, и в первую очередь матерей, посвящены исследования Л. Н. Овчаровой ${ }^{5}$, В. Н. Архангельского ${ }^{6}$, Ф. Слонимчика и А. В. Юрко [18], С. В. Захарова ${ }^{7}$, В. Елизарова [19]. Большинство российских демографов склонны считать, что данные меры поощрения рождаемости (программа материнского капитала и др.) оказали незначительное влияние на итоговую рождаемость, а вызвали лишь краткосрочные изменения календаря рождений ${ }^{8}$ [18]. Согласно результатам моделирования Ф. Слонимчика и А. В. Юрко, политика материнского капитала увеличила долгосрочную рождаемость примерно на 0,15 детей на женщину, при этом разницы в «эффекте материнского капитала для трудоустроенных и нетрудоустроенных женщин не обнаружено», однако «эффект ...был более значительным для женщин, проживающих с супругом» [18].

Ряд авторов исследований по оценке эффективности семейной политики в современной России и в регионах приходят к выводу, что одним из важнейших факторов, влияющих на репродуктивное поведение женщины, является доступ к услугам по уходу за детьми [20; 21$]$. О. В. Синявская полагает, что нехватка детских садов в России и «низкое качество предоставляемых услуг препятствуют раннему выходу женщин на рынок труда после рождения ребенка» ${ }^{9}$.

${ }^{4} \mathrm{O}$ дополнительных мерах государственной поддержки семей: Федеральный закон от 29.12.2006 № 256-Ф3 // «Российская газета». URL: https://rg.ru/2006/12/31/roditelyam-dok. html (дата обращения: 19.02.2019).

5 Овчарова Л. Н. Детерминанты репродуктивного поведения населения и факторы семейного неблагополучия: результаты панельных исследований. Сер. «Научные доклады: независимый экономический анализ». № 211. М.: Московский общественный научный фонд: Независимый институт социальной политики, 2010. 248 с.

${ }^{6}$ Архангельский В. Н., Иванова А. Е., Рыбаковский Л. Л. Результативность демографической политики России. М.: Экон-Информ, 2016. 307 с.

7 Захаров С. В. Какой будет рождаемость в России? [Электронный ресурс] // ДемоскопWeekly. 2012. № 495-496. URL: http://www.demoscope.ru/weekly/2012/0495/tema01. php (дата обращения: 11.03.2019).

8 Исупова О. Г. Чему учит опыт семейной политики [Электронный ресурс] // ДемоскопWeekly. 2017. № 739-740. URL: http://demoscope.ru/weekly/2017/0739/tema01.php (дата обращения: 11.03.2019).

${ }^{9}$ Синявская О. В., Сухова А. С. Институциональные услуги по уходу за детьми: неравенства в доступе. Семья в центре социально-демографической политики. Сб. аналит. ст. / Независимый ин-т соц. политики. М., 2009. С. 73-96. 
Результаты теоретических и эмпирических работ по влиянию родительских отпусков, субсидирования детских садов и другой государственной финансовой поддержки по уходу за детьми неоднозначны и зависят от многих различных факторов: традиционной модели семьи в стране и соответственно степени активности женщин на рынке труда, существующих в стране институциональных условий, качества предоставляемых детскими садами услуг, а также уровня развитости рынка труда.

В целом эмпирические исследования позволяют сделать вывод, что относительно высокого уровня рождаемости в сочетании с высокой женской занятостью удалось добиться тем странам, в которых в рамках демографической и семейной политики проводится комплексная политика сочетания профессиональной и семейной жизни населения, позволяющая женщинам после деторождения вернуться на рынок труда и способствующая активному участию мужчин в воспитании детей. Обеспечить сочетание родителями занятости и ухода за детьми становится возможным в странах, которые ввели гендерно нейтральный отпуск по уходу за ребенком. Так, скандинавские страны лидируют по продолжительности отцовских квот в рамках родительского отпуска и, соответственно, отличаются высоким уровнем занятости женщин на рынке труда ${ }^{10}$ [22].

Представленные исследовательские и научно-литературные источники позволяют говорить о масштабном и диверсифицированном изучении проблем занятости разных категорий населения, об оценках факторного воздействия внешней среды на трансформацию форм занятости, о результатах изменения программ государственного регулирования и сопровождения эффективной занятости. Вместе с тем ряд специальных, в частности региональных, вопросов требует уточнения с целью проведения эффективной политики субъекта Российской Федерации в отношении социально-экономических процессов в обществе.

Материалы и методы. Информационной базой исследования послужили аналитико-статистические материалы, предоставленные министерствами и ведомствами Республики Татарстан, включая статистические показатели, полученные Центром семьи и демографии по муниципальным районам и городским округам Республики Татарстан ${ }^{11}$ [23], а также материалы территориального органа Федеральной службы государственной статистики по Республике Татарстан. Первичные данные были получены Центром семьи и демографии Академии наук Республики Татарстан в результате социологического опроса женщин городских округов

${ }^{10}$ Исупова О. Г. Семейная политика в развитых странах [Электронный ресурс] // ДемоскопWeekly. 2016. № 701-702. URL: http://demoscope.ru/weekly/2016/0701/tema01.php (дата обращения: 11.03.2019).

${ }^{11}$ Демографический доклад - 2018. Семейная и демографическая политика в контексте Стратегии социально-экономического развития Республики Татарстан - 2030: моногр. / под общ. ред. Ф. А. Ильдархановой. Казань: Изд-во Академии наук РТ, 2018. 294 с. 
и сельских районов Татарстана, проведенного в период с июня по октябрь 2018 г. (выборка - 2830 женщин репродуктивного возраста). Анализ основных показателей репродуктивного поведения, полученных из анкет и статистических данных по Республике Татарстан, указывает на продолжающуюся тенденцию сдвига материнства к более поздним возрастам. В республике происходит перераспределение вклада отдельных возрастных групп женщин в формирование общего уровня рождаемости. С 2009 г. возрастная группа 25-29 лет по интенсивности рождений опережает более молодую возрастную группу (20-24 года). Показатели рождаемости в молодых возрастных группах продолжают снижаться, а в старших - увеличиваться. Особенно выросли показатели рождаемости среди женщин возрастной категории 30-34 лет и, как следствие, постепенно выравниваются показатели рождаемости у женщин 25-29 и 30-34 лет.

Средний возраст матери в Республике Татарстан продолжает повышаться: с 26,3 лет в 2000 г. до 28,9 лет в 2017 г. $^{12}$. Неудивительно, что процесс откладывания деторождения в большей степени коснулся районов с центром - городом республиканского подчинения или находящихся в территориальной близости к городским округам (Нижнекамский, Нурлатский, Зеленодольский, Верхнеуслонский, Лаишевский районы). Районы, в которых показатель среднего возраста материнства продолжает оставаться низким, имеют преимущественно сельское население (Сармановский, Атнинский, Новошешминский, Тукаевский районы).

Рост среднего возраста материнства проявляется не только на региональном уровне, но и является характерным для России в целом, а также присущ репродуктивной модели многих зарубежных стран. Возможность карьерного роста, свобода выбора в вопросах репродуктивного поведения и профессиональной занятости в экономике приводят женщин к отложенному деторождению. В данном исследовании определена значимость тех или иных факторов, способствующих данной тенденции в республике, а также основные препятствия для реализации женщинами своих репродуктивных намерений.

Для оценки удовлетворенности женщинами Республики Татарстан существующей в стране и регионе системы поддержки семей и материнства и ее влияния на принятие решений о рождении ребенка в рамках данной статьи авторами сформулированы и протестированы три рабочие гипотезы:

1) среди факторов, препятствующих реализации женщинами своих репродуктивных намерений, наибольшую роль играет материальное положение. Для проверки гипотезы проведен анализ основных фак-

12 Демографический ежегодник Республики Татарстан. 2018: Стат. сб. Казань: Изд. центр Татарстанстата, 2018. 162 с. 
торов, мешающих женщинам республики иметь желаемое количество детей, а также сравнение значимости данных факторов для городского и сельского населения. В случае подтверждения данной гипотезы можно говорить о необходимости повышения финансовой поддержки семей в рамках семейной политики;

2) в условиях существующей семейной политики уровень участия женщин-матерей на рынке труда отличается от женщин, не имеющих детей. Для тестирования данной рабочей гипотезы был использован метод сравнения средних, а переменными, характеризующими степень участия женщины на рынке труда, являются продолжительность рабочей недели и среднемесячный доход;

3) меры семейной политики являются важнейшими факторами, необходимыми для выстраивания женщиной баланса между выполнением родительских обязанностей и карьеры. Проверка рабочей гипотезы проводилась с помощью анализа удовлетворенности и востребованности действующей системы семейной поддержки и таких ее составляющих, как детские пособия, материнский капитал, отпуск по уходу за ребенком, система дошкольных учебных учреждений и др.

Результаты исследования. Рассмотрим возможность эконометрического моделирования ряда факторов, позволяющих оценить степень взаимосвязи социально-экономических процессов, предполагаемых тематикой исследования. С одной стороны, важно показать степень включенности трендовых изменений рождаемости в рассматриваемом регионе в сопоставлении с общероссийской ситуацией, с другой - выявить степень взаимосвязи уровня рождаемости с изменением социально-экономических условий женщин (табл. 1).

Социально-экономическая модель оценки значимости факторов в трансформации процессов рождаемости в регионе рассматривалась нами ранее. Она исходит из общих «эконометрических предпосылок построения регрессионных моделей и предъявляет следующие общие требования к регрессорам и объясняемой переменной:

- зависимость имеет линейный вид;

- количество наблюдений больше, чем оцениваемых коэффициентов;

- математическое ожидание от ошибки при фиксированных регрессорах равно нулю;

- имеет место условная гомоскедастичность;

- имеет место условная некоррелированность случайных ошибок;

- векторы отдельных наблюдений независимы и одинаково распределены;

- среди регрессоров нет линейно зависимых;

- оценки эффективные и несмещенные» ${ }^{13}$.

13 Гневашева В. А. Социальная модель формирования рабочей силы: моногр. М.: Русайнс, 2016. 58 с. 


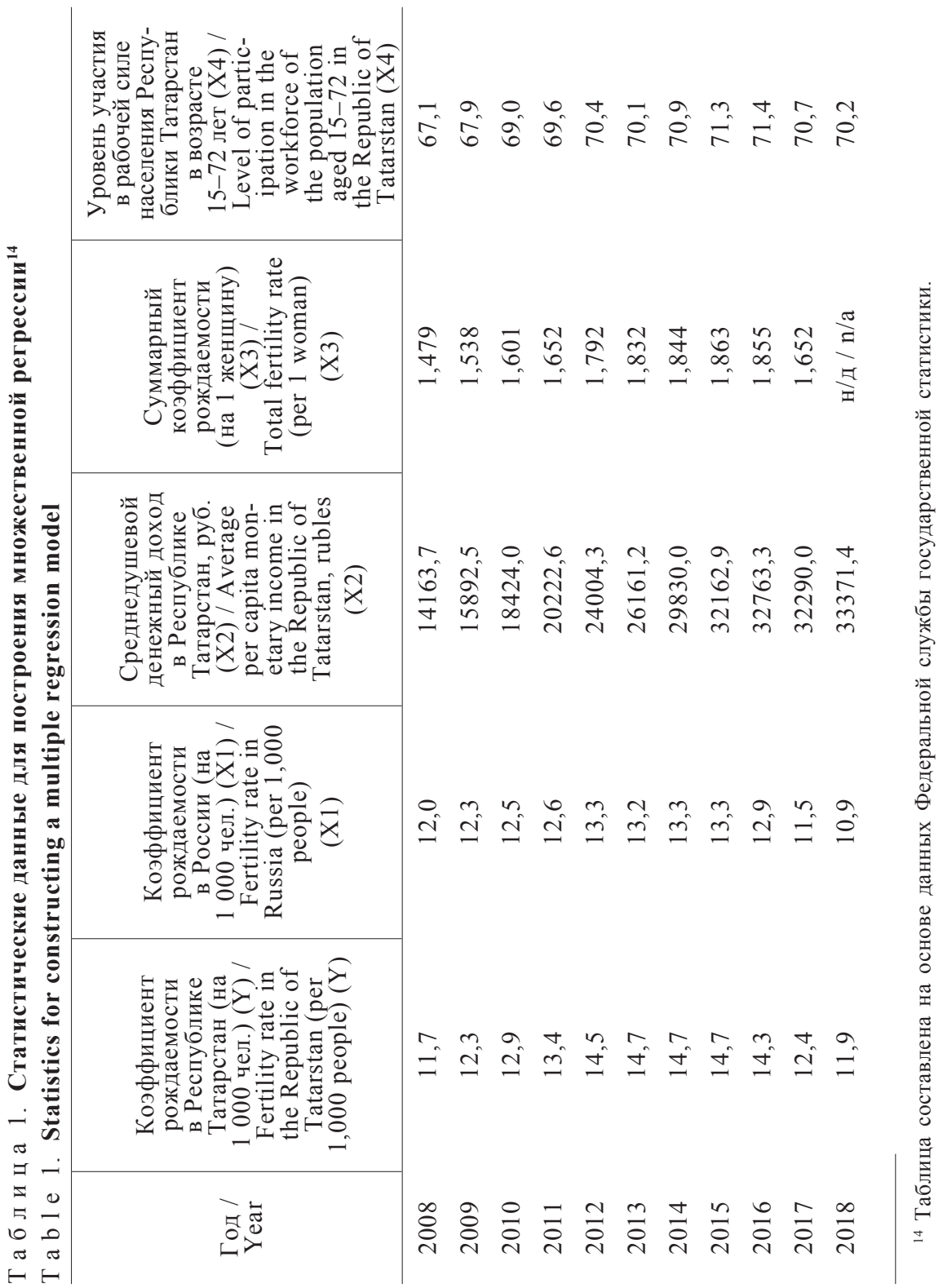


Регрессионная статистика приведена в таблице 2. Полученный $R^{2}$ отражает тот факт, что включенные в модель факторы на $0,05 \%$ объясняют определяемую зависимость, и только $0,5 \%$ неучтенных в модели факторов также могут быть значимы для определения модели.

Т а б л и ц а 2. Регрессионная статистика

$\mathrm{T}$ a b 1 e 2. Regression statistics

\begin{tabular}{lc}
\hline \multicolumn{1}{c|}{ Показатель / Indicator } & Значение / Value \\
\hline Множественный R / Multiple R & 0,997704 \\
R-квадрат / R-squared & 0,995414 \\
Нормированный R-квадрат / Normalized & 0,991745 \\
R-squared & 0,105713 \\
Стандартная ошибка / Standard error & 10 \\
Наблюдения / Observations &
\end{tabular}

Дисперсионный анализ и анализ параметров регрессии позволяют сделать выводы о представленной регрессии (табл. 3). Так как F-фактическое значение F-критерия Фишера больше значимости F-табличное $(271,315>$ 4,97E-06), то корреляционно-регрессионную модель следует считать адекватной, и гипотеза о несостоятельности регрессии отвергается.

Т а б л и ц а 3. Описательная статистика

$\mathrm{T}$ a b 1 e 3. Descriptive Statistics

\begin{tabular}{c|c|c|c|c}
\hline $\begin{array}{c}\text { Переменная / } \\
\text { Variable }\end{array}$ & $\begin{array}{c}\text { Коэффи- } \\
\text { циенты / } \\
\text { Сoefficients }\end{array}$ & $\begin{array}{c}\text { Стандартная } \\
\text { ошибка / } \\
\text { Standard } \\
\text { error }\end{array}$ & $\begin{array}{c}\text { t-статис- } \\
\text { тика / } \\
\text { t- statistics }\end{array}$ & $\begin{array}{c}\text { Р-значение / } \\
\text { p-value }\end{array}$ \\
\hline $\begin{array}{c}\text { Y-пересе- } \\
\text { чение / } \\
\text { y-intercept }\end{array}$ & $-15,9234$ & 6,335654 & $-2,5133$ & 0,053611 \\
X1 & 0,28559 & 0,295298 & 0,967126 & 0,377899 \\
X2 & $-7,5 \mathrm{E}-05$ & $3,08 \mathrm{E}-05$ & $-2,41944$ & 0,060159 \\
X3 & 8,031073 & 2,1857 & 3,674371 & 0,014378 \\
X4 & 0,199812 & 0,104111 & 1,91923 & 0,11304
\end{tabular}

Критическое значение $t_{\text {кр }}$ найдено для уровня значимости $\alpha=5 \%$ и числа степеней свободы $k=9$ и составляет величину $t_{\text {кр }}=2,2622$. По отношению к данному значению оценим t-статистику коэффициентов.

Для свободного коэффициента $\alpha=-15,9234$ определена статистика $t_{\alpha}=-2,5133$, что по модулю больше значения $\mathrm{t}_{\text {кр }}$, Значит, свободный 
коэффициент значим при требуемом уровне значимости $p=0,05$ и им нельзя пренебречь при регрессионном моделировании.

Для коэффициента регрессии $\beta_{1}=0,28559$ определена статистика $t_{\beta 1}=0,967126$, что по модулю меньше значения $t_{\text {кр }}$, значит, данный коэффициент регрессии требует уточнения по степени значимости (формально определяемый как незначимый). Подчеркнем, что в данном случае определяется влияние переменной «коэффициент рождаемости в России в расчете на 1000 чел.» на объясняемую переменную «коэффициент рождаемости в Республике Татарстан».

Для коэффициента регрессии $\beta_{2}=-7,5 \mathrm{E}-05$ определена статистика $t_{\beta 2}=-2,41944$, что по модулю больше значения $t_{\text {кр}}$, Значит, данный коэффициент регрессии значим при требуемом уровне значимости $\mathrm{p}=0,05$ и им нельзя пренебречь при регрессионном моделировании. В данном случае определяется влияние переменной «среднедушевой денежный доход в Республике Татарстан (руб.)» на объясняемую переменную «коэффициент рождаемости в Республике Татарстан».

Для коэффициента регрессии $\beta_{3}=8,031073$ определена статистика $t_{\beta 3}=3,674371$, что по модулю больше значения $t_{\text {кр }}$, Значит, данный коэффициент регрессии значим при требуемом уровне значимости $p=0,05$ и им нельзя пренебречь при регрессионном моделировании. В данном случае определяется влияние переменной «суммарный коэффициент рождаемости (на 1 женщину)» на объясняемую переменную «коэффициент рождаемости в Республике Татарстан».

Для коэффициента регрессии $\beta_{4}=0,199812$ определена статистика $t_{\beta 4}=1,91923$, что по модулю меньше значения $t_{\text {кр }}$, Значит, данный коэффициент регрессии требует уточнения по степени значимости (формально определяемый как незначимый). Подчеркнем, что в данном случае определяется влияние переменной «уровень участия в рабочей силе населения в возрасте 15-72 года Республики Татарстан» на объясняемую переменную «коэффициент рождаемости в Республике Татарстан».

Выводы о значимости коэффициентов модели сделаны на уровне значимости $\alpha=5 \%$.

Рассматривая столбец «Р-значений», отметим, что свободный коэффициент $\alpha$ можно считать значимым на уровне $0,053611=5,4 \%$; коэффициент регрессии $\beta_{1}$ - на уровне $37,7 \%$; коэффициент регрессии $\beta_{2}$ - на уровне $6,0 \%$, коэффициент регрессии $\beta_{3}$ - на уровне $1,4 \%$, коэффициент регрессии $\beta_{4}$ - на уровне $11,3 \%$.

Полученные данные говорят о непосредственной зависимости двух переменных на объясняемую «коэффициент рождаемости в Республике Татарстан», а именно: «среднедушевой денежный доход в Республике Татарстан (руб.)» и «суммарный коэффициент рождаемости (на 1 женщину)». 
Результат регрессионной оценки свидетельствует о значимости фактора денежного дохода для изменения рождаемости в республике, зависимость данных факторов является положительной: при росте среднедушевого дохода (общего уровня благосостояния) уровень рождаемости имеет тенденцию роста. В то же время второй положительно коррелируемый фактор с объясняемой переменной - «суммарный коэффициент рождаемости (на 1 женщину)»- говорит о необходимости адресного, целевого финансирования для увеличения рождаемости. В рассматриваемой модели зависимость уровня занятости, в том числе среди женщин, с изменением уровня рождаемости прослеживается слабо.

Социально-экономические предпочтения женщин в планировании семьи предопределены не тем количеством часов труда, которые они готовы предложить на рынке труда, а уровнем их благосостояния, достигаемым в том числе и за счет нетрудового дохода. Экономические предпочтения смещены с позиции активного трудоустройства в сторону получения необходимого уровня благосостояния, а социальные с общественно-трудового участия на семейное. По данным исследования, возможно предположить, что речь идет о женщинах в возрастной категории 25-35 лет, несмотря на то что до 2015 г. возрастной коэффициент рождаемости для группы 20-24 лет составлял 85,9 \%.

По данным исследования можно сделать вывод о существенных территориально-общественных и национальных особенностях трендовых изменений в рассматриваемом субъекте, во многом отличных от среднего распределения в целом по России, что также подтверждает необходимость формирования адресной поддержки и целевых программ на территории республики.

Полученные данные подтверждают все три ранее выдвинутые гипотезы исследования:

- среди факторов, препятствующих реализации женщинами своих репродуктивных намерений, наибольшую роль играет материальное положение;

- в условиях существующей семейной политики уровень участия женщин-матерей на рынке труда отличается от женщин, не имеющих детей;

- меры семейной политики являются важнейшими факторами, необходимыми для выстраивания женщиной баланса между выполнением родительских обязанностей и карьеры.

Рассмотрим более подробно значимость отдельных факторов.

Результаты микроданных социологического исследования, проведенного Центром семьи и демографии Академии наук Республики Татарстан, позволили авторам выявить основные факторы, препятствующие реализации женщинами своих репродуктивных намерений в Республике Татарстан (рис. 1). Общая тенденция, которую демонстрирует реакция 
респондентов вне зависимости от типа поселения, характеризуется тем, что материальное положение (включающее как финансовые, так и жилищные трудности) занимает лидирующую позицию среди препятствий на пути деторождения (37,6 \%), а на второе место выходит состояние здоровья населения (25\%).

Доступ к услугам (трудности с устройством ребенка в детский сад) / Access to services (difficulties with placing a child in a preschool educational institution) Материальное положение (финансовые, жилищные трудности) / Financial position (financial and housing difficulties)

Профессиональная сфера (желание построить карьеру, большая занятость) / Professional issues (desire to build a career, being very busy)

Состояние здоровья / State of health

Семейная сфера (отсутствие партнера, сложные отношения в семье) / Family issues (no spouse or partner, difficult relationships in the family)

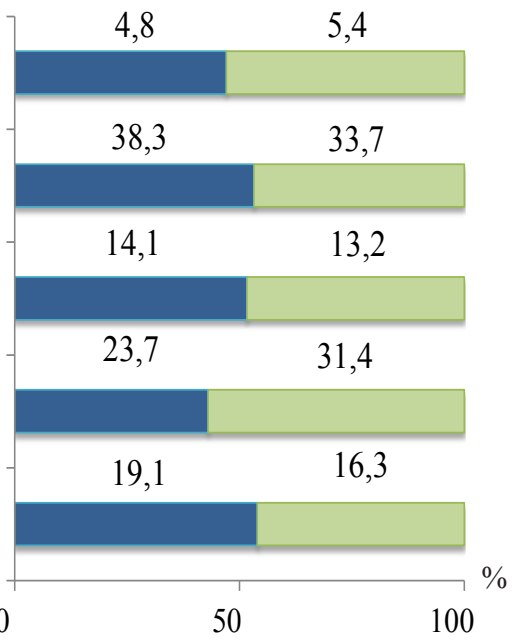

\section{- Город / City $\square$ Село / Village}

Р и с. 1. Сравнение факторов, мешающих иметь желаемое количество детей, в разрезе «город - село»

F i g. 1. Comparison of factors preventing women from having the desired number of children in the opposition of 'city - village'

Анализ данных в разрезе «город - село» показывает, что неудовлетворенность материальным положением городского населения несколько выше, чем сельского (38,3 и 33,7 \% респондентов соответственно отметили этот фактор как решающий), однако максимальное число женщин, указавших материальные трудности в качестве главного препятствия реализации репродуктивных намерений, проживают в поселках городского типа (46 \%). Что касается состояния здоровья как фактора, мешающего иметь желаемое количество детей, отчетливо видно преобладание его значимости для сельского населения, видимо, из-за более высокого качества и лучшего доступа к услугам системы здравоохранения в городах. Проблемы семейной сферы (отсутствие супруга и сложные отношения в семье) были отмечены в качестве препятствия для рождения желаемого числа детей почти 20 \% женщин, проживающих в городе. Это выше, чем процент сельских женщин, указавших на данный фактор. 
Разделение респондентов по типу поселения на категории «город» и «село» показало, что такой фактор, как профессиональная сфера, мешает иметь желаемое количество детей в среднем около $14 \%$ женщин обеих категорий.

Прежде чем приступить к оценке удовлетворенности данными мерами женщинами Республики Татарстан, нам необходимо определить, насколько сильно отличается степень участия женщин-матерей на рынке труда от женщин, еще не вступивших или принявших решение не вступать в материнство. Для сопоставления среднего количества рабочих часов в неделю с детьми и без них у женщин, нами был проведен t-тест для независимых выборок. В таблицах 4 и 5 отражены средние значения длины рабочей недели, стандартные отклонения и стандартные ошибки средних в обеих группах женщин, а также результаты t-теста: значение распределения $t$ и вероятность ошибки $p$.

Т а б л и ц а 4. Групповые статистики

$\mathrm{T}$ a b 1 e 4 . Group statistics

\begin{tabular}{|c|c|c|c|c|c|}
\hline $\begin{array}{c}\text { Показатель / Indi- } \\
\text { cator }\end{array}$ & $\begin{array}{l}\text { Наличие } \\
\text { детей / } \\
\text { Presence of } \\
\text { children }\end{array}$ & $\mathrm{N}$ & $\begin{array}{c}\text { Сред- } \\
\text { неe / } \\
\text { Aver- } \\
\text { age }\end{array}$ & $\begin{array}{c}\text { Стан- } \\
\text { дартное } \\
\text { откло- } \\
\text { нение / } \\
\text { Standard } \\
\text { deviation }\end{array}$ & $\begin{array}{c}\text { Стандарт- } \\
\text { ная ошибка } \\
\text { среднего / } \\
\text { Standard } \\
\text { error }\end{array}$ \\
\hline \multirow{2}{*}{$\begin{array}{l}\text { Количество часов } \\
\text { рабочего времени, } \\
\text { включая сверх- } \\
\text { урочные / Number } \\
\text { of hours of work } \\
\text { time, including } \\
\text { overtime }\end{array}$} & $\begin{array}{l}\text { Нет детей / } \\
\text { No children }\end{array}$ & 426 & 39,54 & 19,64 & 0,95 \\
\hline & $\begin{array}{l}\text { Есть дети / } \\
\text { With } \\
\text { children }\end{array}$ & 1240 & 38,56 & 13,52 & 0,38 \\
\hline
\end{tabular}

Среднее значение длины рабочей недели женщин, не имеющих детей, выше, чем женщин-матерей, однако различия между количеством часов рабочего времени не является статистически значимым, так как вероятность ошибки $p>0,05$.

Анализ таблицы сопряженности для городского населения для двух переменных: среднемесячной заработной платы, характеризующей доход респондента и количества детей, показывает, что на 1, 2 и 3 местах по частоте совместного распределения находятся категории женщин со среднемесячной заработной платой от 10 до 20 тыс. руб., имеющих соответственно двух детей, одного ребенка и женщин, не имеющих детей. С увеличением уровня зарплаты (от 20 до 30 тыс. руб.) доля этих женщин снижается в той же пропорции.

Численность женщин, не имеющих детей, и многодетных матерей (имеющих 3 и более детей) в категории с более низким доходом 


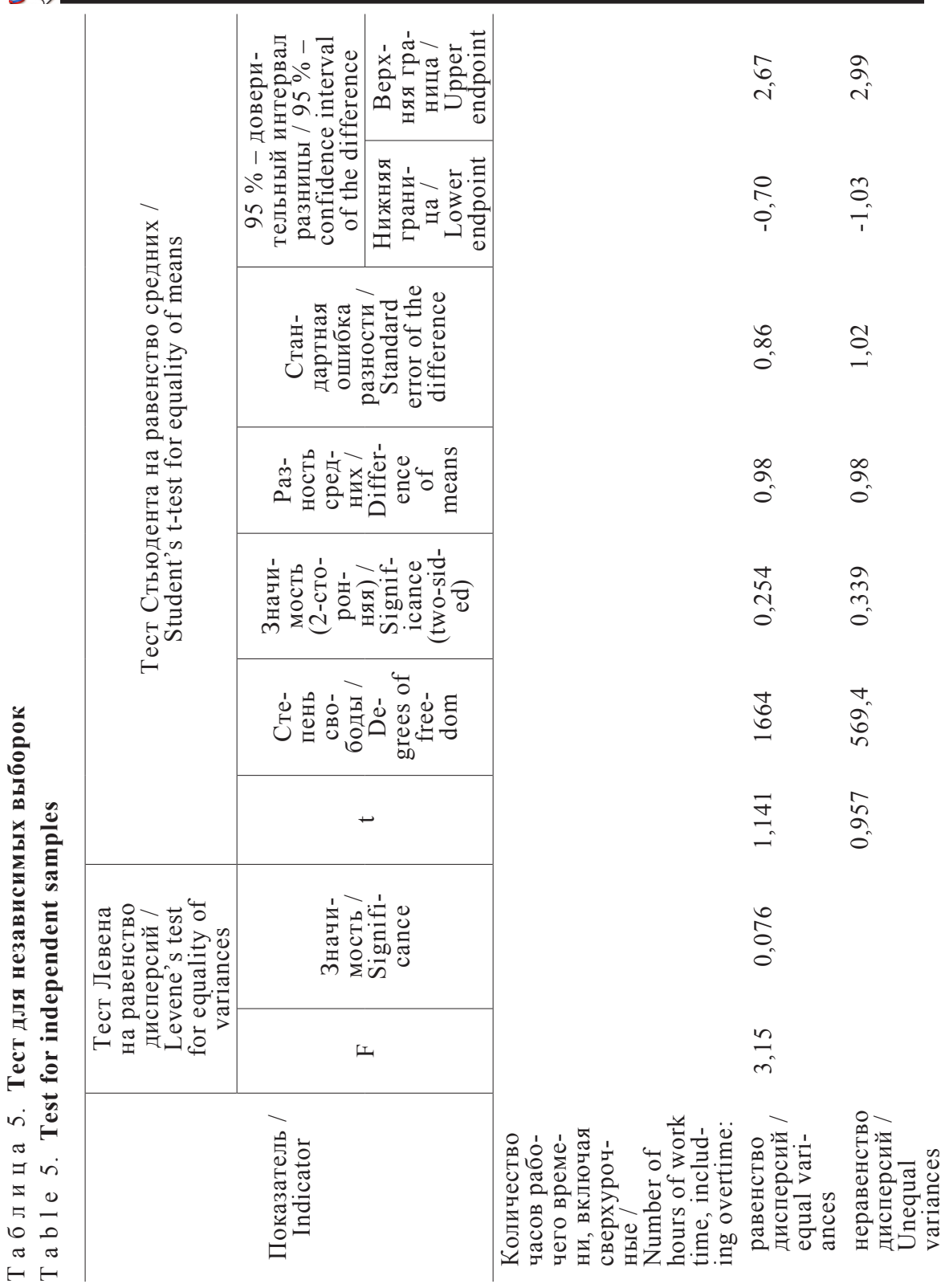


(от 5 до 10 тыс. руб.) превосходит численность женщин групп, относящихся к категории с более высоким доходом (30-40 тыс. руб.). Напротив, женщины, имеющие одного или двоих детей и относящиеся к категории респондентов с более высокой заработной платой (30-40 тыс. руб.), по численности превышают женщин с низким доходом (5-10 тыс. руб.). Объяснить такую тенденцию можно тем фактом, что среди женщин с низким доходом преобладают или очень молодые женщины, не начавшие карьеру, а также работающие студентки (среди них процент женщин, не имеющих детей, очень велик), или многодетные матери, относящиеся к более низкому социальному статусу (не работающие женщины и домохозяйки были исключены из анализа данных переменных).

Результаты анализа таблиц сопряженности для сельского населения отличаются незначительно, однако категория женщин со среднемесячной заработной платой от 10 до 20 тыс. руб. и имеющих двоих детей является доминирующей в совместном распределении доходов и количества детей с большим отрывом от других категорий. Кроме того, в отличие от городских респондентов, достаточно много женщин, не имеющих детей, относятся к занятым, получающим очень низкий среднемесячный доход (до 5000 руб.), что указывает на худшее материальное положение молодежи на селе.

Для оценки эффективности существующей в стране и регионе системы поддержки семей с детьми (гипотеза 3) авторами были проанализированы результаты анкетирования, касающиеся длительности используемого декретного отпуска и отпуска по уходу за ребенком, посещения детьми детских садов, использования матерями возможности гибко организовать рабочее время с учетом семейных потребностей, а также оценки женщинами роли материнского капитала.

Результаты опроса отражают большую роль, которую играет отпуск по уходу за маленьким ребенком в построении матерями баланса между родительскими обязанностями и трудом (рис. 2). Согласно рисунку 2 , доли матерей, использовавших только оплачиваемый отпуск (до достижения ребенком 1,5 лет) и неоплачиваемый (до достижения ребенком 3 лет), разделились приблизительно поровну и составили подавляющее большинство, в то время как на матерей, не вышедших после рождения ребенка на работу или вернувшихся на работу позднее окончания неоплачиваемого отпуска по уходу за ребенком, приходится очень низкий процент. В качестве главной причины досрочного выхода из декретного отпуска и поступления на работу большинство матерей указали необходимость повышения доходов семьи и нехватку денежных средств ввиду слишком маленького детского пособия.

Результаты также указывают на высокую востребованность семьями с детьми детских дошкольных учреждений: в среднем по республике 80 \% респондентов регулярно пользуются услугами детского сада. Отдельно нами было рассмотрено, насколько отличается доступность услуг детских 
садов женщинами с детьми до 3 лет и от 3 до 7 лет включительно (рис. 3). Сравнение отдельных групп продиктовано существующей нехваткой ясельных групп в Республике Татарстан, что отрицательно воздействует на занятость женщин с маленькими детьми.

После исполнения ребенку 3 лет / After the child was 3 years old

На момент беременности / рождения ребенка я не работала / At the time of pregnancy / birth of the child, I did not work

После окончания отпуска по уходу за ребенком я не собираюсь выходить на работу и буду заниматься воспитанием детей / After the end of the parental leave I am not going to go back to work as I will nurture children

До исполнения ребенку 3 лет / Until the child was 3 years old

До исполнения ребенку 1,5 лет / Until the child was 1.5 years old

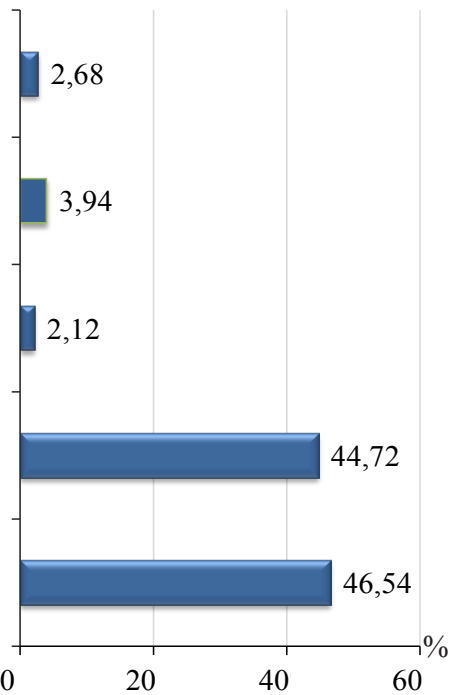

Р и с. 2. Распределение ответов на вопрос «Как долго вы находились в отпуске по уходу за ребенком?», \%

$\mathrm{F}$ i g. 2. Distribution of answers to the question "How long have you been on parental leave?", \%

Согласно данным анкетирования, порядка 90 \% детей в возрасте от 3 до 7 лет регулярно посещают детские сады, в то время процент детей в возрасте до 3 лет, на регулярной основе посещающих детские сады, не столь высок (чуть более 40 \%). Около трети респондентов с маленькими детьми ответили, что не нуждаются в услугах яслей, 23 \% - не могут себе позволить данную услугу. Интересно отметить, что согласно утвержденному в Республике Татарстан региональному проекту «Содействие занятости женщин - создание условий дошкольного образования для детей в возрасте до трех лет» в рамках национального проекта «Демография», «к 2024 году планируется обеспечить 78,9 \% женщин, имеющих детей, возможностью совмещать трудовую деятельность с семейными обязанностями, в том числе за счет повышения доступности дошкольного образования для детей в возрасте до трех лет» ${ }^{15}$.

15 Паспорт регионального проекта «Содействие занятости женщин - создание условий дошкольного образования для детей в возрасте до трех лет». 12.12.2018. URL: http://mert.tatarstan.ru/rus/file/pub/pub_1767410.pdf (дата обращения: 18.03.2019). 
Нет, услуга не нужна / The service is not needed

Нет, не можем себе позволить или недоступно / The child does not attend it as

we cannot afford it or it is inaccessible

Да, посещает, но только на полдня / несколько часов в неделю / The child attends it only for half a day or several hours a week

Да, посещает регулярно / The child attends it regularly

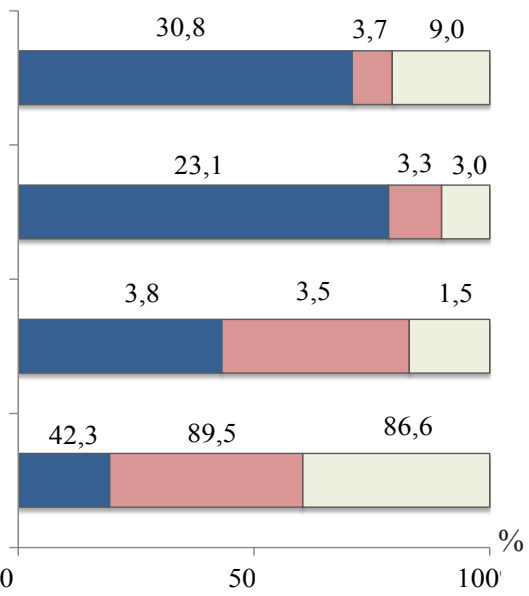

-От 0 до 3 лет / 0 to 3 years of age

$\square$ От 3 до 7 лет / 3 to 7 years of age

$\square \mathrm{B}$ семье есть дети обеих категорий / The family has children of both categories

Р и с. 3. Статистика посещаемости дошкольных учреждений детьми до 7 лет в Республике Татарстан, \%

F i g. 3. Statistics of attendance of preschool institutions by children under 7 in the Republic of Tatarstan, \%

На рисунке 4 показаны результаты опроса женщин Республики Татарстан по вопросу посещения их детьми детских садов в ракурсе сравнения города и села. Больший процент регулярного посещения детских садов детьми, проживающими в городе $(82,7 \%)$, по сравнению с сельскими детьми $(64,3$ \%), наглядно демонстрирует более высокую доступность и востребованность данной услуги в городе. Доля респондентов - жителей села, ответивших, что услуга детского сада им не нужна, более чем в два раза превышает городских женщин, принявших участие в социологическом опросе (27,8 и 9,6 \% соответственно).

Распределение респондентов по посещаемости их детьми детских садов говорит в поддержку рабочей гипотезы о важности системы дошкольных учреждений в достижении женщинами баланса между трудовой занятостью и материнством, при этом степень успеха реализации данной меры семейной политики зависит от типа поселения. Для подтверждения связи между такими переменными, как посещаемость детского сада и тип поселения, авторами был использован критерий независимости $\chi^{2}$ (хи-квардрат) (табл. 6). 
Нет, услуга не нужна / The service is not needed

Нет, не можем себе позволить или недоступно / The child does not attend it as we cannot afford it or it is inaccessible

Да, посещает, но только на полдня / несколько часов в неделю / The child attends it only for half a day or several hours a week

Да, посещает регулярно / The child attends it regularly

$9,6 \quad 27,8$

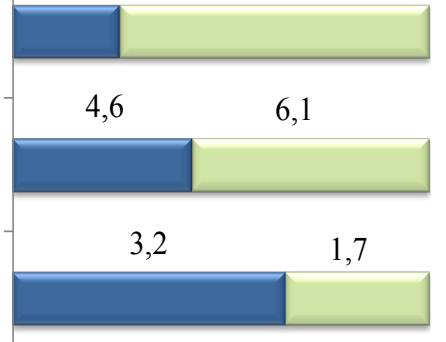

82,7

64,3

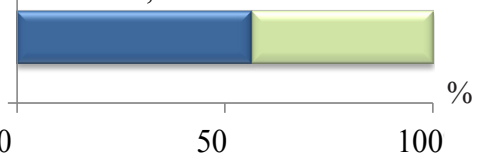

Р и с. 4. Статистика посещаемости дошкольных образовательных учреждений в городских округах и сельских районах Республики Татарстан, \%

F i g. 4. Statistics of attendance of preschool educational institutions in urban districts and rural areas of the Republic of Tatarstan, $\%$

Т а б ли ц а 6 . Критерий хи-квадрат

$\mathrm{T}$ a b 1 e 6 . Chi-squared test

\begin{tabular}{l|c|c|c}
\hline Показатель / Indicator & $\begin{array}{c}\text { Значе- } \\
\text { ние / } \\
\text { Value }\end{array}$ & $\begin{array}{c}\text { Степень } \\
\text { свободы / } \\
\text { Degrees of } \\
\text { freedom }\end{array}$ & $\begin{array}{c}\text { Асимптотическая зна- } \\
\text { чимость (2-стороння) / } \\
\text { Asymptotic significance } \\
\text { (two-sided) }\end{array}$ \\
\hline $\begin{array}{l}\chi^{2} \text { (Хи-квадрат / Chi- } \\
\text { squared) }\end{array}$ & 33,81125 & 6 & 0,000 \\
$\begin{array}{l}\text { Отношение правдопо- } \\
\text { добия / Likelihood ratio }\end{array}$ & 29,56121 & 6 & 0,000 \\
$\begin{array}{l}\text { Количество валидных } \\
\text { наблюдений / Number } \\
\text { of valid observations }\end{array}$ & 780 & &
\end{tabular}

Из результатов вычисления критерия хи-квадрат и расчета уровня значимости данной статистики следует, что нулевая гипотеза о независимости переменных неверна, следовательно, связь между переменными «посещаемость детского сада» и «тип поселения» существует. Таким образом, различия в степени использования данной услуги по уходу за ребенком в городах и сельской местности являются статистически значимыми. 
Другая мера, способствующая совмещению женщинами материнских и трудовых обязанностей, представляет собой появление возможности использовать гибкий график работы, позволяющий женщинам организовать трудовую деятельность с учетом потребностей по уходу за детьми. Ответы респондентов об использовании гибкого графика работы разделились поровну: 49 \% ответили, что имеют возможность работать по гибкому графику, $51 \%$ - не имеют. Таким образом, результаты исследования показали, что на сегодняшний день практика гибких форм занятости используется работодателями пока недостаточно активно. Закрепленное законодательством право родителей, имеющих ребенка в возрасте до 14 лет, использовать гибкий рабочий график, могло бы, на взгляд авторов, посодействовать активизации занятости матерей.

Для оценки удовлетворенности женщинами республики мерами семейной политики, вошедшими в силу с 2007 г., Центром семьи и демографии Академии наук Республики Татарстан было проанализировано, насколько финансовая поддержка в виде материнского капитала, по мнению женщин, повлияла на их репродуктивные намерения (рис. 5). По полученным данным, более половины респондентов оценили влияние такой меры демографической политики 2007 г. как очень сильное; процент отрицательно ответивших крайне низкий (5\%). Такой показатель говорит о важной роли экономических факторов, влияющих на репродуктивное поведение российских женщин.

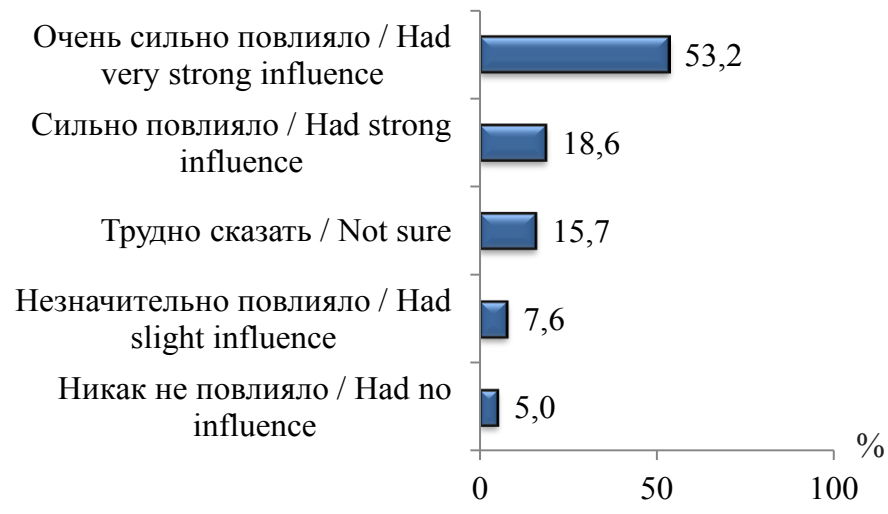

Р и с. 5. Степень влияния материнского капитала на уровень рождаемости в стране по результатам опроса женщин репродуктивного возраста в Республике Татарстан, \%

F i g. 5. Degree of influence of maternal capital on the birth rate in the country according to a survey of women of reproductive age in the Republic of Tatarstan, \% 
Обсуждение и заключение. В настоящей работе рассмотрены вопросы поиска решения для построения женщиной баланса между материнством и собственной реализацией на рынке труда, проведена оценка влияния роли государственной поддержки на такую важную составляющую демографической устойчивости, как репродуктивное поведение женщин. К видам поддержки рождаемости относятся монетарные меры (единовременные выплаты, связанные с рождением ребенка, денежные пособия по уходу за ребенком) и меры, направленные на создание условий для сочетания материнства и трудовой занятости женщин (гарантированный отпуск по уходу за ребенком, субсидируемые государством дошкольные учреждения и пр.).

Теория не дает однозначного ответа по поводу влияния финансовых мер семейной политики на решение женщин работать и совмещать материнство с занятостью. Помимо экономической составляющей в данном вопросе необходимо учитывать такие факторы, как собственные предпочтения женщины, государственную политику на рынке труда, качество институциональных услуг по уходу за детьми, предоставляемых государством. Однако в условиях, когда именно женщины-матери в большей степени сталкиваются с необходимостью совмещения родительских обязанностей с трудовой занятостью, государственная поддержка может облегчить женщинам решение задачи по достижению нужного баланса между оплачиваемым трудом и трудом в семье, благоприятно повлиять на решение женщины вернуться на работу после отпуска по уходу за ребенком и положительно сказаться на степени удовлетворенности работой.

Данный аргумент подтверждается эмпирическими данными исследования на примере Республики Татарстан, проведенного Центром семьи и демографии Академии наук Республики Татарстан. На фоне тенденции повышения возраста материнства и отложенного деторождения были определены основные факторы, препятствующие рождению желаемого числа детей в семьях республики. Среди таких факторов, как в городах, так и в сельских поселениях, лидирующее место заняли материальные трудности, на втором месте оказалось состояние здоровья женщин.

Сравнение степени участия на рынке труда женщин-матерей и женщин, не имеющих детей, показало, что различия в количестве рабочего времени не являются статистически значимыми. Данный вопрос требует более детального анализа. Так, изучение трудовой занятости женщин разных категорий (женщин с маленькими детьми, многодетных матерей, женщин, разделенных по числу уже рожденных детей и др.) является отправной точкой для будущего научного исследования.

Наибольший интерес представляют выводы по оценке роли мер семейной политики в выстраивании диалога между родительством 
и занятостью, сделанные в рамках данной работы. Анализ результатов социологического опроса, касающихся длительности используемого декретного отпуска и институциональных услуг по уходу за ребенком, показал большую роль данных мер государственной поддержки: оплачиваемый отпуск используется большинством опрошенных, а основной причиной досрочного выхода из отпуска по уходу за ребенком выступает необходимость повышения доходов. В ходе сравнительного анализа посещаемости детьми детских садов в городах и сельской местности республики были выявлены существенные различия в сторону более высокой востребованности и доступности данной услуги в городах.

Подытоживая полученные результаты по оценке основных мер семейной политики женщинами Республики Татарстан, можно сделать вывод о достаточно высокой степени востребованности уже существующих составляющих политики государства по обеспечению баланса жизни и труда для женщин-матерей, но и необходимости новых мер, направленных на изменение гендерной роли женщины на рынке труда и более широкую практику гибких форм занятости.

Таким образом, практическая значимость статьи состоит в обосновании существующих методов государственного сопутствия эффективной занятости женщин в регионе, в выявлении значимых положительных и проблемных сторон этой деятельности, а также в определении прогностических направлений оптимизации регионального процесса регулирования занятости женщин.

\section{СПИСОК ИСПОЛЬЗОВАННЫХ ИСТОЧНИКОВ}

1. Cigno A. Economics of the Family. Oxford, England: Clarendon Press, 1991. 224 p. URL: https://www.amazon.com/Economics-Family-Alessandro-Cigno/ $\mathrm{dp} / 0198287097$ (дата обращения: 21.06.2019).

2. Blundell R., Macurdy T. Labor supply: A Review of Alternative Approaches // Handbook of Labor Economics. 1999. Vol. 3. Pp. 1559-1695. DOI: https://doi. org/10.1016/S1573-4463(99)03008-4

3. Захаров С. В. Скромные демографические результаты пронаталистской политики в контексте долговременной эволюции рождаемости в России. Часть 2 [Электронный ресурс] // Демографическое обозрение. 2016. Т. 3, № 4. URL: https://cyberleninka.ru/article/n/skromnye-demograficheskie-rezultatypronatalistskoy-politiki-v-kontekste-dolgovremennoy-evolyutsii-rozhdaemosti-v-rossiichast-2 (дата обращения: 11.03.2019).

4. Fertility, Female Labor Force Participation, and the Demographic Dividend / D. Bloom [et al.] // Journal of Economic Growth. 2009. Vol. 14, issue 2. Pp. 79-101. DOI: https://doi.org/10.3386/w13583

5. Fraser N. After the Family Wage: What do Women Want From Social Welfare? // Social Justice. 1994. Vol 21, no. 1. Pp. 80-86. URL: https://www.amazon.com/ Economics-Family-Alessandro-Cigno/dp/0198287097 (дата обращения: 21.06.2019). 
6. Crompton R. Gender Restructuring, Employment and Caring// Social Politics. 2001. Vol. 8, issue 3. Pp. 266-291. DOI: https://doi.org/10.1093/sp/8.3.266

7. Taylor R. The Future of Work-Life Balance. Swindon: ESRC Future of Work Programme Seminar Series. 2001. URL: http://files.observatoriolaboral.webnode. cl/200000009-56d3857cd6/future_of_work_life_balance_tcm8-13554.pdf (дата обращения: 21.06.2019).

8. Auer M. The Relationship Between Paid Work and Parenthood? A Comparison of Structures, Concepts and Developments in the UK and Austria // Community, Work \& Family. 2002. Vol. 5, issue 2. Pp. 203-218. DOI: https://doi. org/10.1080/13668800220146373

9. Lewis S., Lewis J. The Work-Family Challenge: Rethinking Employment. London: Sage, 1996. DOI: http://dx.doi.org/10.4135/9781446280201

10. Gatrell C. Hard Labour: The Sociology of Parenthood. Maidenhead: Open University Press, 2004. 256 p. URL: https://www.amazon.co.uk/Hard-Labour-Sociology-Parenthood-Family/dp/0335214886 (дата обращения: 21.06.2019).

11. McKie L., Bowlby S., Gregory S. Gender, Caring and Employment in Britain // Journal of Social Policy. 2001. Vol. 30, issue 2. Pp. 233-258. DOI: https://doi. org/10.1017/S0047279401006262

12. Wattis L., Standing K., Yerkes M. A. Mothers and Work-Life Balance: Exploring the Contradictions and Complexities Involved in Work-Family Negotiation // Community, Work \& Family. 2013. Vol. 16, issue 1. Pp. 1-19. DOI: https://doi.or $\mathrm{g} / 10.1080 / 13668803.2012 .722008$

13. Blanchet D., Ekert-Jaffe' O. The Demographic Impact of Fertility Benefits: Evidence From a Micro-Model and From Macro-Data // The Family, the Market and the State in Ageing Societies / J. Ermisch, N. Ogawa, eds. Oxford, England: ClarendonPress. Pp. 79-104. URL: https://global.oup.com/academic/product/thefamily-the-market-and-the-state-in-ageing-societies-9780198288183?cc=ru\&lang=en \& (дата обращения: 21.06.2019).

14. Gauthier A. H. The Impact of Family Policies on Fertility in Industrialized Countries: A Review of the Literature // Population Research and Policy Review. 2007. Vol. 26, issue 3. Pp. 323-346. DOI: https://doi.org/10.1007/s11113-007-9033-X

15. Olivetti C., Petrongolo B. The Economic Consequences of Family Policies: Lessons from a Century of Legislation in High-Income Countries // Journal of Economic Perspectives, American Economic Association. 2017. Vol. 31, issue 1. Pp. 205-230. DOI: https://doi.org/10.3386/w23051

16. Vuri D. Do Childcare Policies Increase Maternal Employment? // IZA World of Labor. 2016. P. 241. DOI: https://doi.org/10.15185/izawol.241

17. Bick A. The Quantitative Role of Child Care for Female Labor Force Participation and Fertility // Journal of the European Economic Association, European Economic Association. 2016. Vol. 14, issue 3. Pp. 639-668. DOI: https://doi. org/10.1111/jeea.12143

18. Слонимчик Ф., Юрко А. В. Оценка влияния политики материнского капитала в России [Электронный ресурс] // Демографическое обозрение. 2015. № 3. URL: https://cyberleninka.ru/article/n/otsenka-vliyaniya-politiki-materinskogokapitala-v-rossii (дата обращения: 14.03.2019). 
19. Elizarov V., Levin V. Family Policies in Russia: Could Efforts to Raise Fertility Rates Slow Population Aging? Russian Federation Aging Project. Washington, D.C.: World Bank Group. 2015. URL: http://documents.worldbank.org/ curated/en/257131468000013801/Family-policies-in-Russia-could-efforts-to-raise-fertility-rates-slow-population-aging (дата обращения: 14.03.2019).

20. Валидова А. Ф. Влияние демографической политики на показатели рождаемости в Российской Федерации и Республике Татарстан // Регионология. 2018. T. 26, № 3. C. 494-511. DOI: https://doi.org/10.15507/2413-1407.104.026.201803.494-511

21. Шадриков А. В. Репродуктивные установки молодых сельских женщин Республики Татарстан // Регионология. 2019. Т. 27, № 1. C. 122-137. DOI: https:// doi.org/10.15507/2413-1407.106.027.201901.122-137

22. Калабихина И. Е., Федотова О. Особенности проведения политики сочетания профессиональной и семейной жизни населения в европейских странах // Научные исследования экономического факультета: Электронный журнал экономического факультета МГУ имени М. В. Ломоносова. 2012. Т. 4, № 2. C. 107-129. URL: https://archive.econ.msu.ru/journal/issues/2012/2012.volume_4. issue_2/The_policy_mix_of_professional_and_reproductive_functions_of_women and_men_in_the_European_countries/ (дата обращения: 11.03.2019).

23. Внутрирегиональная дифференциация демографического потенциала Республики Татарстан / Н. М. Биктимиров [и др.] // Экономические и социальные перемены: факты, тенденции, прогноз, 2019. Т. 12, № 3. C. 189-202. DOI: https:// doi.org/10.15838/esc.2019.3.63.12

Поступила 30.06.2019; принята к публикации 04.08.2019; опубликована онлайн 30.12.2019.

\section{Об авторах:}

Ильдарханова Чулпан Ильдусовна, директор Центра семьи и демографии Академии наук Республики Татарстан (420111, Россия, г. Казань, ул. Лево-Булачная, д. 36а), доктор социологических наук, ORCID: https://orcid.org/0000-0002-3992-0336, Researcher ID: N-6382-2016, chulpanildusovna@gmail.com

Гневашева Вера Анатольевна, главный научный сотрудник Центра семьи и демографии Академии наук Республики Татарстан (420111, Россия, г. Казань, ул. Лево-Булачная, д. 36a), доктор экономических наук, доцент, ORCID: https:// orcid.org/0000-0002-3596-661X, Researcher ID: E-3157-2014, Scopus Author ID: 57197809094, vera_cos@rambler.ru

Валидова Асия Фаритовна, старший научный сотрудник Центра семьи и демографии Академии наук Республики Татарстан (420111, Россия, г. Казань, ул. Лево-Булачная, д. 36а), кандидат экономических наук, ORCID: https:/orcid. org/0000-0001-5227-0940, Researcher ID: O-3406-2018, avalidova@gmail.com

\section{Заявленный вклад авторов:}

Ильдарханова Чулпан Ильдусовна - научное руководство исследованием «Трудовая занятость в структуре репродуктивно-родительских стратегий современной женщины в Республике Татарстан»; организация, реализация эмпирического исследования; сбор и обработка данных. 
Гневашева Вера Анатольевна - работа над теоретической и практической частью статьи; работа над расчетами множественной регрессии и корреляционных зависимостей ключевых факторов исследования.

Валидова Асия Фаритовна - разработка программы исследования; работа над теоретической и практической частью статьи; доработка статьи.

\section{Для ичитирования:}

Ильдарханова Ч. И., Гневашева В. А., Валидова А. Ф. Диалог труда и материнства в условиях социально-экономической и территориальной дифференциации в Республике Татарстан // Регионология. 2019. Т. 27, № 4. С. 801-830. DOI: https://doi.org/10.15507/2413-1407.109.027.201904.801-830

Все авторы прочитали и одобрили окончательный вариант рукописи.

\section{REFERENCES}

1. Cigno A. Economics of the Family. Oxford, England: Clarendon Press; 1991. Available at: https://www.amazon.com/Economics-Family-Alessandro-Cigno/ dp/0198287097 (accessed 21.06.2019). (In Eng.)

2. Blundell R., Macurdy T. Labor Supply: A Review of Alternative Approaches. Handbook of Labor Economics. 1999; 3:1559-1695. (In Eng.) DOI: https://doi. org/10.1016/S1573-4463(99)03008-4

3. Zakharov S.V. Modest Demographic Results of the Pronatalist Policy in the Context of Long-Term Evolution of Fertility in Russia. Part 2. Demograficheskoe obozrenie = Demographic Review. 2016; 3(4). Available at: https://cyberleninka.ru/article/n/skromnyedemograficheskie-rezultaty-pronatalistskoy-politiki-v-kontekste-dolgovremennoy-evolyutsii-rozhdaemosti-v-rossii-chast-2 (accessed 11.03.2019). (In Russ., abstract in Eng.)

4. Bloom D., Canning D., Fink G., Finlay J. Fertility, Female Labor Force Participation, and the Demographic Dividend. Journal of Economic Growth. 2009; 14(2):79-101. (In Eng.) DOI: https://doi.org/10.3386/w13583

5. Fraser N. After the Family Wage: What do Women Want from Social Welfare? Social Justice. 1994; 21(1):80-86. Available at: https://www.amazon.com/EconomicsFamily-Alessandro-Cigno/dp/0198287097 (accessed 21.06.2019). (In Eng.)

6. Crompton R. Gender Restructuring, Employment and Caring. Social Politics. 2001; 8(3):266-291. (In Eng.) DOI: https://doi.org/10.1093/sp/8.3.266

7. Taylor R. The Future of Work-Life Balance. Swindon: ESRC Future of Work Programme Seminar Series; 2001. Available at: http://files.observatoriolaboral. webnode.cl/200000009-56d3857cd6/future_of_work_life_balance_tcm8-13554.pdf (accessed 21.06.2019). (In Eng.)

8. Auer M. The Relationship between Paid Work and Parenthood? A Comparison of Structures, Concepts and Developments in the UK and Austria. Community, Work \& Family. 2002; 5(2):203-218. (In Eng.) DOI: https://doi.org/10.1080/13668800220146373

9. Lewis S., Lewis J. The Work-Family Challenge: Rethinking Employment. London: Sage; 1996. (In Eng.) DOI: http://dx.doi.org/10.4135/9781446280201 
10. Gatrell C. Hard Labour: The sociology of Parenthood. Maidenhead. Open University Press; 2004. Available at: https://www.amazon.co.uk/Hard-Labour-SociologyParenthood-Family/dp/0335214886 (accessed 21.06.2019). (In Eng.)

11. McKie L., Bowlby S., Gregory S. Gender, Caring and Employment in Britain. Journal of Social Policy. 2001; 30(2):233-258. (In Eng.) DOI: https://doi.org/10.1017/ S0047279401006262

12. Wattis L., Standing K., Yerkes M.A. Mothers and Work-Life Balance: Exploring the Contraindications and Complexes Involved in Work-Family Negotiation. Community, Work \& Family. 2013; 16(1):1-19. (In Eng.) DOI: https://doi.org/10.10 80/13668803.2012.722008

13. Blanchet D., Ekert-Jaffe O. The Demographic Impact of Fertility Benefits: Evidence from a Micro-Model and from Macro-Data. In: J. Ermisch, N. Ogawa, eds. The Family, the Market and the State in Aging Societies. Oxford, England: Clarendon Press; 1994. p. 79-104. Available at: https://global.oup.com/academic/product/thefamily-the-market-and-the-state-in-ageing-societies-9780198288183?cc=ru\&lang=en \& (accessed 21.06.2019). (In Eng.)

14. Gauthier A.N. The Impact of Family Policies on Fertility in Industrialized Countries: A Review of the Literature. Population Research and Policy Review. 2007; 26(3):323-346. (In Eng.) DOI: https://doi.org/10.1007/s11113-007-9033-x

15. Olivetti C., Petrongolo B. The Economic Consequences of Family Policies: Lessons from a Century of Legislation in High-Income Countries. Journal of Economic Perspectives. American Economic Association. 2017; 31(1):205-230. (In Eng.) DOI: https://doi.org/10.3386/w23051

16. Vuri D. Do Childcare Policies Increase Maternal Employment? In: IZA World of Labor. Institute for the Study of Labor (IZA). 2016. (In Eng.) DOI: https://doi. org/10.15185/izawol.241

17. Bick A. The Quantitative Role of Child Care for Female Labor Force Participation and Fertility. Journal of the European Economic Association. European Economic Association. 2016; 14(3):639-668. (In Eng.) DOI: https://doi.org/10.1111/jeea.12143

18. Slonimczyk F., Yurko A.V. Assessing the Impact of the Maternity Capital Policy in Russia. Demograficheskoe obozrenie = Demographic Review. 2015; (3). Available at: https://cyberleninka.ru/article/n/otsenka-vliyaniya-politiki-materinskogokapitala-v-rossii (accessed 14.03.2019). (In Russ., abstract in Eng.)

19. Elizarov V., Levin V. Family Policies in Russia: Could Efforts to Raise Fertility Rates Slow Population Aging? Russian Federation Aging Project. Washington, D.C.: World Bank Group; 2015. Available at: http://documents.worldbank.org/curated/ en/257131468000013801/Family-policies-in-Russia-could-efforts-to-raise-fertilityrates-slow-population-aging (accessed 14.03.2019). (In Eng.)

20. Validova A.F. Impact of the Demographic Policy on Birth Rates in the Russian Federation and the Republic of Tatarstan. Regionologiya = Regionology. 2018; 26(3):494-511. (In Russ., abstract in Eng.) DOI: https://doi.org/10.15507/24131407.104.026.201803.494-511

21. Shadrikov A.V. Reproductive Attitudes of Young Rural Women of the Republic of Tatarstan. Regionologiya = Regionology. 2019; 27(1):122-137. (In Russ., abstract in Eng.) DOI: https://doi.org/10.15507/2413-1407.106.027.201901.122-137 
22. Kalabikhina I.E., Fedotova O. Features of Work-Family Reconciliation Policy in European Countries. Nauchnye issledovaniya ehkonomicheskogo fakulteta: Ehlektronnyj zhurnal ehkonomicheskogo fakulteta MGU imeni M. V. Lomonosova = Scientific Research of the Faculty of Economics: Electronic Magazine. 2012; 4(2):107-129. Available at: https://archive.econ.msu.ru/journal/issues/2012/2012.volume_4.issue_2/ The policy_mix_of_professional_and_reproductive_functions_of_women_and_men in the European_countries/ (accessed 11.03.2019). (In Russ., abstract in Eng.)

23. Biktimirov N.M., Gaifutdinova R.M., Ibragimova A.A., Ildarkhanova Ch.I. Intra-Regional Differentiation of Demographic Potential in the Republic of Tatarstan. Ehkonomicheskie $i$ sotsialnye peremeny: fakty, tendentsii, prognoz = Economic and Social Changes: Facts, Trends, Forecast. 2019; 12(3):189-202. (In Russ., abstract in Eng.) DOI: https://doi.org/10.15838/esc.2019.3.63.12

Submitted 30.06.2019; accepted for publication 04.08.2019; published online 30.12.2019.

About the authors:

Chulpan I. Ildarhanova, Director, Family and Demography Center, Tatarstan Academy of Sciences (36a Levo-Bulachnaya St., Kazan 420111, Russia), Dr. Sci. (Sociology), ORCID: https://orcid.org/0000-0002-3992-0336, Researcher ID: N-63822016, chulpanildusovna@gmail.com

Vera A. Gnevasheva, Principal Researcher, Family and Demography Center, Tatarstan Academy of Sciences (36a Levo-Bulachnaya St., Kazan 420111, Russia), Dr. Sci. (Economics), Associate Professor, ORCID: https://orcid.org/0000-0002-3596-661X, Researcher ID: E-3157-2014, Scopus Author ID: 57197809094, vera_cos@rambler.ru

Asiya F. Validova, Senior Researcher, Family and Demography Center, Tatarstan Academy of Sciences (36a Levo-Bulachnaya St., Kazan 420111, Russia), Ph. D. (Economics), ORCID: https://orcid.org/0000-0001-5227-0940, Researcher ID: O-3406-2018, avalidova@gmail.com

Contribution of the authors:

Chulpan I. Ildarhanova - academic supervision of the study 'Employment in the structure of reproductive and parental strategies of the modern woman in the Republic of Tatarstan'; organization and implementation of empirical research; data collection and processing.

Vera A. Gnevasheva - work on the theoretical and practical parts of the article; calculation of the multiple regression and correlation dependencies of the key research factors.

Asiya F. Validova - development of the research program; work on the theoretical and practical parts of the article; revision of the article.

\section{For citation:}

Ildarhanova Ch.I., Gnevasheva V.A., Validova A.F. Dialogue of Labor and Motherhood in the Context of Socio-Economic and Territorial Differentiation in the Republic of Tatarstan. Regionology $=$ Russian Journal of Regional Studies. 2019; 27(4):801-830. DOI: https://doi.org/10.15507/2413-1407.109.027.201904.801-830

The authors have read and approved the final version of the manuscript. 


\section{Научные журналы постсоветских государств: место в национальном и международном информационном пространстве}

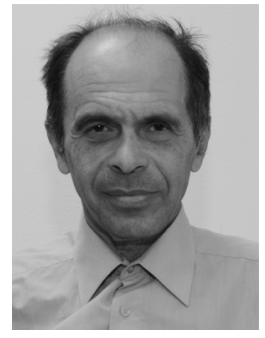

Ю. М. Брумштейн ${ }^{1}$

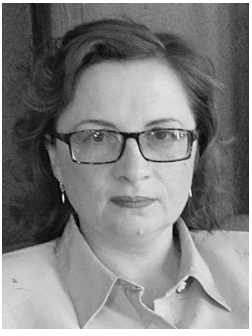

Н. К. Алимова $2^{2 *}$

${ }^{1}$ ФГБОУ ВО «Астраханский государственный университет» (2. Астрахань, Россия)

${ }^{2}$ ООО «Издательство «Мир науки» (2. Москва, Россия), *alimova@mir-nauki.com

Введение. Цель статьи - провести анализ научных журналов постсоветских государств, выявить роль научных журналов в информационно-аналитической поддержке принятия и реализации решений, связанных с управлением научной деятельностью, социально-экономическими процессами в странах и регионах. Проведение анализа научных журналов по ряду показателей позволит определить место этих изданий в национальном и международном информационном пространстве.

Материалы и методы. Использована информация по журналам постсоветских государств, индексируемым в Scopus и Web of Science, сведения о журналах с сайта Высшей аттестационной комиссии России, данные с сайта Российского индекса научного цитирования, информация с сайтов самих журналов, сведения из некоторых иных источников. Для получения количественных показателей изданий применялись штатные средства информационно-поисковых систем на указанных ресурсах. Сведения о численности населения стран и количестве исследователей в них брались из данных официальной статистики.

Результаты исследования. Проанализированы данные о количествах журналов из постсоветских государств, индексируемых в Scopus, Web of Science, Российском индексе научного цитирования, а также изданий, включенных в список Высшей аттестационной комиссии России. Сведения о публикационной активности авторов постсоветских государств оценены в виде абсолютных

(C) Брумштейн Ю. М., Алимова Н. К., 2019 Контент доступен под лицензией Creative Commons Attribution 4.0 License. This work is licensed under a Creative Commons Attribution 4.0 License. 
и относительных показателей. Выявлен ряд общих особенностей редакционной политики и практической деятельности рассматриваемых изданий, их подходов к использованию языков публикаций, выпуску переводных изданий, формированию редколлегий, привлечению национальных и зарубежных авторов.

Обсуждение и заключение. Авторы приходят к выводу, что электронные репозитории научной информации играют важнейшую роль в формировании международного и национального научного пространства. Представленные в статье материалы могут быть полезны для решения исследовательских задач, относящихся к научной периодике для поддержки принятия решений руководителями научных подразделений и редакционно-издательских комплексов.

Ключевые слова: научный журнал, научное информационное пространство, процесс формирования, постсоветское государство, региональная экономика, международные связи, информационно-телекоммуникационные технологии

\title{
Scientific Journals in the post-Soviet States: The Place in the National and International Information Space
}

\author{
Yu. M. Brumshteyn ${ }^{a}$, N. K. Alimova ${ }^{b^{*}}$ \\ a Astrakhan State University (Astrakhan, Russia) \\ b Publishing company "World of science" (Moscow, Russia), \\ alimova@mir-nauki.com
}

Introduction. The objective of the paper is to analyze scientific journals published in the post-Soviet states, as well as to identify the role of scientific journals in the information and analytical support for the adoption and implementation of decisions related to the management of scientific activities and socio- economic processes in countries and regions. Analysis of scientific journals based on a set of indicators will make it possible to identify the place of these publications in the national and international information space.

Materials and Methods. The authors have analyzed available information about scientific journals published in the post-Soviet states and indexed by Scopus and Web of Science as well as information about such journals given on the website of the Higher Attestation Commission of Russia, data from the website of the Russian Science Citation Index and information from the official websites of the journals and from other sources. To obtain quantitative indicators related to the journals, standard means of search engines provided by the abovementioned resources were used. Data on the population of the countries and the number of researchers in them were taken from official statistics.

Results. Data about the number of journals published in the post-Soviet states and indexed by Scopus, Web of Science and the Russian Science Citation Index, as well as those included in the list of the Higher Attestation Commission of Russia have been analyzed. Information on the publication activities of authors from the postSoviet states has been evaluated as absolute and relative indicators. A number of common features of the editorial policies and practical activities of the considered journals have been identified as well as their approaches to the use of publication languages, to the issue of translated editions, to the formation of editorial boards and to the involvement of national and foreign authors. 
Discussion and Conclusion. Electronic repositories of scientific information play a crucial role in the formation of international and national scientific spaces. The materials presented in this article may be useful for coping with research tasks related to scientific periodicals as well as to support decision-making by heads of scientific units, editorial and publishing complexes.

Keywords: scientific journals, scientific information space, formation processes, post-Soviet states, regional economy, international contacts, information and telecommunication technologies

Введение. Важнейшей задачей развития российской науки является усиление интеграции ее региональных и федеральных научных организаций, исследовательских центров, вузов, отдельных ученых и их групп в национальное и международное научное информацчионое пространство (НИП). Также значительную роль играет обеспечение информационноаналитической поддержки принятия и реализации научно-технических, управленческих и иных видов решений, в том числе связанных с социально-экономическим развитием отдельных регионов, отраслей, страны в целом. Особое значение имеет сохранение и углубление научных, образовательных, деловых связей российских ученых с их коллегами и организациями в других постсоветских государствах, прежде всего тех, в которых трудятся много исследователей, владеющих русским языком. В решении этих задач ключевую роль играет редакционная политика и практическая деятельность ведущих научных журналов постсоветских государств, в том числе центральных и региональных российских изданий. К центральным в рамках данной статьи мы будем относить научные журналы, выпускаемые в г. Москве и в Московской области, в г. Санкт-Петербурге, а к региональным - издания из других регионов.

Учитывая важность развития научных коммуникаций между исследователями постсоветского пространства, целью исследования стал сравнительный анализ журналов постсоветских государств в отношении следующих вопросов: цели, редакционная политика и фактические результаты деятельности; методы, используемые редакциями для обеспечения научного статуса изданий на национальном и международном уровнях; их индексирование в ведущих международных системах учета цитирований Scopus и Web of Science; подходы редакций к определению/корректировке тематических профилей изданий, а также отражения в них региональной тематики в условиях конкуренции с другими журналами за статьи и авторов; принципы выработки и реализации редакционной политики, формирования редколлегий изданий, включения в них авторитетных национальных и зарубежных исследователей; номенклатура решений, направленных на обеспечение соблюдения редколлегиями журналов, авторами, рецензентами правил публикационной этики; направления ис- 
пользования информационно-телекоммуникационных технологий (ИТКТ) для повышения конкурентоспособности работы журналов, соблюдения ими норм/правил публикационной этики, обеспечения удобочитаемости/ понятности текстов публикуемых работ.

В настоящее время в России интеграционные процессы в сфере научной деятельности происходят по ряду направлений:

- координация деятельности исследовательских организаций (включая академические, корпоративные) и вузов на региональных уровнях в интересах решения задач социально-экономического развития регионов. Этой работой могут заниматься органы государственного управления регионами, советы ректоров вузов, общественные организации и пр. Однако координации мешает различная ведомственная подчиненность указанных организаций, в ряде случаев - их прямая конкуренция. Так, на региональных уровнях практически не координируется издание научных журналов, их тематика, принципы редакционной политики;

- формирование национального научного пространства за счет публикации результатов исследований, проведенных в различных регионах; обеспечение доступности полученных результатов для заинтересованных лиц и организаций, в том числе для использования в целях управления социально-экономичесими процессами в стране и регионах, научными изданиями; поддержка противодействия нарушениям публикационной этики;

- интеграция российских академических и иных исследовательских организаций, вузов, отдельных ученых и их групп в международное НИП. В этих процессах особую роль играет сохранение и расширение научных взаимосвязей российских организаций (включая НИИ, специализированные исследовательские центры, вузы) с аналогичными им зарубежными организациями; между отдельными исследователями и их коллективами; между приграничными регионами разных стран на основе межгосударственных соглашений.

В начале 80-х гг. ХХ в. в СССР насчитывалось около 1,5 млн научных работников, что составляло четвертую часть ученых всего мирового сообщества ${ }^{1}$. После распада СССР в Российской Федерации и других постсоветских государствах расходы на науку и количество исследователей сократились ${ }^{2}$. В России значительная доля исследователей работают в Москве и Санкт-Петербурге, в Московской области. В этих же регионах издается большинство российских ведущих научных журналов.

В других постсоветских государствах структура и особенности деятельности исследовательских организаций (включая относящиеся к Академиям

\footnotetext{
${ }^{1}$ Народное хозяйство СССР 1922-1982 (Юбилейный статистический ежегодник). М.: Финансы и статистика, 1982. 624 с.

${ }^{2}$ Индикаторы науки: 2019: стат. сб. / Н. В. Городникова [и др.]; Нац. исслед. ун-т «Высшая школа экономики». М.: НИУ ВШЭ, 2019. 328 с.
} 
наук) и вузов также в значительной степени сохраняют черты, присущие временам существования СССР [1;2]. Это относится и к изданию научной периодики, концентрации ее выпуска в столицах этих стран.

Во всех постсоветских государствах (а также большинстве бывших социалистических стран) до сегодняшнего дня осуществляется преимущественно бюджетное финансирование научной деятельности; реализуются меры ее государственной поддержки и регулирования; сохраняются национальные Академии наук с развитыми структурами подчиненных им организаций. В то же время наряду с государственными вузами действуют и коммерческие (в которых научная деятельность развита слабо).

Подчеркнем, что в большинстве постсоветских государств (включая и Россию) на государственном уровне поддерживаются процессы включения научных журналов своих стран в ведущие международные реферативные базы данных, публикации национальных исследователей в зарубежных изданиях, включенных в такие базы.

Обзор литературы. В сравнении с ведущими странами Россия и другие постсоветские государства значительно отстают по абсолютному количеству публикаций, индексируемых в авторитетных международных базах данных (при такой индексации учитываются работы, опубликованные исследователями в научных журналах своих стран и за рубежом). Так, в 2017 г. в Scopus было проиндексировано 2685021 статья из США, 2151673 - из Китая и всего 244500 статей из России и 45771 из Украины. В других постсоветских государствах эти данные были также невелики: от 7500 (Казахстан) до 500 (Кыргызстан).

Увеличение абсолютного и относительного (на душу населения) количества статей, индексируемых в авторитетных международных базах данных, становится все более актуальной задачей, так как общепризнанно, что этот показатель во многом отражает степень развития науки, качество и результативность научных исследований в отдельных странах $^{3}$. Такое увеличение обеспечивает:

- поддержку интеграционных процессов исследовательских организаций, вузов и отдельных ученых в международное НИП4;

- улучшение «видимости» в НИП результатов деятельности национальных исследователей [3];

- развитие научных коммуникаций ученых из разных стран и регионов;

- снижение вероятности проведения дублирующих исследований в сочетании с обеспечением «полноты тематического охвата» публикациями проводимых работ. При этом тематика публикаций,

${ }^{3}$ Пипия Л. К., Дорогокупец В. С. Изменение подходов к управлению наукой в индустриально развитых странах // Наука за рубежом. 2017. № 58. С. 1-35.

${ }_{4}^{4}$ Информационное пространство новых независимых государств / Ю. М. Арский [и др.]. М.: ВИНИТИ, 2000. 200 с. 
посвященных региональной проблематике (например, по экологии и социологии отдельных регионов или их групп), может представлять значительный интерес и для зарубежных исследователей.

Отметим ряд факторов, благоприятствующих развитию международных контактов научных журналов из России и других постсоветских государств: наличие прямых связей между национальными научными организациями и вузами; значительное количество лиц, получивших высшее образование и/или ученую степень в СССР или в России; большое количество исследователей из постсоветских государств (а также бывших социалистических стран), достаточно свободно владеющих русским языком, что исключает языковой барьер; прием для публикации статей на русском языке в журналах ряда зарубежных стран. Как следствие, облегчаются практические возможности работы исследователей из-за рубежа в составе редакционных коллегий российских журналов, взаимообмена членами редколлегий между российскими и зарубежными изданиями; расширяются возможности опубликования русскоязычных научных статей за рубежом.

Ученые постсоветских государств публикуют свои работы на национальных языках (в журналах своих стран), а также на русском (в России, Беларуси и пр.) и английском - в своих странах и за рубежом (в том числе и в России). Русскоязычные публикации зарубежных ученых наиболее доступны для российских исследователей - это потенциально улучшает возможности последующих научных коммуникаций ученых из России и других постсоветских государств с использованием информационно-телекоммуникационных технологий.

В русскоязычной периодике изучены следующие вопросы:

- характеристики публикационной активности отдельных российских ученых [4] (в том числе в Scopus и Web of Science ${ }^{5}$ [5]);

- показатели публикационной активности научно-исследовательских организаций и университетов, а также отдельных российских регионов [6];

- место российских журналов в Web of Science [7];

- отдельные вопросы соблюдения публикационной этики [8; 9];

- некоторые другие тематически смежные вопросы [10-13].

При анализе научной периодики других постсоветских государств целесообразно выделить несколько групп стран - Прибалтика (Латвия, Литва, Эстония), Азия (Казахстан, Узбекистан, Таджикистан, Туркмения, Киргизия), Кавказ (Грузия, Армения, Азербайджан), Восточная Европа (Украина, Беларусь, Молдавия). Подходы к изданию научных журналов в этих группах стран имеют определенные общие черты.

5 Дайджест показателей публикационной активности российских исследователей по данным Web of Science, Scopus / И. А. Мосичева [и др.]; Российский научно-исследовательский институт экономики, политики и права в научно-технической сфере (РИЭПП). M., 2017. 32 c. 
Как показал анализ зарубежных источников, в большинстве работ, посвященных изучению научной периодики в этих странах, исследуются либо отдельные регионы [14-16], либо отдельные научно-тематические области (направления) исследований [17].

Э. К. Завадскас, Р. Кирвайтис, Э. Дагене отмечают, что в прибалтийских республиках (Латвия, Литва, Эстония) после выхода из состава СССР и в процессе развития их более тесных отношений с зарубежными странами (прежде всего в рамках Европейского союза) количество публикаций, индексируемых в авторитетных международных базах данных, значительно увеличилось [14].

Я. Ван с соавторами подчеркивает, что после распада СССР количество проиндексированных публикаций из стран Центральной Азии увеличилось в таких областях, как геология, экология и палеонтология [16]. В то же время количество публикации в области наукометрии, географии и антропологии резко сократилось. Выросло количество статей с международными коллаборациями. Исследование также показало, что высока корреляция между количеством публикаций о Центральной Азии, количеством туристов, экспортом нефти и ростом валового внутреннего продукта этих стран.

Однако мы не нашли в научной периодике (включая зарубежную) сравнения совокупностей научных журналов постсоветских государств в отношении их количеств, индексирования в системах учета цитирований, состава членов редколлегий, принципов декларирования и обеспечения соблюдения правил публикационной этики.

Особый интерес представляет информация по изданиям, индексируемым в авторитетных международных базах учета цитирований; в национальных системах оценки научных журналов, подобных российскому Перечню ВАК, а также в Российском индексе научного цитирования (РИНЦ). Такой анализ важен для планирования и обеспечения развития научных связей между научными организациями и отдельными исследователями разных стран, рационального выбора ими мест публикаций статей (в том числе в зарубежных изданиях) и пр.

Материалы и методы. В рамках проведенного исследования были изучены данные по России и 14 постсоветстским странам (Азербайджану, Армении, Беларуси, Грузии, Казахстану, Киргизии, Латвии, Литве, Молдавии, Таджикистану, Туркменистану, Узбекистану, Украине, Эстонии).

При анализе современного состояния научной периодики России и других постсоветских государств использовался Перечень рецензируемых научных изданий, в которых должны быть опубликованы основные научные результаты диссертаций на соискание ученой степени кандидата наук, на соискание ученой степени доктора наук Высшей аттестационной комиссии Российской Федерации (на 24.07.2019) (далее - Перечень ВАК). 
Для исследования состава журналов, индексируемых в Scopus и Web of Science, использовалась форма запросов на сайте Научной электронной библиотеки eLIBRARY.RU (https:/elibrary.ru/titles.asp), сведения с сайтов самих журналов и из некоторых иных источников. Для получения количественных показателей по журналам применялись штатные средства информационно-поисковых систем на указанных ресурсах.

Использование указанной формы на сайте РИНЦ позволило выявить число журналов по отдельным странам, раздельно оценивать общие количества всех учтенных в РИНЦ журналов и тех, которые выходят в настоящее время. Эта форма допускает три альтернативы отбора изданий из числа индексируемых в Scopus и Web of Science: $a$ - индексируется, $b$ - индексируется переводная версия, $c$ - индексируется частично. При этом журналы категории $b$ входят в $a$, а категории $c$ - не входят.

По данным сайта Научной электронной библиотеки eLIBRARY.RU (на 22.08.2019) в Web of Science индексировались 62 российских журнала категории $c, 378$ - категории $a$. Для других постсоветских государств количество частично индексируемых журналов также было невелико. Поэтому далее приводятся данные только по журналам категории $a$, т. е. индексируемым. Данные для различных стран по количеству исследователей и их публикаций взяты из официальных статистических материалов и статистических сборников ${ }^{6}$.

Валовые внутренние продукты (ВВП, млн долл. США) за 2018 г. были взяты из Рейтинга стран мира по уровню валового внутреннего продукта ${ }^{7}$ и пересчитаны на душу населения (показатель ВВП 1 , тыс. долл. США). Информация о численности населения стран на январь 2019 г. была взята из статистических данных, предоставленных международным валютным фондом ${ }^{8}$ В обоих случаях были использованы актуализированные данные на 28 ноября 2019 г.

Для представления результатов исследования нами были использованы следующие относительные показатели:

- количество исследователей в расчете на 10000 чел. населения страны $\left(R_{0}\right)$;

- отношение количества проиндексированных по отдельным странам публикаций к количествам учтенных исследователей (т. е. фактически «количество публикаций в расчете на одного исследователя»): Scopus $R_{1}$, Web of Science $-R_{2}$;

${ }^{6}$ Индикаторы науки: 2019: стат. сб.

7 Рейтинг стран мира по уровню валового внутреннего продукта [Электронный реcypc]. URL: https://gtmarket.ru/ratings/rating-countries-gdp/rating-countries-gdp-info (дата обращения: 28.11.2019).

${ }_{8}^{8}$ Численность населения стран мира на 2018 год [Электронный ресypc]. URL: https:// infotables.ru/strany-i-goroda/17-tablitsa-chislennost-naseleniya-stran-mira (дата обращения: 28.11.2019). 
- при расчетах относительных показателей $R_{3}$ (для Scopus) и $R_{4}$ (для Web of Science) абсолютные количества изданий, выходящих в соответствующих странах (на 22.08.2018), делились на численности исследователей в этих странах. Эти два показателя можно считать отражающими «уровни обеспеченности» стран национальными журналами, индексируемыми Scopus и Web of Science (отметим, что многие такие журналы одновременно индексируются обоими указанными ресурсами).

На основе анализа сайтов отдельных журналов России и других постсоветских государств (всего исследовано 150 изданий) были оценены персональные составы их редколлегий, языки публикуемых статей, составы публикующихся авторов, места размещения на сайтах правил публикационной этики и правил для авторов, особенности содержания и формулировок этих правил.

Результаты исследования. Место издания научного журнала. Во всех постсоветских государствах высокая концентрация выпуска изданий, индексируемых Scopus и Web of Science, отмечается преимущественно в 1-2 городах. В России такие журналы издаются лишь в нескольких регионах, в то время как издания из Перечня ВАК выпускаются практически во всех субъектах Федерации. Причем для административных центров таких субъектов количество изданий из Перечня ВАК по отношению к численности населения городов растет.

Форма издания журналов. Традиционной формой в России и за рубежом является печатная (бумажная). По действующим в нашей стране правилам, обязательные экземпляры таких изданий должны предоставляться в большое количество организаций, что увеличивает их себестоимость. В последнее время в России растет число электронных изданий (интернет-журналов), в том числе включенных в Перечень ВАК. Они имеют ряд преимуществ перед печатными изданиями в отношении себестоимости и оперативности выпуска, предельных объемов размещаемых материалов и пр. Однако по действующим правилам ВАК механически преобразовывать печатные журналы в электронные нельзя.

Язык публикаций. В России ведущие научные журналы, включая издаваемые в регионах, публикуют статьи как на русском, так и на английском языках. Есть небольшое количество полностью англоязычных журналов. Для публикуемых русскоязычных статей обязательно приводятся переводы на английский язык их метаданных (названий, сведений об авторах, аннотаций и ключевых слов), что, как предполагается, должно способствовать улучшению видимости работ в международном НИП. Однако качество таких переводов во многих случаях невысокое.

В России издаются многочисленные переводные и переводные составные журналы - издания, рассчитанные на зарубежных читателей. В них включаются англоязычные версии статей, ранее уже опубликованных 
в российских изданиях. Работы на французском языке в российских журналах практически не публикуются. В то же время в вузах многих регионов России учатся студенты и аспиранты из Африки, которые в своих странах обучались на французском языке. Поэтому они часто недостаточно хорошо (для написания статей) знают английский и русский языки.

В научных журналах других постсоветских государств публикуются (и индексируются в международных базах данных) статьи на разных языках: национальных (государственных), английском, русском.

Формат представляемых автороами публикаций и требования к рисункам, таблицам. В российских изданиях преобладает прием публикаций в форматах .doc или .docx, реже - .rtf. Во многих зарубежных изданиях (особенно по естественно-научным и физико-математическим дисциплинам) предпочтение отдается форматам типа LaTex. B ряде случаев ограничивается максимальное количество иллюстраций в статьях, а также предельное разрешение файлов с растровой графикой. Возможность размещения на сайтах журналов дополнительных материалов к статьям (например, в виде видеороликов) пока является редким исключением. В некоторых изданиях также ограничивается количество таблиц, но не их доля в площадях страниц, занимаемых статьями.

Состав редколлегий и редакционного совета. В России в составе таких органов есть ученые из разных регионов страны, а также из-за рубежа. В последнем случае предпочтительны лица, владеющие русским языком, что облегчает возможность рассмотрения ими статей и рецензирования их. В редколлегиях журналов других постсоветских государств также есть зарубежные ученые, в том числе и из России. Во всех исследованных авторами журналах зарубежные члены редколлегий составляют меньшинство (обычно не более 15-20\%).

Рецензенты. Состав рецензентов публикуется лишь в немногих журналах, причем даже и в этом случае в силу использования «слепого» рецензирования работ рецензент для автора не известен. Привлекаются рецензенты из своих стран и из-за рубежа. Как правило, в России работа рецензентов не оплачивается.

Состав авторов. Практически все рассмотренные журналы заинтересованы в публикациях зарубежных авторов. Однако зарубежные материалы часто вызывают трудности при редакционной обработке из-за различий в сложившихся правилах оформления статей. Количество совместных публикаций национальных и зарубежных ученых невелико. В России и Беларуси зарубежные авторы публикуют статьи и на английском, и на русском языках. Однако практика редакционной деятельности российских журналов показывает, что для статей некоторых зарубежных авторов требуется исправление синтаксических, орфографических и стилистических ошибок в рамках редакционной обработки. Российские журналы, индексируемые 
в Scopus и Web of Science, стараются придерживаться следующего правила: доля авторов из других регионов (и из-за рубежа) должна быть выше, чем из своего региона. Нередко ограничивается максимально допустимое количество публикаций одного автора в течение года.

Интернет-сайт журнала. Научными журналами используются как собственные (отдельные) сайты, так и группы страниц на сайтах организаций, издающих журналы, включая издательства и вузы. На всех сайтах представлены нормы публикационной этики, однако в них не всегда четко выделены разделы, относящиеся к деятельности редколлегий, рецензентов, авторов, а также правила для авторов статей, перечни необходимых сопроводительных документов к представляемым статьям. В ряде случаев приводятся и шаблоны оформления статей со всеми необходимыми стилями.

Журналы открытого доступа размещают на сайтах архивы номеров. Некоторые издания проводят политику платного доступа к полным текстам опубликованных работ, в том числе размещенных в репозиториях научной информации. Для бесплатного доступа, кроме метаданных, могут выкладываться и превью (2-3 первые страницы).

У многих сайтов журналов на национальных языках есть и англоязычные версии. Ряд исследованных в статье изданий (особенно зарубежных) используют на сайтах «электронные редакции» (электронные офисы), где у авторов, рецензентов, коллектива редакции есть личные кабинеты. Для конструирования таких офисов существует типовое программное обеспечение.

Правила для авторов статей не унифицированы ни на международном, ни на национальном уровнях. Однако в группах журналов с общим издателем часть таких правил одинакова. Отсутствие унификации правил снижает возможности публикационной мобильности авторов, из-за чего уменьшается количество изданий, в которых авторы публикуют свои работы.

Для авторов из России и некоторых других стран проблему может представлять и перевод статей на английский язык, так как многие журналы прямо оговаривают необходимость использования грамотного английского языка. В этом ученым могут помочь фирмы (включая и зарубежные), предлагающие услуги по литературной доработке текстов (proofreading). Причем это не услуги «теневых авторов», а именно техническая корректировка текстов. Для статей, публикуемых в русскоязычных изданиях, корректировка стилистики статей обычно проводится в рабочем порядке: ответственным секретарем редакции, редактором, самим автором.

Нормы публикационной этики и требования к качеству работ. Содержание норм публикационной этики в российских и зарубежных журналах обычно не унифицировано (за исключением групп журналов 
с общим издателем). Во многих случаях публикуемые нормы смотрятся как недостаточно конкретные.

В России проверка оригинальности текста в предоставляемых авторами материалах обычно осуществляется с использованием системы «Антиплагиат» (www.antiplagiat.ru). Она имеет базовую часть и наборы дополнительных модулей контроля, относящихся к использованию компьютерных баз по разным типам материалов. Некоторыми организациями в России применяются и собственные системы контроля оригинальности текстов.

В зарубежных странах степень оригинальности текста также контролируется программными средствами. При этом общей проблемой России и других постсоветских государств является то, что автоматизированный контроль осуществляется пока только по текстам на тех же языках, что и представленные авторами работы.

Соблюдение других компонентов норм публикационной этики обеспечивается рецензентами, ответственными секретарями, членами редколлегий, главными редакторами журналов. Подчеркнем, что на сайтах самих журналов обычно нет форумов, на которых читатели могли бы размещать свои комментарии по соблюдению в изданиях норм публикационной этики, качеству статей и пр.

Внешний (внередакционный) контроль за содержанием статей ведущих журналов в России осуществляется ВАК (государственная организация при Министерстве науки и высшего образования РФ). Ретракция (отзыв) ранее опубликованных в журнале статей обычно выполняется по инициативе редакций изданий, а не авторов. При этом ведение общей базы ретрагированных статей осуществляет Ассоциация научных редакторов и издателей России (https://rasep.ru) - в ее рамках действует Совет по публикационной этике. Аналогичные органы в той или иной форме действуют и в большинстве других постсоветских странах.

Выявлением некорректно оформленных заимствований в диссертациях (преимущественно) и статьях, опубликованных в научных журналах России, активно занимается сообщество «Диссернет» (www.dissernet.org), работающее на общественных началах.

Вопросы несоблюдения норм публикационной этики (включая искусственное накручивание индексов Хирша для авторов) иногда обсуждаются и на российских интернет-форумах, в некоторых группах социальных сетей, на специализированных семинарах.

Название журнала. В России многие журналы из Перечня ВАК включают в себя названия издающих их организаций в сочетании со словами «вестник», «бюллетень», «известия» (иногда используется разделение таких изданий по сериям); часть журналов имеет названия на английском или латинском языках. 
Для журналов других постсоветских государств, индексируемых в Scopus и Web of Science, характерно следующее:

- в некоторых странах используются названия национальных изданий на английском языке (Армения, Беларусь, Грузия, Узбекистан, Эстония);

- в Азербайджане, Казахстане, Молдавии, Украине, Литве, Узбекистане и Эстонии издаются журналы с названиями как на английском, так и на русском языках;

- в названиях некоторых журналов используются национальные алфавиты или транслитерации названий с национальных языков на латиницу;

- встречаются также названия научных журналов, представленные на латыни.

Ряд журналов, включая российские, в своих названиях прямо отражают наименования регионов или групп регионов, в которых они выпускаются.

Тематика публикаций. В целом для зарубежных журналов, индексиpуемых в Scopus и Web of Science, степень тематической специализации глубже, чем для изданий из Перечня ВАК. Это обеспечивает первым более полную агрегацию в них соответствующих публикаций. В России в последние годы также предпринимаются серьезные усилия по углублению тематической специализации изданий на основе рубрикатора научных специальностей ВАК. Однако вопросы ограничения (уменьшения) числа изданий с аналогичными тематическими профилями, в том числе в пределах отдельных регионов страны, пока не ставятся.

Дополнительно отметим, что «территориальная привязка» тематики публикаций к отдельным регионам, географическим объектам возможна лишь для статей по некоторым направлениям: экологии, политологии, биологии, сельскому хозяйству и пр.

Направления использования опубликованных работ. Нами были выявлены следующие направления использования опубликованных работ:

- при проведении дальнейших научных исследований, осуществлении публикаций теми же или иными авторами;

- при подаче заявок на гранты;

- при выработке (корректировке) издательской политики редакциями научных журналов, их учредителями;

- при оценке актуальности научных исследований руководителями НИИ, органами государственного управления наукой, фондами-грантодателями и пр.;

- при выполнении прогнозов (оценок) социально-экономического и научно-технического развития стран и регионов;

- при принятии соответствующих управленческих, технических и иных видов решений.

Международные реферативные базы и системы учета публикаций/ цุитирований. Они выполняют функции агрегации научной информации; 
в определенной степени - оценок качества статей и результативности (качества) деятельности журналов. Наиболее известными являются Scopus и Web of Science, в сфере гуманитарных наук - Erich Plus. Однако ВАК России при оценках авторитетности журналов учитывает и некоторые иные тематически специализированные международные базы публикаций/ цитирований.

Национальные системы категорирования журналов и учета цуитирований. В России для выделения наиболее авторитетных научных журналов используется Перечень ВАК. К входящим в него журналам предъявляются серьезные требования по качеству публикаций, соблюдению их соответствия утвержденной тематике издания и пр. Включение журналов в российский Перечень ВАК активно используется также Таджикистаном (26 изданий в Перечне ВАК, 79 журналов индексируются в РИНЦ). В то же время у 7 постсоветских государств нет ни одного издания в перечне ВАК (табл. 1). Также ВАК публикует справочный список изданий, индексируемых в авторитетных международных базах, причем не только в Scopus и Web of Science.

Т а б л и ц а 1. Количество научных журналов постсоветских государств, включенных в Перечень ВАК (на 01.08.2019)

$\mathrm{T}$ a $\mathrm{b} 1 \mathrm{e} 1$. Number of scientific journals in the post-Soviet states included in the List of the peer-reviewed scientific publications recommended by the Russian Higher Attestation Commission (as of 1 August 2019)

\begin{tabular}{l|c}
\multicolumn{1}{c|}{ Страна / Country } & $\begin{array}{c}\text { Количество журналов } \\
\text { Number of journals }\end{array}$ \\
\hline Россия / Russia & 3020 \\
Азербайджан / Azerbaijan & 0 \\
Армения / Armenia & 0 \\
Беларусь / Belarus & 4 \\
Грузия / Georgia & 0 \\
Казахстан / Kazakhstan & 0 \\
Кыргызстан / Kyrgyzstan & 1 \\
Латвия / Latvia & 1 \\
Литва / Lithuania & 0 \\
Молдавия / Moldova & 1 \\
Таджикистан / Tajikistan & 26 \\
Туркменистан / Turkmenistan & 0 \\
Узбекистан / Uzbekistan & 1 \\
Украина / Ukraine & 2 \\
Эстония / Estonia & 0 \\
Всего / Тоtal & 3056
\end{tabular}


Издателем единственных латвийского и молдавского журналов, входящих в Перечень ВАК России, является издательство Allerton Press, Inc., аффилированное с США.

Из Кыргызстана в Перечне ВАК России находится один национальный журнал - «Вестник Кыргызско-Российского славянского университета». На практике при оценках научных достижений ученых в этой республике учитываются также статьи в российских изданиях, индексируемых в РИНЦ.

В Казахстане действует Национальный научный портал (русскоязычный вариант сайта: http://www.nauka.kz/page.php). На нем сгруппирована информация по ученым Казахстана и их достижениям, включая сведения о публикационной активности в изданиях, индексируемых Scopus и Web of Science, динамике наукометрических показателей. Однако, как отмечают Ю. Ю. Тарасевич и Т. С. Шиняева, казахскими исследователями было опубликовано много работ в зарубежных научных журналах, которые впоследствии были исключены из Scopus и Web of Science из-за нарушения требований к качеству работ [18].

Публикации в научных журналах Беларуси и Украины достаточно активно цитируются в российских статьях. Об этом свидетельствуют высокие показатели таких журналов в Science Index РИНЦ.

В Туркменистане для издаваемых национальных научных журналов сведения об архивах изданий доступны на национальных сайтах. На них размещены и русскоязычные интернет-страницы с названиями опубликованных работ. Однако тексты этих работ в электронной форме дистанционно (через интернет) просмотреть нельзя.

Перечни ВАК, подобные российскому, существуют в Казахстане, Таджикистане, Беларуси. Требования к включению национальных журналов в эти Перечни во многом аналогичны требованиям российской Высшей аттестационной комиссии. Однако подобных Перечней нет в прибалтийских странах, которые ориентируются на отражение своих журналов в международных системах учета цитирований - прежде всего в Scopus и Web of Science.

Для категорирования изданий РИНЦ России (независимо от ВАК) используются два инструмента:

- поддержка индексирования опубликованных в журналах работ. При этом издания, нарушающие общепринятые правила публикационной этики, не проводящие рецензирование работ, исключаются из числа индексируемых. Опубликованные в них работы перестают учитываться при расчетах наукометрических показателей РИНЦ для авторов;

- включение изданий в ядро РИНЦ. По работам авторов, опубликованных в таких изданиях, РИНЦ рассчитывает дополнительные наукометрические показатели.

Сравнение показателей публикационной активности авторов статей по постсоветским странам. При расчетах для таблицы 2 нами использовались описанные выше относительные показатели $R_{0}, R_{1}, R_{2}$. 


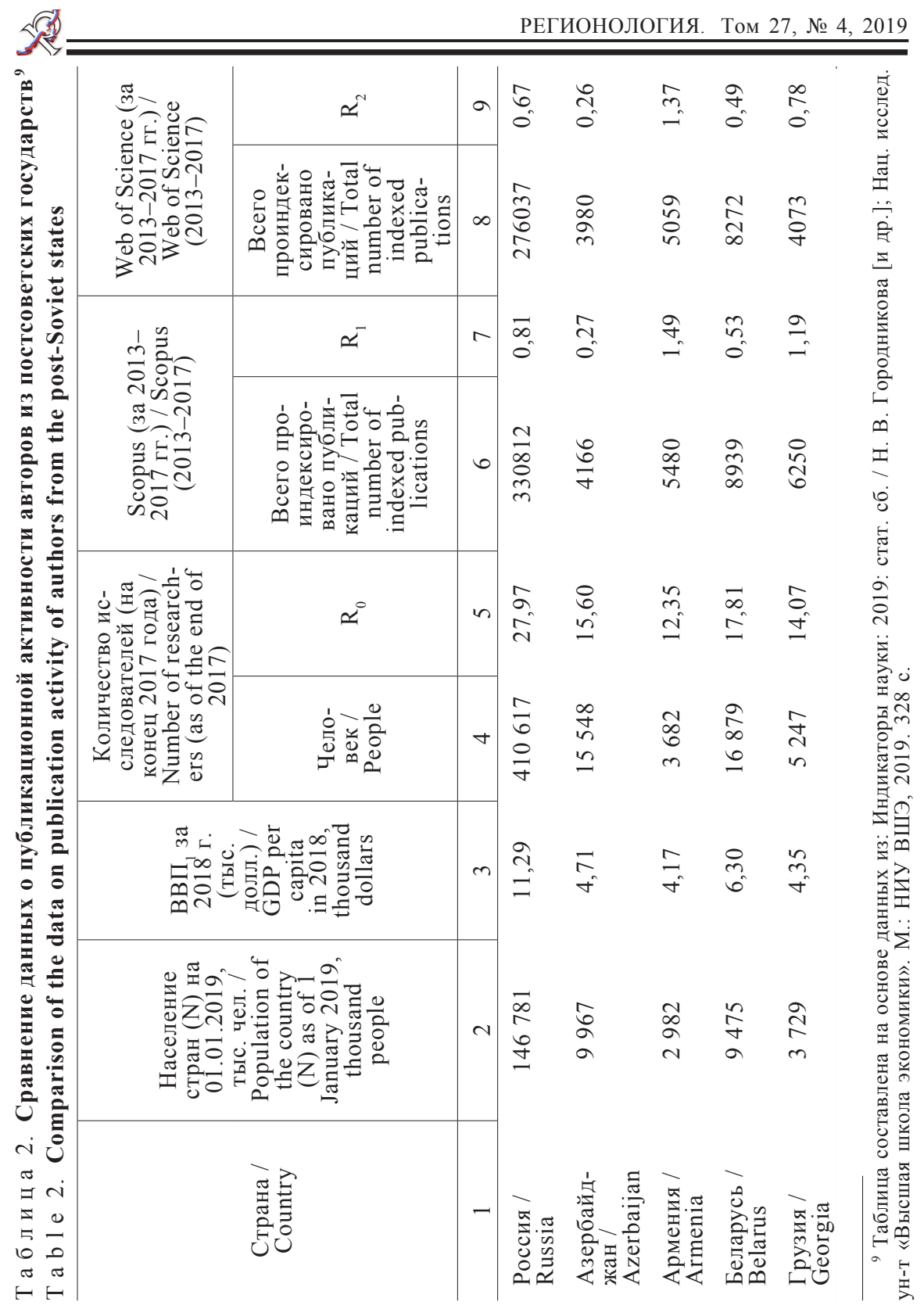




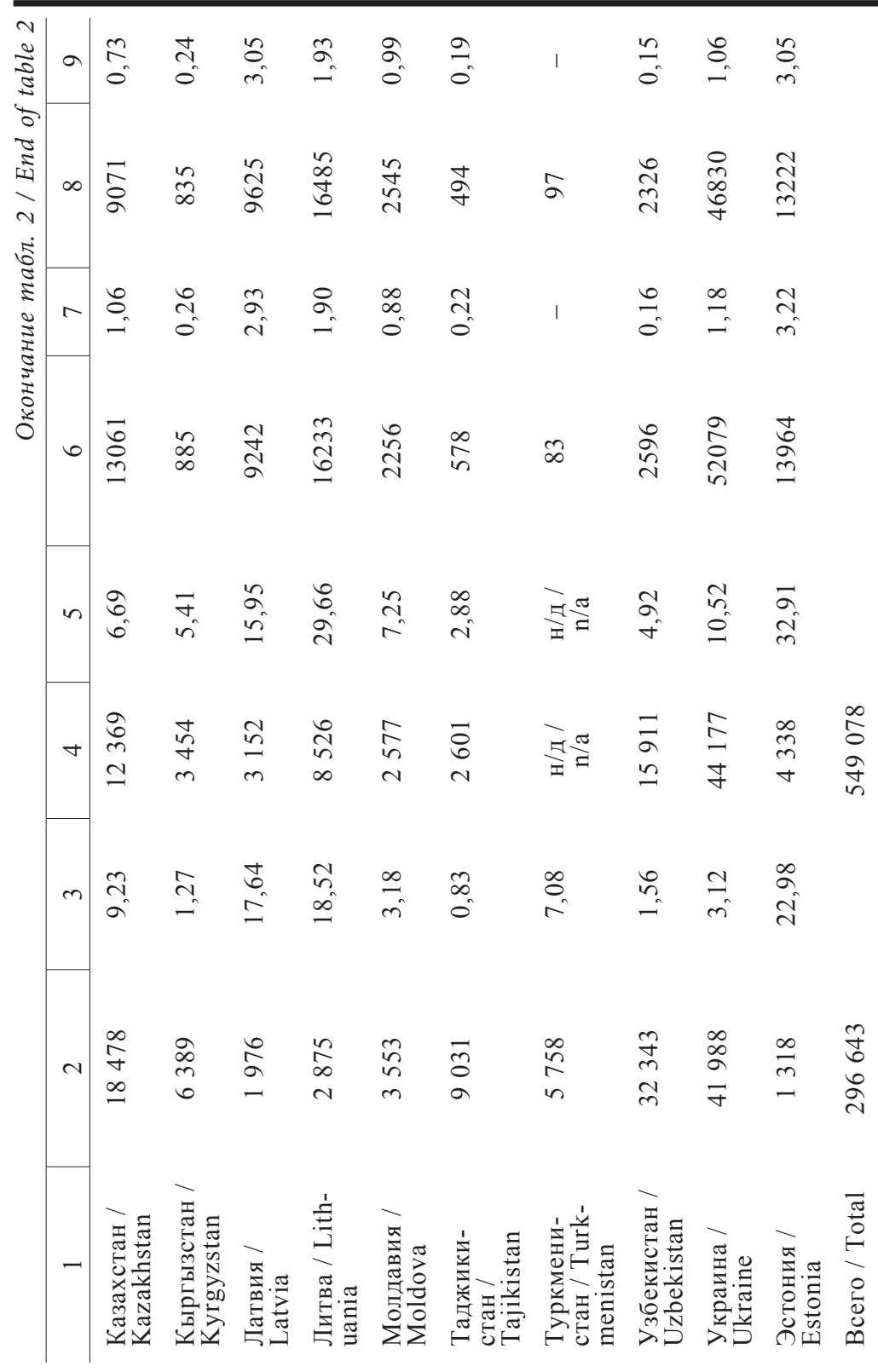


Согласно данным таблицы 2, в России работает наибольшее абсолютное количество публикующихся исследователей, а меньше всего их в Молдавии (2 577 чел.). Однако по относительному показателю $R_{0}$ Эстония и Литва немного опережают Россию. Самый низкий показатель $R_{0}$ у Таджикистана, а по Туркменистану нет данных.

По показателям $R_{1}$ (Scopus) и $R_{2}$ (Web of Science) лидируют Эстония, Латвия, Литва. Это, вероятно, является следствием ориентации исследователей указанных трех прибалтийских стран на публикации в авторитетных зарубежных журналах, так как национальных журналов в этих государствах сравнительно немного. Для большинства постсоветских государств показатели $R_{1}$ и $R_{2}$ невысокие.

Были также рассчитаны коэффициенты парной корреляции по Пирсону между ВВП, и относительными показателями публикационной активности (табл. 3) с использованием данных по всем странам, кроме Туркменистана (по нему данных нет).

Т а б л и ц а 3. Коэффициенты парной корреляции по Пирсону для параметров из таблицы 2

$\mathrm{T}$ a $\mathrm{b} 1 \mathrm{e}$ 3. Pearson correlation coefficients for the parameters from Table 2

\begin{tabular}{c|c|c|c|c}
\hline $\begin{array}{c}\text { Показатель / } \\
\text { Indicator }\end{array}$ & $\begin{array}{c}\text { BBП } / \text { GDP } \\
\text { per capita }\end{array}$ & $R_{0}$ & $R_{1}$ & $R_{2}$ \\
\hline BBП $/$ & 1 & & & \\
GDP per capita & & 1 & & \\
$R_{0}$ & 0,830 & 0,617 & 1 & \\
$R_{1}$ & 0,862 & 0,602 & 0,998 & 1 \\
$R_{2}$ & 0,859 & &
\end{tabular}

Все коэффициенты корреляции статистически значимы на «уровне значимости $0,01 »$ по критерию «t-фактор». Отметим большие значения коэффициентов корреляции параметра ВВП со всеми относительными показателями публикационной активности, а также очень высокое значение коэффициента корреляции между $R_{1}$ и $R_{2}$.

Характеристика научных журналов по данным Научной электронной библиотеки eLIBRARY.RU. При оценке научной значимости российских изданий нами учитывались:

- анализ взаимосвязи между рейтингами отечественных научных журналов в РИНЦ и авторитетных международных базах данных, проведенный Т. С. Шиняевой, В. С. Седышевой, Ю. Ю. Тарасевичем [19];

- результаты включения изданий в перечень Russian Science Citation Index (RSCI), размещенный на платформе Web of Science. 
Доли учтенных и неучтенных изданий из России и других постсоветских государств в Научной электронной библиотеке eLIBRARY.RU отличаются. Так, по трем прибалтийским государствам в РИНЦ индексируется значительно меньше изданий, чем в Scopus и Web of Science.

При расчетах относительных показателей $R_{3}$ (Scopus) и $R_{4}$ (Web of Science) для таблицы 4 соответствующие абсолютные значения для изданий, выходящих на 01.08.2019, делились на численности исследователей в этих странах (тыс. чел.) (см. табл. 1). Показатели $R_{3}$ и $R_{4}$ можно считать отражающими «уровни обеспеченности» стран национальными журналами, индексируемыми Scopus и Web of Science (многие журналы одновременно индексируются обоими ресурсами). Однако авторы из рассматриваемых стран активно публикуются и в зарубежных (для них) журналах, индексируемых Scopus и Web of Science. Применение показателей $R_{3}$ и $R_{4}$ для сравнения России и других постсоветских государств в случае прибалтийских государств выглядит не вполне корректным из-за различий в полноте учета их национальных журналов РИНЦ, Scopus, Web of Science.

Данные таблицы 4 показывают, что для РИНЦ количество научных журналов в категории «Общие» и «Выходят в настоящее время» совпадает или почти совпадает. Это может свидетельствовать об относительной стабильности выпуска таких изданий.

Количество журналов, индексируемых Web of Science, по сравнению co Scopus меньше в 6 случаях из 15, в 5 случаях - больше, в 4 - совпадает (причем в трех случаях это нулевые значения).

В трех постсоветских странах нет национальных журналов, индексируемых Scopus или Web of Science (Кыргызстан, Таджикистан и Туркменистан). При этом Таджикистан лидирует среди других постсоветских государств по присутствию журналов в Перечне ВАК.

Результаты корреляционного анализа некоторых показателей из таблицы 4 представлены в таблице 5.

Видно, что высокие (и статистически значимые по уровню значимости 0,01$)$ положительные коэффициенты парной корреляции по Пирсону

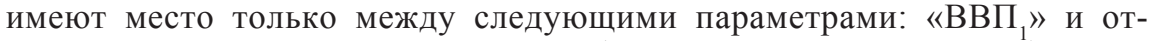
носительными показателями $R_{3}$ и $R_{4}$ (вторая колонка таблицы 5 ); абсолютными показателями количеств индексируемых журналов в РИНЦ, Scopus и Web of Science, некоторыми иными показателями. В то же время многие коэффициенты корреляции в этой таблице близки к нулю.

Обсуждение и заключение. По результатам, представленным в статье, сделаем следующие выводы.

1. Научные журналы постсоветских государств играют важную роль в накоплении (агрегации) научной информации в сочетании с ее тематической структуризацией, в обеспечении известности этой информации для заинтересованных лиц и организаций, в создании потенциальных 


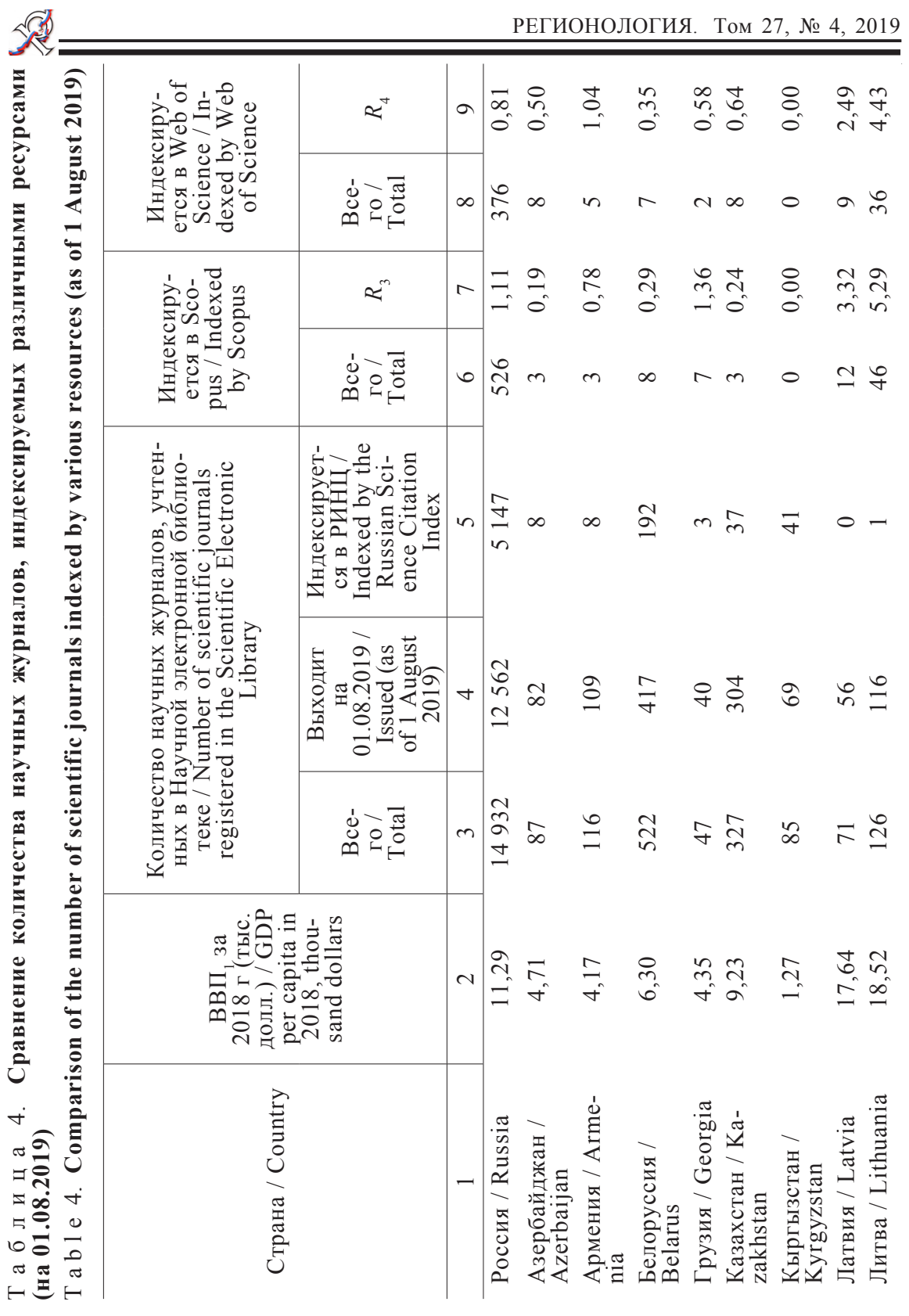




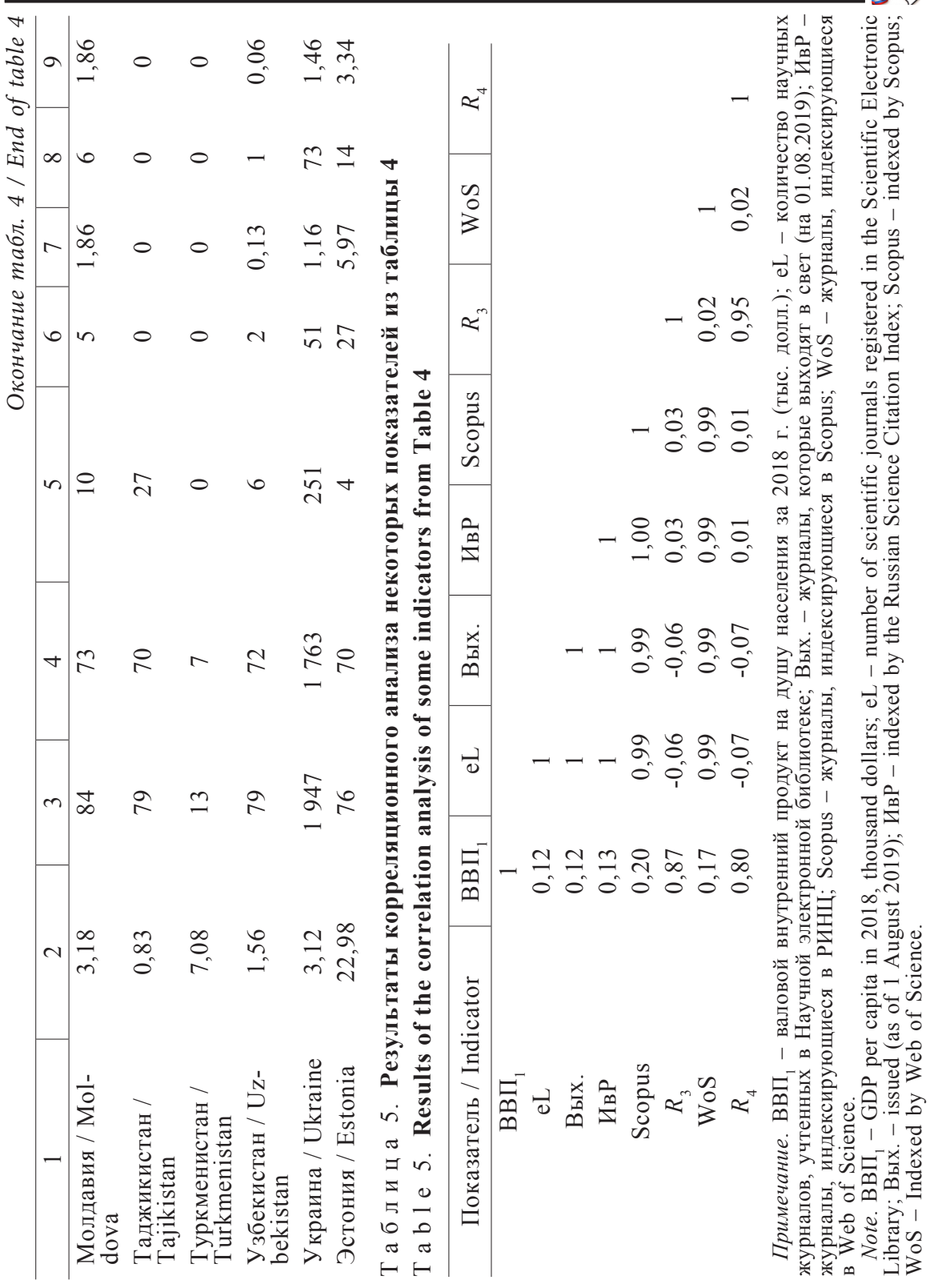


возможностей для авторов в отношении опубликования этой информации, в обеспечении актуальности и качества публикуемых работ.

2. Сайты рассмотренных в статье научных журналов обеспечивают необходимые возможности для авторов по ознакомлению с правилами подачи статей и с уже опубликованными материалами, во многих случаях предоставляют возможности их скачивания.

3. Международные реферативные базы, системы учета цитирований, электронные репозитории научной информации играют важную роль в формировании НИП. Результативность работы репозиториев во многом определяется функциональностью и дружественностью к пользователю их информационно-поисковых систем. В то же время важность издания реферативных журналов постепенно снижается.

4. В России важнейшую роль играет Научная электронная библиотека и ее проект - Российский индекс научного цитирования. Отметим также роль ВАК России и РИНЦ в категорировании научных журналов, поддержке мер по обеспечению качества публикуемых в них материалов.

5. Из других постсоветских государств Перечень ВАК России для категорирования научных изданий использует только Таджикистан.

6. Для расширения международного сотрудничества в редколлегии всех авторитетных журналов постсоветских государств обязательно включаются зарубежные члены, приветствуются публикации зарубежных авторов.

7. В России и ряде других постсоветских стран управление и контроль за деятельностью большинства ведущих журналов во многом осуществляется на государственном уровне. Издания, индексируемые в Scopus и Web of Science, ориентируются преимущественно на их требования, в частности на наукометрические показатели, рассчитываемые этими ресурсами.

8. Несмотря на существование в постсоветских государствах объединений редакторов и издателей (в различных формах), координация деятельности изданий с их стороны пока носит достаточно ограниченный характер. Это во многом определяется конкуренцией журналов за качественные статьи и авторитетных авторов.

9. Существует ряд факторов, ограничивающих публикационную мобильность авторов из постсоветских стран, включая следующие: различия технических требований журналов к предоставляемым материалам в отношении оформления, представления библиографических списков и пр. (в том числе даже и в различных журналах из одних и тех же стран); во многих журналах - необходимость изначального предоставления статей на качественном английском языке.

Предложенные авторами методы сравнительного анализа показателей деятельности научных журналов постсоветских государств могут быть применены при изучении научной периодики из других стран, в том числе стран БРИКС, Европы и др. Продолжение начатых исследований 
через несколько лет позволит получить динамику изменения рассматриваемых показателей для совокупности научных журналов постсоветских государств во времени.

Представленные в статье материалы могут быть полезны для решения исследовательских задач, относящихся к научной периодике, для поддержки принятия решений руководителями научных подразделений, редакционно-издательских комплексов, отдельными исследователями.

\section{СПИСОК ИСПОЛЬЗОВАННЫХ ИСТОЧНИКОВ}

1. Кравцов А. А. Научное сотрудничество России на постсоветском пространстве // Вестник Российской академии наук. 2019. Т. 89, № 7. С. 699-717. DOI: https://doi.org/10.31857/S0869-5873897699-717

2. Михалева О. М., Матюшкина И. А., Игольникова И. В. Тенденции развития науки в России и за рубежом // Международный научный журнал. 2015. № 3. C. 22-26. URL: http://www.tis-journal.com/contents/2015/vypusk-no3/\#c9466 (дата обращения: 27.06.2019).

3. Алимова Н. К. Современные проблемы рынка интеллектуального (научного) труда [Электронный ресурс] // Науковедение. 2011. № 3 (8). C. 11. URL: https:// naukovedenie.ru/index.php?id=181 (дата обращения: 27.06.2019).

4. Гришакина Е. Г. Публикационная активность российских исследователей: университетская наука [Электронный ресурс] // Наука. Инновации. Образование. 2016. № 4 (22). C. 137-151. URL: http://sie-journal.ru/publikaczionnaya-aktivnostrossijskih-issledovatelej-universitetskaya-nauka (дата обращения: 27.06.2019).

5. Шапошник С. Б. Международное научное сотрудничество и публикационная активность российских ученых в Computer Science в 1993-2017 годах: междисциплинарный и межстрановой анализ // Информационное общество. 2018. № 6. C. 39-45. URL: https://elibrary.ru/item.asp?id=37299488 (дата обращения: 27.06.2019).

6. Брумштейн Ю. М., Захарян М. Ю. Распределение ученых по населенным пунктам и регионам России: сравнение сведений официальной статистики и данных о публикационной активности [Электронный ресурс] // Науковедение. 2017. Т. 9, № 4. URL: http://naukovedenie.ru/PDF/39EVN417.pdf (дата обращения: 27.06.2019).

7. Библиометрические показатели российских журналов, индексируемых в Web of Science / С. Л. Парфенова [и др.] // Наука. Инновации. Образование. 2017. № 3 (25). C. 113-126. URL: http://sie-journal.ru/bibliometricheskie-pokazatelirossijskih-zhurnalov,-indeksiruemyih-v-web-of-science (дата обращения: 27.06.2019).

8. Брумштейн Ю. М. Анализ вопросов соблюдения публикационной этики в практике деятельности российских научных журналов [Электронный ресурс] // Науковедение. 2017. Т. 9, № 3. С. 1-31. URL: http://naukovedenie.ru/ PDF/23EVN317.pdf (дата обращения: 27.06.2019).

9. Брумштейн Ю. М. Анализ роли ресурса www.dissernet.org в оценках и управлении качеством деятельности редакций научных журналов России // Научная периодика: проблемы и решения. 2017. T. 7, № 2. DOI: https://doi. org/10.18334/nppir.7.2.37949 
10. Калинин Ю. П., Хорошилов А. А., Хорошилов А. А. Принципы создания системы мониторинга и анализа мирового потока научно-технической информации // Системы и средства информатики. 2016. Т. 26, № 1. С. 139-165. URL: http:// www.ipiran.ru/journal/collected/2016_26_01_rus/ (дата обращения: 27.06.2019).

11. Малкова А. А. Анализ научных журналов как носителей новых знаний // Актуальные вопросы экономических наук. 2013. № 33. C. 63-67. URL: https://elibrary. ru/item.asp?id=20722267 (дата обращения: 27.06.2019).

12. Маршакова-Шайкевич И. В. Библиометрический анализ научных журналов // Социология науки и технологий. 2014. T. 5, № 3. C. 38-48. URL: http://sst.nw.ru/ ru/archive/snit201453/ (дата обращения: 27.06.2019).

13. Анализ качественных и количественных характеристик журнала «Искусственный интеллект и принятие решений» / А. В. Швец [и др.] // Искусственный интеллект и принятие решений. 2015. № 4. C. 89-100. URL: https://clck.ru/ KVMN6 (дата обращения: 27.06.2019).

14. Zavadskas E. K., Kirvaitis R., Dagienè E. Scientific Publications Released in the Baltic States // Scientometrics. 2011. Vol. 88, issue 1. Pp. 179-190. DOI: https://doi.org/10.1007/s11192-011-0394-x

15. Gzoyan E. G., Hovhannisyan L. A., Aleksanyan S. A. Comparative Analysis of the Scientific Output of Armenia, Azerbaijan and Georgia // Scientometrics. 2015. Vol. 102, issue 1. Pp. 195-212. DOI: https://doi.org/10.1007/s11192-014-1452-y

16. What is the Difference in Global Research on Central Asia before and After the Collapse of the USSR: A Bibliometric Analysis / Y. Wang [et al.] // Scientometrics. 2019. Vol. 119, issue 2. Pp. 909-930. DOI: https://doi.org/10.1007/s11192-019-03069-0

17. Lovakov A., Agadullina E. Bibliometric Analysis of Publications from Post-Soviet Countries in Psychological Journals in 1992-2017 // Scientometrics. 2019. Vol. 119, issue 2. Pp. 1157-1171. DOI: https://doi.org/10.1007/s11192-019-03087-y

18. Тарасевич Ю. Ю., Шиняева Т. С. Наука самолетопоклонников: 40 лет спустя // Cloud of Science. 2017. T. 4, № 4. C. 525-547. URL: https://cloudofscience. ru/publications/archive/cos_4_4 (дата обращения: 27.06.2019).

19. Шиняева Т. С., Седышева В. С., Тарасевич Ю. Ю. Коррелируют ли наукометрические показатели отечественных научных журналов, рассчитанные различными организациями? // Информатизация образования и науки. 2015. №. 1. C. 55-71. URL: https://informika.ru/pechatnye-izdaniya/zhurnal-informatizaciya-obrazovaniya-i-nauki/arhiv-vypuskov/2015/vypusk-n25-soderzhanie/ (дата обращения: 27.06.2019).

Поступила 08.08.2019; принята к публикации 17.09.2019; опубликована онлайн 30.12.2019.

Об авторах:

Брумштейн Юрий Моисеевич, доцент кафедры информационных технологий ФГБОУ ВО «Астраханский государственный университет» (414056, Россия, г. Астрахань, ул. Татищева, д. 20a), кандидат технических наук, ORCID: https:// orcid.org/0000-0002-0016-7295, brum2003@mail.ru

Алимова Наталья Константиновна, генеральный директор ООО «Издательство «Мир науки» (127055, Россия, г. Москва, пер. Порядковый, д. 21), 
кандидат экономических наук, ORCID: https://orcid.org/0000-0002-0801-3100, alimova@mir-nauki.com

Заявленный вклад авторов:

Брумштейн Юрий Моисеевич - сбор, первичная обработка и статистический анализ данных; подготовка начального варианта текста статьи; критический анализ и доработка текста статьи.

Алимова Наталья Константиновна - сбор, обработка и анализ информации; подготовка и критический анализ текста статьи; доработка статьи.

\section{Для циитирования:}

Брумштейн Ю. М., Алимова Н. К. Научные журналы постсоветских государств: место в национальном и международном информационном пространстве // Регионология. 2019. Т. 27, № 4. С. 831-857. DOI: https://doi.org/10.15507/24131407.109.027.201904.831-857

Все авторы прочитали и одобрили окончательный вариант рукописи.

\section{REFERENCES}

1. Kravtsov A.A. Scientific Cooperation of Russia with post-Soviet States. Evaluation by Publications Indexed in Web of Science. Vestnik Rossijskoj akademii nauk= Bulletin of the Russian Academy of Sciences. 2019; 89(7):699-717. (In Russ., abstract in Eng.) DOI: https://doi.org/10.31857/S0869-5873897699-717

2. Mikhaleva O.M., Matyushkina I.A., Igolnikova I.V. Tendencies of Development of Science in Russia and Abroad. Mezhdunarodnyj nauchnyj zhurnal = International Scientific Journal. 2015; (3):22-26. Available at: http://www.tis-journal.com/ contents/2015/vypusk-no3/\#c9466 (accessed 27.06.2019). (In Russ., abstract in Eng.)

3. Alimova N.K. [Modern Issues of the Market of Intellectual (Scientific) Labor]. Naukovedenie $=$ Science Studies. 2011; (3):11. Available at: https://naukovedenie.ru/ index.php?id=181 (accessed 27.06.2019). (In Russ.)

4. Grishakina E.G. The Publication Activity of Russian Researchers: Academic Science. Nauka. Innovatsii. Obrazovanie = Science. Innovation. Education. 2016; (4):137-151. Available at: http://sie-journal.ru/publikaczionnaya-aktivnost-rossijskihissledovatelej-universitetskaya-nauka (accessed 27.06.2019). (In Russ., abstract in Eng.)

5. Shaposhnik S.B. International Scientific Cooperation and Publication Activity of Russian Scientists in the Field of Computer Science in 1993-2017: Interdisciplinary and Cross-Country Comparative Analysis. Informatsionnoe obshhestvo = Information Society. 2018; (6):39-45. Available at: https://elibrary.ru/item.asp?id=37299488 (accessed 27.06.2019). (In Russ., abstract in Eng.)

6. Brumshteyn Yu.M., Zakharyan M.Yu. Distribution of Scientists by Russian Inhabited Points and Regions: Comparison of Official Statistics Data and Information about Printing Activity. Naukovedenie = Science Studies. 2017; 9(4). Available at: http:// naukovedenie.ru/PDF/39EVN417.pdf (accessed 27.06.2019). (In Russ., abstract in Eng.) 
7. Parfenova S.L., Bezrodnova K.A., Bogatov V.V., Lyagushkina E.A. Bibliometric Indicators of Russian Journals Indexed by Web of Science. Nauka. Innovatsii. Obrazovanie = Science. Innovation. Education. 2017; (3):113-126. Available at: http:// sie-journal.ru/bibliometricheskie-pokazateli-rossijskih-zhurnalov,-indeksiruemyih-vweb-of-science (accessed 27.06.2019). (In Russ., abstract in Eng.)

8. Brumshteyn Yu.M. Analysis of Printing Ethics Observance Questions in Practice of Russian Scientific Journals Activity. Naukovedenie $=$ Science Studies. 2017; 9(3):1-31. Available at: http://naukovedenie.ru/PDF/23EVN317.pdf (accessed 27.06.2019). (In Russ., abstract in Eng.)

9. Brumshteyn Yu.M. The Analysis of the www.dissernet.org Resource Role in Estimates and Control of Editorial Offices Activity Quality of Russian Scientific Journals. Nauchnaya periodika: problemy $i$ resheniya $=$ Scientific Periodicals: Problems and Solutions. 2017; 7(2). (In Russ., abstract in Eng.) DOI: https://doi. org/10.18334/nppir.7.2.37949

10. Kalinin Yu.P., Khoroshilov A.A., Khoroshilov A.A. Principles of Creation of Monitoring System and Analysis of World Stream of Scientific and Technical Information. Sistemy $i$ sredstva informatiki $=$ Systems and Means of Informatics. 2016; 26(1):139-165. Available at: http://www.ipiran.ru/journal/collected/2016_26_01_rus/ (accessed 27.06.2019). (In Russ., abstract in Eng.)

11. Malkova A.A. [Analysis of Scientific Journals as Carriers of New Knowledge]. Aktualnye voprosy ehkonomicheskikh nauk $=$ Relevant Issues of Economics. 2013; (33):63-67. Available at: https://elibrary.ru/item.asp?id=20722267 (accessed 27.06.2019). (In Russ.)

12. Marshakova-Shaykevich I.V. Bibliometric Analyses of Scientific Journals. Sotsiologiya nauki i tekhnologij = Sociology of Science and Technology. 2014; 5(3):38-48. Available at: http://sst.nw.ru/ru/archive/snit201453/ (accessed 27.06.2019). (In Russ., abstract in Eng.)

13. Shvets A.V., Devyatkin D.A., Zubarev D.V., Tikhomirov I.A., Grigoriev O.G. Analysis of Qualitative and Quantitative Characteristics of the Journal 'Artificial Intelligence and Decision Making'. Iskusstvennyj intellekt $i$ prinyatie reshenij = Artificial Intelligence and Decision Making. 2015; (4):89-100. Available at: https:// clck.ru/KVMN6 (accessed 27.06.2019). (In Russ., abstract in Eng.)

14. Zavadskas E.K., Kirvaitis R., Dagienè E. Scientific Publications Released in the Baltic States. Scientometrics. 2011; 88(1):179-190. (In Eng.) DOI: https://doi. org/10.1007/s11192-011-0394-x

15. Gzoyan E.G., Hovhannisyan L.A., Aleksanyan S.A. Comparative Analysis of the Scientific Output of Armenia, Azerbaijan and Georgia. Scientometrics. 2015; 102(1):195-212. (In Eng.) DOI: https://doi.org/10.1007/s11192-014-1452-y

16. Wang Y., Hong S., et al. What is the Difference in Global Research on Central Asia Before and After the Collapse of the USSR: A Bibliometric Analysis. Scientometrics. 2019; 119(2):909-930. (In Eng.) DOI: https://doi.org/10.1007/s11192019-03069-0

17. Lovakov A., Agadullina E. Bibliometric Analysis of Publications from postSoviet Countries in Psychological Journals in 1992-2017. Scientometrics. 2019; 119(2):1157-1171. (In Eng.) DOI: https://doi.org/10.1007/s11192-019-03087-y 
18. Tarasevich Yu.Yu., Shinyaeva T.S. Cargo Cult Science: 40 Years Later. Cloud of Science. 2017; 4(4):525-547 Available at: https://cloudofscience.ru/publications/ archive/cos_4_4 (accessed 27.06.2019). (In Russ., abstract in Eng.)

19. Shinyaeva T.S., Sedysheva V.S., Tarasevich Yu.Yu. Do Scientometric Indicators of Domestic Scientific Journals Calculated by Various Organizations Correlate? Informatizatsiya obrazovaniya $i$ nauki = Informatization of Education and Science. 2015; (1):55-71. Available at: https://informika.ru/pechatnye-izdaniya/zhurnalinformatizaciya-obrazovaniya-i-nauki/arhiv-vypuskov/2015/vypusk-n25-soderzhanie/ (accessed 27.06.2019). (In Russ., abstract in Eng.)

Submitted 08.08.2019; accepted for publication 17.09.2019; published online 30.12.2019.

\section{About the authors:}

Yuri M. Brumshteyn, Associate Professor, Department of Information Technology, Astrakhan State University (20a Tatishcheva St., Astrakhan 414056, Russia), Ph. D. (Engineering), ORCID: https://orcid.org/0000-0002-0016-7295, brum2003@mail.ru

Natalia K. Alimova, Director General, Publishing Company "World of Science" (21 Poryadkoviy Pereulok, Moscow 127055, Russia), Ph. D. (Economics), ORCID: https://orcid.org/0000-0002-0801-3100,alimova@mir-nauki.com

\section{Contribution of the authors:}

Yuri M. Brumshteyn - collection, primary processing and statistical analysis of data; writing the initial version of the text of the article; critical analysis and revision of the text of the article.

Natalia K. Alimova - collection, processing and analysis of information; writing and critical analysis of the text of the article; revision of the article.

\section{For citation:}

Brumshteyn Yu.M., Alimova N.K. Scientific Journals in the post-Soviet States: The Place in the National and International Information Space. Regionology = Russian Journal of Regional Studies. 2019; 27(4):831-857. DOI: https://doi.org/10.15507/24131407.109.027.201904.831-857

The authors have read and approved the final version of the manuscript. 


\section{Этносоциологические исследования в Республике Мордовия в 1990-2010 гг.: ретроспективный анализ}

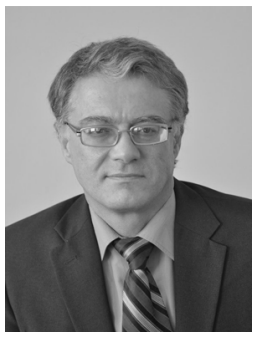

В. В. Козин

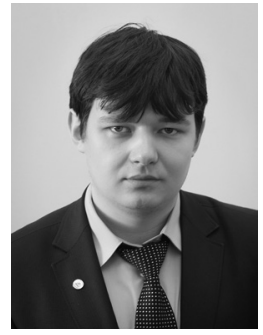

С. Г. Ушкин

ГКУ РМ «Научный изентр социиально-экономического мониторинга» (2. Саранск, Россия), *vladimir.kozin13@mail.ru

Введение. Проведение мониторинговых этносоциологических исследований в полиэтничном регионе обусловлено не только необходимостью осуществления оценки регулирования государственной политики в данной области, но и приумножением эвристического потенциала по предупреждению различного рода социальных конфликтов. Цель статьи - на основе сравнительного анализа научных исследований выявить динамику развития межнациональных отношений в Мордовии, влияние различных стратификационных процессов на развитие национальных отношений.

Материалы и методы. Материалами исследования послужили регулярные социологические замеры, проведенные Научно-исследовательским институтом регионологии при Мордовском государственном университете им. Н. П. Огарева и Научным центром социально-экономического мониторинга в 1990-2010 гг. Интерпретация результатов осуществлялась с помощью институционального, сравнительного и естественно-исторического методов.

Результаты исследования. Выявлены основные тенденции развития массового сознания населения полиэтничного региона в контексте различных социально-политических периодов развития нашего государства: от «парада суверенитетов», последовавшего за распадом Советского Союза, до реактуализации идеологии сильного многонационального российского государства. Подчеркивается, что на протяжении ряда лет основными причинами, оказывающими негативное влия-

(C) Козин В. В., Ушкин С. Г., 2019 Контент доступен под лицензией Creative Commons Attribution 4.0 License. This work is licensed under a Creative Commons Attribution 4.0 License. 
ние на характер межнациональных отношений, выступали преимущественно не межнациональные конфликты, а политически или экономически маркированные факторы (экономический кризис, инфляция, назначение на руководящие должности по национальному признаку, неравенство доходов между представителями различных национальностей и т. д.).

Обсуждение и заключение. Несмотря на то, что межнациональные отношения практически никогда не характеризовались повышенным уровнем конфликтности, руководству республики удалось построить действенную систему их регулирования, которая позволила минимизировать градус социальной и этнической напряженности в социуме. Статья может быть полезна ученым и практикам в области развития межнациональных отношений и всем интересующимся проблемами этносоциологии.

Ключевые слова: этносоциология, межэтнические отношения, межэтнические конфликты, гармонизация, регион, Республика Мордовия

Финансирование. Статья подготовлена при финансовой поддержке Российского фонда фундаментальных исследований и Правительства Республики Мордовия в рамках научного проекта № 18-411-130014 «Национальные сообщества полиэтнического региона: перспективы ассимиляции и диссимиляции».

\title{
Ethnosociological Studies in the Republic of Mordovia in 1990-2010: A Retrospective Analysis
}

\author{
V. V. Kozin*, S. G. Ushkin \\ Scientific Center for Social and Economic Monitoring (Saransk, Russia), \\ *vladimir.kozin13@mail.ru
}

Introduction. Ethnosociological monitoring in a polyethnic region is conducted not only due to the need for an assessment of the public policy regulation in this field, but also due to the increase in the heuristic potential for preventing various kinds of social conflicts. The objective of the paper is to identify the dynamics of the development of interethnic relations in the Republic of Mordovia and the influence of various stratification processes on the development of ethnic relations, based on a comparative analysis of scientific studies.

Materials and Methods. Regular sociological measurements carried out by the Research Institute of Regionology under Ogarev Mordovia State University and by the Scientific Center for Social and Economic Monitoring in 1990-2010 were used as the research materials. The interpretation of the results was carried out using the institutional, comparative and natural historical methods.

Results. The main trends in the development of mass consciousness of the population of a polyethnic region in the context of various socio-political periods of the development of Russia have been revealed: from the 'parade of sovereignties' that followed the collapse of the Soviet Union to the reactualization of the ideology of a strong multiethnic Russian state. It has been emphasized that over the years, the main reasons exerting a negative impact on the nature of interethnic relations have mainly been not the interethnic conflicts, but the politically or economically marked factors (the economic crisis, inflation, appointment to managerial posts based on the ethnicity of a person, income inequality between representatives of different ethnic origins, etc.). 
Discussion and Conclusion. Although interethnic relations in the Republic of Mordovia has almost never achieved an increased level of conflict, the republic's leadership was able to build an effective system for regulating them, which made it possible to minimize the degree of social and ethnic tension in society. The article may be useful to scientists and practitioners in the field of the development of interethnic relations and to all those interested in the issues of ethnosociology.

Keywords: ethnosociology, interethnic relations, interethnic conflicts, harmonization, region, Republic of Mordovia

Funding. The article was done with the financial support from the Russian Foundation for Basic Research and Government of the Republic of Mordovia as part of the scientific project No. 18-411-130014 'Ethnic Communities in a Multiethnic Region: Prospects for Assimilation and Dissimilation.'

Введение. Республика Мордовия является многонациональным и многоконфессиональным регионом, на территории которого веками проживают представители различных национальностей - русские, мордва (мокша и эрзя), татары и др. Несмотря на высокий декларируемый уровень межнациональной и межконфессиональной толерантности, а также полную поддержку политики федерального центра, республика была и остается объектом пристального внимания ряда исследователей социологов, политологов, этнологов, лингвистов и т. д.

Подобный интерес вызван, в первую очередь, процессами, связанными с фрагментацией этнических сообществ и реализацией их политических интересов. Наиболее значимыми событиями в региональной этнополитической сфере после распада Советского Союза эксперты называют раскол мордовского этнонационального движения ${ }^{1}$, конструирование идей об «этнокультурном геноциде» в отношении эрзян ${ }^{2}$, а также распространение деструктивных практик, связанных с проповедованием ислама ${ }^{3}$. Принципиально новым фактором межнациональных отношений стал наплыв беженцев из Украины, который необходимо рассматривать, скорее, со знаком плюс, а не минус 4 .

Цель статьи заключается в выявлении детерминант взаимодействия различных национальных сообществ на территории полиэтничного

${ }^{1}$ Шабаев Ю. П., Чарина А. М. Финно-угорский национализм и гражданская консолидация в России (этнополитический анализ): моногр. СПб., 2010. С. 60.

${ }^{2}$ Межэтнические и конфессиональные отношения в Приволжском федеральном округе: экспертный доклад / под ред. В. А. Тишкова, В. В. Степанова. М.; Ижевск: Ин-т компьютерных исследований, 2013. С. 58.

3 Этнополитическая ситуация в России и сопредельных государствах в 2014 году. Ежегодный доклад Сети этнологического мониторинга и раннего предупреждения конфликтов. В 2-х т. / под ред. В. А. Тишкова, В. В. Степанова. М.: ИЭА РАН, 2016. Т. 2. С. 418.

${ }^{4}$ Состояние межнациональных отношений в Республике Мордовия в 2016 г.: украинская диаспора / Е. А. Абрамова [и др.] // Социально-экономическое развитие Республики Мордовия в 2016 г.: сб. научн. трудов / под ред. В. В. Конакова. Саранск: Изд-во Мордов. ун-та, 2019. С. 318. 
региона на основании результатов многолетних мониторинговых исследований Научного центра социально-экономического мониторинга и Мордовского государственного университета им. Н. П. Огарева и определение перспектив развития межнациональных отношений в русле гармонизационного подхода.

Обзор литературы. Проблемное поле исследований в области межэтнических взаимодействий на сегодняшний день, как в мире, так и в нашей стране, представляется весьма широким [1, с. 88]. Существенную роль в этом сыграли глобализационные процессы, которые не только способствовали отказу от традиционной ассимиляционистской модели национальной интеграции, но и ослаблению регулирующей и консолидирующей роли национальных государств [2, с. 109; 3, с. 26].

В послевоенное время произошла либерализация иммиграционной политики, следствием которой стал постепенный переход многих стран к мультинациональному устройству, хотя мало кто из них принял федеративную структуру [4, с. 121 ; 5, с. 99]. Публичное признание и легитимация различных форм этнокультурного разнообразия стали частью масштабного проекта мультикультурализма, который был направлен на сохранение и развитие в отдельно взятых странах и мире в целом культурных различий, и основан на взаимном признании и уважении, межкультурном диалоге и обмене [6, с. 273; 7, с. 22].

Обрушившаяся на Европу неконтролируемая волна миграции достаточно быстро положила конец идеологии мультикультурализма, столкнув лицом к лицу различные, порой прямо противоположные, типы культур. Политические лидеры «классических национальных» западноевропейских государств (Великобритании, Германии, Франции и др.) в 2010-2011 гг. сделали ряд публичных заявлений, свидетельствующих о полном провале этой политики. Более того, структурный кризис, вызванный притоком большого числа приезжих, послужил одной из причин Брексита, инициированного в 2016 г. гражданами Великобритании. Как отмечают зарубежные исследователи, многие европейские страны сегодня захлестнула волна реакционного популизма, требующая восстановления мифического «золотого века» суверенных национальных государств, определяемых культурной и расовой однородностью [8;9].

Значительно более стрессоустойчивыми в этом отношении оказались государства, исторически объединявшие различные этнокультурные группы (Китай, Россия, США и др.). Национальные идентичности здесь поддерживаются на уровне национальных институтов и укрепляются при помощи системы образования, практик мемориализации и различных форм повседневной жизни, в которых подчеркивается особенность того или иного этноса (спортивные мероприятия, национальные песни, сим- 
волы на деньгах и др. $)^{5}[10 ; 11]$. Важную роль в этом играет тот факт, что многие из них в той или иной степени имеют опыт регулирования так называемого национального вопроса, предлагая отличающиеся друг от друга концепции, начиная от различных вариаций примордиализма (Ю. В. Бромлей ${ }^{6}$, Л. Н. Гумилев ${ }^{7}$, С. М. Широкогородов ${ }^{8}$ ) и заканчивая конструктивизмом (Б. Андерсон ${ }^{9}$, П. Бурдье [12], В. А. Тишков ${ }^{10}$ ). Не менее продуктивными представляются и предложенные преимущественно североамериканскими исследователями метафоричные описания современных мультинациональных обществ - плавильного котла ${ }^{11}$, салатницы ${ }^{12}$ или культурной мозаики ${ }^{13}$ [13], которые частично и с определенными оговорками могут быть применены и к современному российскому обществу ${ }^{14}$.

Нельзя сбрасывать со счетов и тот факт, что именно в исторически мультикультурных государствах произошла институциализация исследований в области межэтнических взаимодействий, появление самостоятельного академического направления. Как правило, в североамериканских и некоторых европейских университетах читаются курсы по социологии расовых и межэтнических отношений, на постсоветском пространстве преподается этносоциология ${ }^{15}$. В то же время нельзя не отметить и существенные сдвиги в западноевропейской социальной мысли, откуда в последние годы пришли такие концепты, как «управление идентичностью» и «политика идентичности» [14].

Теоретической рамкой настоящего исследования выступает гармонизационная парадигма, впервые предложенная в рамках мордовской

${ }^{5}$ Billig M. Banal Nationalism, London: Sage, 1995. 208 p.

${ }^{6}$ Бромлей Ю. В. Очерки теории этноса. М.: Изд-во ЛКИ, 2008. 440 с.

${ }^{7}$ Гумилев Л. Н. Этносфера: история людей и история природы. М.: Прогресс, 1993. 544 с.

${ }^{8}$ Широкогоров С. М. Этнос: Исследование основных принципов изменения этнических и этнографических явлений. Владивосток: Изд-во Дальневосточ. ун-та. 2002. 148 с.

${ }_{9}^{9}$ Андерсон Б. Воображаемые сообщества. М.: КАНОН-Пресс-Ц, Кучково поле, 2001. $135 \mathrm{c}$.

10 Тишков В. А. Реквием по этносу: исследования по социально-культурной антропологии. М.: Наука, 2003. 544 с.

${ }^{11}$ Turner F. J. The Frontier in American History. New York: Henry Holt, 1921. 375 p.

12 Schmidt A. J. The Menace of Multiculturalism: Trojan Horse in America. Santa Barbara: Praeger, 1997. 232 p.; Хантингтон С. Кто мы? Вызовы американской национальной идентичности. М.: АСТ, 2008. 640 с.

${ }^{13}$ Gibbon J. M. Canadian Mosaic: The Making of a Northern Nation. Toronto: McClelland \& Stewart Limited, 1938. 455 p.

14 Тишков В. А. Российский народ: история и смысл национального самосознания. М.: Наука, 2013. 649 с.

15 Воецкая Т. В. Этносоциология и перспективы ее исследования // Культура, личность, общество в современном мире: методология, опыт эмпирического исследования. [XI Международная конференция, Екатеринбург, 19-20 марта 2008 г.]: в 5 частях. Екатеринбург: [Факультет политологии и социологии Уральского государственного университета]. 2008. Ч. 1. С. 47-50. 
школы социологии профессором А. И. Сухаревым. Под гармонизацией понимается динамическая характеристика состояния национальных отношений и процесс, нацеленный на достижение гармонии в отношениях национальных сообществ, а также модель национальных отношений, предполагающая сохранение идентичности национальных сообществ при их интеграции в полиэтническое сообщество на основе равного партнерства. Направление строится на диалектическом подходе к цивилизационному устройству, предполагающем реализацию принципа приоритетов, позволяющего более гибко и мягко сочетать интересы и полномочия федерального центра и субъектов федерации, опираться на волеизъявление составляющих их народов, т. е. стать потребностью и устремлением гражданского общества ${ }^{16}$. Помимо А. И. Сухарева разработкой и последующим его развитием занимались О. А. Богатова [15], Е. И. Долгаева [16], В. В. Козин [17] и др.

Гармонизационная парадигма представляет собой советскую вариацию североамериканской концепции «салатницы», но наполненную собственными аутентичными «ингредиентами». Данное направление нашло свое отражение в ряде принимаемых в Республике Мордовия документов, направленных на развитие межнациональных отношений, а результаты проводимых регулярных социологических замеров позволили снизить уровень социальной и этнической напряженности в регионе. Гармонизация органично сочетается с этническим патриотизмом и общечеловеческим интернационализмом, взаимным уважением национального достоинства людей на основе признания равноправия и неповторимой самоценности каждого народа, каждого этноса. Признавая примордиалистскую трактовку национальных сообществ как объединения людей «по крови» с неизменными признаками, она вносит элементы конструктивистской и инструменталистской теорий (в частности, заметная роль при регулировании национальных отношений и формирования образа нации отводится региональной власти).

Материалы и методы. В настоящее время в Республике Мордовия проживают 796 тыс. чел., из них 444 тыс. чел. - русские, 333 тыс. мордва (мокша и эрзя), 43 тыс. чел. - татары. Несмотря на то, что социология, этнография в регионе начали развиваться еще с середины 20-х гг. XX в. [18], традиция проведения регулярных обследований населения, в том числе и по вопросам этносоциального характера, была положена в 1991 г. в связи с созданием при Мордовском государственном университете НИИ регионологии. Основной задачей института было осуществление научной деятельности, направленной на координацию и проведение фундаментальных и прикладных исследований по

${ }^{16}$ Сухарев А. И. Основы регионологии. Саранск: НИИ регионологии, 1996. 120 с. 
проблемам комплексного социально-экономического развития региона и государственной региональной политики. Заметное место в этой работе занимала этносоциологическая проблематика.

На протяжении 20 с лишним лет НИИ регионологии при Мордовском государственном университете им. Н. П. Огарева, а затем Научным центром социально-экономического мониторинга проводилось комплексное социологическое исследование «Резервы гармонизации социальных отношений в Мордовии» (1994 г., 1995 г., 1999 г., 2004 г., 2008 г., 2014 г.). В анкете всегда присутствовал блок вопросов, посвященный межнациональным отношениям: в частности, содержались и параметры для оценки доли граждан, положительно оценивающих состояние межнациональных отношений, и уровень толерантного отношения к представителям другой национальности, которые впоследствии стали ключевыми индикаторами реализации ФЦП «Укрепление единства российской нации и этнокультурное развитие народов России (2014-2020 годы)» [19].

Объем выборочной совокупности в различные годы варьировался от 1,5 до 2,5 тыс. чел. Выборка квотная, репрезентирует население региона по полу, возрасту и территориальному признаку. Поскольку она является неслучайной, то строго оценить ошибку выборки не представляется возможным. Тем не менее погрешность случайной выборки того же размера не превышала бы $3,4 \%$.

В исследовании были использованы общенаучные методы анализа: институциональный, сравнительный и естественно-исторический.

Результаты исследования. В 1994 г. в качестве основной причины, порождающей противоречия в межнациональных отношениях, респонденты в первую очередь указали экономический кризис и инфляцию и только во вторую - проявление неравенства одних наций по отношению к другим ${ }^{17}$. Также была выявлена проблема, весьма характерная для этого периода развития российского общества, а именно: нечеткость в распределении функций и полномочий между органами исполнительной и законодательной власти. Демонтируя административно-командную систему государственного управления, в центре которой находилась КПСС, формирование новой системы осуществлялось методом проб и ошибок, поэтому законодательная и исполнительная ветви власти еще долгое время «перетягивали одеяло на себя». Окончательно проблема выстраивания вертикали власти была разрешена только в начале 2000-х гг.

Респонденты указали на невнимательность органов власти к национальным нуждам и интересам трудящихся, подбор руководящих кадров по признакам национальности, родства, землячества и т. п., непрофессио-

17 Этнополитические и этнокультурные отношения // Резервы гармонизации социальных отношений в Мордовии: Итоги анкетного опроса // НИИ регионологии. Саранск, 1994. C. $41-45$. 
нальное решение национальных проблем. На основе анализа данных социологического исследования сделан вывод о слабой организации информирования населения республики относительно состояния межнациональных отношений, законодательных актов по их гармонизации, решения проблем в межнациональных отношениях.

Значительного внимания в тот период заслуживало отношение населения республики к государственному статусу Мордовии. В средствах массовой информации активно обсуждалась возможность изменения государственного статуса республики. Представители в основном творческой национальной (мордовской - активисты культурно-просветительского общества «Масторава») интеллигенции еще с начала 90-х гг. ратовали за принятие Мордовией декларации о государственном суверенитете ${ }^{18}$. Это был весьма популярный тренд того времени, дань которому отдали многие субъекты Российской Федерации. В политологии и политической социологии это явление в последствии получило название «парад суверенитетов». Большого значения подобная псевдосуверенизация в процессе государственного строительства не имела, но тешила самолюбие региональных властей.

В противоположность этой точки зрения активистами культурнопросветительского общества «Русь» была высказана идея о ликвидации национально-государственного статуса Мордовии и преобразовании ее в Саранскую область. Обосновывалось это отсутствием на территории республики природных богатств, незначительным количеством населения (на тот период - чуть более 800 тыс. чел.), параличом промышленного и сельскохозяйственного комплексов республики, ее дотационностью и т. п. ${ }^{19}$. Также высказывалась не менее экзотическая идея о разделении Мордовии на Мокшанскую и Эрзянскую республики ${ }^{20}$.

Естественно, большинство респондентов высказались за сохранение национально-государственного статуса республики, наиболее активными в этом вопросе были респонденты мордовской национальности. Из вышесказанного следует наличие в тот период относительно жесткого идеологического противостояния между интеллигенцией республики (русской, мордовской и татарской) и некоторой напряженности в межнациональных отношениях среди населения и конфликтогенного потенциала, пока не переходящего в открытое столкновение. Республика, как и вся страна, «шла по лезвию бритвы». При этом активность национальных общественно-культурных организаций не прибавляла

${ }^{18}$ Юрчёнков В. А. Масторава: основные тенденции развития // Этнографическое обозрение. 1994. № 1. С. 15-23.

19 Жерехов О., Дроздов Н. Саранская область: представляем проект возможного административного устройства // Вечерний Саранск. 1994. 10-16 февр.

${ }^{20}$ Нуянзин А. Голосую за Эрзянскую республику // Советская Мордовия. 1991. 12 ноября. 
им популярности. Большая доля опрошенных вообще не знала об их существовании, а среди осведомленных 43 \% высказали мнение о том, что их деятельность скорее не является стабилизирующим фактором развития межнациональных отношений в республике, а 39 \% уклонились от ответа. Это свидетельствует о неоднозначном отношении населения республики к деятельности подобных структур.

По мнению опрошенных, программы развития национальной культуры народов республики должны финансироваться из всех возможных источников: федерального и местного бюджетов и добровольных пожертвований. При этом респонденты высказали обеспокоенность снижением функциональности национальных традиций, обычаев и подчеркивали необходимость возрождения традиционных черт национальной культуры.

В процессе исследования было выявлено отношение населения республики к беженцам и вынужденным переселенцам - русским, мордве, татарам и представителям других национальностей из стран постсоветского пространства: Казахстан, Закавказье, Средняя Азия, Молдова, Прибалтика. Они представляли собой довольно высококвалифицированных специалистов промышленности, строительства, здравоохранения, образования и т. д., вынужденных покинуть место своего проживания из-за межнациональных конфликтов и их выдавливания коренным населением. Исследование показало, что в условиях растущей безработицы в республике треть населения восприняла переселенцев настороженно.

В процессе обсуждения проекта закона «О языках в республике Мордовия» ставился вопрос о необходимости знания одного из мордовских языков в качестве квалификационного требования при занятии административных управленческих должностей (Председателя Совета Министров, Председателя Верховного Совета, руководителя министерства, главы администрации, руководителя органа образования, культуры). Подавляющее большинство опрошенных посчитали знание мордовских языков не обязательным, а в качестве квалификационного требования назвали профессионализм, опыт работы и порядочность.

Исследовательский проект «Резервы гармонизации социальных отношений в Мордовии» изначально задумывался как комплексное и долгосрочное исследование. Оно предусматривало использование унифицированной методики, структуры (с незначительными изменениями и корректировками), что в перспективе делало его онтологически состоявшимся и гносеологически значимым. Впоследствии это и было достигнуто.

Аналогичное (повторное) исследование было проведено в 1995 г. Столь небольшой промежуток времени между исследованиями объясним стремительной динамикой общественно-политических процессов в стране вообще и Мордовии в частности. Возникла необходимость 
некоторой корректировки методики. Был отмечен определенный потенциал напряженности в межнациональных отношениях, но особенностью этнополитической ситуации в республике являлось то, что взаимодействие населяющих ее этносов не обрело характера противостояния, оно базировалось на общем поиске выхода из кризисных процессов в экономике и социальной сфере ${ }^{21}$.

Как и год назад, основными причинами, порождающими противоречия в области межнациональных отношений, респонденты назвали экономический кризис, инфляцию, этнические стереотипы, отсутствие взаимодействия между различными органами государственной власти. Также была отмечена крайне низкая осведомленность населения о деятельности национальных культурно-просветительских организаций, а знающие о них крайне неоднозначно оценили их деятельность ${ }^{22}$. Также категорично респонденты высказались за сохранение государственного статуса республики. Характерно то, что так ответили 83 \% мокшан и эрзян, что является ярчайшим доказательством абсолютной неадекватности рассуждений лидеров национального движения того периода объективным реалиям.

Подчеркивалась необходимость возрождения фундаментальных основ национальной культуры с использованием различных механизмов. Назывались разработка и принятие программы развития этносов Мордовии (в 1997 г. она была разработана НИИ регионологии, но в силу ряда причин так и не была принята Правительством Республики Мордовия) ${ }^{23}$, изучение национальных языков в учебных и воспитательных учреждениях, активизация деятельности республиканского Центра культуры и национальных обществ, принятие закона «О языках» и т. д.

Опрос 1996 г. подтвердил правильность выбранного комплексного подхода к анализу социально-экономического и духовного развития региона. Однако опрос решал еще одну важную задачу - изучение электоральных предпочтений населения республики. Приближалось событие, определившее на многие годы вектор развития страны - выборы Президента Российской Федерации 1996 г. Учитывая тот факт, что Мордовия того периода относилась к так называемому красному поясу, т. е. региону, где сильны левые (прокоммунистические) настроения, то практическое значение знания электоральных предпочтений трудно было переоценить.

${ }^{21}$ Специфика этнополитической ситуации в Мордовии // Резервы гармонизации социальных отношений в Мордовии: Вып. II. Итоги анкетного опроса в 1995 г. / НИИ регионологии. Саранск, 1996. С. 41-42.

22 Особенности межнациональных отношений в Республике Мордовия // Там же. C. $35-38$.

${ }^{23}$ Программа национального развития и межнационального сотрудничества народов Республики Мордовия. Саранск, 1997. 300 с. 
На вопрос: «Какие политические партии (движения) способны улучшить положение в стране в случае прихода их к власти?» $17 \%$ назвали Коммунистическую партию РФ, 8 \% - «Наш дом - Россия» и 7 \% ЛДПР, $29 \%$ - таких партий пока не знают, а $15 \%$ посчитали, что таких партий нет ${ }^{24}$. С одной стороны, опрос показал некоторую неопределенность электоральных предпочтений, с другой - выявил двукратное преимущество коммунистических идей по сравнению с «демократическими». Выборы подтвердили правильность сделанного прогноза: в первом туре с большим отрывом победила КПРФ. Только во втором туре благодаря использованию всех механизмов административного ресурса разница между КПРФ и «Наш дом - Россия» была нивелирована.

Следующий опрос был проведен в 1999 г. Он также характеризовался комплексностью и масштабностью. Анкета включала в себя блоки вопросов, посвященных здоровью населения и его отношению к окружающей среде, социально-экономическим проблемам регионального социума, социальному самочувствию различных групп населения, его политическим предпочтениям, отношению к различным социальным ценностям и межнациональным отношениям. Во всех опросах структура выборочной совокупности полностью соответствовала не только демографическому, социальному, но и этническому составу населения республики.

Именно это исследование впервые за весь постсоветский период отметило стабильный, добрососедский характер межнациональных отношений в республике, основывающихся на равноправном партнерстве и высокой степени интегрированности этносов в общество 25 . Указывалось и на то, что существующий в республике паритет в сфере межнациональных отношений не исключает проявления межэтнической конкуренции. В качестве конфликтогенных факторов снова были названы экономический кризис, неуважение к языку, культуре людей других национальностей, назначение на руководящие должности по национальному признаку, неравенство доходов между представителями различных национальностей.

Опрос не выявил различий в оценке состояния межнациональных отношений в Мордовии различными этническими группами, но причины межнациональных противоречий ими характеризовались по-разному. Русские в качестве таковой на второе место (после экономического кризиса) поставили назначение на должности по национальному признаку, а мордва и татары - неуважение к языку, культуре людей других

${ }^{24}$ Резервы гармонизации социальных отношений в Мордовии: Вып. II. Итоги анкетного опроса в 1995 г. Саранск, 1996. С. 77.

${ }^{25}$ Богатова О. А. Межэтнические отношения: факторы конфликта и согласия // Резервы гармонизации социальных отношений в Мордовии: Вып. III. Итоги анкетного опроса в 1999 г. / НИИ регионологии. Саранск, 2000. С. 118-139. 
национальностей. Исследование показало, что наметившаяся в республике социально-экономическая стратификация не дублирует этническую структуру населения. Социально-профессиональный состав населения не дифференцирован. Уровень жизни и экономическое расслоение у различных этносов одинаковы, за исключением татар. Оценивая свое материальное положение, они в большей мере, чем другие, назвали свой доход средним, а не низким, как большинство представителей других национальностей.

Анализ ответов на вопрос относительно отмены в российском паспорте графы «национальность» выявил преобладание в массовом сознании того периода «этнической» концепции нации над «гражданской». Вместе с тем исследование показало, что среди факторов, разъединяющих людей, этничность играет второстепенную роль по сравнению с экономическим и профессиональным статусом.

Несмотря на некоторые этномобилизационные процессы в Мордовии, повышения статуса мордовской культуры не произошло ${ }^{26}$, что вызывало озабоченность у представителей титульной нации. Однако региональная национальная политика должна учитывать не только озабоченность за состояние мордовской культуры, но и обеспокоенность русского населения республики возможностью этнократических проявлений в различных сфеpax социальной жизни. Экспертный опрос, также проводимый в 2002 г., подтвердил правильность сделанных ранее выводов.

На II съезде мордовского народа (март 1995 г.) произошло окончательное размежевание позиций относительно направлений развития мордовского народа и методов достижения поставленных целей. На III съезде (октябрь 1999 г.) принципиальные отличия в подходах и трактовках событий только усилились. Общественное мордовское национально-культурное движение разделилось на умеренное, конструктивное и радикальное крыло.

Особое место в популяризации идей этнического радикализма принадлежало печатному органу Фонда возрождения эрзянского народа им. А. П. Рябова газете «Эрзянь Мастор» («Мать Земля»), издававшейся с 1994 г. Объективность и научность высказываемых на страницах газеты положений могут стать предметом отдельного рассмотрения, хотя палитра предлагаемых корреспондентами газеты идей не отличалась широтой и оригинальностью. Из номера в номер, из года в год не доказывались, а утверждались геноцид русским государством эрзянского народа, отсутствие мордвы как этноса и существование двух субэтнических групп (мокши и эрзи), существование родственных, но разных народов - мок-

${ }^{26}$ Трофимова Г. А. Социальная и культурная дистанции в представлении этнических групп // Там же. С. 139-150. 
ши и эрзи. Ничего более оригинального псевдообщественные деятели придумать были не в состоянии ${ }^{27}$.

Исследование 2004 г. также содержало блок вопросов, касающихся межнациональных отношений. Данные опроса не выявили политизации этничности, проблемы во взаимоотношениях людей различной национальности проявлялись на бытовом уровне. К факторам, определяющим потенциальную межнациональную напряженность, были опять отнесены сложная ситуация в экономике республики, неуважение к языку, культуре людей других национальностей и исторически сложившиеся стереотипы и предубеждения в отношении людей других национальностей ${ }^{28}$. Культура, образование и средства массовой информации были названы сферами проявления этнических проблем на институциональном уровне.

Не было выявлено существенных различий в ценностных предпочтениях людей различных национальностей. Представителей разных национальностей волновали сходные проблемы - рост цен, тяжелое материальное положение, социальная несправедливость и т. д. Тем не менее татарам чаще, чем русским и мордве, приходилось сталкиваться в повседневной жизни с неприязненным отношением к людям своей национальности. Почти у всего населения республики было отмечено позитивное отношение к своей этнической принадлежности. Вместе с тем «большинство опрошенных не придавали собственной этничности большого значения» ${ }^{29}$.

В этот период Республика Мордовия начинает характеризоваться как стабильный регион в контексте межнациональных и межконфессиональных отношений. Однако даже в таком стабильном регионе существуют предпосылки для межнациональной напряженности. Они коренятся в культурных отличиях, необходимости сохранения этнокультурной стабильности, с одной стороны, и интеграции в поликультурное общество - с другой.

В исследовании 2005 г. анализировалась проблема оценки представителями различных национальностей республики своего социального статуса, финансового положения, удовлетворенности различными сторонами своей жизни ${ }^{30}$. Существенных отличий в оценке своего материального

${ }^{27}$ Козин В. В. Эволюция идей этнополитической оппозиции // Культура и проблемы межэтнической коммуникации: материалы IV междунар. науч.-практ. конф. по региональной культуре (21-23 мая 2002 г.). Н. Новгород: НГЛУ им. Н. А. Добролюбова. 2002. С. 116-119.

28 Богатова О. А. Межэтнические отношения // Резервы гармонизации социальных отношений в Мордовии: Вып. IV / НИИ регионологии. Саранск, 2004. С. 139-144.

29 Богатова О. А. Гармонизация межэтнических отношений в Мордовии // Резервы гармонизации социальных отношений в Мордовии: Вып. V. Итоги анкет опроса в 2005 г. $/$ НИИ регионологии; науч. ред. проф. А. И. Сухарев; сост.: С. В. Полутин, Е. А. Абрамова, Н. Н. Азисова. Саранск, 2006. С. 44-51.

${ }^{30}$ Факторы и механизмы гармонизации социальных отношений в Республике Мордовия: моногр. / науч. ред. проф. А. И. Сухарев; отв. за выпуск О. А. Богатова; Науч. центр соц.-экон. мониторинга Республики Мордовия. Саранск, 2009. 240 с. 
положения у представителей различных национальностей выявлено не было. Представительство различных этнических групп в органах власти, по уровню жизни, доходам, сферам занятости и уровню образования одинаково, что говорит о сбалансированности этносоциальной структуры Мордовии.

В качестве дополнительного источника дохода жители республики указывали личные подсобные хозяйства, при этом русские в наименьшей степени использовали их в качестве дополнительного источника дохода. Причина такому явлению заключается в том, что русские в Мордовии являются наиболее урбанизированными. За исключением татар, уровень доходов и экономическое положение различных национальностей Мордовии одинаков. У татар больше людей со средними и высокими доходами по сравнению с низкими. Большее значение респонденты мордовской национальности придавали безработице и росту цен, татары - росту цен и алкоголизму. Респонденты татарской национальности несколько чаще представителей других национальностей (8 \%) указали на ухудшение межнациональных отношений в республике. Это «подтверждает выявленную в предыдущих исследованиях тенденцию к самоидентификации татар в качестве этнического меньшинства» ${ }^{31}$. В целом межнациональные отношения оценивались как стабильные и добрососедские. Как и в предыдущих исследованиях отмечалась латентная межнациональная напряженность на бытовом уровне.

Опрос 2008 г. проводился сотрудниками Научного центра социальноэкономического мониторинга Республики Мордовия ${ }^{32}$. Объем выборочной совокупности составил 1 тыс. чел. Как и в предыдущих исследованиях, значительных различий в уровне доходов и уровне жизни, оценке своего материального благосостояния и социального самочувствия (за исключением татар) выявлено не было ${ }^{33}$. Также подтвердился стабильный и добрососедский характер межнациональных отношений. В некоторых муниципальных районах республики были отмечены столкновения местного населения с трудовыми мигрантами на бытовом уровне.

Результаты исследования выявили снижение внимания населения республики к межэтническим и культурным различиям как показателям латентности межнациональных отношений. В процессе опроса респон-

31 Мотькин В. Н. Социальный портрет этносов Мордовии // Факторы и механизмы гармонизации социальных отношений в Республике Мордовия: моногр. Саранск, 2009. C. $141-145$.

${ }^{32}$ Богатова О. А. Гармонизация межэтнических отношений в Республике Мордовия // Там же. С. 147.

33 Состояние межэтнических и межконфессиональных отношений в Республике Мордовия. Аналитическая записка / авт. кол.: В. В. Конаков (ответственный редактор), О. А. Богатова, Н. В. Ивашкина, Л. В. Калачина, В. В. Козин (ответственный за выпуск) и др. / Материалы НИИ регионологии ФГОБОУ ВО «МГУ им. Н. П. Огарева». Саранск, 2014.36 с. 
денты больше акцентировали свое внимание на различиях по доходам, между населением и властью, политиками, указывали на социально-классовые различия, возрастные, по месту жительства (город - село). Как уже было отмечено, «доля респондентов, придающих большее значение этническим различиям, на порядок меньше, чем тех, кто считает наиболее важным различия между богатыми, бедными и средними слоями (по доходам)» [20].

В 2014 г. НИИ регионологии Мордовского государственного университета по заказу Министерства по национальной политике Республики Мордовия провело социологическое исследование «Состояние межэтнических и межконфессиональных отношений в Республике Мордовия» [21]. Исследование было направлено на оценку состояния и динамики межэтнических отношений в регионе по параметрам стабильности и напряженности на межличностном, межгрупповом и институциональном уровнях, а также конкретизацию сфер проявления межэтнической напряженности в республике. В рамках данной работы подтвердилось, что межэтнические отношения между этническими группами населения в Республике Мордовия носят стабильный (без заметных изменений) и добрососедский (без напряженности) характер. В идеологии этнокультурной политики преобладают установки на межэтническое сотрудничество, выражающиеся в гармоничном сочетании этнической, региональной и общегражданской российской идентичности (самосознания). Основными сферами проявления межэтнической напряженности являются бытовая и экономическая сферы, а также средства массовой информации. Причины проявления межэтнической напряженности в Республике Мордовия кроются в исторически сложившихся предрассудках и предубеждениях, неуважении к языку и культуре представителей других национальностей, ситуации на рынке труда.

Обсуждение и заключение. Этносоциологические исследования в Мордовии имеют не только давние традиции, но и собственную научную школу, в основе которой - гармонизационная парадигма, впервые предложенная профессором А. И. Сухаревым. Результаты научных изысканий стали базисом при реализации национальной политики в регионе, направленной не просто на сглаживание противоречий между представителями различных национальных сообществ, а на формирование толерантного мировоззрения, характеризующегося низким уровнем социальной напряженности в целом. На эмпирическом уровне было доказано, что в контексте региональной специфики людей чаще всего разъединяют не национальные, а политические и экономические основания.

Понятно, что метод опроса субъективен и представляет собой определенный «срез» общественного мнения, а механическая сумма субъективных мнений не дает объективного знания. Чтобы снизить вероятность 
ошибки, исследователи сопоставляли данные, полученные в результате опроса, с данными официальной статистики. Например, когда речь шла об определении уровня материальной обеспеченности людей, отнесения людей к тому или иному социальному слою и т. д. При сопоставлении субъективных и объективных значений выяснялось, что их разброс не превышал 2-3 \%. Это говорит о качественно разработанном инструментарии и эффективности выбранной методики.

Впрочем, нельзя не отметить и того факта, что постепенно практика использования количественной методологии дополняется и результатами качественных исследований (например, экспертным опросом, дискурсанализом и др. ${ }^{34}$ [22]. Новый вектор исследований задали проведенные в последние годы на территории региона мегасобытия - Кубок мира по спортивной ходьбе (2012 г.), Тысячелетие единения мордовского народа с народами Российского Государства (2012 г.), Чемпионат мира по футболу (2018 г.), благодаря которым сформировался определенный национально маркированный бренд, повысивший узнаваемость Мордовии в России и мире [23; 24]. В первую очередь, это исследования на стыке этносоциологии и экономической социологии, направленные на выявление туристской привлекательности территорий [25; 26], возможностей принимающих национальных сообществ и проблем миграции ${ }^{35}$, влияния материальных факторов на социальное самочувствие населения [27] и др. Продолжает активно изучаться и политическая составляющая национального строительства [28; 29]. Таким образом, можно констатировать, что перспективы развития этносоциологических исследований в Республике Мордовия являются благоприятными, при этом они были и остаются одним из флагманских направлений социологического знания в регионе.

Материалы данной статьи будут полезны представителям органов государственной власти, ученым, аспирантам и студентам, занимающимся проблемами межнациональных отношений, и всем, кто интересуется проблемами этносоциологии вообще и межэтническими отношениями в регионе в частности.

${ }^{34}$ Козин В. В., Пантюшин А. И. Развитие религиозного туризма в Мордовии // Развитие социального пространства России: новые вызовы и перспективы: VII Сухаревские чтения: материалы Всерос. науч.-практ. конф., г. Саранск, 30 ноября 2017 г. Саранск, 2018. C. $80-84$.

${ }^{35}$ Калачина О. С., Ефимова А. И. Миграционные процессы в Республике Мордовия (по данным социологического опроса) / Социологический альманах. Вып. 9: «Трансформация современного общества: вызовы и перспективы»: Материалы VIII Орловских социологических чтений 9 декабря 2016 г. / под общ. ред. П. А. Меркулова, Н. В. Проказиной. Орел: Из-во Среднерусск. ин-та управления - филиала РАНХиГС, 2017. С. 117-120; Кирдяшкина Т. И. Мотивация миграционного поведения населения Республики Мордовия // Региональная дифференциация и консолидация социального пространства России: реалии и новые вызовы: V Сухаревские чтения: материалы Всерос. науч.-практ. конф. с междунар. участием, г. Саранск, 15-16 октября 2015 г. Саранск, 2015. С. 187-189. 


\section{СПИСОК ИСПОЛЬЗОВАННЫХ ИСТОЧНИКОВ}

1. Арутюнян Ю. В., Дробижева Л. М. Этносоциология перед вызовами времени // Социологические исследования. 2008. № 7. C. 85-94. URL: https://www. isras.ru/socis_2008 7.html (дата обращения: 20.06.2019).

2. Зайка К. В. Модели национальной интеграции в Германии, Франции, Великобритании, США и Канаде в послевоенный период в условиях возрастающих иммиграционных потоков // Comparative politics. 2014. № 3. C. 109-127. DOI: https://doi.org/10.18611/2221-3279-2014-5-3(17)-109-127

3. Черныш М. Ф. Теоретико-методологические основы изучения причин межэтнической напряженности // Социологический журнал. 2016. № 4. С. 25-41. DOI: https://doi.org/10.19181/socjour.2016.22.4.4806

4. Ян Э. Государственное и этническое понимание нации: противоречия и сходство // Полис. Политические исследования. 2000. № 1. С. 114-123. URL: https://www.politstudies.ru/article/2697 (дата обращения: 20.06.2019).

5. Антонова В. К., Карпова Г. Г. Политика мультикультурализма на российской почве: есть ли перспективы? // Журнал исследований социальной политики. 2011. T. 9, № 1. C. 99-128. URL: https://jsps.hse.ru/index.php/jsps/article/view/3534 (дата обращения: 20.06.2019).

6. Суконкина Т. Н. Формирование мультикультурного общества в регионе // Регионология. 2010. № 2. С. 265-274. URL: http://regionsar.ru/ru/node/520 (дата обращения: 20.06.2019).

7. Кивисто П. Теперь мы все действительно мультикультуралисты // Журнал социологии и социальной антропологии. 2016. Т. ХІХ, № 2. С. 19-45. URL: http://jourssa.ru/sites/all/files/volumes/2016_2/Kivisto_2016_2.pdf (дата обращения: 20.06.2019).

8. Virdee S., McGeever B. Racism, Crisis, Brexit // Ethnic and Racial Studies. 2018. Vol. 41, issue 10. Pp. 1802-1819. DOI: https://doi.org/10.1080/01419870.2 017.1361544

9. Benson M., Lewis C. Brexit, British People of Colour in the EU-27 and everyday racism in Britain and Europe // Ethnic and Racial Studies. 2019. Vol. 42, issue 13. Pp. 2211-2228. DOI: https://doi.org/10.1080/01419870.2019.1599134

10. Brubaker R., Feischmidt M., Fox J., Grancea L. Nationalist Politics and Everyday Ethnicity in a Transylvanian Town. Princeton: Princeton University Press, 2008. 504 p. DOI: https://doi.org/10.2307/j.ctv346r9g

11. Gellner E. Nations and Nationalism, New York: Cornell University Press, 2009. 152 p. URL: https://www.amazon.com/Nations-Nationalism-New-Perspectives-Past/ dp/0801475007 (дата обращения: 20.06.2019).

12. Бурдье П. Идентичность и репрезентация: элементы критической рефлексии идеи «региона» // Ab Imperio. 2002. № 3. C. 45-60. URL: https://elibrary. $\mathrm{ru} / \mathrm{item} . \mathrm{asp}$ ? id=17958419 (дата обращения: 20.06.2019).

13. Kelley N., Trebilcock M. J. The Making of the Mosaic: A History of Canadian Immigration Policy. Toronto: University of Toronto Press, 2010. 689 p. URL: https:// utorontopress.com/us/the-making-of-the-mosaic-4 (дата обращения: 20.06.2019). 
14. Богатова О. А. Социальные технологии управления республиканской и российской идентичностью в оценках населения Республики Мордовия: опыт качественного социологического исследования // Вестник Удмуртского университета. Социология. Политология. Международные отношения. 2017. Т. 1, вып. 1. C. 54-70. URL: http://ru.sociology.vestnik.udsu.ru/archive/show/7-2017-1-6 (дата обращения: 20.06.2019).

15. Богатова О. А. Механизмы гармонизации межэтнических отношений в региональном социуме // Регионология. 2003-2004. № 4/1. С. 169-182. URL: http://regionsar.ru/ru/node/1650 (дата обращения: 20.06.2019).

16. Долгаева Е. И., Капкаева Н. К. Отношение православной и мусульманской молодежи к социальным практикам, противоречащим нормам религиозной морали // Регионология. 2015. № 2. C. 144-151. URL: http://regionsar.ru/node/1385 (дата обращения: 20.06.2019).

17. Козин В. В., Курков В. М. Развитие этносоциологических исследований в Мордовии // Регионология. 2004. № 4. С. 190-201. URL: http://regionsar.ru/ru/ node/1650 (дата обращения: 20.06.2019).

18. Сухарев А. И., Козин В. В., Сидоркина В. М. Социология в Мордовии: становление и направления исследований // Социологические исследования. 2006. № 8. C. 35-42. URL: https://cyberleninka.ru/article/n/stanovlenie-i-razvitie-sotsiologii-v-mordovii (дата обращения: 20.06.2019).

19. Хайкин С. Р., Бережкова С. Б. Социологический мониторинг межнациональных и межконфессиональных отношений Федерального агентства по делам национальностей // Мониторинг общественного мнения: экономические и социальные перемены. 2016. № 5. C. 97-110. DOI: https://doi.org/10.14515/ monitoring.2016.5.07

20. Ушкин С. Г. Тональность дискурсов национальной (этнокультурной) политики в средствах массовой информации Приволжского федерального округа // Регионология. 2014. № 2. C. 159-169. URL: http://regionsar.ru/ru/node/1275 (дата обращения: 20.06.2019).

21. Богатова О. А., Чиркова О. Н. Формирование этнокультурного образа Республики Мордовия в региональном брендинге // Регионология. 2013. № 3. C. 68-75. URL: http://regionsar.ru/ru/node/1145 (дата обращения: 20.06.2019).

22. Чиркова О. Н. Влияние имиджевой политики и этнокультурного брендинга региона на формирование и развитие региональной идентичности // Регионология. 2016. № 3. C. 88-105. URL: https://regionsar.ru/ru/node/1474 (дата обращения: 20.06.2019).

23. Козин В. В., Кирдяшкина Т. И. Мониторинг посещаемости объектов этнического туризма в Республике Мордовия в 2017 г. // Финно-угорский мир. 2018. T. 10, № 3. C. 86-94. DOI: https://doi.org/10.15507/2076-2577.010.2018.03.086-094

24. Фофанова К. В., Борисов Д. М. Сетевой ресурс как фактор интеграции иностранных трудовых мигрантов в региональный социум // Журнал исследований социальной политики. 2013. Т. 11, № 2. С. 189-206. URL: https://jsps.hse. ru/article/view/3438 (дата обращения: 20.06.2019).

25. Козин В. В. Взаимоотношения трудовых мигрантов и принимающего сообщества // Социальное время. 2015. № 4. С. 93-97. URL: URL: https://www. volgatech.net/sociotime/archive/ (дата обращения: 20.06.2019). 
26. Сычев А. А., Коваль Е. А., Жадунова Н. В. Проблема классификации языка вражды в отношении мигрантов (на примере Республики Мордовия) // Регионология. 2018. Т. 26, № 4. С. 798-815. DOI: https://doi.org/10.15507/24131407.105.026.201804.798-815

27. Вишнякова Н. А. Как живешь, Мордовия? Влияние материальных и нематериальных факторов на социальное самочувствие населения // Российский хороший журнал. 2019. № 1. С. 43-49. URL: http://rgoodj.ru/wp-content/ uploads/2019/06/vishnyakova_na_n1.pdf (дата обращения: 20.06.2019).

28. Бахлов И. В., Бахлова О. В. Концептуализация понятия «нациестроительство» в политологическом дискурсе // Социально-политические науки. 2018. № 2. C. 26-29. URL: http://urvak.ru/articles/sotsia-vypusk-2-kontseptualizatsiya-ponyatiya-nats/ (дата обращения: 20.06.2019).

29. Бахлова О. В., Бахлов И. В. Государственная политика нациестроительства в России: содержание, институты и механизмы // Регионология. 2019. Т. 27, № 3. C. 413-435. DOI: https://doi.org/10.15507/2413-1407.107.027.201903.413-435

Поступила 12.07.2019; принята к публикации 22.10.2019; опубликована онлайн 30.12.2019.

\section{Об авторах:}

Козин Владимир Васильевич, ведущий научный сотрудник отдела мониторинга демографии и трудовых процессов ГКУ РМ «Научный центр социальноэкономического мониторинга» (430005, Россия, г. Саранск, ул. Б. Хмельницкого, д. 39a), кандидат социологических наук, доцент, ORCID: https://orcid. org/0000-0002-1646-6636, vladimir.kozin13@mail.ru

Ушкин Сергей Геннадьевич, ведущий научный сотрудник отдела мониторинга социальных процессов ГКУ РМ «Научный центр социально-экономического мониторинга» (430005, Россия, г. Саранск, ул. Б. Хмельницкого, д. 39a), кандидат социологических наук, ORCID: https://orcid.org/0000-0003-4317-6615, Researcher ID: E-7455-2017, ushkinsergey@gmail.com

Заявленный вклад авторов:

Козин Владимир Васильевич - научное руководство; анализ литературы по проблеме исследования; подготовка начального варианта текста.

Ушкин Сергей Геннадьевич - формулирование цели, научной новизны и практической значимости исследования; анализ литературы по проблеме исследования; развитие методологии; критический анализ и доработка текста.

Для иитирования:

Козин В. В., Ушкин С. Г. Этносоциологические исследования в Республике Мордовия в 1990-2010 гг.: ретроспективный анализ // Регионология. 2019. T. 27, № 4. C. 858-879. DOI: https://doi.org/10.15507/2413-1407.109.027.201904.858-879

Все авторы прочитали и одобрили окончательный вариант рукописи. 


\section{REFERENCES}

1. Arutyunyan Yu.V., Drobizheva L.M. Ethnosociology Facing Challenges of the Time. Sociologicheskie issledovaniya = Sociological Studies. 2008; (7):85-94. Available at: https://www.isras.ru/socis 2008 7.html (accessed 20.06.2019). (In Russ.)

2. Zayka K.V. Models of National Integration in post-War Germany, France, the UK, the US and Canada with Growing Immigration Influx. Comparative politics Russia. 2014; (3):109-127. (In Russ., abstract in Eng.) DOI: https://doi.org/10.18611/22213279-2014-5-3(17)-109-127

3. Chernysh M.F. Theoretical and Methodological Study of Ethnic Tension Causation. Sotsiologicheskij zhurnal = Sociological Journal. 2016; (4):25-41. (In Russ., abstract in Eng.) DOI: https://doi.org/10.19181/socjour.2016.22.4.4806

4. Jan E. Interpretation of Nation from the State Interpretation and from Ethnic Positions: Contradictions and Similarities. Polis. Politicheskie issledovaniya $=$ Polis. Political Studies. 2000; (1):114-123. Available at: https://www.politstudies.ru/ article/2697 (accessed 20.06.2019). (In Russ., abstract in Eng.)

5. Antonova V.K., Karpova G.G. The Russian Version of Multiculturalism: Are There any Perspectives? Zhurnal issledovanij sotsialnoj politiki = Journal of Social Policy Studies. 2011; 9(1):99-128. Available at: https://jsps.hse.ru/index.php/jsps/ article/view/3534 (accessed 20.06.2019). (In Russ., abstract in Eng.)

6. Sukonkina T.N. Formation of a Multi-Cultural Society in a Region. Regionologiya $=$ Regionology. 2010; (2):265-274. Available at: http://regionsar.ru/ru/ node/520 (accessed 20.06.2019). (In Russ., abstract in Eng.)

7. Kivisto P. We Really Are All Multiculturalists Now. Zhurnal issledovanij sotsialnoj politiki $=$ Journal of Sociology and Social Anthropology. 2016; 19(2):19-45. Available at: http://jourssa.ru/sites/all/files/volumes/2016_2/Kivisto_2016_2.pdf (accessed 20.06.2019). (In Russ., abstract in Eng.)

8. Virdee S., McGeever B. Racism, Crisis, Brexit. Ethnic and Racial Studies. 2018; 41(10):1802-1819. (In Eng.) DOI: https://doi.org/10.1080/01419870.2017.1361544

9. Benson M., Lewis C. Brexit, British People of Colour in the EU-27 and Everyday Racism in Britain and Europe. Ethnic and Racial Studies. 2019; 42(13):2211-2228. (In Eng.) DOI: https://doi.org/10.1080/01419870.2019.1599134

10. Brubaker R., Feischmidt M., Fox J., Grancea L. Nationalist Politics and Everyday Ethnicity in a Transylvanian Town. Princeton: Princeton University Press; 2008. (In Eng.) DOI: https://doi.org/10.2307/j.ctv346r9g

11. Gellner E. Nations and Nationalism. New York: Cornell University Press; 2009. Available at: https://www.amazon.com/Nations-Nationalism-New-PerspectivesPast/dp/0801475007 (accessed 20.06.2019). (In Eng.)

12. Bourdieu P. Identity and Representation: Elements of Critical Reflection of the Idea of "Region". Ab Imperio. 2002; (3):45-60. Available at: https://elibrary.ru/ item.asp?id=17958419 (accessed 20.06.2019). (In Russ.)

13. Kelley N., Trebilcock M.J. The Making of the Mosaic: A History of Canadian Immigration Policy. Toronto: University of Toronto Press; 2010. Available at: https:// utorontopress.com/us/the-making-of-the-mosaic-4 (accessed 20.06.2019). (In Eng.) 
14. Bogatova O.A. Social Technologies of Management of Republican and Russian Identity in Estimations of the Population of the Republic of Mordovia: Experience of Qualitative Social Research. Vestnik Udmurtskogo universiteta. Sotsiologiya. Politologiya. Mezhdunarodnye otnosheniya = Bulletin of Udmurt University. Sociology. Political Science. International Relationships. 2017; 1(1):54-70. Available at: http://ru.sociology.vestnik.udsu.ru/archive/show/7-2017-1-6 (accessed 20.06.2019). (In Russ., abstract in Eng.)

15. Bogatova O.A. Mechanisms for Harmonization of Inter-Ethnic Relations in Regional Socium. Regionologiya $=$ Regionology. 2003-2004; (4/1):169-182. Available at: http://regionsar.ru/ru/node/1650 (accessed 20.06.2019). (In Russ.)

16. Dolgaeva E.I., Kapkaeva N.K. Attitudes of the Orthodox and Muslim Youth to Social Practices Contrary to the Norms of Religious Morality. Regionologiya = Regionology. 2015; (2):144-151. Available at: http://regionsar.ru/node/1385 (accessed 20.06.2019). (In Russ., abstract in Eng.)

17. Kozin V.V., Kurkov V.M. Development of the Ethno-Sociological Research in Mordovia. Regionologiya = Regionology. 2004; (4):190-201. Available at: http:// regionsar.ru/ru/node/1650 (accessed 20.06.2019). (In Russ.)

18. Sukharev A.I., Kozin V.V., Sidorkina V.M. Sociology in Mordovia: The Formation and Directions of Development. Sociologicheskie issledovaniya = Sociological Studies. 2006; (8):35-42. Available at: https://cyberleninka.ru/article/n/stanovlenie-irazvitie-sotsiologii-v-mordovii (accessed 20.06.2019). (In Russ.)

19. Haykin S.R., Berezhkova S.B. Sociological Monitoring of Inter-Ethnic and Inter-Confessional Relations of the Federal Agency for Ethnic Affairs. Monitoring obshhestvennogo mneniya: ehkonomicheskie $i$ sotsialnye peremeny $=$ Monitoring of Public Opinion: Economic and Social Changes. 2016; (5):97-110. (In Russ., abstract in Eng.) DOI: https://doi.org/10.14515/monitoring.2016.5.07

20. Ushkin S.G. Tone of the Discourse of National (Ethno-Cultural) Policy in Mass Media of the Volga Federal District. Regionologiya = Regionology. 2014; (2):159-169. Available at: http://regionsar.ru/ru/node/1275 (accessed 20.06.2019). (In Russ., abstract in Eng.)

21. Bogatova O.A., Chirkova O.N. Formation of the Republic of Mordovia Ethno-Cultural Image in the Regional Branding. Regionologiya $=$ Regionology. 2013; (3):68-75. Available at: http://regionsar.ru/ru/node/1145 (accessed 20.06.2019). (In Russ., abstract in Eng.)

22. Chirkova O.N. Influence of the Image Policy and Ethno-Cultural Branding of a Region on Formation and Development of Regional Identity. Regionologiya = Regionology. 2016; (3):88-105. Available at: https://regionsar.ru/ru/node/1474 (accessed 20.06.2019). (In Russ., abstract in Eng.)

23. Kozin V.V., Kirdyashkina T.I. Attendance Monitoring of Ethnic Tourism Objects in the Republic of Mordovia in 2017. Finno-ugorskij mir = Finno-Ugric World. 2018; 10(3):86-94. (In Russ., abstract in Eng.) DOI: https://doi.org/10.15507/20762577.010.2018.03.086-094

24. Fofanova K.V., Borisov D.M. Network Resource as the Factor of Integration of Foreign Labor Migrants to Regional Society. Zhurnal issledovanij sotsialnoj politiki = Journal of Social Policy Studies. 2013; 11(2):189-206. Available at: https://jsps.hse. ru/article/view/3438 (accessed 20.06.2019). (In Russ., abstract in Eng.) 
25. Kozin V.V. Mutual Relations of Labour Migrants and Accepting Community. Sotsialnoe vremya $=$ Social Time. 2015; (4):93-97. Available at: https://www. volgatech.net/sociotime/archive/ (accessed 20.06.2019). (In Russ., abstract in Eng.)

26. Sychev A.A., Koval E.A., Zhadunova N.V. The Issue of Classification of Hate Speech against Migrants (The Case Study of the Republic of Mordovia). Regionologiya $=$ Regionology. 2018; 26(4):798-815. (In Russ., abstract in Eng.) DOI: https://doi.org/10.15507/2413-1407.105.026.201804.798-815

27. Vishnyakova N.A. How Live, Mordovia? Influence of Material and Intangible Factors on the Social Benefit of the Population. Rossijskij khoroshij zhurnal = Russian Good Journal. 2019; (1):43-49. Available at: http://rgoodj.ru/wp-content/uploads/2019/06/ vishnyakova_na_n1.pdf (accessed 20.06.2019). (In Russ., abstract in Eng.)

28. Bakhlova O.V., Bakhlov I.V. Conceptualization of the Concept of «Nation Building» in Political Discourse. Sotsialno-politicheskie nauki = Sociopolitical Sciences. 2018; (2):26-29. Available at: http://urvak.ru/articles/sotsia-vypusk-2-kontseptualizatsiya-ponyatiya-nats/ (accessed 20.06.2019). (In Russ., abstract in Eng.)

29. Bakhlova O.V., Bakhlov I.V. State Policy of Nation-Building in Russia: Content, Institutions and Mechanisms. Regionology = Russian Journal of Regional Studies. 2019; 27(3):413-435. (In Russ., abstract in Eng.) DOI: https://doi.org/10.15507/24131407.107.027.201903.413-435

Submitted 12.07.2019; accepted for publication 22.10.2019; published online 30.12.2019.

\section{About the authors:}

Vladimir V. Kozin, Leading Researcher, Department for Monitoring Demography and Labor Processes, Scientific Center for Social and Economic Monitoring (39a B. Khmelnitskogo St., Saransk 430005, Russia), Ph. D. (Sociology), Associate Professor, ORCID: https://orcid.org/0000-0002-1646-6636, vladimir.kozin13@mail.ru

Sergey G. Ushkin, Leading Researcher, Department for Monitoring Social Processes, Scientific Center for Social and Economic Monitoring (39a B. Khmelnitskogo St., Saransk 430005, Russia), Ph. D. (Sociology), ORCID: https://orcid.org/0000-0003-4317-6615, Researcher ID: E-7455-2017, ushkinsergey@gmail.com

\section{Contribution of the authors:}

Vladimir V. Kozin - academic supervision; analysis of the literature on the research question; writing the initial version of the text of the article.

Sergey G. Ushkin - formulation of the objective, scientific novelty and practical significance of the research; analysis of the literature on the research question; development of methodology; critical analysis and revision of the text of the article.

For citation:

Kozin V.V., Ushkin S.G. Ethnosociological Studies in the Republic of Mordovia in 1990-2010: A Retrospective Analysis. Regionology = Russian Journal of Regional Studies. 2019; 27(4):858-879. DOI: https://doi.org/10.15507/2413-1407.109.027.201904.858-879

The authors have read and approved the final version of the manuscript. 


\section{ИНФОРМАЦИЯ ДЛЯ АВТОРОВ И ЧИТАТЕЛЕЙ}

Редакция журнала «Регионология» принимает не опубликованные ранее оригинальные научные исследования, посвященные актуальным проблемам региональной политики, экономики и социологии, анализу комплексного развития регионов Российской Федерации и зарубежных стран. Не допускается направление в редакцию уже опубликованных статей или статей, отправленных на публикацию в другие журналы. В случае обнаружения одновременной подачи рукописи в несколько изданий опубликованная статья будет ретрагирована (отозвана из печати). Мониторинг несанкционированного цитирования осуществляется с помощью систем «Антиплагиат» и CrossCheck.

Журнал приветствует статьи, имеющие потенциально высокий импакт-фактор и/или содержащие материал о значительных достижениях в указанных направлениях. Особое внимание следует уделить качеству перевода. Желательно, чтобы он был выполнен носителем английского языка.

При подготовке статьи к публикации в журнале «Регионология» необходимо учесть следующие пункты.

1. Указать Удк.

2. Заголовок статьи должен кратко и точно отражать содержание статьи, тематику и результаты проведенного исследования. Приводится на русском и английском языках.

3. Аннотация (200-250 слов.) выполняет функцию расширенного названия статьи и повествует о ее содержании. В ней должны быть четко обозначены следующие составные части:

1) Введение (Introduction);

2) Материалы и методы (Materials and Methods);

3) Результаты исследования (Results);

4) Обсуждение и заключение (Discussion and Conclusion).

Приводится на русском и английском языках.

4. Ключевые слова (5-10) являются поисковым образом научной статьи. В связи с этим они должны отражать основные положения, достижения, результаты, терминологию научного исследования. Приводятся на русском и английском языках.

5. Благодарности. В этом разделе следует упомянуть людей, помогавших автору подготовить настоящую статью, организации, оказавшие финансовую поддержку. Хорошим тоном считается выражение благодарности анонимным рецензентам. Приводятся на русском и английском языках.

6. Основной текст статьи излагается на русском или английском языках.

1) Введение - постановка научной проблемы, ее актуальность, связь с важнейшими задачами, которые необходимо решить, значение для развития определенной отрасли науки или практической деятельности.

2) Обзор литературы. Необходимо описать основные (последние по времени) исследования и публикации, на которые опирается автор; современные взгляды на проблему; трудности при разработке данной темы; выделить нерешенные вопросы в пределах общей проблемы, которым посвящена статья.

3) Материалы и методы. В данном разделе описываются процесс организации эксперимента, примененные методики, использованная аппаратура; даются подробные сведения об объекте исследования; указывается последовательность выполнения исследования и обосновывается выбор используемых методов (наблюдение, опрос, тестирование, эксперимент, лабораторный опыт и т. д.).

4) Результаты исследования. Это основной раздел, цель которого - при помощи анализа, обобщения и разъяснения данных доказать рабочую гипотезу (гипотезы). Результаты должны быть изложены кратко, но при этом содержать достаточно информации для оценки сделанных выводов. Также должно быть обосновано, почему 
для анализа были выбраны именно эти данные. Все названия, подписи и структурные элементы графиков, таблии, схем и т. д. оформляются на русском и английском языках. Рисунки могут быть представлены в растровом или векторном формате с разрешение не ниже $300 \mathrm{dpi}$. Они должны допускать перемещение в тексте и возможность изменения размеров. Все графические данные помещаются в текст статьи, а также высылаются дополнительно в виде отдельных файлов.

5) Обсуждение и заключение. В заключении суммируются результаты осмысления темы, делаются выводы, обобщения и рекомендации, вытекающие из работы, подчеркивается их практическая значимость, а также определяются основные направления для дальнейшего исследования в этой области.

7. Список использованных источников (оформляется в соответствии с требованиями ГОСТа Р 7.0.5-2008). Ссылаться нужно в первую очередь на оригинальные источники из научных журналов, включенных в глобальные индексы цитирования. Желательно использовать 30-40 источников. Из них за последние 3 года - не менее 20 , иностранных - не менее 15 . Следует указать DOI или адрес доступа в сети Интернет. Оформляется на русском и английском языках.

8. Информация об авторах. Ф.И.О., организация(и), адрес организации(й) (требуется указать все места работы автора, в которых выполнялись исследования (постоянное место, место выполнения проекта и др.)), должность и ученое звание, ORCID ID, Researcher ID, Scopus ID, электронная почта, телефон, почтовый адрес для отправки авторского экземпляра. Приводится на русском и английском языках.

9. Вклад соавторов. В конец рукописи необходимо включить примечания, в которых разъясняется фактический вклад каждого соавтора в выполненную работу. Приводится на русском и английском языках.

10. Авторам необходимо прислать свое фото отдельным файлом для публикации в журнале - качественный лицевой портрет в формате *jpg или *tif с разрешением не менее 300 точек (формат 10х15 см).

При подаче статьи в редакцию автор соглашается с положениями прилагаемого лицензионного договора.

Важным этапом в процессе отбора статьи является рецензирование. В журнале «Регионология» принято «двойное слепое» (рецензент и автор не знают имен друг друга) рецензирование статей (срок действия рецензии - 1 год). Рецензент на основании анализа статьи принимает решение о рекомендации ее к публикации или о ее отклонении. В случае несогласия автора статьи с замечаниями рецензента его мотивированное заявление рассматривается редакционной коллегией.

Допускается свободное воспроизведение материалов журнала в личных целях и свободное использование в информационных, научных, учебных и культурных целях в соответствии со ст. 1273 и 1274 гл. 70 ч. IV Гражданского кодекса РФ. Иные виды использования возможны только после заключения соответствующих письменных соглашений с правообладателем.

Электронные версии статей размещаются на сайте Научной электронной библиотеки. Журнал распространяется по подписке, заявкам высших учебных заведений, учреждений образования и отдельных лиц. Подписной индекс в каталоге агентства «Роспечать»- 73335 .

Вдовин Сергей Михайлович - главный редактор. Тел.: +7 (8342) 24-48-88.

Полутин Сергей Викторович - заместитель главного редактора. Тел.: +7 (8342) 32-81-57. Гордина Светлана Викторовна - ответственный секретарь. Тел.: +7 (8342) 48-14-24. 


\section{INFORMATION FOR AUTHORS AND READERS OF THE JOURNAL}

Russian Journal of Regional Studies journal accepts previously unpublished original scientific papers devoted to topical issues of regional policy, economy and sociology, as well as to the analysis of the integrated development of the regions of the Russian Federation and other countries. It is not allowed to submit papers that have already been published or sent for publication to other journals. In case of multiple submission of a manuscript, the published article will be retracted. Monitoring of unauthorized citation is implemented by means of Antiplagiat and CrossCheck systems.

The Journal gives preference to the articles with potentially high impact factor and/ or containing materials about significant achievements in the specified areas of science. Special attention should be paid to the quality of the translation. Preferably it should be made by a native English speaker.

When preparing an article for publication in Russian Journal of Regional Studies, the following points should be taken into account.

1. It is necessary to indicate the Universal Decimal Classification (UDC) code.

2. The title of the article should accurately reflect the content of the article, the subject matter and the results of the research conducted.

The title should be written in Russian and English.

3. The abstract (200-250 words) serves as an enhanced title of the article and briefly presents its content. The abstract consists of the following components:

1) Introduction;

2) Materials and Methods;

3) Results;

4) Discussion and Conclusion.

The abstract should be written in Russian and English.

4. Keywords (5-10) make the search profile of the scientific article. In this regard, they should reflect the main provisions, achievements, results and terminology of the scientific research.

Keywords should be written in Russian and English.

5. Acknowledgements. In this section the author may mention the people who helped them to prepare the article or the organizations that provided financial support. It is considered good style to express gratitude to anonymous reviewers.

Acknowledgements should be written in Russian and English.

6. The main body of the article should be written in Russian or in English.

1) Introduction. It contains formulation of the scientific problem, its relevance, connection with the most important tasks to be solved, the importance for the development of a particular area of science or practical activities.

2) Literature review. It is necessary to describe the main (recent) pieces of research and publications relied upon by the author, modern views on the problem, difficulties in solving the problem as well as to highlight the unresolved issues within the general problem of the article.

3) Materials and methods. This section describes the process of designing the experiment, the methods and equipment used; it gives detailed information about the subject and sequence of the research, justifies the choice of the methods used (observation, survey, testing, experiment, etc.).

4) Results. This is the main section, the purpose of which is to prove the working hypothesis (hypotheses) by analyzing, generalizing and explaining the data. The results should be brief, but they should provide sufficient information to evaluate the conclusions drawn. It should also be justified why the particular data were chosen for the analysis. All names, signatures and structural elements of graphs, tables, diagrams, etc. should be written in Russian and English. Figures should be presented in a raster or vector format 
with a resolution of at least $300 \mathrm{dpi}$. It should be possible to move them in the text and resize them. All graphic data should be placed in the text of the article and also should be attached as separate files.

5) Discussion and conclusion. In conclusion, the results of understanding the topic should be summarized; conclusions, generalizations and recommendations arising from the work should be made, their practical significance should be emphasized and the main directions for further research in the studied area should be determined.

7. References should be given in accordance with the requirements of the GOST $R$ 7.0.5-2008 standard. The original sources from scientific journals included in the global citation indices should be cited first of all. It is desirable to refer to 30-40 sources. Of these, at least 20 sources should be those published over the past 3 years and at least 15 foreign ones. DOI or the URL of the source should be indicated.

References should be written in Russian and English.

8. Information about the author(s) includes: the author's first name and last name, the name of the institution and its address (it is required to specify all the institutions where the author works and where the research was conducted (permanent place of work, the place where the project was done, etc.)). The author's position and academic title, ORCID, Researcher ID, Scopus ID, e-mail, phone number, postal address for sending a personal copy of the Journal issue.

Information about the authors should be written in Russian and English.

9. Contribution of the authors. At the end of the manuscript, the authors should include notes that explain the actual contribution of each co-author to the work performed.

Contribution of the authors should be written in Russian and English.

10. Authors should send their photos as separate files for publication in the Journal. They should be good quality portraits in *jpg or *tiff format with a resolution of at least 300 dpi (10x15 cm format).

When submitting an article to the Journal, the author agrees with the provisions of the attached license agreement.

As part of the submission, the Journal will peer review your article before deciding whether to publish it. Russian Journal of Regional Studies uses double-blind review, which means that both the reviewer and author identities are concealed from the reviewers, and vice versa (a review stays valid for 1 year). On the basis of the analysis of the article, the reviewer makes a decision whether to recommend the article for publication or reject it. If the author disagrees with the reviewer's comments, their reasoned statement shall be considered by the Editorial Board.

Free reproduction of the Journal's materials for personal purposes and free use for information, scientific, educational and cultural purposes is allowed in accordance with articles 1273 and 1274 of Chapter 70, part 4 of the Civil Code of the Russian Federation. Other types of use are possible only after the conclusion of relevant written agreements with the right holder.

Electronic copies of the journal with full text of the articles in PDF are in free access at the website of Academic Electronic Library. The Journal is distributed on the basis of a subscription, requests of higher education institutions, educational institutions and individuals. The subscription index in the catalogue of the agency of Rospechat is 73335 .

Sergey M. Vdovin - Editor-in-Chief. Tel.: +7 (8342) 244888.

Sergey V. Polutin - Deputy Editor-in-Chief. Tel.: +7 (8342) 328157.

Svetlana V. Gordina - Executive Editor. Tel.: +7 (8342) 481424. 


\section{РЕГИОНОЛОГИЯ REGIONOLOGY}

Редактор E. С. Суркова.

Компьютерная верстка $A$. С. Полутина.

Перевод А. В. Пузакова.

Выпускающий (редактор по выпуску) Е. П. Гордина.

Информационная поддержка сайта журнала А. А. Парамонова.

Подписной индекс в каталоге АО Агентство «Роспечать» - 73335.

Территория распространения журнала: Российская Федерация, зарубежные страны

Журнал зарегистрирован в Федеральной службе по надзору в сфере связи, информационных технологий и массовых коммуникаций (Роскомнадзор). Свидетельство о регистрации средства массовой информации ПИ № ФС77-65932 от 06 июня 2016 г.

Подписано в печать 11.12.2019. Дата выхода в свет 30.12.2019. Формат 60x84 1/16. Усл. печ. л. 16,97. Тираж 1000 экз. І завод - 120 экз. Заказ № 2415. Свободная цена.

Адрес редакции: 430005, Республика Мордовия, г. Саранск, ул. Большевистская, д. 68/1.

Тел./факс: (8342) 48-14-24, (8342) 32-86-14.

E-mail: redreg@mrsu.ru, regionology@mail.ru

http://regionsar.ru

Адрес учредителя и издателя: 430005, Республика Мордовия, г. Саранск, ул. Большевистская, д. 68.

Адрес типографии: 430005, Республика Мордовия, г. Саранск, ул. Советская, д. 24 (Издательство федерального государственного бюджетного образовательного учреждения высшего образования «Национальный исследовательский Мордовский государственный университет им. Н.П. Огарёва»)

Фотографии предоставлены самими авторами и опубликованы с их согласия.

\section{Russian Journal of Regional Studies}

Editor E. S. Surkova.

Desktop publishing by A. S. Polutin.

Translation by A. V. Puzakov.

Sub-editor E. P. Gordina.

Informational support of the Journal's website by A. A. Paramonov.

Subscription index in the catalogue of Rospechat Agency: 73335.

The Journal is distributed in the Russian Federation and abroad.

The Journal is registered with the Federal Service for Supervision of Communications, Information Technology, and Mass Media (Roskomnadzor); mass media registration certificate: PI No. FS77-65932 of 6 June 2016

Signed to print 11.12.2019. Date of publishing 30.12.2019. Sheet size $60 \times 841 / 16$. Conventional printed sheets 16,97. Number of copies: 1,000. Print run 1: 120 copies. Order No. 2415. Open price.

Editorial office: 68/1 Bolshevistskaya St., Saransk 430005, Republic of Mordovia, Russia.

Tel/Fax: +7 8342 481424, +7 8342328614

E-mail: redreg@mrsu.ru, regionology@mail.ru

http://regionsar.ru

Address of the Founder and Publisher: 68 Bolshevistskaya St., Saransk 430005, Republic of Mordovia, Russia.

Address of the Printing House: 24 Sovetskaya St., Saransk 430005, Republic of Mordovia (Publishing House of National Research Mordovia State University)

The photographs are provided by the authors and are published with their consent. 